\title{
Te Papa: a forum for the world? A narrative exploration of a global public sphere
}

\author{
By \\ Philipp Schorch
}

\begin{abstract}
A thesis
submitted to the Victoria University of Wellington in fulfilment of the requirements for the degree of

Doctor of Philosophy in

Museum and Heritage Studies
\end{abstract}

Victoria University of Wellington

2010 


\section{Contents}

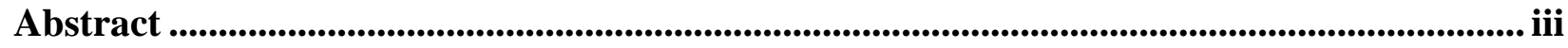

Acknowledgements .......................................................................................................................... iv

Chapter One - Introduction and theoretical framework ........................................................................ 1

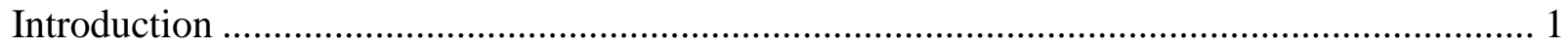

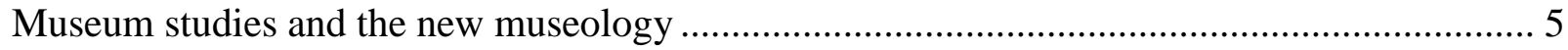

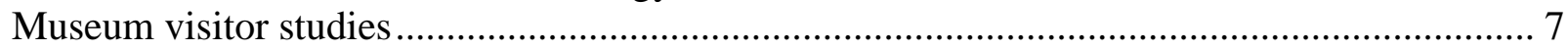

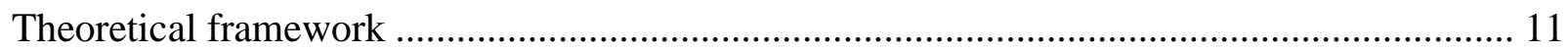

Traveling cultures in a cosmopolitanised world ......................................................... 12

Contact zones, museums and Third Spaces............................................................ 18

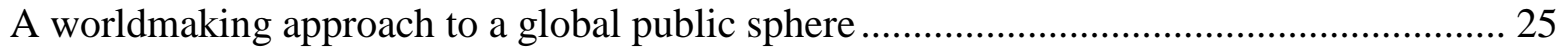

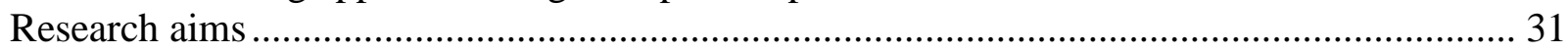

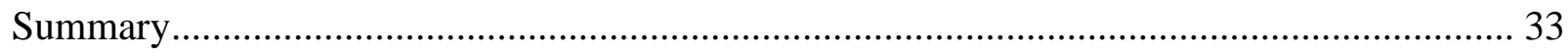

Chapter Two - A narrative exploration of the Te Papa 'forum' .............................................. 34

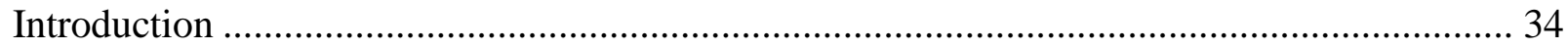

Hermeneutic methodology: action, narrative, meaning, Self ....................................... 35

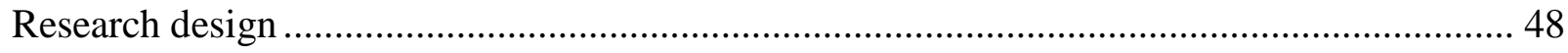

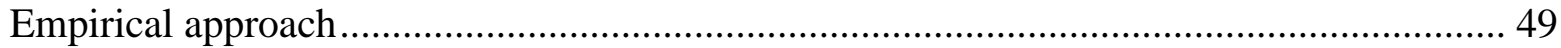

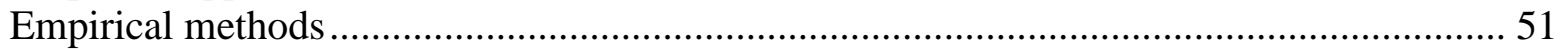

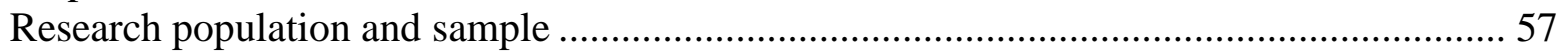

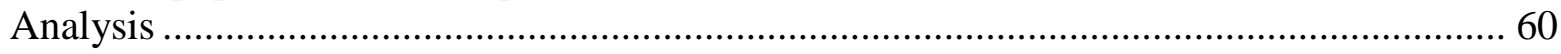

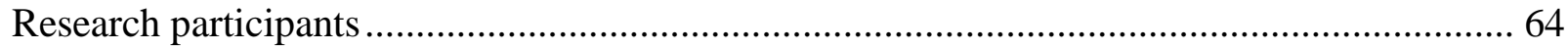

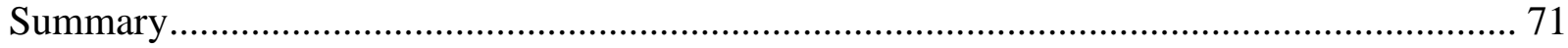

Chapter Three - The conditions of meaning-making ................................................................ 72

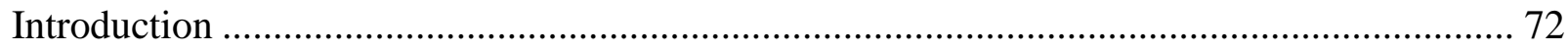

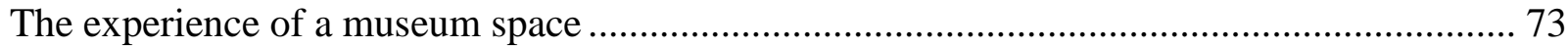

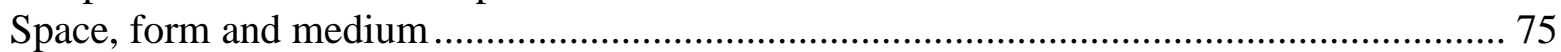

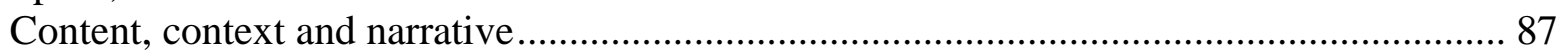

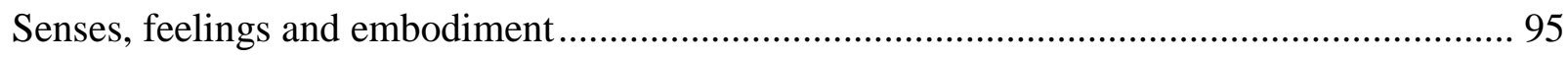

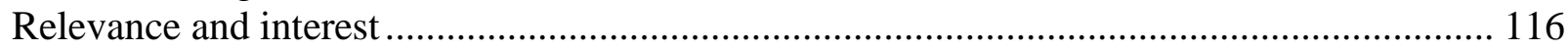

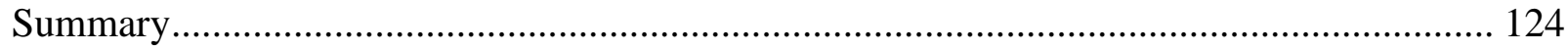


Chapter Four - Cross-cultural journeys................................................................................................. 127

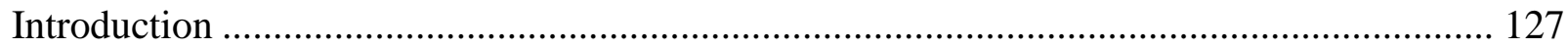

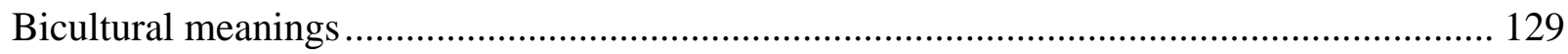

From bicultural meanings to cross-cultural dialogue ………............................................. 139

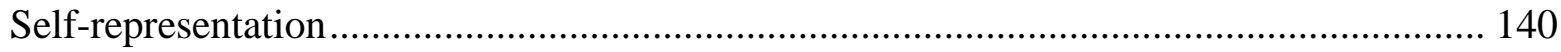

The reframing of understandings.............................................................................. 144

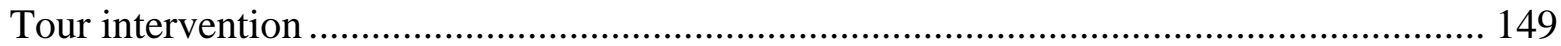

Cross-cultural hermeneutics: the shifting Self ................................................................. 165

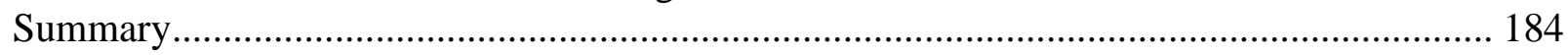

Chapter Five - Te Papa: a forum? ........................................................................................................... 187

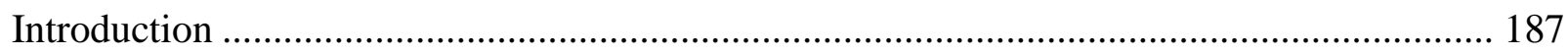

Self-reflexivity, Self-critique and Self-transformation......................................................... 189

Political opinions and moral demands........................................................................... 209

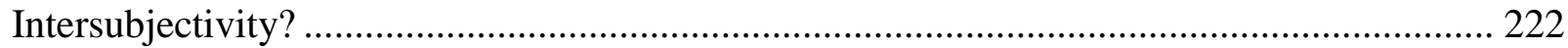

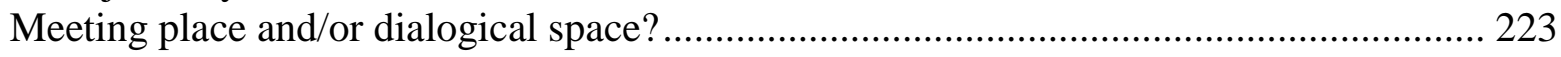

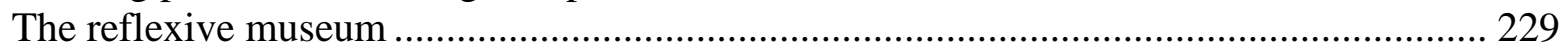

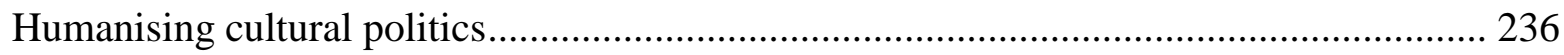

Summary

Chapter Six - Conclusion .................................................................................................................................. 240

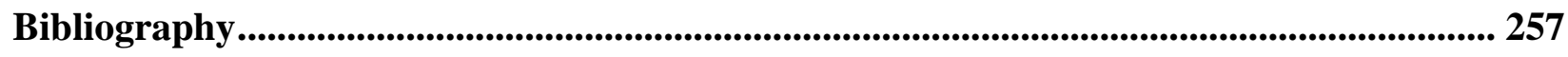

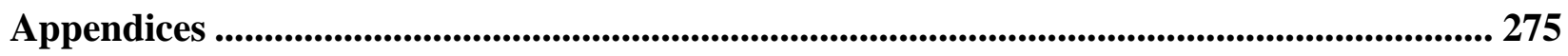

Appendix A: Focus group format with global visitors ………………………………...... 275

Appendix B: Focus group format with Te Papa tour hosts .................................................. 276

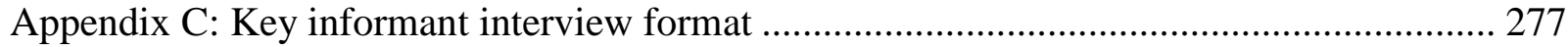

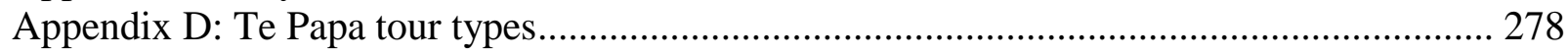

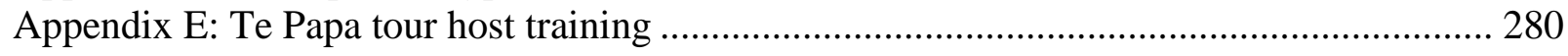

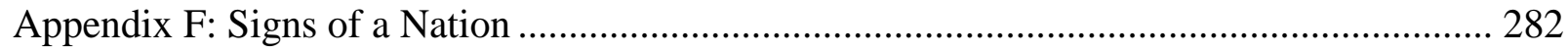

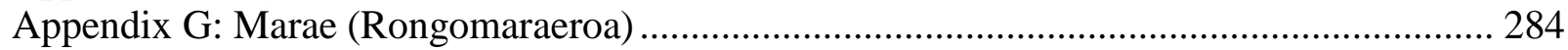

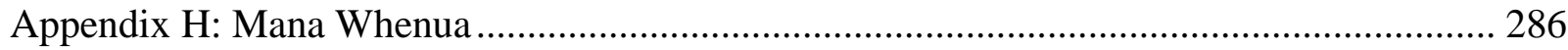

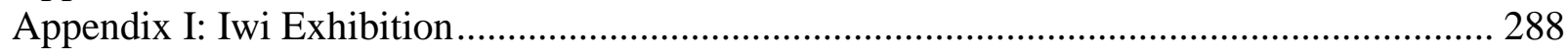

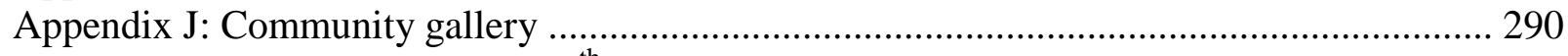

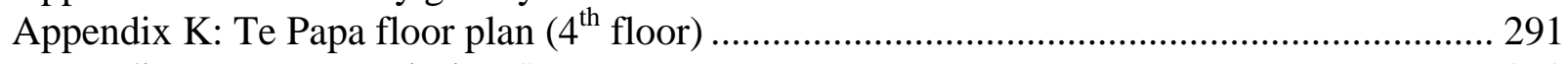

Appendix L: Te Papa Mission Statement .......................................................................... 292

Appendix M: Mana Taonga Principle ............................................................................. 293

Appendix N: Te Papa Bicultural Policy ……………….................................................. 294 


\begin{abstract}
The reinvention of the museum as 'forum' within the new museology and the notion of the 'public sphere' are inextricably linked. Both concepts have been theoretically scrutinised in museum studies, critical theory, cultural studies and other academic disciplines, but there is a lack of empirical insights into their actual functioning. This thesis offers an empirical interrogation of the 'museum forum' idea. It sheds ethnographic light on cross-cultural encounters in a 'cosmopolitanised' world illuminating what it means to experience a museological space and how a public sphere is 'lived'.
\end{abstract}

Drawing on a long-term narrative study of global visitors to the Museum of New Zealand Te Papa Tongarewa (Te Papa), this thesis humanises Te Papa as a particular global public sphere, or discursive space. The critical hermeneutic analysis facilitates an understanding of 'cross-cultural dialogue' and the 'public sphere' as interpretive actions, movements and performances made by cultural actors. By exploring individual experiences instead of totalised abstractions, this study dissects the complexity of cultural worldmaking and politics elucidating 'interpretive contests' and their 'enunciation'. Due to the in-depth empirical insights and their multilayered contextualisation, the 'museum forum' evolves from an abstract idea into a concrete discursive world of negotiations.

This thesis examines Te Papa as a particular place, space and empirical reality. It interrogates seemingly universal concepts such as 'culture' and 'politics' producing empirically situated, contextualised and rich theoretical propositions of significance for the human sciences in general as well as critical museum studies in particular. 


\section{Acknowledgements}

Over the long course of completing this thesis, I have amassed enormous intellectual and personal debts which I can hardly settle in a few sentences. I want to stress that these acknowledgements do not represent a compliance with academic conventions, but reflect my heartfelt gratitude. While I draw a broad distinction between the professional and the personal, it is in my view impossible to separate these dimensions. In other words, all academic companions throughout the journey of this thesis have offered personal qualities which significantly contributed to its completion.

I have been extremely fortunate to have received supervision from Dr. Lee Davidson and Dr. Conal McCarthy for this research project. Both complemented each other perfectly with their individual expertise and strength, supported me consistently without hesitation and have always been more than formal supervisors. I really feel they paved the way for my academic future. At Te Papa, I enjoyed the unconditional support from my mentor Jette Sandahl as well as my managers Annette Meates and Raewyn Smith-Kapa creating the perfect conditions for my personal and academic growth. Stephen Owen and Arapata Hakiwai acted as very helpful advisors at different stages of the project. A special thanks also to Lynda Kelly at the Australian Museum and Zahava Doering at the Smithsonian Institution who invited me to their respective institutions to exchange ideas and share research insights.

This thesis would have been impossible without the Bright Future Enterprise Scholarship cofinanced by the Tertiary Education Commission Te Amorangi Mātauranga Matua and Te Papa. A New Zealand Postgraduate Study Abroad Award (NZPSAA) from Education New Zealand as 
well as several faculty research grants from Victoria University of Wellington enabled me to present at various international conferences and gain relevant experience at the Australian Museum and Smithsonian Institution. I extend my appreciation to these organisations.

On a personal level, I have been blessed with the 'best family and friends in the world'. I simply could not imagine life without them. Although there have been numerous and invaluable personal influences over time, I focus here on the people who helped me sustaining a major personal crisis in the midst of this thesis. First and foremost I am deeply grateful to my parents, who have always supported me, especially when I needed them most. This thesis would not exist without them. A massive thanks to my sister and brother-in-law, who let me live with them for several months; to the rest of my family, especially my cousin and fellow scholar; to Danielo for being a 'brother'; to Veiter, Klemmi, Schmidde, Krusty, Elli and Anne for being true and lasting friends; to Lili for taking me along on a big escape to Rarotonga; to 'hermana' Genevieve for providing me with shelter and comments on my first research ideas and proposals; and last but not least to Clayton and his family, who offered me accommodation during the last stage of this academic endeavour. Again, I could not include all individuals who contributed to my life, and I hope they can forgive me their exclusion in this particular context. But they all embody the roots of my life wherever my wings take me. 


\section{Chapter One}

\section{Introduction and theoretical framework}

\section{Introduction}

What is enlightenment? To have the courage to make use of one's cosmopolitan vision and to acknowledge one's multiple identities - to combine forms of life founded on language, skin colour, nationality or religion with the awareness that, in a radically insecure world, all are equal and everyone is different. (Beck, 2006a)

The title of this thesis poses the question: Te Papa: a forum for the world? This question captured my intellectual curiosity and evolved into an academic endeavour. It has remained at the heart of this study from the first proposal up to its completion. In this chapter, the reader is invited to retrace the historical evolution of this question. I establish the disciplinary context and theoretical framework of this thesis before formulating specific research questions underpinning the empirical investigation in the next chapter (see page 48).

I introduce first the disciplinary parameters of this study. This is a $\mathrm{PhD}$ in museum studies focusing on museum theory and practice, and in particular aspects of the strand of critical analysis called the 'new museology' (Vergo, 1989). I begin by offering a brief overview of the 'new museology'. My aim is not to offer an exhaustive historical chronology or conceptual critique. Rather, I intend to identify the deficiency most pertinent to this study: the lack of empirical evidence of the actual functioning of the proclaimed 'new museology'. The visitor focus leads the discussion to the sub-field of 'museum visitor studies'. Again I do not set out to 
present a complete survey, but focus instead on distinguishing the shortcoming most significant for this thesis: the lack of in-depth and long-term visitor insights.

I proceed by developing the theoretical framework of this thesis. This is most appropriately done by more closely inspecting the title and overarching question itself, since this has been the very point of departure for several years of thinking and rethinking, writing and rewriting. Te Papa: a forum for the world? I draw the individual terms out of this question and interrogate their meaning within the context of this thesis. I opt for a funnel-like approach, from the broad to the specific, which should allow the reader to re-travel my theoretical journey prior to the empirical interrogation.

In the section 'Traveling cultures in a cosmopolitanised world', I illuminate the 'cosmopolitanisation' (Beck, 2006a) of life in the $21^{\text {st }}$ century. This entails a sociological analysis of lived reality rather than a philosophical postulation of an ideal. While the inescapable interrelations and interdependencies of a 'cosmopolitanised' world have multifaceted economic, political and social ramifications, I concentrate on the cultural praxis of 'traveling cultures' (Clifford, 1997). I further specify the discussion by focusing on touristic travel, which provides the platform for the subsequent examination of cross-cultural dialogue in this thesis. At the same time, however, I do not lose sight of the diverse forms of travel such as migration, study and work, which merge even within one individual biography. This enables me to pave the way for the narrative exploration of travel experiences beyond oversimplified generalisations that treat contemporary tourism as elitist decadence or the peak of postmodern superficiality. 
In the next section, 'Contact zones, museums and Third Spaces', we move from the broader contemporary world to focus in on museums as particular 'contact zones' (Clifford, 1997) within the 'cosmopolitanised' clash of cultures. During this process, the cultural institution known as 'the museum' is embedded in the wider context of 'traveling cultures' which has always shaped museological production, representation and visitation. The Museum of New Zealand Te Papa Tongarewa (Te Papa) is introduced as a specific 'contact zone' negotiating the bicultural nature of Aotearoa New Zealand. The associated focus on encounter, dialogue and conflict avoids the reductionist and deterministic traps of many cultural critiques. In the course of this thesis, I seek to humanise and expand the idea of a museum as 'contact zone', a place of contentious and collaborative relations and interactions. My work sets out to move beyond its initial focus on museological production by shedding ethnographic light on global visitors to Te Papa. The translation of a physical 'contact zone' into a discursive 'Third Space' (Bhabha, 1994) builds the theoretical basis for such an endeavour.

In the last section of the theoretical framework, 'A worldmaking approach to a global public sphere', I relate the preceding discussion on 'contact zones' to the idea of a museum as 'forum' or place of debate and cultural politics. Surveying the views on the 'public sphere', I venture beyond systems, structures and substances towards actions, movements and performances as constitutive elements of the public realm. To put it another way, cultural politics are characterised by an inevitable hermeneutic complexity which arises out of the act of interpretation or cultural worldmaking. Given the 'cosmopolitanised' human condition of our times, the discussion cannot ignore the global dimension. I reconceptualise Te Papa as a particular global public sphere and lay the foundation for its empirical dissection. The section concludes with the presentation of 
'narrative' as a theoretical and methodological tool to illuminate the discursive dynamics of cultural politics and worldmaking.

This creates the transition to the research aims, which attempt to address the identified gaps in museum and visitor studies and have risen out of the theoretical framework. Here, the process of funnelling from the contemporary world to Te Papa as a specific place and space within it ends. This leads to the methodological framework in Chapter Two, 'A narrative exploration of the Te Papa forum', which further specifies the research aims in the form of research questions and translates the theoretical argument into an empirical research design.

Given the narrative character of this research, I intend to start telling a story which begs for fluid coherence and richness rather than compartmentalised categorisation. This way I acknowledge the cross- and trans-disciplinary nature of this thesis within the inherently interdisciplinary field of museum studies (Macdonald, 2010). The theoretical argument presented in this chapter frames and contextualises this study. Further literature, however, has been interwoven throughout the text. Such an analytical strategy guarantees, according to Clandinin and Connelly (2000, p. 41), a 'seamless link between the theory and practice embodied in the inquiry' and is appropriate for narrative research. Adhering to the qualitative spirit of this study, I ensured that the themes and concepts emerged from the empirical evidence itself. However, the endless hermeneutic circle of interpretive examination required the constant use of theoretical tools to dig ever deeper into the realm of understanding. It follows that the merging of empirical findings and theoretical reasoning reflects the trajectory of my own research journey. 
This brings me to some concluding remarks on my own position as a researcher. I have lived, studied, worked or traveled in more than thirty countries worldwide. I speak several languages, can relate to distinct cultures and call many places home. In short, cross-cultural dialogue has been at the heart of my life. In this sense, I embody an 'informed reader' (Denzin, 2001) within the context of this study. I think this equips me with a particular sympathy and empathy for the informants' experiences and the phenomenon under scrutiny. While this might be regarded as an inherent bias, I consider it as a meaningful advantage with regards to empirical understandings and theoretical propositions. And agreeing with Said (2003, p. 339), I am convinced that a thesis is, at least to a certain extent, 'a partisan book, not a theoretical machine'.

\section{Museum studies and the new museology}

Macdonald (2010) relates the development of the new museology to a critical turn in museum studies as part of changing perspectives and the representational critique within social and cultural disciplines during the 1980s. The purpose of this section is to highlight a proclaimed paradigmatic shift within museum studies and the new museology; but I am not offering a detailed account of its various ramifications, because that would exceed the scope of this thesis and not necessarily strengthen my argument. In the early stages of my research, I surveyed the museum literature and will here use the main points to embed this study in current museum theory, practice and research. Once I have identified the relevant gap and made the case for this thesis within its disciplinary setting, I progressively deepen the argument throughout the text.

Museums as cultural institutions have changed dramatically since their establishment during the European Enlightenment. Historically, the museum was a place of universal truth and higher 
value, a sacred temple reflecting the newly born ideals of the enlightened individual. The aim was to provide moral and content based education to the middle and upper social classes - 'from an authoritative source to an uninformed receiver' (Hooper-Greenhill, 2000, p. 133). The focus was on the museum's intellectual functions such as collections and research, which depended on the financial support of wealthy individuals (Carbonell, 2004; Preziosi \& Farrago, 2004).

Today, most museums are public institutions. Although many still embody the reformist agenda, they are nevertheless affected by dramatic changes in western societies, which have meant new accountabilities and responsibilities. Just as Cameron (1971) demanded in the groundbreaking article 'The museum: A temple or the forum', the new museum sees itself as place for debate, experimentation and confrontation, 'a safe place for unsafe ideas' (Gurian, 2006). Consequently, the new museology cannot not be grasped without considering broader philosophical questions (MacLeod, 2001). In short, the development from the old to the new museology is associated with the shifting focus from the museum's scientific apparatus towards its institutional meaning and purpose (Vergo, 1989).

It is claimed that the new museum, with Te Papa being a prominent example, has developed from a sterile refuge of academic scholarship into a vivid place of public learning and has renegotiated its various relationships. On the one hand, it actively involves the cultures and communities it represents and thereby abandons the anachronistic colonial attitude. It speaks with plural voices from distinct perspectives within equalitarian partnerships. On the other hand, the new museum actively involves the audience and moves from the linear transmission of universal knowledge to a dynamic and complex relationship with the visitor in which multiple meanings and identities 
are negotiated through the dialogue of ideas (G. Allen \& Anson, 2005; G. Anderson, 2004;

Boswell \& Evans, 1999; Corsane, 2005; Hooper-Greenhill, 1992, 2000; Karp, Kreamer, \& Lavine, 1992; Karp \& Lavine, 1991; MacLeod, 2001; Marstine, 2005; Sandell, 2002; Vergo, 1989; Weil, 1990).

Naturally, this museological vision with its seemingly idealistic connotations invites critique. However, there is a major problem with both proponents and opponents: the fact that most of the museum literature has been 'highly theoretical and not well-grounded in practice' (McLean, 2004, p. 205) failing to achieve a much needed 'synergy or synthesis' between theory and practice (MacLeod, 2001). Extending this line of critical thought, I argue that the actual functioning of the new museology is insufficiently understood in empirical terms. Although Macdonald (2010) discerns a growing number of ethnographic approaches to museological production and reception, I am not aware of any study of the political museum experience. But without such insights, a theoretical paradigm change such as the shift from 'temple' to 'forum' remains somewhat detached and abstract. It is my task to move the debate from the realm of thought into the social world of life, and so it is necessary to embed this thesis in the associated field of 'museum visitor studies'.

\section{Museum visitor studies}

As in the previous section, I do not attempt a comprehensive survey of this topic. Rather, this introduction contextualises this thesis and allows the reader to retrace the identification of the gap, the development of the topic and the formulation of the research aims at the early stages of the research process. For this purpose, I focus here on a critique of current research practice. 
When presenting the research design in Chapter Two, I refer to further relevant and affiliated approaches within museum visitor studies and other related fields.

Preziosi \& Farrago (2004, p. 1) emphasise that 'more has been written about museums in the past decade, it seems, than in the previous century'. As we have seen, the new museum's purpose, responsibility and potential as a forum for debate as well as an agent of social change and cultural inclusion has been widely recognised and theorised. But does it work in practice for and with the visitor, the central focus of the new museology? Research on the long-term impact of museums on visitors, and therefore on society, has been largely neglected; consequently we are not able to answer 'the question we must ultimately ask ourselves', as Weil (in G. Allen \& Anson, 2005, p. 159) reminds us: 'do our museums make a real difference in, and do they have a positive impact on, the lives of other people?'

Black (2005) gives an historical overview of the development of museum visitor studies as a new feature of the visitor-focused museum and points out that it gained increased importance only in the 1990s. Research data is primarily of a quantitative nature and serves mainly marketing purposes 'to pump up the attendance statistics that are so gleefully printed in annual reports', as Cameron (1971, p. 21) aptly puts it. Vergo (1989, p. 3) supports this critique and laments that the museum's 'success' is measured 'merely in terms of criteria such as more money and more visitors'. But taking into account that, in the words of Janes and Conaty (2005, p. 108), 'it is unwise to equate popularity with external usefulness or individual enlightenment', such simplistic and reductionist approaches cannot reveal the impact of a museum on people's lives beyond 
figures, numbers and statistics. Furthermore, these indicators can hardly be sufficient attributes for institutions 'whose purpose is their meaning' (Janes \& Conaty, 2005, p. 12).

At this point, I want to stress that this strongly worded line of critical thought serves well to make my case but does not intend to discredit all quantitative approaches, which make sense in certain contexts such as annual reporting and public accountability. However, if the goal is an understanding of the meaning and purpose of the new museology, then qualitative insights are of fundamental significance. Hooper-Greenhill (2000) expands on the critique of the predominant marketing focus of visitor research and demands an examination of multi-cultural audiences' interpretive processes as well as the political ramifications of visual culture in museums. According to Hooper-Greenhill (2000), it is paramount to re-conceptualise the museum-visitor relationship by placing the issue of meaning at the heart of the 'post-museum'. So far the reception of, and impacts on, audiences have been largely neglected (Sandell, 2002). G. Allen \& Anson (2005, p. 211) lend further weight to this assertion by concluding that 'the understanding of how meanings are made and changed, and how perceptions are formed and altered... is still in its infancy in terms of research practices'. Although the relationship between viewer and viewed has become a subject of analysis, with the "location of meaning at the destination rather than the source' (Kirshenblatt-Gimblett, 1998, p. 12), it lacks direct reference to the museum and is mainly of a theoretical nature 'with much less attention to the empirical study of the meanings' (Hooper-Greenhill, 2000, p. 108).

In the past, more sophisticated visitor research has mostly focused on learning outcomes and the factual recall of content (RCMG, 2003). But the concept of 'meaning-making' has been of 
growing importance within the museum community, since it can help to converge the human experience and museological practice as well as human needs and the role of museums within society (R. Mason, 2005; Silverman, 1995). The comprehensive studies 'Making meaning in art museums' (RCMG, 2001a, 2001b) highlight the lack of substantial research on the lived visitor experience. By applying multiple qualitative methods, the researchers discern the interrelation between individuals' cultural repertoires and interpretive strategies, and the social framework in the form of interpretive communities. Hecht (2004) also refers to link between the individual experience and the socio-cultural context, and postulates a new synthesis approach integrating both the small scale psychological as well as the large-scale socio-cultural paradigms to gain a deeper understanding.

As we have seen, the impact and value of museums have been widely theorised, but similar to the museum experience there do not exist sufficient empirical insights and most studies define potential indicators only (Kelly, 2006; Scott, 2003). Scott (2003) argues that empirical evidence is required to support these claims. In this context, D. Anderson (2005, p. 21) highlights the need for a 'new language' to describe museum impact and value contributing to the momentum of this debate in the museum world (Scott, 2002; Scott \& Soren, 2009). Apart from the paucity of qualitative perspectives, the dominant short-term focus of research initiatives emerges as another crucial limitation to visitor understandings. Scott (2002) emphasises that the complex role of museums within society cannot be appropriately grasped by quantitative, short-term indicators. Consequently, Black (2005, p. 156) calls for long-term research instead of short-term evaluation while recognising the complexity of such 'qualitative research at the cutting edge'. Long-term and in-depth approaches would facilitate shifting the focus from delivering 'cultural 
commodities' to marketing target groups towards understanding 'individuals in cultural reflection and responsible action' (Janes \& Conaty, 2005, p. 145). This thesis responds to Sandell's (2007) call for longitudinal studies and attempts to develop a 'new language' of museum purpose and value.

The preceding overview of the new museology and museum visitor studies served to identify a disciplinary gap of significance for this study: the lack of qualitative and long-term visitor insights into the functioning of the postulated new museology. In other words, it became clear that paradigmatic shifts such as the reinvention of the museum as forum are of a theoretical nature and not empirically grounded. It follows that museum theory, practice and research operate in a disjointed fashion drawing partial and hermetically sealed pictures. Above all, the expanding, pluralised and critical field of museum studies is characterised by a growing sensitivity for complexity. It requires sophisticated theoretical and methodological concepts and approaches to examine complex processes and prevent simplistic reductions (Macdonald, 2010). Gable (2010) stresses that the ethnographer seeks and dissects cultural complexity and HooperGreenhill (2006) considers ethnography as the most advanced form of museum visitor research. At this point, I have completed the disciplinary contextualisation of this thesis, which embodies a critical museological ethnography. For this purpose, it is necessary to establish sophisticated theoretical and methodological frameworks underpinning the empirical investigation.

\section{Theoretical framework}

Te Papa: a forum for the world? This question has been the driving force of the intellectual journey behind this thesis. In this section, I lay out the theoretical route leading to methodological 
approaches and empirical answers in the following chapters. My theoretical argument inspects the individual components of the overarching question proceeding from the broad world through the museum phenomenon up to a discursive understanding of Te Papa. This argumentative strategy makes sense to me and should enable the reader to retrace the theoretical evolution of this thesis before considering its methodological and empirical manifestations.

\section{Traveling cultures in a cosmopolitanised world}

'Cosmopolitanisation' in this sense means latent cosmopolitanism, unconscious cosmopolitanism, passive cosmopolitanism which shapes reality as side effects of global trade or global threats such as climate change, terrorism or financial crisis. My life, my body, my 'individual existence' become part of another world, of foreign cultures, religions, histories and global interdependencies, without my realising or expressly wishing it. (Beck, 2006a, p. 19)

The recent financial meltdown, which started in the USA and left no single country unaffected culminating in the most severe global economic crisis in nearly a century, epitomises Beck's (2006a, p. 19) view of a 'latent cosmopolitanism, unconscious cosmopolitanism, passive cosmopolitanism which shapes reality'. This is the 'really existing cosmopolitanisation' in an 'empirical sociological sense' as opposed to 'cosmopolitanism' in a 'normative-philosophical sense', as Beck (2006a) further argues. Given the economic, environmental, political, social and cultural interrelations and interdependencies on a global scale, the national is exposed as a 'zombie-category' (Beck, 2006b) mirroring the 'territorial prison theory of identity, society and politics' (Beck, 2006a, p. 6). Due to exploding 'mobilities' (Urry, 2007) in transportation and communication, the 'cosmopolitanisation' of life forms and human experiences is in fact successively amplified and appears unstoppable. 
This thesis is devoted to the hermeneutic complexities of cross-cultural encounters in a 'cosmopolitanised' world. As we shall see in the course of this section, the mixing of 'traveling cultures' (Clifford, 1997) is no contemporary novelty but an endemic process with concrete histories at the level of practice. What is new, however, is the evolution of a 'world horizon' (Beck, 1997), a ubiquitous sense of globality in lived experience induced and magnified by modern means of communication and transportation. This leads to a 'biographical globalisation' or 'polygamy of place' (Beck, 1997) which embodies the entrance of a broader globality into a specific life. Contemporary identities are characterised by 'transnational forms of life' and 'multiple loyalities', as Beck (2006a) points out, which require a constant 'inner mobility' (Beck, 1997) by actors to manage life 'in-between' (Bhabha, 1994) differing, overlapping and conflicting worlds. 'Ambivalence' and 'reflexivity' become key demands and characteristics of our time (Beck \& Bonss, 2001). A 'world of', in Appadurai's (1993) words, 'disjunctive global flows', is thereby threatened not by linear and hierarchical homogenisation, as Appiah (2006) emphasises, but by 'interpretive contests' (Said, 2003). According to Kendall, Woodward \& Skrbis (2009, p. 19), 'there must be an active process of interpreting cultural difference by social agents'.

As stated before, I focus on the cultural praxis of 'traveling cultures' (Clifford, 1997) to further dissect the 'cosmopolitanised' world and specify the research context of this study. With the support of Clifford (1997, p. 25; 36), I am able to establish a view of 'culture (along with tradition and identity) in terms of travel relations' with 'specific histories, tactics, everyday practices of dwelling and traveling: traveling-in-dwelling, dwelling-in-traveling'. I think it is paramount to consider this inherently human travel behaviour in order to illuminate its 
contemporary manifestations. Any other over-simplified and over-generalised approach might deliver a condemning critique, but without excavating the roots of cultures in motion. I turn again to Clifford (1997, p. 25) to get a glimpse of complex 'histories of travel' eroding the above described 'territorial prison theory of identity':

How do groups negotiate themselves in external relationships, and how is a culture also a site of travel for others? How are spaces traversed from outside? To what extent is one group's core another's periphery? If we looked at the matter in this way, there would be no question of relegating to the margins a long list of actors: missionaries, converts, literate or educated informants, people of mixed blood, translators, government officers, police, merchants, explorers, prospectors, tourists, travelers, ethnographers, pilgrims, servants, entertainers, migrant laborers, recent immigrants.

It does not come as a big surprise that intellectuals with personal biographies of 'traveling cultures' are responsible for the most exciting thinking beyond territorially defined traditions and rigid national perspectives. Said's (2003) work on the discourse of 'Orientalism' has been groundbreaking despite its essentialising limitations, as Clifford (1988) rightly comments. The following passage supports my previous point:

For those of us who by force of circumstance actually live the pluri-cultural life...it is incumbent upon us to complicate and/or dismantle the reductive formulae and the abstract but potent kind of thought that leads the mind away from concrete human history and experience and into the realms of ideological fiction, metaphysical confrontation, and collective passion. (Said, 2003, p. xxiii) (my emphasis)

Appiah (2006) and Ong (1999) follow suit by offering examples of such concrete cosmopolitan histories and experiences within the non-Western environments of Ghana and Chinese overseas migration respectively. Bhabha (1994), who plays a significant role throughout this thesis, dissects the 'location of culture' and interrogates 'cultural differences' as discursive 'in-between spaces' within ‘border lives'. The prominent Māori scholar Royal (2008) transposes Said’s reasoning into the context of Aotearoa New Zealand's cultural politics and the realm of this 
thesis. Royal $(2008$, p. $6 ; 2 ; 1)$ demands the deconstruction of 'reductive formulae', which 'fail to represent the diversity - of experience, thought and values - that exists within populations', and asks for 'articulations of identity' allowing 'a more complicated, complex but ultimately richer view of life and identity than that afforded by the terms 'Māori' and 'Pakeha".

This argument is informed by the inherently 'cosmpolitanised' character of New Zealand's society. Royal's (2008, p. 9) call to 'respect difference and diversity whilst participating in a whole called Aotearoa-New Zealand' mirrors the multiple identifications of a 'cosmopolitan vision' (Beck, 2006a). Importantly, this is not a contemporary novelty but the current stage of a historical process. 'Pakeha' (European New Zealand) settlers have come from all over the world while 'Māori' have equally traveled and migrated throughout the Pacific always maintaining their connection to the spiritual homeland Hawaiki (Salmond, 1991). In other words, both abstract ethnic categories are characterised by an empirical multiplicity and 'difference within' (Bhabha, 1994). The ongoing cosmopolitan orientation within Māoridom becomes clear in the strategic outlook of the School of Māori Arts and Crafts, founded in 1927, as formulated in that institution's philosophy:

It must be something signifying the blended cultural life of the present-day Māori, with Māori and Pakeha elements combined in it; and it must be something that indicated the persisting individuality of the Māori people; not only what they have adopted, but what they had adopted to their own ancient usages, after one hundred years of contact with Western civilisation. (Anon, 1940)

Bhabha (1994, pp. 35-36) insists that 'cultures are never unitary in themselves, nor simply dualistic in the relation of Self and Other'. The common simplistic and artificial binaries are opened by historical 'in-between spaces', 'the cutting edge of translation and negotiation...that carries the burden of the meaning of culture' (Bhabha, 1994, p. 38). In the context of 
contemporary indigenous cultures, accusations of cultural plasticity and commodification exist of course in abundance and attack from any conceivable angle. Somewhat ironically, the debate itself fuels the inescapable processes of the 'construction of culture' and 'invention of tradition' (E. M. Bruner, 2005). Hakiwai, whom I interviewed as part of this research, presents an indigenous perspective which liberates itself from the claws of an 'oppressive authenticity' (Sissons, 2005) and emphasises that staying "stagnant in one time period" would amount to cultural death:

I think our ancestors were always innovating and creating. You have a look at colours, designs, shapes, thought processes going on, never static. So that whole knowledge system is always engaging, re-engaging, I won't say re-inventing but always developing in an ongoing way. And to me that's what Mātauranga Māori is. I'd hate to sort of think that the koru for example was a fixed pattern and remained there forever. But I like to think that it is now continuing, unfolding in different ways to respond to different things. And that's to me about cultural growth, cultural development... I am not a person to say that we should maintain something that we may perceive or see because I don't think that's healthy. I think that actually goes towards the ultimate death of that art form.

The limited scope of this theoretical introduction does not allow me to draw a picture in greater breadth and depth. However, it should have become obvious that there exists a 'concrete human history and experience' of 'traveling cultures' in a 'cosmopolitanised' world. For the purpose of this study and the development of my argument, it is required to further specify the travel context. Global touristic travel or tourism provides the platform for the subsequent examination of cross-cultural journeys in this thesis. At the same time, I need to stress once again that I do not lose sight of the diverse forms of travel such as migration, study and work, which combine even within one individual biography. This holistic awareness enables me to bypass the trap of a dichotomous analysis which generalises from an inherently partial perspective without taking proper heed of the complexities of any human affair. 
Tourism has evolved as a major political, economic, social, cultural and environmental phenomenon with a global scope. It is an industry with far reaching impacts on any sphere of life in any part of the world. In fact, the field of tourism is inextricably linked to the dynamics of identity formations, articulations and contestations (E. M. Bruner, 2005; Lanfant, Allcock, \& Bruner, 1995). Although it has experienced an explosion of significance over the last decades through major technological advances in communication and transportation, it is again important to note that tourism as a particular kind of travel is not a modern invention. Instead, the current era only witnesses new dimensions of a historically grounded human process (Ludwig, Has, \& Neuer, 1990).

Given the dominance of the economic domain in political affairs, academic investigations of tourism have been mostly conducted within this context (Lanfant, et al., 1995). The logical outcome is the production of narrow perspectives. On the one hand, such a research focus overdetermines the economic sphere of tourism and reduces its multifaceted nature. On the other hand, it discards the historical fact that economic relationships have always been part of 'traveling cultures' long before the establishment of a capitalist system in its current form. It would be, of course, naive to deny the centrality of economic processes in contemporary life in general and in tourism in particular. However, the problem starts when we translate "the economy' into a self-defined homogeneous instance operating as the ground of society...a single, self-defining mechanism', as Laclau (2005, p. 237) argues. It is therefore crucial to understand capitalism as an essentially heterogeneous 'complex' rather than a 'self-enclosed totality' (Laclau, 2005, p. 230). The complex phenomenon 'tourism' begs for the same careful analytical 
treatment, as done in more balanced cultural and social studies of travel experiences (E. M. Bruner, 1991, 1995, 2005; Suvantola, 2002).

I conclude this section with my own understanding of touristic travel or tourism. My perspective is aided by the etymology of the adjective bewandert in the German language. Today, this word is a synonym for 'educated' or 'knowledgeable' while in texts of the $15^{\text {th }}$ century it would have meant 'well traveled' (Bauerkaemper, Boedeker, \& Struck, 2004). I set out from the view that 'culture' represents the 'webs of significance...man...himself has spun' (Geertz, 1973, p. 5), a 'contingent scheme of meaning' (Ong, 1999, p. 243). I perceive tourism as a particular cultural praxis and medium for the dynamic interaction and transfer between cultural worlds of meaning (Bauerkaemper, et al., 2004; Boomers, 2004; Dworschak, 1994). Accordingly, it requires hermeneutic explorations of traveling as interpretive engagement and discursive negotiation in order to elucidate travel experiences that have been mostly ignored in tourism research (E. M. Bruner, 1995; Crick, 1995). This facilitates the analytical move beyond the economically determined terminology of 'production' and 'consumption' (Ateljevic, 2000), which renders the 'most ineffable of cultural phenomenon - experience' (Healy \& Witcomb, 2006, p. 1.4.) as purely economic and forecloses a more nuanced picture, which I intend to draw in this thesis.

\section{Contact zones, museums and Third Spaces}

Contact approaches presuppose not socio-cultural wholes subsequently brought into relationship, but rather systems already constituted relationally, entering new relations through historical processes of displacement. (Clifford, 1997, p. 7) 
In the previous section, I have broken down the 'cosmopolitanised' human condition of the $21 \mathrm{st}$ century through the ubiquitous cultural praxis of 'traveling cultures'. I further specified the travel context by introducing tourism. In this section, I continue with the funnelling approach to shed light on the places and spaces of cross-cultural engagements generated through tourism practices.

It is again Clifford (1997) who assists with the development of this study's theoretical framework. 'Contact approaches', which he borrows from Pratt, epitomise a promising analytic perspective on the complex clash of cultural worlds. Clifford (1997, p. 7) stresses that other cultural concepts, such as 'acculturation' with 'its overly linear trajectory' and 'syncretism' with 'its image of two clear systems overlaid', do not reflect the multifaceted, ambivalent and contingent processes of cross-cultural encounters. A 'contact perspective' instead, Clifford (1997, p. 216) convincingly argues, 'complicates diffusionist models, whether they be celebratory...or critical'. While the latter certainly deserve their role in academic investigations, it is important to keep in mind that, in Clifford's (1997, p. 198) words, 'a wholly appropriate emphasis on coercion, exploitation, and miscomprehension does not, however, exhaust the complexities of travel and encounter'.

Other scholars have followed this vein of thought. Appiah (2006, p. 113), for example, highlights that 'cultural purity is an oxymoron' and speaks instead of an organic 'cosmopolitan contamination'. By addressing the generally alleged threat of cultural homogeneity through globalisation, Appiah (2006, p. 111) emphasises the reductionist and deterministic nature of the debate itself:

Talk of cultural imperialism structuring the consciousnesses of those in the periphery treats Sipho and people like him as tabulae rasae on which global capitalism's moving 
finger writes its message, leaving behind another homogenised consumer as it moves on. It's deeply condescending. And it isn't true.

Ong (1999, p. 10) lends further support to this assertion by stating that 'cultural forms have not been homogenised across the world' and even the

widespread dissemination of the trappings of globalisation - world markets, mass media, rapid travel, and modern communications... have had the effect of greatly increasing cultural diversity because of the ways in which they are interpreted and the way they require new meanings in local reception. (my emphasis)

We have entered the realm of 'interpretive contests' and the associated phenomena of 'polyphony' and 'heteroglossia' (Holquist, 2002) within the hermeneutic terrain of 'contact zones'. But before I proceed with this argument in the course of this section, I conclude the current discussion by pointing out a major limitation of Clifford's particular 'contact approach'.

Although Clifford $(1988,1997)$ refers to contemporary and historical cosmopolitan experiences, his unconditional defence of cultural relativism and scepticism towards 'cosmopolitan essences' and 'universal values' fails to provide 'contact zones' with a shared symbolic terrain which can potentially lead translations to understandings. Appiah (2006) instead points out that one of the greatest achievements of anthropology itself is the awareness that we can make sense of each other. Given the 'cosmopolitanised' world of the 21st century, 'contact zones' are inevitably embedded in such context. This is not to be misunderstood as some artificial 'cosmopolitan essence' or 'universal value', but should be seen as a common framework in which the 'inescapable hermeneutic complexity in moral and political affairs' (Held, 2008, p. 161) can be contested. 
Despite this deficiency, for which I attempt to compensate through empirical examinations and theoretical propositions, Clifford (1997) links 'contact zones' to the museum world. The conceptual understanding of museums as 'contact zones', as places of contentious and collaborative relations and interactions, represents the most appropriate starting point for this thesis. Unsurprisingly, this conceptual vision has been critiqued as being merely a reconstruction of the reformist agenda and citizenry technology of the state (Bennett, 1998). However, in a remarkable shift in thinking, from seeing museums as totalitarian state expressions and powerhouses to understanding them as 'differencing machines', Bennett (2006) himself later admitted that museums might indeed be associated with 'contact zones'. More contextualised and historicised research shows that a museum can function as a site where a complex web of demands and articulations is expressed, negotiated and contested (Macdonald, 2002; McCarthy, 2007; Witcomb, 2003).

In my view, museums are inextricably connected with the cultural praxis of 'traveling cultures' and 'contact zones' as particular places and spaces of encounter. 'Cosmopolitanised' contacts shape the cultural institution 'museum', which inherently depends on the contextualisation, decontextualisation and re-contextualisation of cultures, people and objects through different forms of travel and cross-cultural engagements. Consequently, as a research site for this thesis, the Museum of New Zealand Te Papa Tongarewa, and its bicultural policies, practices and programmes, is best approached through a 'contact' perspective.

Fleras \& Spoonley (1999, p. 236) write that in Aotearoa New Zealand 'a commitment to biculturalism has served as de facto government practice since the late 1980s, following moves to 
acknowledge the Treaty as a foundation document between partners'. The establishment of the Waitangi Tribunal and the acceptance of Te Reo Māori as an official language reflected the political support for this development (King, 1999, 2003). Nevertheless, the socio-political concept is a work and struggle in progress that is heavily contested. Different understandings, interpretations and claims have led to new potential orientations such as 'binationalism', which arguably offer a better model for 'living together differently' in a plural democracy such as New Zealand (Fleras \& Spoonley, 1999; Maaka \& Fleras, 2005).

Although widely regarded as one of the most 'bicultural' institutions in Aotearoa New Zealand, museums in general as well as Te Papa in particular have been sites of controversy and conflict. Several scholars have discussed the limitations of bicultural practice in museum management and museological representation (Butts, 1994; Coster, 1994; O’Regan, 1997a, 1997b). Others have questioned biculturalism's contemporary socio-cultural (O'Sullivan, 2007; Royal, 2008) and museological relevance (Henare, 2005; Message, 2006; Thomas, 1994; Williams, 2003).

Surveying Aotearoa New Zealand's bicultural experiment in more detail is clearly beyond the scope of this thesis. It is worth highlighting that, given the hermeneutic complexity of human affairs, 'biculturalism' has never been a linear, one-dimensional and superimposed ideology by the state, but is instead the dynamic outcome of the 'war of positions' in the fluid, ambiguous and indeterminate spaces 'in-between'. McCarthy (2007) shows how the remarkable encounter of Māori and Europeans unfolded throughout the colonial cultures of display in museums, ultimately leading to Māori control and ownership of Māori collections and exhibitions. Today, Te Papa is committed to developing as a bicultural organisation based on the principle of 
partnership enshrined in the Treaty of Waitangi, signed in 1840 between the British Crown and Māori. The Treaty is widely regarded as the founding document of Aotearoa New Zealand; and after decades of negligence it has gained constitution-like status in recent years. Concrete policies and practices such as Mana Taonga and Mātauranga Māori ensure Māori participation and involvement in the museum (Hakiwai, 2006; Smith, 2006) (see Museum of New Zealand Te Papa Tongarewa Bicultural Policy in Appendix N and Mana Taonga Principle in Appendix M).

Before I continue with the refinement of the theoretical framework, it is helpful to briefly point out the fruitful overlap of appropriate critique and contact perspectives. O'Sullivan (2007) lists the limits of biculturalism, which forces a homogeneous treatment on heterogeneous entities such as 'Pakeha' and 'Māori', reduces the latter to the role of a junior partner at the expense of potential self-determination, and neglects other forms of partnerships beyond an allegedly monolithic and all dominating state. Royal (2008, p. 11) develops this critique by lamenting the 'ethnicisation of the Treaty' and demanding the liberation of values such as 'tino rangatiratanga and kāwanatanga out of a constricting ethnic and cultural paradigm'. 'Contact approaches', which according to Clifford (1997, p. 7), 'presuppose not socio-cultural wholes subsequently brought into relationship, but rather systems already constituted relationally' provide the analytical basis to reach beyond the rigid confines of an 'ethnic absolutism' (Ong, 1999) or 'ethnic structuralism' (Williams, 2003). The doors to the 'difference within' are opened, but it remains to flesh out the theoretical strategy for its empirical investigation.

According to Clifford (1997, p. 7), 'cultural action, the making and remaking of identities, takes place in the contact zones, along the policed and transgressive intercultural frontiers of nations, 
peoples, locales'. Clifford's 'contact zone' concludes with the problem of 'translation'. Bhabha (1994) in return theorises this 'translation' as 'moments' or 'processes' in the 'articulation of cultural differences', and provides a distinctive and particularly useful perspective on 'cultural action' in 'contact zones'. Bhabha (1994, pp. 1-2) paves the way from the physical place of encounter to the discursive space of dialogue:

What is theoretically innovative, and politically crucial, is the need to think beyond narratives of originary and initial subjectivities and to focus on those moments or processes that are produced in the articulation of cultural differences. These 'in-between' spaces provide the terrain for elaborating strategies of selfhood - singular or communal that initiate new signs of identity, and innovative sites of collaboration, and contestation, in the act of defining the idea of society itself. (my emphasis)

Bhabha (1994, p. 2) expands on the border experience, the 'liminal space', and illuminates the 'interstices - the overlap and displacement of domains of difference' which are further magnified in the 'cosmopolitanised' life world of our time. By offering 'cultural difference as an enunciative category', Bhabha (1994, p. 60) opens a hermeneutic terrain of cultural negotiation and contestation without resorting to the last bastion of binary oppositions, which are produced by the immanently essentialising concept 'culture' itself. With the help of Bhabha (1994, p. 36), I can lay the theoretical foundation for the empirical exploration of 'cultural action' as 'interpretive contests' in 'contact zones':

The pact of interpretation is never simply an act of communication between the I and the You designated in the statement. The production of meaning requires that these two places be mobilised in the passage through a Third Space.

The intervention of the 'Third Space', Bhabha (1994, p. 37) continues, 'makes the structure of meaning and reference an ambivalent process', which echoes the hermeneutic phenomenon of 'polysemy' (Ricoeur, 1981) and exposes any claim of cultural purity as an impossibility even before unearthing empirical evidence. Consequently, 'the meaning and symbols of culture have 
no primordial unity or fixity', Bhabha (1994, p. 37) further argues, 'even the same signs can be appropriated, translated, rehistoricised and read anew'. In other words, there is no a priori in the 'mind-constructed world' (Dilthey, 1976) apart from the mind itself. Further inspecting the dialogical 'processes', Bhabha (1994, p. 228) concludes that the 'moment' of 'translation' is the 'movement of meaning'. 'Translation' embodies the 'performative nature of cultural communication' which works through the 'continua of transformation' (Benjamin in Bhabha, 1994). Before I present my approach to illuminate the 'articulation of cultural differences', it is still required to complete the theoretical framework by introducing the public sphere of cultural politics.

\section{A worldmaking approach to a global public sphere}

The fleeting nature of the public and of public space - its phantom quality meaning that the public cannot be pinned down as a thing - is actually what constitutes its democratic character. Hence, the idea that the public is a phantom, a powerful intellectual concept which shifts the definition of politics from a substance, which is always there no matter what we do, to a movement that can be interrupted at any moment if we fail to carry it further. (Weibel \& Latour, 2007, p. 101)

So far I have traveled the theoretical journey from the 'cosmopolitanised' world through 'traveling cultures' to museums as particular 'contact zones'. I reconceptualised physical 'contact zones' of encounter as discursive 'Third Spaces' of dialogue to elucidate the 'moments' and 'processes' of cross-cultural 'translation'. This opened a hermeneutic terrain of negotiation and contestation, which needs to be further theorised in order to shed light on the political dimension in the making of culture. Te Papa defines itself as a 'forum', or place of cultural politics, and before I can interrogate this claim throughout this thesis I need to turn first to an introduction of the 'public sphere'. 
The reinvention of the museum as 'forum' in the course of the new museology and the notion of the 'public sphere' are closely linked. Within this context, the site 'museum' is a relatively new and burgeoning object of academic analysis. It has been appropriated by a myriad of related disciplines and research tends to operate in discursive cycles producing such essentialised totalities as the museum, the culture, the state or the visitor. Abstract and theoretical concepts like 'discourse' and 'structure' assume the obscure and all dominating role of an 'invisible actor behind the scenes' (Arendt, 1958) leading to an 'emanatist vision' (Bourdieu, 1990) which reduces historical subjects to incidents of discourse and embodiments of structure.

The main reason for such simplistic and reductionist accounts is a misunderstanding of 'hegemony' and the political. By reading museums as cultural texts and hegemonic extensions of the reformist agenda and citizenry technology of the state, such perspectives fail to consider that 'hegemony' is no totalising frame but an inherently contested terrain (Laclau, 2000a). In other words, the state itself is a heterogeneous and relational complex, and, in the case of New Zealand, indigenous and other agencies are at work within and not outside the state and its institutions like museums. Consequently, culture and politics can be seen not as linear, normative prescriptions but instead as dynamic, hermeneutic contestations.

The standard approach also suggests that museum visitors are passively interpellated by hegemonic ideologies and their 'preferred readings'. However, empirical research has proven that such assertions are only theoretical assumptions (Hooper-Greenhill, 1995). The making of history, culture and politics are 'cacophonous' (Gable, 2006) processes of coercion, resistance and negotiation. Research needs to shed light on these 'interpretive contests', which begs for 
critical hermeneutic studies of experiences and meanings as in this thesis beyond 'anemic' (Ong, 1999) and reifying cultural perspectives in the purely normative sense.

Discussions of the 'public sphere' usually start with Habermas (1989) and 'The structural transformation of the public sphere'. The title itself indicates that again a singular and unitary 'structure' is the point of departure leading to the above assumption of an 'invisible actor behind the scenes'. Although still being influential and useful, Habermas' conception has been widely critiqued and refined stressing a plurality of 'competing counterpublics' (Fraser, 1993) or a 'public of publics' (Bohman, 2004). Further specifying such a line of thought, political theorists such as Laclau (2005) and Butler (2000a) remind us that political identities, which Habermas thought of only in the Bourgeois sense, are not determined by an a priori structural logic but are instead the outcome of concrete processes and practices among heterogeneous elements.

Another limiting aspect of Habermas' view is the nature of the political discourse itself. Envisaging an unconstrained rational debate requiring the 'bracketing of differences' (Fraser, 1993) remains an abstract illusion. It fails to address what the political actually means. Mouffe (1999) stresses in her plea for an 'agonistic pluralism' that the political is never free of power and antagonism. Passions, which Habermas considers impediments to an ideal speech situation and rational consensus, are in fact the ontological basis of any political engagement. It follows that the required 'utopian self-abstraction' (Warner, 1993) could never grasp the ontological dimension of identity politics which is characterised by 'discursive contestation' (Fraser, 1993) rather than 'deliberation' (Habermas, 1999). 
The anthology 'The phantom public sphere' edited by Robbins (1993) facilitates a much needed shift in thinking about politics and the public sphere 'from a substance...to a movement' (Weibel \& Latour, 2007, p. 101). It lays the foundation for dissolving the 'emanatist vision' of selfexplanatory and perpetual systems and structures towards the interrogation of actions and performances which simultaneously constitute and are affected by such wider socio-political realities. This is what Sartre (1976) meant with his circular critique of dialectical reason. Men make their own history, but under specific historical, political and socio-cultural circumstances. We mediate and are mediated at the same time. Sartre (1976, p. 36) further argues that such a dialectic must 'proceed from individuals and not from some kind of supra-individual ensemble'. This leads us to an understanding of human agency beyond Bourdieu's (1990) sense of incorporated structures which seems to elevate the 'habitus' without consciousness, will and reflection to the same 'emanatist' status he reserves for the 'social physics' of structures. It opens the door to worldmaking.

The political making of cultural worlds requires further theoretical substantiation before I introduce the tool for its empirical dissection. Within the realm of cultural theory, Appiah (2006, p. 107) highlights that any 'tradition was once an innovation', Ong (1999, p. 243) concludes that 'culture-making involves...processes of cultural self-theorising and re-envisioning', and Clifford (1997, p. 46) inspects 'identity as a politics rather than an inheritance' highlighting 'the tense interaction between these two sources'. Calhoun (2002) elaborates on such cultural politics and carries it into the 'public sphere'. Using the term 'world-making' in Hannah Arendt's sense, Calhoun (2002, p. 148) asserts that 'the production of new culture is as important as inheritance' and, in fact, 'distinctions between the two are less clear than common usage implies'. According 
to Calhoun (2002, p. 152; 154), 'world-making is a way of approaching culture that emphasises agency and history' and 'it is precisely the kind of question of personal identity that produces passions that escape conventional categories of the political', as I argued earlier. Calhoun's (2002, p. 158) demand creates the seamless transition to my approach to the public sphere: The key is to reject the notion - which nationalist ideologies indeed commonly assert that the cultural conditions of public life, including both individual and collective identities, are established prior to properly public discourse itself.

To put it succinctly, there exists no independent a priori logic of reified structures, systems and substances emanating from some divine ground. Instead, cultural politics are constituted through interpretive actions, movements and performances. As I insist throughout, it would be naive and negligent to deny the existence and the impact of wider discursive realities. However, everything must originate in an individual, as Latour (2005) argues, or rather in a 'complex, historical subject' to use Clifford's (1997) words, and is no mechanical product of some mysterious 'invisible actor'. With the help of Laclau (2000b, p. 58), Sartre's (1976) circular dialectic can be brought into the political realm to attest to the hermeneutic reciprocity between the whole and its parts (Dilthey, 1976):

...we do not simply have subject positions within the structure, but also the subject as an attempt to fill these structural gaps. That is why we do not have just identities but, rather, identification. If identification is required, however, there is going to be a basic ambiguity at the heart of all identity.

A worldmaking approach to cultural politics and the public sphere has not entered museological thinking, as Karp, Kratz, Szwaja, \& Ybarra-Frausto’s (2006) latest work indicates. One of the contributors, Bennett (2006, p. 50), for example refuses to accept 'museums as parts of public spheres if by that term we mean a set of institutions standing outside the state and functioning as a means of criticising it'. Given my previous argument, it is clear that Bennett's point of critique 
is still stuck in the structural logic of diametric oppositions. On the one hand, it does not attest to the 'social as a circular fluid... and not a specific type of organism' (Latour, 2005, p. 13). On the other hand, it fails to consider that 'civil society' itself 'is constituted as a political space' (Laclau, 2000b, p. 51). Laclau (2000b, p. 53) concludes that 'a political dimension becomes constitutive of all social identity, and this leads to a further blurring of the line of demarcation state/civil society'. Bennet's reasoning on museums and the public sphere, instead, is trapped in a dichotomised political spectrum of monolithic entities without paying tribute to the "war of positions' in the spaces 'in-between'.

Interestingly, Karp et al. (2006) even considered the title 'Museums and global public spheres' for their anthology, but ultimately decided against it due to the allegedly predominant association of the concept 'public sphere' with Habermas' thinking. This reservation was proven right in the context of Bennet's essay. In this thesis, however, I venture beyond such reductionist and reifying perspectives. For this purpose, Habermas $(1999$, p. 251; 248) himself offers a view on a 'decentred society' with a 'higher-level intersubjectivity' evolving 'in the informal networks of the public sphere'. In my opinion, a museum such as Te Papa functions as a 'contact zone' of cultural politics within a 'cosmopolitanised' world. It represents a global public sphere or discursive space, which is 'heterogeneous, multilayered and overlapping' like any other public space (Howarth, 2008). But how is it experienced, lived and performed? What does identity politics actually mean? 
To explore these crucial questions I draw on Arendt (1958, p. 198) who states:

...the political realm arises directly out of acting together, the 'sharing of words and deeds'. Thus action not only has the most intimate relationship to the public part of the world to us all, but is the one activity which constitutes it.

Arendt (1958, p. 178) further argues that 'most acts are performed in the manner of speech'. In fact, an act without speech loses its subject and becomes mechanical. Departing from such an assertion, which puts narrative and action at the heart of the human condition, I am able to lay out the methodological framework of this study. Narrative, according to Bhabha (2008, p. 45), 'that peculiar intersection of words and actions', provides me with the tool to shed light on the complex dynamics of interpretive worldmaking as I subsequently lay out in the research aims.

\section{Research aims}

As the title indicates, this thesis interrogates the 'museum forum' idea through a case study of the Museum of New Zealand Te Papa Tongarewa (Te Papa). I have shown that the reinvention of the museum as 'forum' within the new museology and the notion of the 'public sphere' are inextricably linked. Both concepts have been widely scrutinised, with most favouring a democratic domain governed by reason and rational debate. But what does it mean to experience a museological space, and how is a public sphere lived? The title signals that this thesis is embedded in a radically 'cosmopolitanised' world, facing a myriad of unforeseen cross-cultural encounters which are the side effects of global trade and threats (Beck, 2006a). The potentially positive role of museums in this context has been broadly recognised and conceptualised. But what does cross-cultural dialogue mean for the person experiencing it, and how is it negotiated within time and space? 
Drawing on a long-term narrative study of global visitors to Te Papa, this thesis provides a critically informed empirical exploration of these crucial questions. While the narrative approach is recognised as the most appropriate way to facilitate meaning-making among visitors ( $\mathrm{O}^{\prime} \mathrm{Neill}$, 2007; L. C. Roberts, 1997), it has rarely been used as a visitor research method (S. Allen, 2002; Everett \& Barrett, 2009; Lelliott \& Pendlebury, 2009; Paris \& Mercer, 2002; Rowe, Wertsch, \& Kosyaeva, 2002). This leads to the narrative exploration and humanisation of Te Papa as a particular global public sphere, or discursive space, by giving it stories and faces through ethnographic research on global visitors, or cultural actors. In doing so I seek to expand the idea of 'contact zone' beyond its initial focus on museological production by illuminating meanings actively made by visitors, who are extensively tested and categorised but barely understood beyond the evaluation of predefined education goals and learning outcomes. By employing hermeneutics as a theoretical and methodological tool, I have approached 'cross-cultural dialogue' and the 'public sphere' as interpretive actions, movements and performances, rather than unitary and totalised abstractions. That allows this study to dissect the complexity of cultural politics and worldmaking by elucidating 'cultural action' in the form of 'interpretive contests' and their 'enunciation' through a narrative examination.

This research sets out to offer theoretically and critically informed qualitative, long-term visitor insights into the functioning of the proclaimed new museology. On the one hand, this thesis tries to fill the identified gap in museological research. On the other hand, it hopes to contribute to the expansion of critical museum studies by embedding the visitor experience in a complex ethnographic web of representational and process-related analysis. 


\section{Summary}

In this chapter, I embedded this thesis within the disciplinary parameters of museum and visitor studies. I identified the lack of qualitative and long-term visitor insights into the functioning of the new museology. I proceeded by laying out the theoretical rationale of my research approach funnelling from the broad to the specific. This should have provided the reader with a comprehensive sense of the theoretical framework of this thesis. Based on the disciplinary gap, the narrative exploration of the 'museum forum' idea through a case study of Te Papa was determined as the main research aim. In the following chapter, I present the methodological strategy for the subsequent empirical investigation. Chapters Three to Five reveal the findings as well as my own interpretations and theoretical propositions. In the concluding Chapter Six, I draw the interpretive threads together and refer to the fulfilment of this study's aims and its empirical, theoretical and disciplinary contributions. 


\section{Chapter Two}

\section{A narrative exploration of the Te Papa 'forum'}

\section{Introduction}

...action and speech create a space between the participants which can find its proper location almost any time and anywhere. It is the space of appearance in the widest sense of the word, namely, the space where I appear to others as others appear to me, where men exist not merely like other living or inanimate things but make their appearance explicitly. (Arendt, 1958, pp. 198-199)

In the preceding chapter, I established the theoretical framework of this thesis. I argued for museums as 'contact zones' in a 'cosmopolitanised' world and proposed a worldmaking approach to the public sphere to shed light on 'cultural action' as discursive negotiations and 'interpretive contests'. I concluded by briefly introducing 'narrative' as a theoretical and empirical tool to investigate cultural worldmaking. In this chapter, I present the methodological framework which attempts to humanise Te Papa as a particular global public sphere through the stories and faces of real persons or visitors.

In the first section, 'Hermeneutic methodology: action, narrative, meaning, Self', I elaborate on the dynamic interrelation and interdependence of 'action', 'narrative', 'meaning' and 'Self'. The discussion interrogates the human condition, and the concept 'narrative' facilitates the translation of the theoretical into the methodological framework paving the way for the subsequent empirical investigation. I argue for a narrative construction of meaning and Self through discursive actions, movements and performances. Consequently, this thesis requires hermeneutics as methodological choice and interpretation as its analytical method. 
The next section introduces the 'Research design'. I lay out the empirical conceptualisation of this research and the rationale behind its design. The proposed narrative exploration is conducted through narrative interviews. I explain this specific interview type and its longitudinal application in detail. Additional empirical methods are presented as contextualising material. I utilise a particular model of interpretive analysis which illuminates the narrative performance of Self in a cross-cultural context. Given the ethnographic nature of this thesis, I stress my own role within all stages of the research process, from the formulation of the research questions through the complex field work up to the writing stage.

In the last section, I introduce the 'Research participants' and provide short biographical profiles of the interviewees. The reader gets a sense of the 'faces' behind the stories and therefore of the persons behind this research. I opt to directly include the personal introductions rather than relegating these to an appendix. On the one hand, this enables me to complete the methodological humanisation of this thesis, the narrative exploration of the Te Papa 'forum' through the stories and faces of global visitors. On the other hand, it allows the reader to become familiar with the human beings at the heart of this study. This sets the scene for the following narrative journeys of the participants as well as my own hermeneutic examination and theoretical propositions.

\section{Hermeneutic methodology: action, narrative, meaning, Self}

The space of appearance comes into being wherever men are together in the manner of speech and action, and therefore precedes all formal constitution of the public realm and the various forms of government, that is, the various forms in which the public realm can be organised. (Arendt, 1958, p. 199) 
It is, of course, no coincidence that I both completed the theoretical framework and started this chapter and section with quotations from Arendt's pondering on the human condition. At a crucial stage of my own thinking, it enabled me to bridge the theoretical and methodological frameworks, the public sphere and its empirical exploration, through 'narrative'. By following Arendt's argument, one may see clearly that 'narration...makes action the characteristic feature of the human condition', as Corvellec (2007, p. 202) aptly summarises. For the purpose of this thesis, it is necessary to flesh out the linkage between 'action' and 'narrative' in more detail. In the course of doing this, we inevitably encounter the human concepts of 'meaning' and 'Self'. In fact, the simultaneous presence and interwoven nature of these human spheres complicate their partial inspection and require the argument to evolve in an oscillating rather than a linear fashion.

Ricoeur (1992, p. 155) refers to Weber and helps specifying the term 'action' as 'human behavior when and in so far as the acting individual attaches a subjective meaning to it'. This crucial association of 'behavior' and 'subjective meaning' allows me to distance myself from 'behaviourism' as 'scatter-brained reductionism' (Taylor, 1991) and other positivist perspectives with their 'ideals of reductionism, causal explanation and prediction' (J. Bruner, 1990). It becomes paramount to illuminate the meanings of action through 'an exploration of the meaning systems that form human experience' (Polkinghorne, 1988, p. 1) to understand persons in their complexity beyond purely observable characteristics.

I return to Ricoeur's philosophy of action which synthesises Arendt's 'words and deeds'. Ricoeur (1992, p. 17) stresses that 'speech acts are themselves action and, by implication, speakers are themselves actors'. This is an important point to make. Any discursive articulation is an act in 
itself, or to put it differently, any 'word' is a 'deed' and telling is doing. The inextricable link between action and speech draws our attention to 'narrative'. Fisher (1987, p. 58) emphasises this pervasive interdependence by stating that 'narration' represents 'symbolic actions - words and/or deeds - that have sequence and meaning for those who live, create or interpret them'. Their empirical examination becomes inescapably a hermeneutic task as I further discuss later in this section.

It is again Ricoeur (1992) who aids the development of my argument by highlighting that 'action is interaction'. It follows that narrative is dialogue and subject to what Bakhtin termed 'polyphony' (Holquist, 2002). This inherently dialogic quality of narrative is twofold. On the one hand, human life is characterised by its 'interactive character', the fact that 'practices are based on actions in which agents take into account, as a matter of principle, the actions of others' (Ricoeur, 1992, p. 155). This external interaction can, however, become an 'internalised interaction' as in the agent's gradual acquisition of competence through learning (Ricoeur, 1992). In both cases, it becomes clear that narrative action is a relational phenomenon.

Polkinghorne (1988, p. 142) theorises 'narrative action' as 'expression of existence' and 'its organisation manifests the narrative organisation of human experience'. J. Bruner (1990, p. 56) lends supports to this claim by concluding that 'the typical form of framing experience (and our memory of it) is in narrative form'. Continuing this line of thought, Polkinghorne (1988, p. 145) asserts that "narrative is the form of hermeneutic expression in which human action is understood and made meaningful. Action itself is the living narrative expression of a personal and social life'. According to MacIntyre (1981, p. 197; 201), 'human actions' embody 'enacted narratives', 
which makes 'man...in his actions and practice, as well as in his fictions, essentially a storytelling animal'.

The above literature, just like the vast majority of Western academic knowledge production, can rightfully be critiqued for its purely Western focus. However, Māori scholars such as Royal (2004) equally stress the central role of narrative in constructing reality and transmitting meaning especially in oral cultures. In the course of this section, I return to the sphere of 'hermeneutic expression' when completing the methodological framework of this research. For now it is important to reiterate that we act through narratives which render our actions meaningful.

I have argued from 'action' through 'narrative' leading to 'meaning', the next term of this complex web, which demands a more detailed dissection. J. Bruner (1990, p. xii) synthesises the link in the book Acts of Meaning by emphasising 'the nature and cultural shaping of meaningmaking, and the central role it plays in human action'. In other words, we act to make sense through narrative. The 'quest for meaning' is, as J. Bruner (1990, p. 20) puts it, 'the proper cause(s) for human action'. It follows that there are 'processes and transactions involved in the construction of meanings' (J. Bruner, 1990, p. 33). The 'realm of meaning is not a thing or a substance, but an activity', as Polkinghorne (1988, p. 4) alerts us, which is why I talk of interpretive actions, movements and performances throughout this thesis. J. Bruner (1990, p. 67) allows the conceptual symbiosis of 'action', 'narrative' and 'meaning' by highlighting that 'negotiating and renegotiating meanings' proceed through the 'mediation of narrative interpretation'. 'Meaning making, given the narrative condition', J. Bruner (1996, p. 98) 
concludes, 'is interpretation'. And, in Polkinghorne's (1988, p. 6) succinct words, 'narrative meanings' correspond to 'human actions'.

I think the evolution of my argument is further supported by digging deeper into the acts of narrative meaning through illuminating human perception. Abbott $(2002$, p. 6) points out that 'narrative is so much part of the way we apprehend the world in time that it is virtually built in to the way we see'. To put it differently, we perceive through narrative. Abbott $(2002$, p. 6) interrogates the working of such 'narrative consciousness' through the experience of a picture, drawing the conclusion that 'the human tendency to insert narrative time into static, immobile scenes seems almost automatic, like a reflex action'. Any experience has a narrative quality since 'without understanding the narrative, we often feel we don't understand what we see', as Abbott (2002, p. 11) argues, 'we cannot find the meaning'. It follows that 'meaning and narrative understanding are very closely connected' in a multifaceted way (Abbott, 2002, p. 11). This claim is backed up by the etymology of the word 'narrative' encapsulating both 'knowing' and 'telling', which 'catches the two sides of narrative' as 'tool for knowing as well as telling, for absorbing knowledge as well as expressing it' (Abbott, 2002, p. 11).

The inextricable link between perception, narrative and meaning helps to erode their widespread dichotomy into separate psychological categories. J. Bruner (1995, p. 19) draws the term 'experience' into the discussion and insists that 'meaning is not after the fact'. Any 'experience is already an interpretation' (J. Bruner, 1995, p. 19) or 'assignment of meaning' (Abbott, 2002). Ricoeur (1981, p. 123) allows another conceptual closure by emphasising that 'perception 'represents' because it is already the seat of a work of interpretation'. Consequently, 
'phenomenology' immediately 'encounters the concept of interpretation' and 'can be realised only as hermeneutics' (Ricoeur, 1981, p. 123; 128). I further elaborate on the nature of a phenomenological hermeneutics when finalising the methodological framework. First, however, Bakhtin's thinking enables me to proceed with the current discussion in this section. According to Bakhtin, 'reality is always experienced, not just perceived, and further...it is experienced from a particular position' (Holquist, 2002, p. 21). We can sum up that 'perception', 'experience', 'interpretation', 'meaning' and 'narrative' are not different stages but only different abstractions of the same process. Bakhtin's understanding of 'position' as 'event, the event of being a self' (Holquist, 2002, p. 21) brings us the concept of 'Self'.

J. Bruner $(1995$, pp. 27, 28) assists with the transition by arguing that 'Self...is the centre of gravity of all the systems of meaning-making' as well as the 'intersection of culture and individual identity'. Importantly, J. Bruner (1990, p. 20) stresses 'culture' as an inherently human dimension which embeds the 'quest for meaning' both forming 'the proper causes of human action' which I referred to above. It follows that 'action' and 'Self' are 'situated' in a sociocultural context and 'distributed' or 'dialogue dependent' (J. Bruner, 1990). 'Self', J. Bruner (1990, p. 108) continues, represents a 'construction...from culture to mind as well as from mind to culture'. The dissection of this 'balancing act' between 'autonomy' and 'commitment' (J. Bruner, 2002) or between agency and discourse is at the heart of this critically and theoretically informed empirical study of the human experience. But first I need to shed more light on the construction of Self which pulls us once again back to 'narrative'. 
'Self-making is', according to J. Bruner (2002, p. 65), 'a narrative art' consisting of 'narrative acts'. We construct ourselves through narrative and the 'concept of selfhood' represents a 'concept of self whose unity resides in the unity of a narrative' (MacIntyre, 1981, p. 191). 'Narrative' facilitates a 'dynamic identity' (Ricoeur, 1992) negotiating the 'balancing act' between cultural conventions and personal individuality. Consequently, 'Self-narrating' proceeds 'from the outside in as well as from the inside out' (J. Bruner, 2002, p. 84), a circular dialectical performance which I further theorise at the end of this section. At this stage, I have finalised the synthesis of 'action', 'narrative', 'meaning' and 'Self' as tightly interwoven dimensions of the human condition. I add another comment on the 'Self' before transforming the theoretical argument into a methodological strategy.

Like narrative action, the narrative Self is 'profoundly relational' (J. Bruner, 2002). Ricoeur (1992) emphasises the 'relational structure of the self' leading to Derrida's (1981, p. 67) convincing conclusion that the "dialectics" of the same and the other...are... among the most contorted ones'. To Deleuze (1994, p. 281), 'it is the Other-structure that ensures individuation within the perceptual world'. Supporting such a vein of thought, Ricoeur (1992, p. 317) asserts that the 'polysemic character of otherness...is not added on to selfhood from outside...but that it belongs instead to the tenor of meaning and to the ontological constitution of selfhood'. In short, Self and Other or selfhood and otherness are tightly entangled and can at no point be separated. Throughout the cross-cultural journeys of this research's participants, I shed light on this dynamic interplay and propose a particular understanding of the narrative performance of Self and its relation to the Other. 
But how can we empirically explore the complex web of 'action', 'narrative', 'meaning' and 'Self'? I devote the remainder of this section to answer this question and pave the way from theoretical pondering to methodological exploration. Geertz (1986, p. 373) offers an appropriate starting point for such an endeavour:

We cannot live other people's lives, and it is a piece of bad faith to try. We can but listen to what, in words, in images, in actions, they say about their lives...it is with expression representations, objectifications, discourses, performances, whatever - that we traffic...Whatever sense we have how things stand with someone else's inner life, we gain it through their expressions, not through some magical intrusion into their consciousness.

As I have indicated before, I need to return to the problem of 'hermeneutic expression' to frame the methodological route of this thesis which epitomises 'not an experimental science in search of law but an interpretive one in search of meaning' (Geertz, 1973, p. 5).

The term 'expression' in this context dates back to Dilthey (1976, p. 175) who states that 'the interrelation of life, expression and understanding, embraces gestures, facial expressions and words, all of which men use to communicate'. Dilthey (1976, pp. 177-178) further argues that 'the human studies rest on the relationship between experience, expression and understanding'; 'what we grasp through experience and understanding is life as the interweaving of all mankind'. Turner (1986) builds on Dilthey's distinction between 'experience' and 'an experience', the former being processed in consciousness while the latter is intersubjectively articulated. Turner (1986, p. 37) asserts that 'experience urges toward expression, or communication with others'. This highlights once again the profoundly relational character of 'action', 'narrative', 'meaning' and 'Self'. E. M. Bruner (1986b, p. 7) carries the discussion into the realm of 'narrative' as particular human 'expression': 'As expressions or performed texts, structured units of experience, such as stories or dramas, are socially constructed units of meanings.' 'Every telling', E. M. 
Bruner (1986b, p. 7) continues, 'is interpretive'. Any examination of 'an experience' and its 'expression' becomes therefore a hermeneutic task.

In this thesis, I intend to 'withdraw from the objectifications and explanations of historical science and sociology to the artistic, historical and lingual experience which precedes and supports these objectifications' (Ricoeur, 1981, p. 119). This is what hermeneutics promises. According to Ricoeur (1981, p. 119), it enables us to 'return to the Lebenswelt...construed as designating the reservoir of meaning, the surplus of sense in living experience, which renders the objectifying and explanatory attitude possible'. In other words, the individual experience is the point of departure from which to understand, explain, theorise and critique.

To put it succinctly, hermeneutics is 'the methodology of the interpretation' (Dilthey, 1976). Although I am not dealing with a text as such in this research into a three-dimensional museum space, it becomes clear that museological representation also 'is a dumb object which only the act of interpretation-by-placement can force to speak' (Bauman, 1978, p. 230). In Bauman's (1978, p. 230) words, the 'intimate bond between the meaning and the reader's world' entails the 'intrinsic variability of possible meanings and their interpretations' or 'polysemy' (Ricoeur, 1981). The 'endemic fluidity of meaning...keeps changing together with the reader's world' (Bauman, 1978, p. 229), a phenomenon which will accompany us throughout this thesis. It follows that 'the fullest understanding one can think of is still context-dependent and contextdefined', as Bauman (1978, p. 230) reminds us. The 'sensitivity to context', Ricoeur (1981, p. 44) demands, is therefore the 'necessary complement and ineluctable counterpart of polysemy'. 
Hermeneutics places the individual experience within a socio-cultural context and in the process illuminates the hermeneutic circle connecting the whole and its parts (Dilthey, 1976). 'The individual person in his independent existence is', as Dilthey (1976, p. 181) argues, 'a historical being' entangled in a 'whole web of relationships'. The interpretive dissection of this complex cultural world contrasts 'hermeneutics' with 'phenomenology' since 'the subject of which it speaks is always open to the efficacy of history' (Ricoeur, 1981, p. 111). Ricoeur (1981, p. 123) continues the fruitful comparison by emphasising that 'phenomenology encounters the concept of interpretation' in the perceptive act and so 'can be realised only as hermeneutics', as I have mentioned. Ricoeur (1981, p. 118; 115), however, stresses equally the 'phenomenological presupposition of hermeneutics' by 'subordinating Sprachlichkeit', the claim of 'the lingual condition...of all experience' and its 'expressibility in principle', to the 'pre-linguistic...structure of experience'.

Ricoeur's (1981) emphasis on the phenomenological dimension of hermeneutics is a crucial point but it is still linguistically dominated since the proclaimed 'subordinating' implies that experience 'comes to language' in its search for meaning. While I equally argue for hermeneutics due to its historical contextualisation of the subjects under scrutiny, I fundamentally disagree with such 'linguistic absolutism' and the exhaustive reduction of meaning to language. In fact, I intend to hermeneutically prove this assertion to be an impoverishing view of the human experience. Although I interrogate experiences as interpretations via a narrative analysis, as I will show in the following section, this does not amount to a claim that we would ever be able to verbalise all meanings. Many meanings will be interpreted but remain feelings or 'embodied meanings' (Johnson, 2007). Dewey (1934, p. 74) lends weight to my position by stating that: 'If all 
meanings could be adequately expressed by words, the arts of painting and music would not exist.' Supporting such a vein of thought, Johnson (2007) refers to our innate 'body-based intersubjectivity' as the 'birthplace of meaning' as well as to the philosophical problem of 'qualia', felt qualities which cannot be reduced to conceptual structures such as words. J. Bruner (1990), while stressing the key function of language as a cultural tool to fully realise the world, equally reserves space for some prelinguistic 'readiness for meaning'.

The conclusion of this introduction to hermeneutics is again aided by its etymological history. The word 'hermeneutics' has a Greek origin meaning 'related to explaining' (Bauman, 1978). Consequently, Ricoeur (1981, p. 43) is correct in branding 'the opposition...between explanation and understanding...disastrous' and demanding a 'complementarity between these two attitudes'. The interpretive analysis in this thesis is therefore characterised by a 'synthesis between explanation and understanding' (Oedman, 2007), which is moreover 'united with a moment of critique' shaping what Thompson (1981) called a 'critical hermeneutics'. Giddens (1987) emphasises the significance of critical theory within the social sciences which are inherently 'double hermeneutic'.

This study engages in such double mediation or 'double hermeneutics', a reflective interpretation first by the interviewees and subsequently by me. I regard this, however, not as a threat to a 'pure' understanding, but as further evidence that 'all investigators...lack access to another's unmediated experience' (Riessman, 2008, p. 23). Bauman (1978, p. 234) elaborates on the hermeneutic mediations of human life further relativising the scholastic perspective. It is worth quoting him at length to sum up my point: 
It is not just that the 'laboratory' of sociologists is the wide society upon which they have little, if any, control. More importantly, the phenomena they study - the meanings - are facts to which they have no more privileged access than do laymen...In addition, sociology is a reflection on practices which are themselves self-reflective.

My argument for hermeneutics as a preferred methodological choice is completed by elaborating on two dimensions of significance for this thesis. In Chapter One, I laid out the theoretical rationale for a worldmaking approach to the public sphere through an exploration of interpretive actions, movements and performances. I referred to Sartre's (1976) circular dialectic and its reasoning that men simultaneously mediate and are mediated. Or, in other words, human agency creates culture and history while at the same time being affected by specific and wider contexts. The hermeneutic analysis in this study sheds light on the 'moments' or 'processes' of structural 'renewal' (Taylor, 1991) when interpretive agency changes discourse from within. According to Dilthey (1976, pp. 201-202), 'every individual mental state represents a new attitude, a new relation of the whole person to things and people'. It follows that the 'balancing act' between individual autonomy and cultural commitment is itself constitutive. To put it differently, culture is constantly constructed, deconstructed and reconstructed through hermeneutic agency and the act of interpretation, which allows us to return once again to the dynamics of 'narrative' and its inherently circular relationship to 'life' (Ricoeur, 1991b).

Cultural narratives create for us the 'common sphere' (Dilthey, 1976) needed for intersubjective understandings. However, this is not a linear but a circular process. E. M. Bruner (1986a, p. 151) highlights that 'narrative is transformed with each retelling' while Ricoeur (1991a) emphasises that the cultural tool 'language' or 'langue' is consistently renewed through linguistic performance or 'parole'. We draw from culture but we find our Self through personal 
interpretation which reconstitutes culture in these 'moments' or 'processes'. Consequently, cultural worldmaking can only be understood through the individual since, in E. M. Bruner's (1986b, p. 24) words, 'we have in culture an uncontrollable plurality, such that the production of meaning can never be contained'. In the course of this thesis, I propose a specific form of discursive pluralism to understand public spheres in a 'cosmopolitanised' world.

A narrative hermeneutics allows us, in my view, to investigate the relationship between the psychic and the social as mutually constitutive dimensions of any interpretive performance (Redman, 2005). By illuminating these 'spiralling exchanges' and their 'inescapable hybridity' (Redman, 2005), I argue that without using formalist and deterministic reductions we can find answers to the open question "why it is that certain individuals occupy some subject positions rather than others' (Hall, 1996, p. 10). I concur with Hall (1996, p. 14), who stresses the remaining 'requirement to think this relation of subject to discursive formations as an articulation', or more specifically a narrative articulation. Such processual understanding of discursive engagements shifts the analytical focus from identities as essential traits to 'identifications' as positional and strategic performances (Hall, 1996). Butler (2000a, p. 149; 171) elaborates that 'no identification is reducible to identity' and reminds us once again that there exists 'no single structure or a single lack that underscores all discursive formations. Our exile in heterogeneity is, in this sense, irreversible.'

In this study, I explore the heterogeneous 'articulations' and 'identifications' expressed through the 'narrative negotiation' and 'performative construction' of Self (Kraus, 2006). This enables me to humanise such abstract totalities such as 'culture' and 'politics' to 'encounter humanity face to 
face' avoiding that 'living detail is drowned in dead stereotype' (Geertz, 1973, p. 53; 51). Having translated the theoretical into a methodological framework, I turn to the research design underpinning this study in the following section.

\section{Research design}

The empirical route of this thesis set out from the central research question: to what extent and in which forms do bicultural meanings negotiated by global visitors relate to Te Papa's forum mission? Shkedi's (2005) differentiation between first and second order research questions represented a very useful strategy to critically relate the museum experience to the wider research context. The context was presented in Chapter One which concluded with the proposed narrative exploration of Te Papa as a particular global public sphere in a 'cosmopolitanised' world.

First order research questions:

- What kinds of bicultural meanings do global visitors make when visiting Te Papa?

- What are the underlying processes (individual, social, cultural, political) influencing such meaning-making?

- How does the bicultural Te Papa experience affect these processes in return and longterm?

Second order research questions:

- Does the museum function as a forum leading to open discourse, critical debate and free argumentation of its bicultural nature among global visitors? 
- Does such potential cross-cultural dialogue provide some empirical insight into the ‘cosmopolitanisation' of contemporary reality?

Narrative interviews with global visitors after their Te Papa visit as well as follow-up narrative interviews after six months via phone facilitated the in-depth examination of museum experiences and the associated cultural worldmaking. My hermeneutic investigation of bicultural meanings offered answers to the first order research questions. Additional methods such as three focus groups with global visitors, a focus group with Te Papa tour hosts, and two key informant interviews with museum experts involved in Te Papa's conceptual design helped to contextualise the narrative insights. This multilayered empirical research design addressed the second order research questions revealing the 'cosmopolitanised' discursive dynamics of the Te Papa 'forum'. After providing this overview, I now discuss the empirical research design's methods and sources in more detail.

\section{Empirical approach}

In the preceding section, I argued extensively for an exploration of narrative 'actions', 'meaning' and 'Self' through a hermeneutic analysis. The biographical narrative approach enabled me to translate the theoretical argument and methodological strategy into an empirical research design. Given the nature of the research questions and context, this study belongs to the 'experiencecentred and culturally oriented approaches to narrative' (Squire, 2008) to synthesise broader socio-cultural as well as specific individual perspectives as stated above. To put it differently, the narrative approach in this thesis allowed me to closely interrogate museum experiences without inspecting entire biographies. However, these narrative meanings were never exclusively bound 
to the Te Papa visit, but revealed biographical traces of other travel and life experiences, as we shall witness in the interpretive chapters.

Narrative research has been conducted within museum and visitor studies although with varying degrees of sophistication (Everett \& Barrett, 2009; Lelliott \& Pendlebury, 2009; Paris \& Mercer, 2002; Rowe, et al., 2002). This study differs above all with regards to the extent and depth of its analysis. Furthermore, my hermeneutic examination moves beyond the inspection of individual narratives, experiences and meanings towards wider critical discussions and theoretical propositions. This becomes clearer to the reader when I reflect on methodological implications in the concluding Chapter Six. Although clearly being situated within museum studies, I feel that this thesis is more closely related to ethnographic perspectives investigating the site 'museum' from other academic fields especially anthropology (E. M. Bruner, 2007; Gable, 2006; Gable \& Handler, 2007). The interdisciplinary and sophisticated use of narrative methods distinguishes this research from other qualitative approaches and represents a methodological innovation in museum studies and related disciplines.

In my view, the biographical narrative approach offers the most appropriate empirical strategy to understand meaning-making processes among human beings. It seeks an understanding of the individual in relation to their socio-cultural environment and therefore of society within a sociopolitical and historical context. Sartre called for a methodology to study humans as 'universal singulars' (Denzin, 1989a), and the literature provides several examples of the biographical narrative approach shedding light on the universal and particular dimensions of human experiences (Davidson, 2006; Denzin, 1989b; Elliott, 2005; B. Roberts, 2002; Wengraf, 2001). 
The limitations are, of course, multifaceted as with any research in general as well as qualitative strategies in particular. This narrative study fails to cover vast populations and to offer representative claims. It succeeds, however, in formulating 'generalisation to theoretical propositions' (Riessman, 2008, p. 13), which is in my view more fruitful and philosophically sound as I further argue when presenting the model of narrative analysis.

\section{Empirical methods}

\section{Narrative interviews with global visitors}

The primary method chosen to follow the empirical approach was semi-structured and in-depth narrative interviews with visitors to Te Papa. The main advantage of this method for this study is that it avoids having the findings, or knowledge claims, 'artificialised' (J. Bruner, 1990) by the researcher's 'system of relevancy' (Wengraf, 2001). Other available methods, even if of qualitative nature, are organised by the researcher and more likely to lead to consciously constructed and, in the case of a controversial topic, socially desired responses (Davidson, 2006; Elliott, 2005). A narrative description instead leaves it up to the interviewee to retrospectively construct meanings.

The researcher gets access to the subconscious level of a lived experience without pre-structuring or guiding the flow of the interview. Wengraf (2001, p. 115) confirms this methodological advantage by stating that:

precisely by what it assumes and therefore does not focus upon, narrative conveys tacit and unconscious assumptions and norms of the individual or of a cultural group. At least in some respect, they are less subject to the individual's conscious control. 
Wengraf (2001, p. 118) further argues that narratives 'enable the researcher to consider both the conscious and unconscious contexts and conditions of action as well as the observed and less observed consequences of action'.

Each narrative interview was only broadly framed and successively prompted to harmonise the narrative description with the research question, in this case the bicultural meanings among global visitors. Wengraf (2001) proposes the following three-stage analytical structure of biographical narrative interviews (which was applied for this thesis):

\section{Stage one:}

The researcher asks a single question to initialise the interview and elicit the interviewee's narrative. It must be made clear that the interviewer will not interrupt or prompt and any intervention must be of non-directional nature.

Stage two:

Following the narrative-eliciting question in stage one, in stage two 'narrative-pointed questions' will be asked, which are restricted to the topics and themes brought up by the interviewee and the order in which these were raised in stage one. This limited intervention and guidance by the researcher in stage one and two facilitates the 'system of relevancy' of the interviewee to reveal itself.

\section{Stage three:}

The third and final stage is organised by the researcher's 'system of relevancy' and asks 'narrative-pointed' or non-narrative questions to harmonise the narrative material of the first two stages with the research question. 
Ideally this final stage is conducted as a separate interview at a later date after analysing the first two stages. Wengraf (2001), however, highlights that any research design is a compromise, and for pragmatic reasons I preferred to conduct one interview while maintaining the three analytical stages. The fact that I conducted follow-up interviews via phone with the interviewees after six

months in their respective home environment should outweigh this methodological limitation and was crucial for understanding the context-dependent 'endemic fluidity of meaning' (Bauman, 1978). This longitudinal narrative research design further distinguishes this thesis from other studies in terms of analytical extent and depth. It enabled me to closely investigate the dynamic relationship between meaning and memory, which, according to Silverman (1995, p. 162), 'may be viewed as the core mechanism of meaning-making'. As we see below, I basically asked the same questions in both interviews and therefore gained insights into the impact of time and space, or temporal and spatial context, on the narrative negotiation of meaning, Self and Other. The three-stage interview structure as applied in this study unfolded in the following way:

\section{Narrative interviews:}

\section{First stage:}

Please tell me about your Te Papa visit today. Begin wherever you like, I will just listen and will not interrupt. I am interested in your perspective and story, and will only take some notes for after you have finished telling me about the museum experiences of importance to you.

\section{Second stage:}

Elaboration on arising themes and topics 


\section{Third stage:}

How did you experience New Zealand's cultures at Te Papa? (Prompts: Indigenous, settler, Maori, British, Pacific, other migrants)

What role did the Te Papa tour guide play in this regard? (Prompts: Introduction, guidance, background, museum, New Zealand's cultures)

How does your cultural Te Papa experience relate to your travel and museum experiences in New Zealand and beyond? (Prompts: cultural contacts, interactions, travel experiences, museums, New Zealand, other countries)

\section{Follow-up narrative interviews:}

\section{First stage:}

Please tell me about your past Te Papa visit. Begin wherever you like, I will just listen and will not interrupt. I am interested in your perspective and story, and will only take some notes for after you have finished telling me about the museum experiences of importance to you.

\section{Second stage:}

Elaboration on arising themes and concepts

\section{Third stage:}

How does your Te Papa experience of New Zealand's cultures relate to your life back home? (Prompts: Indigenous people, cross- and multicultural situations and dialogue)

How does your cultural Te Papa experience relate to subsequent travel and museum experiences in New Zealand and beyond? (Prompts: cultural contacts, interactions, travel experiences, museums, New Zealand, other countries) 
It becomes clear that the term 'bicultural' was not used in the interviews and, in fact, only one interviewee brought it up while expressing her museum experience. While my stated goal has always been the investigation of bicultural meanings, I adhered to the interview format allowing each informant's 'system of relevancy' to reveal itself through the narration and associated sensemaking. In other words, I gained access to cross-cultural meanings beyond the word 'bicultural', which is why 'the hermeneutical problem begins...where linguistics leaves off' (Ricoeur, 1991b, p. 27). The interview structure was, however, conducted in an organic and flexible way. Some interviewees elaborated in such depth in their initial narrative that I skipped stage two and went directly into the last stage. Others did not touch on any theme or topic related to my research questions in their opening narration. In this case I skipped the second stage and moved directly to stage three and my own 'system of relevancy'.

In addition to the longitudinal in-depth narrative interviews, which generated multiple layers of narrative and meaning, additional methods were used to further contextualise the qualitative material. Wengraf (2001) stresses the need for such 'instrumentation theory' if theoretical concepts beyond the biographical narrative itself are the object of analysis. The proposed critical hermeneutic approach in this thesis also requires supporting social-cultural, political and historical contextualisation of the individual experience.

\section{Focus groups with global visitors}

There is little literature on narrative focus groups, but Shkedi (2005) argues that these are useful to triangulate narrative material of multiple populations. Shkedi (2005) suggests a 'trigger question', similar to Wengraf's (2001) narrative-eliciting question, to broadly frame the topic and 
ignite discussions. In this thesis, I ran focus groups with Te Papa visitors as a contextualising method. However, instead of focussing on subconscious meanings I was interested in conscious and deliberated debates on the forum idea. What do visitors associate with a public forum? How does a museum such as Te Papa fit into this sphere? As we have seen, there do not exist sufficient empirical insights into the actual functioning of the new museology. In order to achieve the proclaimed cultural democratisation and participation, I argue that cultural actors need to be involved in theoretical discussions on topics such as the nature of the public sphere. Such empirical theorising builds on an inherently human critical rationality (Habermas, 1984) and is a crucial part of creating a forum which actually works (see detailed focus group format in Appendix A).

\section{Focus group with Te Papa tour hosts}

Furthermore, I conducted a focus group with Te Papa tour hosts using their insights gained through observing and interacting with global audiences (see Te Papa tour host training in Appendix E). Tour hosts simultaneously carry the museum's narratives and through their personal experience add another 'layer of meaning' (West, 1995) to the museum visit. As well, they 'engage their visitors in dialogue and discussion' and 'encounter the perspectives of visitors in some depth' (Pekarik, 2008, pp. 147, 148). Pekarik (2008) calls tour guides or docents 'ambassadors', and we will witness their multiple dialogical functions throughout this thesis. The sample of four tour hosts in the focus group (one Māori, one Pakeha, one Australian and one Afro-American) corresponded to the research questions and population, the latter being further explained in this section. These tour hosts were therefore familiar with both visitors' respective socio-cultural backgrounds and the fluid movement between cultures. Their accumulated 
experiences in communicating with global audiences were incorporated in the interpretive analysis (see detailed focus group format in Appendix B). Both types of focus groups were designed based on Krueger's (1998) categorical focus group structure (see Appendices A and B).

\section{$\underline{\text { Key informant interviews }}$}

I interviewed two stakeholders involved in the conceptual design of Te Papa as a museum forum, Ken Gorbey and Arapata Hakiwai. The former works today as a museum consultant on a global level while the latter still holds the position of Scholar Mātauranga Māori with the museum. The interviews provided me with experts' understandings of museums and the public sphere, in contrast to visitors' associations and experiences (see detailed key informant interview format in Appendix C). The key informants' public roles made it impossible to conceal their identities; that was declared and signed off in the consent form complying with the ethical requirements of Victoria University of Wellington. With all other research participants, anonymity was guaranteed through the use of pseudonyms. The expert interviews, like the focus groups, were not aimed at a narrative analysis of the individual museum experience but led instead to deliberate discussions on theoretical concepts. In this case I applied a more conventional format of semistructured interviews.

\section{Research population and sample}

Given the previously described global context, this study is limited to non-New Zealanders, whom I call 'global visitors'. Although the interviewees were defined based on their national background, the research nevertheless sheds light on the 'cosmopolitanisation' from within, which does not reject the national domain but relates it to the global perspective. All participants 
encounter global experiences beyond the boundaries of their national origin, especially when entering cross-cultural arenas such as museums. In other words, all 'global visitors' are linked to geographical places but simultaneously face the 'cosmopolitanised' dynamics of discursive spaces, an interrelated distinction which threads its way through this thesis.

Global visitors account for circa $40 \%$ of Te Papa's average annual visitation of 1.3 million. Of the remainder, $21 \%$ live in Wellington City, $10 \%$ elsewhere in Wellington Region and 27\% elsewhere in New Zealand. Visitation by overseas tourists has grown steadily from 416,000 (25\%) in the opening year 1998/99, to a peak of 669,000 (53\%) in 2004/05 (Davidson \& Sibley, forthcoming). For conceptual as well as pragmatic reasons, I limited the study to visitors from countries with similar colonial backgrounds and contemporary post-colonial concepts to New Zealand and each other; Australia, USA and Canada. These countries represent significant shares of Te Papa's global visitation (Australia: 18\%, USA: 11\%, Canada: 4\%, Total: $33 \%$ ), and the literature offers comparative museological and socio-cultural studies which served as helpful sources to contextualise the interpretive sections throughout the text.

I followed the principles of purposive and theoretical sampling in the process of selecting interviewees of the research population (Strauss \& Corbin, 1998). Twelve narrative interviews were conducted, four each with Australians, Canadians and US Americans. Other demographic sampling criteria considered were gender, six each female and male, and age. The latter was defined along the lines of broader generations, six younger and six older than 35 years, to empirically investigate potential shifts in cross-cultural discourses affecting the 'balancing act'. The initial interviews were conducted in Te Papa meeting rooms after the participants concluded 
their museum visit and lasted between 40 and 90 minutes. I followed up via phone with all informants in their respective home environment or while still traveling, which was unavoidable in some cases given the endemic mobility of 'traveling cultures'. The follow-up interviews were, quite naturally, shorter and lasted between 10 and 30 minutes. The three focus groups were also sampled in relation to nationality, one each with Australians, Canadians and US Americans, and consisted of 5-7 participants. In the case of the focus groups, I did not consider gender and age as sampling criteria for pragmatic reasons to manage the complex recruitment process.

The interviewees were recruited at Te Papa's information desk after signing up for an 'Introducing Te Papa Tour', which is delivered by Te Papa tour hosts and covers the museum highlights within one hour, when the nationality of visitors is always requested (see Te Papa tour types in Appendix D). This simplified the identification and recruitment of participants from the specific countries. The procedure also guaranteed that the respondents underwent at least two types of museum experience (guided tour, individual visit) and visited for several hours (Jack was the only exception, see p.65). On the one hand, both the diversity and the extent of the Te Papa experience enriched the research material. In this context, I highlighted earlier the importance of human intervention in the form of guides, which is supported in the museum literature. On the other hand, this can be regarded as an inherent bias with regards to the particular tour information and interaction, but not in terms of visitation time which, according to Te Papa's visitor profile, lasts between 60 and 209 minutes for $73.4 \%$ of overseas visitors.

The Australian and US American focus groups were arranged via 'Te Papa Tours', which is the business unit at Te Papa that manages all guided tour bookings from tourism operators. The 
former consisted of students on an exchange visit (younger than 35 years) and the latter of senior cruise ship passengers (older than 35 years). Both focus groups were conducted after their respective guided tour. Since Te Papa Tours did not have any pre-booked Canadian travel groups, I recruited the participants via various Canadian institutions in New Zealand. The informants, some younger and some older than 35 years, had lived in Wellington over longer time periods than temporary tourism visits so we ran the focus group one evening after work. All three focus groups had a fairly even gender balance without such a prior sampling focus as stated above.

\section{Analysis}

In the preceding section, I introduced the critical hermeneutic approach to investigate the individual experience and relate it critically to wider entities and dimensions, in this case the museum forum within a 'cosmopolitanised' world. Kincheloe and McLaren (2000, p. 286) stress such focus on micro- and macro-dynamics of the particular and the general as well as the 'backand-forth of studying parts in relation to the whole and the whole in relation to parts' as the main

characteristics of a critical hermeneutics. Kincheloe \& McLaren (2000, p. 288) further argue that:

researchers inject critical social theory into the hermeneutic circle to facilitate an understanding of the hidden structures and tacit cultural dynamics that insidiously inscribe social meanings and values.

In this study, narrative interviews built the empirical basis for the interpretive synthesis of understanding, explaining and critique.

Pamphilon's (1999) 'zoom model' represented an appropriate technique for narrative analysis within this methodological framework and situated the individual within wider socio-cultural, political and historical contexts. Pamphilon's model revealed the multiple layers of meaning by 
focusing on the different levels of narratives: macro-zoom on the socio-cultural dimension, mesozoom on the process of the individual story, micro-zoom on the oral dimensions of the story and interactional-zoom on the interviewer-interviewee-relationship. This facilitated the exploration of the 'balancing act' of Self between individual agency and cultural conventions through 'analysing narrative contexts' (Phoenix, 2008). These narrative spheres, however, are to be seen not as distinct and isolated subcategories, but instead as interrelated traces which make sense only in their relations within the Self as I demonstrate in the interpretive chapters.

In practice, this meant that I debriefed myself after each interview to capture the first impressions and kept a research journal for general ideas during the entire study. The 'word by word' transcription enabled me to become closely familiar with both the research participants and their narrations. In fact, I still feel I am able to attach all quotations, or each story, to the respective person, or face. This, of course, enriched the analytical stage since transcription itself becomes a form of interpretation (Riessman, 2008). I read through the fully transcribed interviews after these were reviewed by the interviewees. While carefully studying the interviews and with my research questions in mind, I marked relevant sections of the respondents' narratives with different colors corresponding to the different zooms. I analysed all initial interviews and afterwards repeated the same procedure with all follow-up interviews. I finalised the analytical stage by comparing each informant's initial and follow-up interview with my debriefing notes to get a sense of interpretive continuities, emergences and renegotiations. During this sometimes tedious but mostly adventurous process, hermeneutic themes and concepts emerged and subsequently structured the interpretive chapters. 
I need to stress that my interpretive examination did not isolate or dichotomise categories, but followed distinct thematic routes emerging from the research material while simultaneously highlighting their interrelated nature within the narrated experience. Given that in 'life that is truly life, everything overlaps and merges' (Dewey, 1934, p. 18), the empirical insights revealed overlapping themes and required interwoven analysis beyond chapter and section 'distinctions'. I treated these as dynamic traces to be interpreted instead of static categories to be defined and left the integrity of the narratives as untouched as possible without embarking on some coding procedure which would ultimately make sense only to me. On a practical level, I used double quotations for the empirical voices to distinguish them from theoretical perspectives in the literature in single quotations. Either the whole narrative quote or bolded sections gave rise to themes and concepts supporting my own interpretation. The associated theoretical propositions were represented in italics throughout the text.

Any analytical focus is a somewhat arbitrary endeavour. While this is unavoidable in an inherently partial analysis, it remains possible to emphasise the relations among scientifically and therefore artificially differentiated phenomena. As I have argued throughout, the emphasis on relations is at the very heart of this study. In this context, Dewey's (1934) contrasting of 'distinction' and 'separation' provides a conscious remedy for this dilemma. Dewey stresses that a 'distinction' is not only an inescapable but a desirable academic undertaking. However, it is impossible to stretch this so far as to become a 'separation' within a naturally integrated experience. This would amount to what Dewey branded 'the philosophical fallacy' (Jackson, 1998), the elevation of intellectual inventions to the status of 'ultimate truths'. 
It follows that it has never been my goal to formulate a claim of representativity among vast populations or throughout the museum world, a shaky positivist attempt contradictive to the interpretive spirit of this study. Instead, I envisage presenting 'a form of lens, a way of seeing things' (Gergen, 1991, p. 2) or a 'travel book' which 'offers suggestions rather than imposing itself on the reader' (Latour, 2005, p. 17). It is ultimately up to the reader to decide if the hermeneutic mix of empirical findings, my own interpretations and theoretical propositions 'sounds true' and can be transferred to other sites or situations.

Positivist research attributes such as objectivity, validity and reliability are either reframed or incompatible with the underlying philosophy of qualitative research (Elliott, 2005; Wengraf, 2001). However, credibility needs to be guaranteed in any research and can be best achieved through transparency, reflexivity and contextualisation. My own position as a researcher is emphasised from Chapter One and the formulation of the research questions, through the data collection and analysis in this section, up to the interpretive chapters and conclusion of this thesis in Chapter Six. Being a hermeneutic study, it was both inescapable and desirable to continuously reflect on my own background as an integral part of data collection and analysis. For example, I have been interacting with global visitors to Te Papa while delivering guided tours and dealing with cultural tourism operators when managing the 'Te Papa Tours' business unit for two years prior to this research. Furthermore, I lived in the USA and Australia and am familiar with the respective indigenous situations and socio-cultural discourses. These accumulated personal experiences were constantly interwoven in the research process. The research design outlined here with its multiple sources facilitated the contextualisation of the research material and its interpretation. 


\section{Research participants}

In this chapter, I have so far laid out the methodological framework and its translation into an empirical research design. It remains to further humanise the narrative exploration by providing biographical profiles of the research participants. This allows me to temporarily leave the academic discourse behind and emphasise that I am dealing with human beings in this research endeavor. Readers are invited to familiarise themselves with the 'faces' of the interviewees before hearing their 'stories' in the following interpretive chapters. I introduce the informants chronologically in the order I conducted the initial interviews and, of course, can only offer a biographical glimpse rather than an exhaustive biography. This, however, should serve the purpose of both this thesis and its readers.

Before I introduce each individual person, I begin with the analytical zooming by offering some general comments on the interviewer-interviewee relationship. In all interviews, I found it helpful to relate to the informant's life and 'break the ice' at the start of the interview. With Australian and US American participants, this personalising strategy was further simplified since I had lived and traveled in both countries. Virtually all interviewees started with a preconception of being interviewed in a structured way guided by my own 'system of relevancy'. I always simply highlighted that it is about them and whatever they wanted to share which opened the door to indepth narrations. With all participants I got the feeling that they were interested in both the museum and my research project. The zoom shifts now to each interview and its individual story. 


\section{Bruce, USA}

The first interviewee, Bruce, traveled with his partner on their honeymoon through Aotearoa New Zealand. They had seen quite a bit of the country, and Wellington was their last stop before returning to the USA. Bruce is thirty-one years old and lives in New York working as a financial attorney. It was fairly easy to build up rapport since I could talk with him about my own time in the USA and New York at the beginning of the interview. Bruce was very supportive and comfortable to be with especially after I said that my empirical journey started with him. I noticed right from the outset a certain unfamiliarity with the open interview format causing Bruce to ask for reassurance if he is providing the 'correct answers'. During the interview, Bruce delivered the initial story in a very chronological order, his visit from A to B without getting into much detail. None of the themes was particularly related to my research questions so I skipped stage two of the Wengraf model and went right back into stage three, but nevertheless asked narrative-eliciting questions.

\section{$\underline{\text { Jack, Canada }}$}

Jack, from British Columbia, is retired and traveled alone on a cruise through the Pacific. He conducts research before any trip and Te Papa was a "must see" in his mind. Jack used to work as a museum professional and did not want to go on a guided tour as a matter of principle when he found out about the research at the Te Papa information desk. But he was very interested in supporting the project so I accepted this exception within a necessarily flexible qualitative research design. Like Bruce, Jack expressed a chronological first narrative starting from the top to the bottom of the museum without getting into depth. This time, however, I conducted the three interview stages since themes brought up in the initial narrative were of interest to my 
research and required further elaboration in stage two. Jack was very pleasant to spend time with and, in fact, after the interview concluded we shared some ideas on the museum world and visitor research projects.

\section{$\underline{\text { Charlotte, Australia }}$}

Charlotte is a New Zealand born Australian, an embodiment of 'traveling cultures', in her mid thirties. She was on a family trip with her mother and both decided spontaneously to visit Te Papa. Charlotte straight away appeared very kind and keen to support my study. Again it was easy to build up rapport by sharing Australian and New Zealand experiences and anecdotes creating a relaxed and open atmosphere. Charlotte was particularly interested in the research project as such since she was just finishing a BA in Social Sciences and was working as a disability advocate. I again conducted all three stages of the interview since themes brought up were of interest to my research so I asked for more elaboration.

\section{$\underline{\text { Mike, Australia }}$}

During his professional career, Mike worked with museums and Aboriginal art in Australia and the USA. He is well travelled and visited New Zealand for the first time together with his wife and friends. 'Word of mouth' brought them to Te Papa, which was the only attraction holding their interest in Wellington. Mike is in his late fifties and was very forthcoming, and gave detailed and eloquent responses. He narrated his initial Te Papa story in such depth that I skipped stage two for that reason (almost the opposite to Bruce), and went directly to my questions in the last stage of the interview. 


\section{$\underline{\text { Michelle, USA }}$}

Michelle, from Sacramento in California, has an interesting life history. Being an American of Armenian origin and having a son living in Fiji, she is accustomed to cultures in motion. Again, I could easily relate to such a biography which drew her interest to my own background. Michelle is a pensioner and worked as a teacher and special events coordinator before running her own tour company for twenty-six years. She is a very kind, warm and sensitive person in both appearance and articulation. The interview went on for much longer than we both expected. Although being quite hesitant at the beginning, she clearly enjoyed the interview experience.

\section{$\underline{\text { Julia, Australia }}$}

Julia was born in New Zealand and moved to Australia after getting married. She has four children who are all Australian and her family is settled in Sydney. Julia came back to New Zealand to visit her parents who had never been to Wellington and wanted to go to Te Papa. Julia stressed right from the beginning when being recruited that she was very interested in the interview since, according to her, it would surely help to understand the museum. This initial expectation seemed to be fulfilled as her email to me after reviewing the interview transcription indicates: "I also want to thank you for giving me an opportunity to stop and think about my experience in a way I normally never would have. Quite enlightening!” Julia sometimes struggled to express herself and find the appropriate words reflecting her thoughts and feelings. I never rushed her, gave her all the time needed and made her feel comfortable. This was simplified by Julia's great sense of humour and uncomplicated and friendly manner. She was good fun to be with and I enjoyed her company. 


\section{$\underline{\text { John, USA }}$}

John, a former teacher from Arizona outside the Phoenix area, was on vacation with his wife celebrating their fortieth anniversary. For this occasion they decided to travel to Australia and New Zealand. Both had seen quite a bit of the latter before arriving at Te Papa. The interview with John was characterised by another pleasant atmosphere with distinct narrative features. His initial story was very brief, referred to broader themes only on a very generic level and lasted only a few minutes. The topics raised, however, offered space for further elaboration which was no problem for John to achieve in the second stage of the interview.

\section{$\underline{\text { Andrew, Canada }}$}

Born and bred in western Canada, Andrew has lived in Alberta his entire life. He has traveled fairly extensively and visited New Zealand with his wife primarily on business with a little bit of vacation tied in. As a CEO of a farming company, Andrew inspected an agricultural facility and was heading to a trade show in Christchurch in the South Island. Their primary reason for stopping at Te Papa was the limited knowledge of New Zealand's history especially of the indigenous people. Andrew wanted to be interviewed the previous day which did not work out so he came back and contacted me, which is a rather stunning dedication even exceeding the other participants' interest. He came across as a pragmatic, straightforward man who nevertheless used emotive language in a passionate way. Andrew certainly is a very fast talker, which he is completely aware of and made us laugh occasionally throughout the interview. 


\section{$\underline{\text { Mark, Australia }}$}

Mark lives in Melbourne, is 23 years old, and is doing a Bachelor of Arts in Journalism at Monash University. He studies part-time and works full-time in a video game store. Mark visited Wellington because his girlfriend attended an engineering conference. He appeared to be a fairly cautious and reserved person asking a lot of questions about the interview during the recruitment conversation. During the interview, however, he turned out to be easy to build rapport with. We both felt comfortable which prompted him to ask personal questions at the end.

\section{$\underline{\text { Susan, USA }}$}

Susan is 24 years old and calls Indianapolis in the USA home. Together with a friend she embarked on a work and travel trip through Japan, Australia and New Zealand. Susan described herself as a museum person and agreed to the interview commenting that she is interested to help because museums are important. Compared to the other interviewees, Susan has by far the most enthusiastic, outgoing and extravert personality. This made the interview experience most enjoyable for me although I was left almost overwhelmed and struggled during the debrief session. The interview itself started with a very short narrative going through the sequences of Susan's Te Papa visit. The subsequent elaborations in stage two offered in-depth insights into her experience of Te Papa, New Zealand and pretty much the world.

\section{Claudia, Canada}

Claudia lives in Halifax, Nova Scotia, on the eastern seaboard of Canada and is 32 years old. She has worked all through her career in finance, but got tired of it and decided to take a working holiday to see what else is out there in the world. Claudia chose New Zealand as her starting 
point and had been traveling the country on a working holiday visa. She just arrived in Wellington the day before and 'word of mouth' attracted her to Te Papa. Claudia stressed that she would not be back in Canada but still be in New Zealand by the time of the follow-up interview. After some moments of hesitation I decided to conduct the interview since my research design had to allow flexible space to accommodate the dynamics of 'traveling cultures'. Claudia began with a very generic sequential narrative but her subsequent elaborations unfolded in a deeply emotive and sensuous way.

\section{Nicole, Canada}

Nicole was my last interviewee. She is another Canadian on a working holiday visa and was based in Wellington for a longer time frame. During that period, Nicole worked doing research on education, the assessment of international qualifications and international curriculum for the New Zealand Qualification Authority (NZQA). Her time in New Zealand was about to expire and together with her boyfriend she planned to keep on travelling and find work in Japan before eventually going back to Canada in a few years. Given this life plan, it was obvious that I had to follow-up with Nicole sometime and somewhere on the road. I ended up calling her in a hotel in Goa, India, which was another postmodern moment reminiscent of cultures on the move. Nicole had been to Te Papa several times while living in Wellington. During the interview, she first related her initial narration to the latest visit after which I asked her to talk about her accumulated Te Papa experience. This helped to avoid any artificial separation of meaning and memory, and enriched the research material through such long-term perspective. 


\section{Summary}

In this chapter, I presented the methodological framework of this thesis with hermeneutics shedding light on the narrative dynamics of 'action', 'meaning' and 'Self'. I proceeded by translating the methodological argument into an empirical research design facilitating the proposed narrative exploration of Te Papa as a global public sphere. The methodological humanisation was completed by introducing the 'faces' of this research's participants. In the subsequent interpretive chapters, the reader is invited to engage with their 'stories'. The narrative journey begins with an examination of 'The conditions of meaning-making' in the following Chapter Three. 


\section{Chapter Three}

\section{The conditions of meaning-making}

\section{Introduction}

Up until this point, I have established the theoretical and methodological frameworks of this thesis. The previous chapter ended with an introduction of the research participants' biographical 'faces'. In this chapter, I turn to their 'stories' and my investigation of the research material. I lay out the conditions of meaning-making, the foundations which facilitate the subsequent interpretive processes of meaning-making. The emerging themes have driven the hermeneutic analysis, shaped my theoretical propositions and formed the following outline of this chapter.

The first section, 'The experience of a museum space', addresses the beginning of the informants' narrative journeys: the experience of a museological space. This reflects a fundamental characteristic of the human condition: Wherever we are and whatever we do, our life is always experienced within spatial and temporal parameters. It makes sense then, to start my examination by treating Te Papa as a physical space or form with its individual components such as architecture, exhibition design and display. After that, I inspect the content dimension which reveals the key function of 'narrative' as a human meaning-making tool in mediating the mutual relationship of spatial form, museological content and visitor experience.

The second section, 'Senses, feelings and embodiment', deals with the multisensory, emotive and embodied nature of the museum experience. The Te Papa visit starts off as a feeling, which 
becomes both the condition and an integral part of the processes of meaning-making. Visitors' narrations reveal the ubiquitous presence of the emotive dimension throughout the experience. This enables me to shed light on the felt beyond the spoken. The exposure of the Cartesian split between 'body' and 'mind' as a philosophical and scientific myth requires a hermeneutics which is sensitive to more than verbal expressions or words.

The third section presents 'Relevance and interest' as further conditions of meaning-making. The empirical material provides insights into not only multifaceted ways to generate interpretive connections but also failures to build the required hermeneutic links within the museum experience. Relevance relates to the ontological form of understanding which precedes meaningmaking processes or interpretations and enables the entrance into a hermeneutic circle. Interest maintains the interpretive engagement with a particular subject or topic and builds on relevance.

These three spheres: the experience of a museum space and its interplay and tension of form and content; the multisensory, emotive and embodied nature of the museum experience; and the importance of relevance and interest - all represent the conditions of meaning-making leading to interpretive processes of meaning-making. In this chapter, I illuminate this relationship and pave the way for the next stages of the narrative journeys discussed in the subsequent chapters.

\section{The experience of a museum space}

The notion that 'medium' and 'message' are identical, that what we say and how we say it are two halves of the same apple, is nowhere more evidently true than in the material world, the tangible and visible world of objects and the meaningful patterns which we make with them (Pearce, 1995, p. 15). 
As I outlined in Chapter Two, my interpretive analysis and the writing of this thesis grew out of the research material and the various stages of its dissection. More specifically, the research design emphasised that I did not focus on the spatial dynamics of the museum experience at the outset of this research. Instead, my thinking was guided by the interviewees' narrations. Taking note of hermeneutics, however, each empirical insight has been further interrogated and theorised, so forming an endemic circle of hermeneutic understandings. I briefly set the scene by referring to relevant theory (as above) to give a sense of the broader scene and the subsequent play of human experience, meaning and interpretation.

In this particular section, my analysis of the narratives is aided by a short discourse on the dynamic interplay of form and content, which plays a crucial role in this chapter and has been scrutinised in various disciplines within the human sciences. The most interesting example, not least because of its narrative link to this interpretive study, is Ricoeur's close inspection of the relationship between 'narrativity' and 'historicity'. Ricoeur (1981, p. 288) reminds us of the intriguing and ambiguous etymology of the term 'history' in most European languages, 'meaning both what really happens and the narrative of those events'. In German, Geschichte refers to 'history' and 'story', to the content of events as well as the form of their telling. These hermeneutic implications of 'narrativity' and 'historicity' highlight the inextricable link of form and content in human 'language games'. Consequently, Derrida (1981) is right in emphasising the complementary character of thematic and formalist criticism. Likewise, Butler (2000b) and Laclau (2000b) stress the reciprocal mediation of form and content in political discourse and rhetoric. 


\section{Space, form and medium}

But what does this mean for the experience of a museum space? To answer this question, I introduce Susan and the beginning of her interview:

...it's such an amazing beautiful building ... Well I guess I liked how it's set up in different rooms, but you don't feel like you are in a confined area. It seemed to feel like you are in a big open area...You just kind of walk in and you walk right into an exhibit and then you walk upstairs and you have your exhibits and everything kind of branches off and kind of goes smoothly from one place into another. And I liked that... it was nice and when you walk in it's so simple. There is just a globe there, the fountain. It's very simple, like it's not too overbearing. It doesn't intimidate you with anything at first.

Susan's visit starts with a feeling, a spatial feeling. Both the generous spatial layout and the flowing relations among individual exhibition spaces provoke an emotive response. Such primordial bodily movement within an environment is a 'good way to start our account of meaning-making', as Johnson (2007) points out, and during the course of this thesis we witness the 'growth of meaning' (Johnson, 2007) through embodied interactions. Being human means living in time and space. Without temporal and spatial points of reference our life would be simply impossible. We would not know where and when to move. Susan's spatial experience attests to Dewey's (1934, p. 13) view that 'life goes on in an environment; not merely in it but because of it, through interaction with it'. She feels invited and not threatened by a potentially overwhelming space. Jack clearly shares this feeling:

...it's a place which is not intimidating for the not prepared. It's nothing at all intimidating about it.

I turn to Mike, who conveys a further nuanced spatial understanding of the museum experience:

...change the landscape, you know. It's another thing this museum does well; it changes the landscape you are walking through. You don't feel like you are in gallery A, B, C, D all in a line and you are moving off to a room left and right. They have tried to visually break up the spaces even though it's probably, you know, I don't know whether it's just square underneath?! But it doesn't look like from the outside. They have broken the spaces into really unusual movements of people, which means you are not sort of, you 
don't feel like you are in a room with a whole lot of people. But you seem to be sneaking around and you are not quite sure where you are, but you are you sort of, you know that it goes vaguely and is right.

We can observe again that a spatial experience manifests itself first and foremost as a feeling. In Mike's case, his spatial feeling is inextricably linked to a theoretical speculation about the underlying structures of the space and the reasons for its spatial flow replacing a 'sequential locomotion' (Bennett, 1995) with “unusual movements of people”. While I elaborate more explicitly on the mythical isolation of emotion and reason in the section on 'Senses, feelings and embodiment', Mike's narrative gives a first indication of another theme emerging from this research which transcends another standard dichotomy: the separation of theory and empiricism.

Mike provides insights into what Treinen (1995) calls 'theoriegeleitete Wahrnehmung' ('theorydriven perception'). Theories are constitutive of perceptive actions, which are always already interpreted as we have seen in Chapter Two. It becomes obvious that nothing is ever 'only experienced' and the very act of interpreting requires a theoretical reasoning that goes beyond the experience itself. Without employing such 'Alltagstheorien' ('everyday life theories') (Treinen, 1995), which are of course less specialised than their academic counterparts but still of a theoretical nature, we could not use linguistic tools to make sense of things and communicate. Consequently, this phenomenon of 'theory-driven perception' will accompany us through the thesis.

Another aspect of Mike's story which struck me is his use of the term "landscape". It seems to portray the inherently artificial museum layout as an organism, a living landscape rather than a static building. Hillier and Tzortzki (2006, p. 283) argue that spatial experiences are inherently 
human phenomena and 'patterns of spatial relations are so basic to our existence that they form part of the apparatus we think with, rather than think of'. Mike, however, shows that spatial configurations can become the conscious object of interpretive inspection within human experiences such as a museum visit. In other words, Mike clearly thinks of and not only with the surrounding museological space.

Nicole's narration lends further empirical weight to the vitality of a spatial "landscape". In fact, the Te Papa space made the most prominent and lasting impression on her:

And the other thing I noticed right away when I first came was just this layout of the building was like really beautiful. Just especially the fourth floor, just like when you walk up there it's just so open and it just feels really nice, like the actual space... It was just really peaceful, like it was quite out of the way of all the noise and stuff and you kind of looked on to everything which I liked. And it just was a good environment to read in, like it wasn't really hectic and busy... it seems it's so open, it doesn't feel like there is a floor per se, you know what I mean, like it's just kind of gradations of information...

To Nicole, the open museum space assumes the character of a "peaceful...environment" that simply "feels really nice", an organic arrangement instead of "a floor per se". She continues:

...the other thing that I find, if there weren't all those walls there it would be really chaotic I think. But the walls kind of mitigate the chaos, like they separate. Once you walk in, yes, there is a lot going on. But if you are just standing in the middle of the fourth floor it seems really calm and you are not caught up in everything that's going on because the walls kind of block that if you know what I mean?! I think that's a big thing as well ... yeah, I think just how everything is laid out it makes sense that on the fourth floor, you know, there is the Māori and then the immigrant section as well. And it's just kind of all together in one area so in that way like the layout makes sense to me.

Nicole offers insights into spatial compositions which pacify environments, "mitigate the chaos" and ultimately "make[s] sense". She relates Te Papa's "layout" to New Zealand's broad cultural categories of "Māori” and "immigrant" (see Te Papa floor plan in Appendix K). Nicole’s experience indicates the fluid transition from space to medium, from spatial configuration to communicative agency. According to her, the cultural connotation of the spatial "layout makes 
sense to me". At this point, space becomes an interpretive agent 'active in the making of meaning' (MacLeod, 2005, p. 1). This highlights the mutual dependence of spatial form and thematic content, what we tell and how we tell it, within human communication and the museum experience. I move to a closer analysis of museological content later in this chapter, but for now it is becoming clear that the museum space acts as a medium in dialogue with the visitor and emerges as an integral part of interpretative processes. The relationship between the conditions and the processes of meaning-making is constantly performed and mediated in a circular hermeneutic way.

Nicole's follow-up interview after six months reveals the long-term impact of this dynamic interplay on her memory:

I think the thing I always remember about Te Papa is just the actual layout of the building and the structure. I don't know why, but just that huge, open concept that they have... there is like that part where they have the Treaty of Waitangi on the wall, that whole area. I don't know for some reason, not so much the information there but just the actual layout of $i$. The thing that really sticks out for me is how open it was and how it was just really well presented and really like a beautiful space to be in. I just felt really calm there...So again a lot of it is structural for me...just because of how it's laid out. I think it's just really well laid out.

In Nicole's case, the "actual layout of the building and the structure" has clearly left the most meaningful traces in her memory. The spatial form, however, does not exist in interpretive isolation but is intertwined with the cultural content of the "Treaty of Waitangi" exhibit. To put it succinctly, form and content or "layout" and "information" are differently pronounced in each individual experience, but make sense only in their reciprocal hermeneutic relationship. 
The following quotes, which collectively strengthen this argument, highlight the translation of a physical space as condition of meaning-making into an interpretive space as process of meaningmaking:

And the other thing we really like is the amount of space that's left between things, even when there are a lot of people that you don't feel cramped. Like sometimes in an oldfashioned box place you feel, you know, one person is standing up against the glass display and the other person comes in and then it's too deep and it's, you don't see as well. We really liked the amount of free space, especially in that Màori, ahm the, what was the name of the house again?...(Marae)...Marae, especially in the marae. There was a lot of entry space there. People could be standing, taking pictures, taking pictures of the glass windows behind it, and it felt very comfortable in there. (John)

Yeah, more than a museum and it's not all squished in, like there is space. So you can actually look at something and you can contemplate what you think because it's not just this squash. I just feel, you know, there is a, yeah it's comfortable being here. (Julia)

It felt, I find often times with museums so much information is cramped into a tiny physical space that it's not only overwhelming, but I actually start to feel like dizzy and just 'ah, I gotta get out of here!' You know what I mean, almost like a mall or something, like too much energy in a contained space. But in Te Papa it's just so open that yes, there is a ton of information, but there is also space to get away from that information if you need a break or if you just need to, you know, figure out where you wanna go next... like just the fact that you can actually have space to walk from exhibit to exhibit. It's not like you are just moving two steps and that's a brand new exhibit, and then you move another two steps and 'oh, its something else!' It's kind of like there is room to just digest everything as you are going along...(Nicole)

All three respondents appreciate the existence of "free space" which simultaneously creates a "comfortable...feel" as well as "room to just digest everything" and "contemplate what you think". The descriptions epitomise once again the emotive and intellectual reciprocity in visitors' responses, a mutual relationship which is further interrogated in the upcoming chapters. In order to exploit the interpretive potential of museological space and therefore the dynamic interplay of form and content, spatial compositions need to leave 'gaps', as Witcomb (2009) argues. Spatial gaps or "free space" merge 'architectural and curatorial intent' (Hillier \& Tzortzki, 2006), create 
'narrative ruptures' (Witcomb, 2003) for embodied interpretive engagements and facilitate the movement from a didactic transmission to a hermeneutic dialogue. At this point, the condition of a physical space is consciously opened up for the polysemic processes of an interpretive space.

In this section, I began my investigation of the experience of a museum space by considering $\mathrm{Te}$ Papa as a physical space or form. The analysis illuminated the communicative interdependence between broad spatial forms such as architecture or exhibitionary configuration and museological content. The discussion can be further specified by dissecting the museum space and focussing on particular displays. For the purpose of exploring the conditions of meaning-making, I interrogate 'display' as a communicative and aesthetic medium (Kaplan, 1995; Staniszewski, 1998) which provides the multisensory, emotive and embodied context for interpretive actions. The political implications of cultural representations, as discussed by various scholars (Karp \& Lavine, 1991; McCarthy, 2007; Staniszewski, 1998), play a key role in the subsequent chapters on the processes of meaning-making. Visitors' stories provide us once again with interrelated traces rather than isolated categories, and my analytical focus follows the respective emphasis emerging from the research material.

I return to Nicole's narrative journey through Te Papa from the "actual layout of the building and the structure" to the particular "Treaty of Waitaingi" display (see exhibition description in Appendix F):

I was looking at the Treaty of Waitangi upstairs, the one where it's talking about like land claim settlement and stuff like that. And I liked just how it was organised...the thing that was really memorable for me on that for me was often times I find museums there is so much to read that you just stop reading halfway through. But I liked it in that exhibition or display, they had kind of a summary on one side of the like placards and then you flipped around if you wanna more information. So if you wanted to be there five minutes 
and just get a brief summary you could, but if you wanna more information it's there. I liked that, but I didn't feel that I was forced to read everything, you know what I mean!? Sometimes you feel like 'oh I need to take all this' and then read it all, so I felt that was really good...

It is clear that for Nicole, the significance of "free space" and "room to just digest everything" carries through the experience from the broader museum space to a specific display. The "really memorable" spatial organisation invites her to intellectual engagement without becoming emotionally overwhelmed. Nicole goes on:

...like there is, you know, some dense information there, but then in the middle with the Treaty of Waitangi there is not as much information. And it's just kind of a nice space where the Treaty is on the wall and if you want some information you can listen to, you know, where they have the poles and you can listen to it. But there is not a lot of words and like it's just using other mediums for information. And I think that's really good on that level because it just, it makes it way less overwhelming. Instead of just seeing like hundreds of words and just going 'aaaaaaaah!

The significance of a changing media "landscape" (to use Mike's term again), which facilitates meaning-making processes and avoids "overwhelming", will be further examined in this section.

For now, Nicole continues her exploration of the "Treaty of Waitangi" exhibit:

I just liked that on one side was the crown and on the other side was, like in a way, I am sure they weren 't trying to make a strong division. But it kind of seemed, you know, on the one side there was the crown and on the others side was Mäori. And just like the two separate stories and then the middle was kind of joining up.

Nicole's narration attests once again to the communicative agency of spatial forms. Both the exhibition "layout" as well as the display's media "landscape" feed directly into the interpretation of content, the "two separate stories" and their "joining up". Nicole's follow-up interview lends further empirical weight to the long-term implications of this dynamic interrelation and its impact on memory beyond the acquisition of factual information:

One piece of information that really sticks out again is upstairs on the fourth floor... where the Treaty of Waitangi is. Then you go upstairs and I think it tells the story about the Treaty of Waitangi and it has the Mäori side and then the kind of Pakeha side. That really sticks out...I can't tell you like one specific piece of information but that area 
there. But again yeah, when I picture Te Papa I don't necessarily think of the information, I think of the layout of it and the structure.

The apparent domination of "layout" and "structure" over "information" in Nicole's memory might be regarded as evidence for the failed achievement of educational goals and learning outcomes, the predominant indicators of museological success. In the context of this thesis and the development of my argument, however, Nicole's experience serves to emphasise the inescapable interplay of form and content in the making of meaning and memory beyond an illusionary linear transmission of facts. Spatial composition, installation design and thematic content need to be harmonised and mutually enriched to carry relevant critiques from the world of the 'thought' into the realm of the 'lived'. To put it simply, no processes of meaning-making can be elicited without understanding and accepting their conditions.

Jack's experience of the same exhibition provides more insights into the detailed spatial dimensions of the museum experience:

Very clearly, very simply, it got a real presence to it. And the imposition of the original under a glass panel suspended there with the Māori on the one side and the English to the other and the presentation below. I don't think most people coming to New Zealand as tourists probably realise that the Treaty was done in two languages and that part of the difficulty of it was whoever did the translation didn't do it well (sarcastic mimic, both laughing). And there we have the ongoing contentions of the Treaty of Waitangi. I read about that before I came so I was aware of that and I thought it was presented simply... So I thought in that regard that was designed extremely well and I liked the entrance to it, you know, the photographs and I expect the design is premised on the Màori poles. I just thought that was very inviting.

As with Nicole, the "Treaty of Waitangi" display made a lasting impact on Jack, as he points out in his follow-up interview:

The thing that still stands out most for me, when I think of it that comes immediately to mind was the Treaty of Waitangi exhibit, which I found extremely good, very memorable in both its presentation and very helpful in its information... And it just creates a whole, there is a great ambience in that area...I found the exhibit itself very 
impressive, very accessible, like it has a bit of majesty to it in the way it is presented. But very accessible to read and one of the very clearest understandings or explanations of the Treaty and how the variations have occurred between the English and Māori version, what happened there and why it is still contentious. I just thought that was very well explained.

We can observe once again the interplay of "presentation" and "information", of form and content, which conditions interpretive processes. The exhibition's monumental character, its sense of "majesty", runs thereby the risk of turning into an indoctrinating symbol which ‘discourages scepticism' (Williams, 2003, p. 249) and forecloses any critical engagement. However, this potential ideological threat of interpellation, which mostly remains a generalised theoretical assumption as empirical studies have shown (Hooper-Greenhill, 1995), does not prevent Jack from drawing his main conclusion: "it is still contentious".

The preceding examples showed that display compositions and their spatial juxtapositions form another layer of a museum space. They function as a condition of meaning-making, as syntactic devices which need to be semantically filled. In this context, Mike demonstrates in more detail the performative nature of a media "landscape":

There is a mixture of how the information is delivered, which is, it's not unique but someone has really thought about the problem of people's attention. If you don't have different ways of delivering information you get bored, it's like listening to the same song over and over and over again. But this museum has all sorts of odd devices that keep your attention. Whereas if they would be telling the whole story in one medium it would be quite, quite difficult...there is a mix of the way things are done. And I particularly liked down on the bottom in the second storey, in the gallery of the trees and birds, how odd it is the children describing some of the things about the birds and what not. Whereas it would be easy just to put a dry commentary on the top of it...And all through the museum it seems they have tried to mix the way they are telling you the story. There is, you know, plenty of image stuff, there is plenty of touching stuff that's delivered in different mediums. And I think that's the real key to this museum, you don't get bored over a long period of time, which is quite easy in museums. Art galleries are a classic example, I mean I defy anyone to go to an art gallery anywhere and spend five hours in there. I mean, you cannot just look at, you know, a thousand paintings, it's ridiculous (me langhing). And it's the same with the museum if you don't spread that message around 
completely differently... So I think from a presentation point of view it is one of the best museums I have seen for that particular issue of just keeping people interested over a period of time.

Mike simultaneously experiences and theorises Te Papa's changing media "landscape" again blurring the apparent boundary between 'empiricism' and 'theory'. The interview provides further evidence of 'theory-driven perception' (Treinen, 1995) and 'communicative rationality' (Habermas, 1984), which build on the inherently human capability of critical thought beyond its parochial definition as an academic prerogative. To put it differently, Mike's narrative descriptions contain both theoretical reasoning and evaluative critique. These narrative dimensions are interwoven, in contrast to the redundant notion of a separate "narrative evaluation' in the formalist tradition of Labov (Gwyn, 2000). Gwyn goes further in showing that any description itself assumes an evaluative character by consciously selecting and excluding.

Mike recognises the "mixture of how the information is delivered" and concludes that in Te Papa "it seems they have tried to mix the way they are telling you the story". His experience grew out of the dynamics of a multifaceted media "landscape", the various ways of telling, which becomes part of the story told. In this context, Mike alerts us to the alienation of specialised forms of communication from everyday perceptual habits. The latter can never be sterilised and reduced to monotonous sensory engagements such as "look[ing] at a thousand paintings" or deciphering scientific taxonomies. By producing such artificial "landscapes", art galleries and museums make sense only for the initiated, the holder of sufficient communicative capital who is able to decode the specialist enigma and therefore 'deserves' the access to such 'higher' grounds. This contributes to, and perpetuates what Bourdieu calls 'social distinction' (1984) and the 'feeling of 
exclusion' (1991). For a New Zealand case study in this context see P.D.M. Mason \& McCarthy (2006).

Mike's follow-up interview continues his narrative thread from meaning to memory:

I did like about your museum the presentation of things. And I can't actually remember every gallery, but the way that there wasn't a singular deliverance of the message in the manner which it was done. Some of them were done using voices which I thought was really good. They weren't just sort of dry voices but I think even one of the galleries had children talking. I can't remember which one it was, but I do remember there were some children giving the description of what it was. And you know, of course there was signs, and there was hologram pictures and all sorts of different ways of actually getting over some information. And it's sort of a fault of museums that you get rather bored if you just have one delivery of a message. And I thought that was pretty good the way it was done. Yeah that was a memorable thing, the way it was put together.

Similar to Nicole's precedence of "layout" and "structure" over "information" in memory, Mike “can't actually remember every gallery, but the way that there wasn't a singular deliverance of the message". Rather than seeing this as the museum's 'failure' to successfully teach the subject matter of its galleries, I see it as offering more evidence for the interweaving, merging and overlapping of "deliverance" and "message", or form and content, in human communication. In other words, the medium becomes an integral part of the message. In Mike's case, this condition of meaning-making, "the way it was put together", evolves in fact into the most "memorable thing”.

I turn to Charlotte, who offers more insights into this long-term negotiation and, quite remarkably, narrated her experience of space and display first in the follow-up interview:

I guess I had expectations it was gonna, you know, just be a bit stuffy and just another museum and stuff. But then when I got there I was very impressed with the building, with the way the displays are set out and yeah just with all the interesting articles and the variety of things. You know there is something there if you wanna get right into the history and the details that information is there, but if you are only looking at it I guess 
from a display and entertainment perspective then you can have that too because there is lots of diversity and colour and the different ways things are displayed. So yeah I was pleasantly surprised by what I saw... Probably I am thinking of the things that I remember the most...I think it was called the 1950s shop where you went in... I guess the dramatic effect of walking into the shop and sitting down and seeing all the things on display and that sort of timeline of history.

The "building", "the way the displays are set out" as well as "the variety of things" have made a lasting impression on Charlotte. The usual "fault of museums", to use Mike's words, made Charlotte initially expect a "stuffy" place build on the dichotomous notion of "information" or education versus "entertainment", of either meaningful enlightenment or frivolous enjoyment. Although still a prevalent notion among cultural elites in the normative sense, this rigid opposition has been proven senseless both theoretically (Chakrabarty, 2002) and empirically (Kelly, 2007). I expand on the mutual relationship of learning and experience in the course of this chapter but for now bring to a close the discussion in this section.

John seems to share Charlotte's "dramatic effect" of the same Golden Days display and gives us some glimpses into his wider critical reasoning on the museum world:

...one thing I really like about the museum is how clever all the exhibits are. And part of it I have noticed is in the newer museums, a lot of the older museums are, things are in showcases...showcases of gems, showcases of animals and you walk from one showcase to another. In recent years I have noticed a lot of museums are taking things out of showcases and make them closer and more interactive and giving less a sense of categorised boxes but things where you walk around. And I think the Te Papa has done a magnificent job of that, and has done an excellent job of little bits of humour in things, like the 'Golden Days' when the shopkeeper pulls down the screen and then the shop comes alive. And all the analogies you can draw from other shops being closed up and the animals come alive at night in Christmas and Geppetto and Pinocchio and a bunch of those things, very clever with that...

John's narrative highlights that museum exhibits communicate primarily through the senses, as Kaplan (1995) rightly argues. Performative and integrated multi-media displays, demanded by Brueckner (2006) and Kirchberg (2006), can provoke inseparable emotional and intellectual 
responses and trigger imagination, through "all the analogies you can draw", leading to a form of interactivity beyond 'pushing a button or hiring a headset' (Witcomb, 2007, p. 3). Ill-informed dismissals of sensory environments and the naive contrasting of feeling and evocation with 'truth' and knowledge might count for much as detached cultural critiques (Williams, 2003), but remain ontological illusions. As I argue below, following the call to erase sensory contexts would serve to erase the human conditions of meaning-making.

In this section, I started exploring the experience of a museum space. The research material revealed that the spatial composition of Te Papa with its individual components such as architecture, exhibition design and display performs as a medium framing and shaping the visitor experience. Physical space inevitably becomes an interpretive space moving from meaning to memory. The empirical evidence presented here offered first insights into the mutual relationship between such spatial forms and museological content. I complete the illumination of this tension and interplay by turning now to a closer examination of content.

\section{Content, context and narrative}

In the previous chapter, I laid out the theoretical rationale for 'narrative' as a fundamental meaning-making tool and characteristic feature of action, elevating it to the heart of the human condition. In this section, we see how narrative's dual function of contextualising space and content in a particular museum setting interacts with the broader phenomenon of human sensemaking. The fusion of content, context and narrative becomes another condition of meaningmaking. Mike's detailed narration is a good starting point for the analysis and deserves to be quoted in its entirety: 
...this museum is set up rather differently to quite a few museums. And it seemed to me that it's really telling the story of New Zealand rather than trying to specifically direct your attention to each section of a story in depth. It's really, it's not covering it in depth, you know, it's not an in-depth type museum. But it seems after a period of time that it's trying to cover a whole and show you that these things are interlinked... it's actually told in a different context which I really liked, because you know, you don't necessarily as a visitor want to see a thousand stuffed birds. But when it's in a context of, which I didn't know, the clearing of the land in this country and the burning of the land and other reasons; and I mean I have thought Europeans had destroyed most of the landscape but now I found out it was about 50/50, the Màori did exactly the same as the Europeans, then you see the context of the displays on the birds and the wildlife. You know, they have some meaning to what it is I thought. And similarly each of the galleries has a linkage in some way. And I thought the gallery that had the story of the specific tribe and their experience in land rights...it lays in context and a number of the other things in the museum, because it tells the story of their loss of land right, if they ever had one... But that sort of interestingly links back to the other galleries. When you look back at the immigration gallery you can see all the enthusiasm of new migrants coming here. But if you have been to the gallery of that particular tribe, which I never pronounce, you see that their gain over there for the Europeans was a severe loss on the gallery on the other side. And it made some sense...

Mike goes on to conclude:

So I think that's the overall impression of this museum is a very interesting linking of the land, the people and the history of it. It flows a bit better here than in most museums I have been to. Most museums specialise in certain things. This museum doesn't necessarily specialise...it doesn't present itself as an in-depth academic museum...But here it's a story of the land from the beginning through to the current. And I guess that's the impression I will take away from this museum. If you spend the time, you can't do it in an hour, you need to go to most of the galleries to see the impact of what these things are. And I particularly liked it. It was the most impressive thing I have seen.

Mike provides another theoretically and critically spiced narrative of his Te Papa visit. In his view, a "story" generates the "linkage" between each gallery's subject matter and its respective "context" as well as the different exhibitions within the overall museum setting. To Mike, this dynamic interplay just "made some sense", and previously unfamiliar thematic content gains "some meaning" through narrative contextualisation. The perceived lack of in-depth information bears considerable risks and invites legitimate criticism. At this stage, however, Mike's experience sheds light on the conditions of meaning-making which make any potential in-depth 
engagement possible. Any critique of an apparent lack of depth in museum displays needs to

build on the interdependence of content, context and narrative to facilitate more in-depth insights

without compensating what might be called 'postmodern superficiality' with 'specialist

taxonomies'. The latter might adhere to the scientific ethos of an ever increasing factual

knowledge, but will remain devoid of meaning.

In his follow-up interview, Mike elaborates on the "memorable highlights" and "biggest impression":

The memorable highlights for me thinking back, the biggest impression that I've left with that museum and I still think about is the linkage of the galleries and how there is a narrative being told here at that museum rather than a display of information. And it's one of those museums that might not go into huge depth, but it seems to me it's setting out to achieve something else apart from, you know, in-depth information. It's really setting out to tell a story of that country and the people. So you don't necessarily need indepth if you are trying to tell a story when someone is there only for a day. I mean locals would go back I suppose, but for me it was, I could see how they were linking some of the galleries so that the thing made sense in some sort of a way. And that's the key memorable thing about that museum was that when you looked at issues of the land and the animals and what happened to the vegetation, it's linked back in a gallery later on which tells you about how there was a lot of clearing done, not necessarily by the white people but by the Mãori and white settlers that came in. And then it sort of made sense about the narrative told in the previous gallery, about why certain things were like they are. So I guess that was like the overall impression I brought away from the museum, that there was a linkage particularly with the people, the Mäori and the new settlers...I don't think either was given a superior role in what shaped New Zealand. But they were sort of both shown that these are forces that were at work. So the museum sort of had this feel that there were forces of nature and then there were forces of people that made sense when you actually looked at all the galleries...

Mike's remarkably detailed recall of his Te Papa visit after six months makes it clear that the narrative "linkage" has passed through meanings into memory. Along this long-term interpretive negotiation, the contextualisation of museological content encounters human sense-making through 'narrative'. Mike continues with the 'hermeneutic expression' of his experience which, quite astonishingly, mirrors the flow of the initial interview and emphasises the fluid transition 
from the conditions to the processes of meaning-making, from the syntactic frame to the semantic filling. To put it differently, the interaction of content, context and narrative "made sense" and opens the gates to in-depth interpretive engagements with cultural phenomena as we can observe:

I think at the time it was some sort of South Island tribe that was on display there... (Ngai Tahu)... Yeah, I thought that was really interesting after visiting the immigration gallery where you saw the white perspective on things, then you saw the Marori gallery and the destruction of a considerable portion of their country and civilisation. And they had been there for a thousand years or whatever. It sort of made you realise that the renewing of the country with immigration from another race helped part of the destruction of an existing race that was there. And I just thought those galleries sort of really clearly showed that there was optimism in one gallery of the new world, and then the struggle of the indigenous population to handle the new world. And I think that was handled better than I have seen it handled in most Australian museums who tend to pigeon-hole the Aboriginal experience. They are a little bit shy of I guess putting out the concept that we as the immigrant have destroyed something on the way through here. Yeah I thought that museum did it really well...

'Context' is a heavily debated issue in today's museum world, one camp regarding it as essential to democratise cultural institutions and the other side accusing it of desecrating divine aesthetic pleasures. In my view, the nature of the parochial either/or argument itself is the most limiting aspect of this debate. While I certainly regard museums as places of wonder and imagination, as I strongly argue in the next section, I am also conscious of the fact that the "pure gaze' is a historical invention' (Bourdieu, 1984, p. 3) and no innate human disposition. Even more importantly, given the hermeneutic nature of being, Ricoeur (1981, p. 44) argues that 'a sensitivity to context is the necessary complement and ineluctable counterpart of polysemy', the characteristic by which all human phenomena 'have more than one meaning when considered outside of their use in a determinate context'.

In a museum setting, narrative contextualisation loosens the futile positivist grip on 'historicity' and its 'imaginative reconstruction' (Ricoeur, 1981, p. 289), which exposes any accusation of 
'historical revisionism' as tautology. Performing as a condition of meaning making, narrative

also lays the foundation for a form of interactivity beyond its usual mundane understanding as we

can see in the case of Bruce:

But I can't think of any other museums that are particularly similar. I have probably been to a few Native American Indian, you know, artefact kind of museums and it all seems very out of context. Seeing it in that respect I didn't spent any time at displays here that were, you know, like one of the things that stopped me pointing that out was one of the jade weapons, little jade axes, a short blade that was probably about a hand span and a half long. And those were not really interesting because they are sort of an artefact. They are not really, they are a dead thing. They are a thing that's outside of context now. They are not really a living thing, whereas the stories that were, you know, the story of the creation... the explanation and the understanding of how earthquakes happen and the explanation of how the islands came to be, those are still at least to some extent living things. They are things that can still have an impact on the world rather than just looking at them and reading the inscription. That makes them more I guess the trite way of saying would be a more interactive experience, but probably the better way would be it's a more writerly experience in that it's information that once you have it you can interact with it ... it will be something that at some point in the future I can imagine bringing into a conversation with somebody else whereas, you know, a life-size mock-up of a canoe that was used to travel between islands I am not really sure how to use that. I mean it's interesting information being a sailor to sort of see how the boats were built and what not, but what was more interesting was the presentation of the information in a, you know, I guess the story in a useful way.

Bruce provides empirical evidence of what Abbott (2002) calls a 'narrative consciousness', the processing of human experiences through narrative structures which I discussed in Chapter Two.

To him, "stories" represent "living things" allowing for a "writerly experience" which goes beyond an "interactive experience", "the trite way of saying" unable to capture the sort of active engagement he intends to describe. A plain "artefact", instead, is a "dead thing...outside of context" lacking the animate qualities to "have an impact on the world". Witcomb (2003) expands on this in her fruitful exploration of 'interactivity' as an imaginative and conceptual activity beyond its usual technological, physical or mechanical connotations, an assertion reminiscent of Dewey's insistence on imaginative qualities in any thought process (Jackson, 1998). 
Witcomb (2003) equates ‘interactivity' with ‘self-inscription', a process which blurs the boundaries between 'production' and 'consumption' involving both sides in the making of pluralised meanings, perspectives and subjectivities. Dewey (1934) equally dismisses the meaningless distinction of 'production' and 'perception' in his interrogation of the 'aesthetic experience', and it seems that Bruce's "writerly experience" via "stories" builds the interpretive bridge facilitating their integration. Unlike a de-contextualised object, a "story" invites him to actively 'self-inscribe' "rather than just looking at them and reading the inscription" passively. Narrative provides the hermeneutic means to travel from "symbol" to "mean[ing]" as we can observe in Andrew's reference to his wife's experience:

I have visited a number of museums in different parts of the world for basically the same reason, to find out something. This one is as good as I have seen anywhere. It's well done, well laid out. I think the major advantage of the visit we had is it answered some questions but it opens you up also to learning a little bit more. It made us a little more knowledgeable of questions we could answer or if not answer, questions we could ask and things to look for... Little things like the example that we were given about the art and what some of the symbols meant in the carvings. My wife spent some time down in the shop looking for some of the symbols that were there and they now mean a little bit to her rather than just a pretty fish symbol.

The interplay of content, context and narrative operates on several communicative levels within a museological space. Human interventions in the form of guided tours can add another contextual layer and facilitate meaning-making through face to face interaction. The multifaceted role of tour hosts in generating translation, dialogue and understanding in cross-cultural encounters will accompany us through the next chapter. For now, Susan provides some insights into the communicative functioning of "shar[ing]" tour "stories" as part of the overall museum media "landscape":

I got the stories out of it...And so I mean those are the kind of things that stick out in my mind, the stories. But when we got to the Mäori people he really brightened up and you could tell that was his people and he wanted to share stories...he explained it and I am a 
bit more auditory, I need to hear things sometimes...I kind of get fried sometimes walking through the museums. You look at the displays and you are reading and you are reading and you keep on reading, and I don't remember what was that about. So it's just a different joy... He was just really excited and hearing somebody who is really excited about what they are talking about is really important to me... he was very, very interested in finding out what we wanted to know and like very interested. And he was just very excited about sharing his knowledge with everybody.

Susan's follow-up interview shows that the "shar[ing]...of...stories" still belongs to the "kind of things" which, according to her, "stick out in my mind":

I was able to take a tour and I had a Māori guide. And that was really interesting because he was able to refer and give us a bit more Māori history and Māori displays and kind of share some of his stories...so he explained some different things...

In the next interview example, we can observe the tour impact moving beyond the "writerly experience" of "shar[ing] stories" towards the broader contextualising "linkage" I explored at the beginning of this section. Nicole says:

So what I found that really stood out were on the tour just things... like there is the world on the floor, about right in front of Passports. And like okay it's a world on the floor, but then he was actually explaining, you know, just trying to show how far New Zealand is from the rest of the world, like little things like that...I never would have thought about it. If I wasn't on that tour I wouldn't have even really looked, like I'd look at it, but that's about it, you know what I mean!? And so I found that tour is really, really good for just pointing out things that, not even that you miss some when you are just walking by yourself, but you wouldn't even consider them. You know, it's just kind of your brain isn't even processing them because there is so much to see kind of thing (laughing). So I felt that was really good... Pounamu, that stone I had seen before and just thought it was a stone with water running over it (laughing). I knew there was probably some significance to it, but you know, I didn't really consider it. It meant to me like 'oh that's nice' but like that was about it. And then he was just explaining all about that...

Nicole continues and sums up her experience of the tour:

...also interesting I thought on the tour they point out like the structure and the organisation of the museum. For example he was talking about the Scottish exhibition upstairs and every two years it's a new group of immigrants who have an exhibition there. And the same with the Iwi, like different Iwi every four years have an exhibition and it just peeked my interest and made me think... he was just explaining a bit more about what each section was about. And like, I find when you are in a museum of this size it's overwhelming sometimes and you don't even really know what you are looking at. I mean 
you understand, you know, on a micro level, but on a macro level you don't understand how it all is relating. So I just found that he was good at kind of looking at the macro level...like just laying out the museum on a macro level rather than in the little tiny bits of information that are all throughout the museum...

The narrative tour intervention facilitates the "linkage" which Mike experienced through the 'reading' of exhibitions in their spatial and thematic composition. The tour host enables the translation of objects and structures which, according to Nicole, one might not visually "miss" but one might nevertheless fail to "consider" their meaning. She clearly appreciates the introduction to the "macro level", a "relating" contextualisation of an otherwise "overwhelming" museum space. As I already indicated, such interpretive aids will play an even more significant role in the subsequent inspection of cross-cultural dynamics.

In bringing this section to a close, and demonstrating the interplay of content and context, we conclude with Claudia's case which opens the gates to imagination:

And I have been fortunate enough to have been here for a couple of months in New Zealand already. Ahm and I have been hearing with the Moa and the Kiwi bird, you know, a lot of these different words. So the museum is great for me in that respect because where I don't know a lot New Zealand, and I have been slowly accumulating knowledge, this I guess in a way gave me a way to tie some of it together. And the exhibits and collections of the animals that would have lived here and birds that have lived here, gives me some sense of perspective in their size and theories on what they may have sounded like, how they may have interacted with each other. But before I came it was just bits and pieces. Yes, there was a bird called the Moa here, a big bird that was all I knew! (both laughing) And now it's extinct, but you know this let me actually see it so I can both visualise it and see what footprint would have been like. And most of the exhibits upstairs were wonderful as with the giant eagle and the giant Moa. It just gets you thinking what really would it have been like other than just some abstract thing as 'there was this bird in the past'. Yeah, so it really gives it more perspective, you can really visualise and imagine what it was like.

Claudia's story represents a crucial crossroads in this study. She stresses that the contextualisation of an otherwise "abstract thing...gives it more perspective". The museum visit enables Claudia to synthesise disjointed "bits and pieces" of knowledge and interpretively "tie 
some of it together". In other words, the interaction of content, context and narrative facilitates the hermeneutic dissection of the whole and its parts. Importantly, Claudia's narration encapsulates the non-textual hermeneutic spheres of the human existence in the form of sensory and imaginative engagements.

The interrogation of these interpretive spheres requires a hermeneutic sensitivity beyond the spoken word, as I argued in Chapter Two. I stressed that narrative interpretations of experiences are subject to verbal limitations. Many meanings are inherently interpreted but remain feelings or 'embodied meanings' (Johnson, 2007). This is the point, when the interplay of content, context and narrative flows into the working of senses, feelings and embodiment as further conditions of meaning-making. Once again, I can only draw an analytical 'distinction' which never amounts to a claim of experiential 'separation'. Claudia's interpretive actions, movements and performances to "really visualise and imagine" pave the way to the next section. Given these inherently human features, it also becomes clear that cultural critiques treating exhibitions as texts not only are museologically lop-sided, as various scholars have argued (Gable, 2006; McCarthy, 2007; Thomas, 1994), but remain 'anemic' (Ong, 1999) and ontologically impaired.

\section{Senses, feelings and embodiment}

The world in which we immediately live, that in which we strive, succeed, and are defeated is preeminently a qualitative world. What we act for, suffer, and enjoy are things in their qualitative determinations. This world forms the field of characteristic modes of thinking, characteristic in that thought is definitely regulated by qualitative considerations (Dewey in Johnson, 2007, pp. 71-72). 
In the previous section, I illuminated the experience of a museum space. The research material revealed the mutually dependent dimensions of space, form and medium as well as content, context and narrative as conditions of meaning-making. I highlighted that this particular thesis chapter was exclusively driven by the empirical investigation without prior theorising and research focus. In this section on the multisensory, emotive and embodied nature of the museum experience, the empirical insights have led to extensive theorising on my part since it allowed me to enrich my understanding of cross-cultural encounters and identity politics in the following chapters. This section is structured in a similar fashion through the analysis of the research material, but concludes with a more detailed theoretical discussion reflecting my own circular hermeneutic journey. The end of this interpretive part provides an appropriate place for its inclusion into the thesis facilitating the transition of my argument and the orientation of the reader.

It is clear that by employing a narrative approach with its double-hermeneutic condition, I will get access to only mediated and reflective feelings rather than subconscious emotions. Given the inherently evaluative nature of such feelings, which I lay bare both empirically and theoretically, I am able to hermeneutically grasp their meaning even when they lack elaborated verbalisation. As reiterated throughout this study, some meanings remain feelings without further linguistic expression. In Davidson's (2006) study of mountaineers, it was a 'mountain feeling'. What is required I believe is an embodied hermeneutics which is alert to more than just words. Language, although being inherently selective and reductive of the Gestalt experience, is our 'great vehicle for the growth of meaning' (Johnson, 2007, pp. 266-267). It is this 'growth of meaning' or interpretation as a 'development of understanding' (Ricoeur, 1981) that we witness in this thesis. 
In this section, we first observe the functioning of senses, feelings and embodiment as conditions

of meaning-making through Claudia's narrative:

I just found when I walked into an exhibit, when you are actually completely surrounded by sound as if you were walking into that environment, it kind of really catches me...I really enjoy sensory experiences. I try to be very aware of whether it's, I mean sight you take for granted, but if I am hearing or smelling something, like walking down the bush walk, bush city. You know you can smell damp leaves or whatever it was and it just adds that element. And with that earthquake simulation for example, you know, I know it was a very tame earthquake, but I have never experienced an earthquake. So to be in there and have that sensation, and with sound...I heard a quote once, somebody said that 'it would be nice if you had, I've always wanted a soundtrack to my life!' See we watch movies and if there is some dramatic scene on the television and they've got this sweeping, dramatic song in the background and it really, if you are into music at all and maybe even if you are not, it just really tugs at you. You really get drawn into the scene, or I do anyway speaking from my perspective.

For Claudia, an "exhibit" is transformed into an "environment" through "sensory experiences".

This "adds that element" to "get drawn into the scene". Claudia continues her narration on "the feeling of being enveloped by a space' (Gregory \& Witcomb, 2007, p. 5) and it would simply feel wrong to further interrupt her story:

So when I walked into an exhibit, like the 'Blood, Earth \& Fire', if that's what it's called?! When you first walk in and the red lava spewing and you can hear the sounds of things erupting, it just really (paused) makes me more aware of what they are trying to get me to understand. The one with the earthquake simulation, it just really adds to the experience. It's one thing to watch videos or to read about something or, you know, see the lava rocks that may have been the result after the thing, but to be given the chance to try to comprehend what it really sounded like, felt like, smelled like for me as a person, I don't know if everyone would feel the same way, (paused) but once you are trying to experience it firsthand, and even though it's a simulation, it may be the closest thing an individual may get to experiencing it. I hope I never have to experience an earthquake. I am in New Zealand so it's quite possible I will (both laughing), but if I was only travelling to New Zealand for a couple of weeks it's very possible that I wouldn't experience one. So being in that and coming from Canada, the east side there is no earthquakes there either, so it gives me an opportunity to, you know, get a sense of what it may be like. And just it broadens my understanding of what occurs when there is an earthquake for example and what people might go through and how the people would feel. So maybe at home when I go back like watching the news and I hear about an earthquake I won't just discount it. I will actually be able to appreciate that piece of news because it's something that I've now more information, more internal understanding of. 
Although Claudia does not "know if everyone would feel the same way", I am convinced that any "person" can somehow relate to her story and reflected experience: we can never help but feel! As we have seen in the preceding section 'Content, context and narrative', interpretation depends on, and is bound to, context. Claudia's narration exemplifies that an interpretive context can be achieved through multi-sensory and embodied performances, a sensory and emotive contextualisation leading to an "internal understanding" and empathy.

On the one hand, this "internal understanding" or embodied interpretation could never be exhausted by linguistic expressions transcending its bodily anchoring. At least to a certain extent, it will always remain a felt rather than a spoken experience, meaning and understanding. On the other hand, no one could ever copy Claudia's "internal understanding", for it arises out of a bodily interaction with an environment, an individual experience of a particular 'situation' (Jackson, 1998) with a specific 'pervasive quality' (Johnson, 2007). Dewey (1934, p. 67) lends further weight to such experiential terminology, arguing that 'there is no such thing as the emotion of fear, hate, love. The unique, unduplicated character of experienced events and situations impregnates the emotion that is evoked.' It follows that emotions and feelings perform as a 'cementing force' unifying the experience's whole or Gestalt (Dewey, 1934). 'Experience', Dewey (1934, p. 42) continues, 'is emotional but there are no separate things called emotions in it.' This statement might first appear puzzling to the dichotomously conditioned mind, but it just highlights the fact that 'emotion belongs of a certainty to the self' (Dewey, 1934, p. 42).

Emotions and feelings are not separated stages but continuous dimensions of any experience. This is the inescapable interpretive condition that, in Denzin's (1989b, p. 102) words, 'no 
experience has the same meaning for two people...because meaning is emotional and biographical'.

Here Michelle narrates her experience of the same earthquake house:

We walked into the little house and then there was an earthquake and it reminded me a little bit about when I lived in Los Angeles. Well, I think I was probably a teenager and we had an earthquake and I woke up with my bed just shaking and shaking. I couldn't figure out what was happening. And then I finally realised 'oh it's an earthquake'. It wasn't a terrible earthquake where people were, you know, losing their homes, but things fell off the shelf and dishes could have been broken. But homes weren't destroyed as happened I think in...there was an earthquake somewhere in the late 80s in Los Angeles, which was very severe. But just experiencing an earthquake in the museum, I am sure a lot of people had never experienced what that would be like.

The significance of prior understandings (Ricoeur, 1981) and prior experiences (Dewey, 1934) for any experience, which becomes obvious in Michelle's story, will be further discussed in the upcoming section. In this context, the narration provides another example of a multisensory and emotive contextualisation as condition of meaning-making. This leads to an embodied "writerly experience”, 'self-inscription' and 'interactivity' beyond 'narrative'. The latter could never fully capture or contextualise the human experience of an earthquake since it can only objectify the visceral dimension. Experiencing an earthquake lacks 'expressibility', the alleged 'lingual condition...of all experience' (Ricoeur, 1981, p. 115), and will remain a feeling or "internal understanding". Michelle's articulation also proves that any conscious experience and thought process has an imaginative quality (Jackson, 1998). In other words, "experiencing an earthquake" can never be disassociated from feeling, rationalising and imagining an earthquake.

Susan refers below to the same exhibit and provides further empirical evidence of these assertions: 
And I also found interesting that New Zealand was at such a big risk for earthquakes, I found that interesting. I wasn't home, but at home this past summer there was a 5.2 on the Richter scale in Chicago and they felt it in St. Louis and Indianapolis, which is kind of big because like St. Louis is more than 400 miles away from Chicago, Indianapolis is 300 miles from Chicago. It's kind of a big deal. Standing in the house like feeling it shake, I was like 'oh, so this is what my mom was talking about, this is kind of interesting'... when you walk into the house and you get to feel an actual house shaking, most people have never lived through an earthquake.

Susan's experience arises out of a multisensory, emotive and embodied 'object-subject interaction' (Dudley, 2009), a process of active and mutual engagement between Self and the physical world. "Standing in the house like feeling it shake" provokes a deeper understanding of "what", according to Susan, "my mom was talking about". This emphasises the active character of 'perception', discussed in Chapter Two in a narrative context. Dewey (1934, p. 54) stresses that perceptions are not passive and isolated receptions but transactionally constituted actions because 'for to perceive', he puts it, 'a beholder must create his own experience'. Damasio (1994, p. 225) offers neuroscientific support for this philosophical claim: 'Perceiving is as much about acting on the environment as it is about receiving signals from it.'

In continuing her story, Susan's reflections assume a theoretical quality which is once again reminiscent of a 'theory-driven perception':

The whole museum is set up to almost be like a children's museum for adults... like you can take off your shoes and actually walk into the building and experience and touch that and feel that and look at that. And there is something different when you can actually feel the carvings instead of just looking at it. There is (paused), we have all of our senses for a reason and so being able to feel that and actually experience it is a little different. And I think that's one of the reasons why I really enjoyed it...

"We have all of our senses for a reason", Susan exclaims. And "being able to...experience and touch that and feel that and look at that" makes the museum experience "a little different". In fact, the multisensory access to exhibitions and objects appears to Susan "almost...like a 
children's museum for adults". This conclusion applauds Te Papa's "set up", but equally highlights the artificial sensory alienation from childhood to adulthood in traditional approaches to education, learning and human development. 'Pervasive qualities' of any experience, however, are 'at once visual, auditory, tactile, social and cultural' (Johnson, 2007, p. 72). Susan attests both empirically and theoretically to this 'relational character of perception' (Jackson, 1998).

Susan proceeds with the narrative reflection on her multisensory museum journey:

Well, I mean you can always look at the carvings and you can see the intricate detail, but not until you actually feel the wood or the stone, because your eyes can only see so much detail depending on how good your vision is, but your finger tips are extremely sensitive and you can feel the detail even more than just viewing it. And you just take on a more a better appreciation, you realise 'that's right, this is wood, that's extremely difficult to do, this is stone, this takes so much time, so much back ache and can you imagine having to bend down and look at it like this?!' And just it's a different appreciation like something you don't normally think about in everyday life... I don't know it's just a very, it's awe, I was very awestruck, it was beautiful. And I think I was really impressed by the carvings, it's so much time...

Susan's multisensory, emotive and embodied engagement flows into the interpretive construction of meanings once again connecting the conditions and processes of meaning-making in a circular hermeneutic trajectory. Jackson (1998, p. 57) sums up the preceding theoretical line of thought by stating that 'to perceive an object is not simply to see, hear, smell or touch it', as 'the psychological fallacy' would have us believe, 'it is to make sense of what one senses, to partake of its meaning'. In Susan's case, 'to partake of its meaning' leads to a "better appreciation" beyond "everyday life" which leaves her "very awestruck". Senses and feelings merge in the process of meaning-making causing an embodied or "internal understanding" far beyond linguistic 'expressibility'.

If the interpretive human condition could never be completely grasped by words, then neither do our innate sensory and emotive engagements pose a threat to some 'higher' form of knowledge 
and 'truth' in a museum context, as Williams (2003) claims. Dewey (1934, p. 118) reminds us that, instead, 'sense qualities are the carriers of meanings'. Dewey (1934, p. 119) continues to alert us to the 'qualitative determinations', the 'felt sense' (Johnson, 2007), of any thought, knowledge or 'truth' itself and exposes such dichotomising accusation as naivety: 'We cannot grasp any idea, any organ of mediation, we cannot possess it in its full force, until we have felt and sensed it, as much so as if it were an odor or color.'

It is again Susan who provides more empirical insights on this point:

And then looking at the canoe and seeing how small of a canoe that is, how wide it is and trying to imagine a six-foot man sitting in that cross-legged or even hunched down, being able to feel that and like 'that's crazy'. You know, I wouldn't be able to experience that if it was set up behind glass and like looking at it. I wouldn't actually be able to tell the depth I feel. And that not just me personally, but you just, you can almost feel yourself stepping into the canoe when it's set up in the middle of the floor like that and when you are able to walk into the building...

We can again discern that senses, feelings, imagination, thought and understanding are not separate or diametrically opposed entities, but mutually dependent, interrelated and overlapping dimensions of the conditions and processes of meaning-making. Remarkably, even this narrative reflection and retrospective mediation of the actual experience reveals these dynamics of the Gestalt, the unified whole. Given the limits of this study and the general impossibility of gaining direct access to a 'pure' experience, we can only speculate about the intermeshed richness of Susan's actually experienced 'situation' and its 'pervasive' or 'individualising quality' (Jackson, 1998). Susan carries on to "to tell the depth I feel":

I have always loved jade. I have always loved jade, I have always found it to be a beautiful stone. And I can't remember the name of the stone that they have here, but it's on the...(Pounamu)... Yeah, it's on the South Island and it's the green. And being able to see the big stone sitting in the, is it the Blood, Earth \& Fire display?! Just being able to touch that, again it's touching it and feeling it and seeing exactly how smooth it is and just being able to really look at the detail instead of it sitting in the glass behind a case. 
And hop, there it is, you know, you can't really touch it and like oh that's great. And my brain kind of it gets fried eventually. You know you are walking around looking at the displays and you are reading over it and you start just skimming through and picking up keywords and you halfway understand it, but if you can like feel it and you are interested in it a little more you gonna understand it a little better...

It becomes clear that to "feel" invites us to be "interested" and enables us to "understand". It follows that feelings possess an immanently hermeneutic quality. While I focus on the interpretive condition of relevance and interest in the subsequent section, Susan's follow-up interview offers evidence of the long-term impact of the multidimensional interplay of senses, feelings and embodiment. 'Experience and memory are', according to Chakrabarty (2002, p. 11), 'embodied knowledge'. Embodiment performs simultaneously as condition and process of meaning-making. It lives on in memory, in Susan's case as a "fe[lt] ...presence":

The displays and exhibits that I really remember were the Mäori displays and the, I don't remember what it was called, not like a temple but a meeting room where they perform their meetings?! And you were able to take off your shoes and enter in and just kind of sit there and soak it all in. You feel the presence and everything and like all the beautiful carvings and it's nice being able to touch everything and just look at the different, the very beautiful intricate details on the carvings.

Susan's reflection is reminiscent of Nicole's ongoing experience of the museum space where she "just felt really calm" and remembered "not so much the information there but just the actual layout of it". For Susan, a "fe[lt]...presence" also seems to imprint on her memory more profoundly than factual information such as the name of the "Māori displays". While cultural critiques may delight in detecting new ammunition for their accusations of sensory and emotive 'trivialisation', I find that conversely this presents further evidence for the inescapably embodied anchoring of meanings. The challenge in life as in museums lies in maintaining and nurturing a healthy balance of all dimensions of the conditions of meaning-making. 
By following Mike's follow-up interview, we can detect another example of a "fe[lt]...presence" or "eerie sense" embodied in memory:

I don't necessarily remember every gallery but I do remember the delivery of some of the items. The house was very impressive, the Māori house that's being reconstructed within the museum or the two of them there. But the big one I felt gave a real, I mean has an eerie sense when you are inside it. It had a really eerie presence when you walked down the stairs and into it. And sitting there and you can sort of imagine the meetings that were going on there...so often you see these particular either constructions or reconstructions in museums and you are not allowed to actually go in and actually be inside them, but look from behind the rail. But I think that in this particular case it really works that you go inside and the light is sort of dimmed to the stage of where it would be normally in the evening perhaps. So I thought that it sets the scene of what it is rather than if you just sat behind a barrier and looked at it, which is sort of too often done. I guess they are precious items so you gotta trust the public that they don't get out their pocket knife and carve their name in the side of it. If you don't have access to the item, then you don't make a link and you don't think with it. That was memorable.

Like the preceding discussion on space, form and medium and the associated museological media "landscape”, Mike again stresses that “I don't necessarily remember every gallery but I do remember the delivery of some of the items". Mike's expressions reveal the productive and creative role of sensory and emotive evocation in museological interpretation towards the dialogical creation of meanings. "If you don't have access to the item", he asserts, "then you don't make a link and you don't think with it". This is what, according to Mike, makes a museum experience "memorable". His view echoes the museum literature (Gregory \& Witcomb, 2007; Hutchison \& Collins, 2009; Kaplan, 1995) with scholars highlighting dimensions such as 'resonance and wonder' (Greenblatt, 1991), imagination (Bedford, 2004) and empathy (Gregory \& Witcomb, 2007). In the context of this thesis, the empirical evidence demonstrates anew that the conditions and processes of meaning-making are tightly interwoven with the construction of memories. 
By turning to Nicole's experience of Rongomaraeroa, Te Papa's contemporary marae and

meeting house (see exhibition description in Appendix G), we gain insights into the sensory and

emotive dimensions of 'resonance and wonder':

And oh the other part that really stood out... was the contemporary meeting house that you guys have made, like the I don't know what it's called...(marae)...The marae, yeah sorry my Māori pronunciation (laughing). And just yeah I really, really, really liked that space. Just how it feels, how it's so open and light and then just the contemporary take on like a meeting house... Again, first the size of the room because it's a huge room for what's actually in that space. And second the lighting because it's all, I thinks it's almost all windows that one side, isn't it, yeah?!...And just the actual house itself I just find it, the colours that were used they are really, really calm. They are not like the bold bright colours that you see on some of the other houses, which I still like, but it's just for that space it works really well. And I just found that structure to be really interesting to look at, like it's just so detailed, but it just looks like the material it is constructed out of is different from what you normally see. And so it's just really interesting to, like to me it actually looks like paper, like it's made out of paper or something. And just how fine it is and also I really like walking up to that space... I don't know, there is just something about how it feels like, it just feels like you are being welcomed (laughing). That's probably what it's supposed to feel like I am sure!? And it does feel like that I think! And it just feels really inviting!

In the previous section, Nicole offered detailed articulations of her spatial Te Papa experience causing the apparent precedence of "layout" and "structure" over "information" in memory. This experience of a museum space now gains a deeper sensory and emotive quality. The impact of the exhibition "space" is heightened through "colours" and "material" culminating in a "really inviting" feeling of "being welcomed", which reflects the actual purpose of this exhibit as Nicole correctly speculates.

Michelle engages profoundly with the same Rongomaraeroa in a remarkably similar but distinctive way:

The stain glass was just outstanding. But the way the actual building or structure, I don't know what you call it, I know there is a name for it? ...(marae)...marae. That was so creative because it was nothing like the historical one and yet it captured the essence of it. I mean they still had the head and the spine and, you know, all the same parts, but then 
in a totally different way. And the colours were so beautiful. And yeah, it almost looked like it was cut out of paper, coloured paper, when you first looked at it from a distance. And there is an art form from another culture that is cut out paper in beautiful designs. I think it's done by the Mexican people or the Canadian people who are of Eastern European descent. And they cut out these very intricate designs and then the light comes through them. But it sort of reminded me of that and it was, my breath was taken away when I first saw it. I thought that was so beautiful.

Michelle's impression that "it almost looked like it was cut out of paper" resembles Nicole's previous imagination. The exhibit provokes an interpretive 'resonance' through the apparent relation to "an art form from another culture". Michelle is left in state of 'wonder' since her "breath was taken away" by the "beautiful" design. Greenblatt (1991, p. 42) offers a useful theoretical elaboration of the associated experiential terminology:

By resonance I mean the power of the displayed object to reach out beyond its formal boundaries to a larger world, to evoke in the viewer the complex, dynamic cultural forces from which it has emerged and for which it may be taken by the viewer to stand. By wonder I mean the power of the displayed object to stop the viewer in his or her tracks, to convey an arresting sense of uniqueness, to evoke an exalted attention.

Greenblatt (1991, p. 54) further argues that 'both the poetics and politics of representation are most completely fulfilled in the experience of wonderful resonance and resonant wonder'. In the case of Michelle, Rongomaraeroa seems to achieve such fruitful symbiosis.

Michelle refers back to her experience in the follow-up interview highlighting the long-term implications of the "breathtaking...design":

...the one that was just so beautifully done, that was probably the most outstanding thing that we had seen. It was just breathtaking in its design. And I really was impressed with that. I wish I had a picture of it, I don't think I do. But that was really quite extraordinary and I remember they told us that that was going to be used or was used for someone's memorial service or funeral.

To Charlotte, in quite a different way, the "image" of the same exhibit seems to have developed retrospectively in her "memories" and appears first in the follow-up interview: 
And the colours in terms of display and visual effect, that it wasn't in timber, it wasn't in traditional timber colours but it was colourful, it was bright. And yeah, that sort of image of it I guess is one of the big memories that I have of it, walking around the corner and just seeing it there.

In his initial narration, John simply stated that he "liked the new marae" so I asked for more elaboration in stage two of the narrative interview structure. His response made me first feel awkward in my role as 'interrogator' but led to the personal realisation, described above, of a non-linguistic turn in the exploration of meaning-making. John says:

...just spontaneously we liked, we walked in and we just liked it because it was colourful, bright. The room is very bright and that's probably one thing, oh yeah, we came out of a dark room into a bright room. It called our attention probably because it was from darkness to bright with all the windows back there and the light on it. And it just (paused), it felt good just to see modern artists working in a traditional theme. Yeah (paused), that's, I am no deeper than that. I don't, I don't have any more, any deeper emotion than that.

At this point, I reacted by assuring John that this interview did not intend to categorise a hierarchy of 'deep' or 'shallow' experiences. I sensed a certain discomfort with my 'scientific intrusion' and was relieved that the interview had come to a conclusion. The story itself, however, never ceased to ignite my intellectual curiosity.

Having 'thought' through feelings and 'felt' through thoughts within the scope of my research, I consider that John provides the clearest evidence yet of meanings beyond the limiting 'lingual condition... of all experience'. The claim of 'expressibility' implies a correlation between meaningful experiences and linguistic fluency. It might be said, only the master of language games finds access to meaning in experience otherwise concealed to the less eloquent. In this context, it appears that John failed the test. I think, however, that John attempted to elaborate on an embodied meaning which resists any formal attempt of verbalisation. This reminds us of 
Johnson's (2007) 'qualia', felt qualities which cannot be reduced to conceptual structures such as words. John becomes a victim of the linguistic trap by assuming that he is "no deeper than that" although he clearly does not lack emotional depth but only faces the dilemma of not finding words which can exhaustively describe his feelings. Most importantly, this lack of 'expressibility' is no lingual failure, but an inescapable condition of meaning-making. We are always left struggling to find simple words for complex feelings, meanings and understandings.

In the section 'Space, form and medium', I briefly touched on the dichotomous notion of education versus entertainment and promised a more detailed elaboration in the course of this chapter. Dealing now with senses, feelings and embodiment, I explore the almost axiomatic opposition of learning and experience. In view of John's narration, it becomes clear that the debate is not confined to the realm of expert voices but is instead experienced, theorised and critiqued within the supposedly passive field of 'consumption' itself:

...and it's interesting, my wife and I were just talking about this, about going to museums to get information or going to museums to have an experience. And some of the newer museums like this you get an experience without coming away with as many facts necessarily. Some museums you go to and you see the longest dinosaur and the oldest culture or you read about a famous person in history. And some museums you go and you feel an experience, but you, if you talk about it a day later you think 'well, I didn't really learn a lot, but I had a good time!' And I think this museum is a nice combination of both. It's not a fun ride; well I guess there are some fun rides now. But it, it has some fun things to do like standing in an earthquake, which makes you feel much more like you know what an earthquake is, even though you might not have any factual information saying 'oh, there have been eight earthquakes on the Richter Scale of five and so many of six and seven'. But it was a neat experience, and there were a lot of things that were factual like the population in New Zealand that we found very, very interesting. So a very nice combination of both (paused), an experience and information, which I think that's what at least we go to museums for... I don't know, that's just, that's just our recent musings about museums.

John alerts us to the obvious risk of "fun rides" preventing learning and factual memorising.

Creating an unnatural and unhealthy overstimulation of senses and feelings in serious contexts 
can ultimately lead to 'emotional empathy without historical understanding', as Witcomb (2003, p. 140) warns. John also highlights that the remedy for this predicament is to be found not in some rigid separation of either experience or education, but instead in its productive synthesis. It is again Dewey who shows us how to overcome such conventional dichotomy by treating ‘education as experience' (Hennes, 2002). As stated earlier, this artificial opposition popular among cultural elites has been exposed as meaningless both theoretically (Chakrabarty, 2002) and empirically (Kelly, 2007). John's learning experience of the earthquake house, "which makes you feel much more like you know what an earthquake is", attests to the inextricable link between feeling and knowing and its potentially fruitful interpenetration.

John continues with his "musings about museums" in the follow-up interview offering a nuanced long-term picture:

It reminded us of how Disneyworld exhibits are put together, just a lot of cleverness and a lot of attention to details. Like when the shopkeeper pulls down the blind how it got dark and then how seeing the people on the street outside the windows. That part was entertaining. And I think I mentioned to you that we really liked the combination of things that were entertaining and that were informative. And that is I think hard to do sometimes because it's easy just to entertain people and they think 'oh, this is great' and they don't learn anything. And then it's also old-fashioned museums tend to explain a lot and not entertain people so much and they lose people's attention. And we thought the combination of both was very good.

John's "Disneyworld" analogy would doubtless be devoured as easy prey by theoretical critiques in their crusade against postmodern 'trivialisation'. Following such voices, knowledge and 'truth' need to be liberated from the siege of superficiality and protected against any 'colonisation' in Habermas' (1987) sense. But the museum literature provides some examples of related theory and research beyond such detached and alienated perspectives (Fina, 1978; Haller, 2003; Merz, 2006; Treinen, 1995). Damasio (2000) refers to empirical evidence of the positive impact of 
emotions on learning processes and memory. Hennes (2002), however, emphasises that Dewey's legacy in educational theory has been largely ignored in museum practice. This echoes Kesner's (2006) point that complex insights of perceptual research, which considers emotions as integral and interrelated processes (Woelke \& Paus-Hasebrink, 2005), are oversimplified in typical conceptualisations of visitor experiences.

Expanding on the issue of experience and learning, the following respondents offer more critical reflections which seem to be related to John's "musing":

I noticed you have here various children areas. I didn't go into those, but I believe from what I saw was hands on, touchy, feely stuff for kids. It's how they learn. (Jack)

...something I think that might have been interesting that I just passed through was the children's area with the games and things. And we just happened by when there were three kids who were playing with the sticks, doing their thing and a whole bunch of kids watching them. I guess it was kind of nice to see them there in a natural state, but we couldn't really get involved because there were too many kids around playing. And I guess that corner is built for the kids so that's all right. (Andrew)

I did see it and, you know, I didn't go in there because we don't have any children here, but there is a real direction by the museum for involving kids. The spaces that they got for them at the different levels are quite exciting little spots and there is a lot happening in those activity areas whereas museums can be pretty dull for kids unless they are involved in some way. And I am not an expert in how you keep children entertained, but what I did notice in this museum that they were doing things in the activity areas. It wasn't like a penalty of education (laughing) which it can so often be when you go to a museum, you know, record this and then go back to the classroom and recount it and describe it and do whatever. The kids that were here today and I don't know what ages and I don't know whether it's school holidays, but they were all sort of involved in doing things, which I hadn't seen very often in, in museums. But that may come back to again the way the museum is structured in not presenting a boring presentation for all the things. It's plenty of things that kids can do. So I thought that's true about this particular museum and there has been lots of arguments about people pushing and pulling things and whether there is in fact any benefit whatsoever to learning anything (sighing laugh). But this museum doesn't overdo it, it has mixed it up a bit. So if you have, you know, an endless row of touch screens, by the fifth touch screen kids won't be touching it. So they 
only just did certain spots. They haven't overloaded the experience for people get bored really quickly. (Mike)

In my view, it is parochial and harmful to limit the above observations to the juvenile world. This would only promote the 'utopian self-abstraction' (Warner, 1993) of adulthood which relegates the "natural state", the simultaneously sensory, emotive and intellectual engagement with the world, to the early and 'unsophisticated' stages of human evolution. It is this alienated sense of reality which drove Susan to the conclusion that "the whole museum is set up to almost be like a children's museum for adults", as we have seen earlier in this section. Multidimensional "involving" is no infantile need but the ontological basis for the 'growth of meaning' (Johnson, 2007) and 'development of understanding' (Ricoeur, 1981).

Mark highlights the predominantly technological view of "involving" in the museum world. However, this limiting and impoverishing form of 'interactivity' as mechanical rather than imaginative activity, which I discuss here and elsewhere in this study, might nevertheless represent a first move beyond illusionary abstractions:

... what I found most enjoyable though was that area near where the rides are, where you actually have control of that massive wall television. I had good fun with that like spinning all the pictures around and making them repeat the animations that I was doing and graffiti on them (laughing) Yeah, it's like really interactive stuff like that I like in a museum ...this museum is really aiming for the new age of people who are more interested in like touching and actually being involved, which is good.

In the section 'Content, context and narrative', we obtained first glimpses of the multifaceted impact of human interventions in the form of guided tours. In the upcoming chapters, I will further inspect their role in creating a humanised form of 'interactivity' and dialogue. For now, 
Julia offers insights into the emotive dimension carrying through the experience of such face to face interaction:

I think some of it too comes from the staff here, like the guides and just people around. I mean you can walk about to anybody and start up a conversation and I just chat away. It's like the most friendliest place I have ever been which is really amazing (laughing)...So that's really part of the feeling of being inclusive as well I guess as a visitor. You are put at your ease straight away. There is a comfort, for me anyway. I don't know how some other cultures might feel it, you know, it might feel quite off to them!? But to me it felt, 'this is great to be able to share it with you' sort of feel, you know!?...Yeah, it's just the feel about the place I guess, it is interesting I have to say.

To Julia, the presence of "guides and just people around" is "really part of the feeling of being inclusive...as a visitor". It clearly provokes an emotive response as the basis for any intellectual engagement. John's comment supports this interpretation since, according to him, the exchange with a particular tour host "made us feel very comfortable":

We, my wife and I started our museum visit with a tour by Robert who was excellent. And he showed us the highlights and then we went back and looked at some more items in detail... Robert personally was excellent. He was very personable and he was very comfortable to be with... it made us feel very comfortable.

As I stressed before, the need to draw analytical 'distinctions' cannot be stretched to the level of 'separation'. While I devoted a 'distinctive' section to 'Senses, feelings and embodiment', this does not amount to the postulation of corresponding 'separated' experiential stages. On the contrary, feelings perform as a continuous dimension of any experience, 'growth of meaning' and 'development of understanding'. This crucial point is strengthened by the following quotations encapsulating the entry of feelings into the realm of culture:

I really felt well introduced to the country. I don't feel I understand New Zealand in great depth but I certainly have a greater feel for the whole of the country and how it feels about itself and how it sees itself. (Jack)

We like to go visit museums and you get a feel of the culture and everything...because you get a feeling for the people and you understand what their culture is. 
Jack's "feel for...the country" and Susan's "feel of the culture" mirror the notion of an

emotionally embedded cultural memory:

Culture begins in the mind, more precisely in memory. The more emotional it is the more it is sustained. This emotional factor is actually more important than anything which bureaucrats of remembrance, administrators of history and memorials can affect with regards to individual and collective memory. (Schaefer, 2006, p. 59) (Translated from German by the author of this thesis)

At the outset of this section, I indicated that I would conclude with a refinement of the theoretical framework. This becomes necessary since the research material itself prompted me to theorise on senses, feelings and embodiment within the context of this study. The following chapters shed more light on cultural feelings and their significance for the meanings of identity politics. A brief theoretical discourse enables me to substantiate the link between the conditions and processes of meaning-making and guarantee the orientation of the reader through the evolution of my argument.

In my view, nothing has been more harmful in the history of Western thought, an essentialised and reductionist demarcation I only reluctantly use to make this overarching point, than the philosophical and scientific separation of 'body' and 'mind', the illusion that we could break a leg without suffering mental repercussions or that we could think without feeling the thought. The fundamental ontological division has led to the all-dominating dichotomies of cognition/emotion, thought/feeling, fact/value, knowledge/imagination and consequently to a 'cultural ontology of dualism' which is absent from many Asian intellectual traditions (Liu, Ng, Gastardo-Conaco, \& Wong, 2008, pp. 11-12). This particular way of thinking is so entrenched that our languages do not seem to provide the means to transcend such a dualistic trap. Dewey opted for 'the body-mind' as a linguistic attempt stressing that 'body' and 'mind' are inseparable 
ontological dimensions of an interactive process (Johnson, 2007). My ongoing discussion on the differentiation between 'distinction' and 'separation' highlights the difficulties in overcoming dichotomies without employing another dichotomous vocabulary.

Groundbreaking insights into the embodied origin of our interactions with the world have, however, challenged the above notion culminating in such work as Descartes' error: Emotion, reason and the human brain (Damasio, 1994). Interweaving empirical findings from neuroscience with philosophical pondering, Damasio (1994, p. xii) sets out to show that 'feeling was an integral component of the machinery of reason' and that 'emotions and feelings may not be intruders in the bastion of reason at all: they may be enmeshed in its networks'. The Cartesian dualism, this almost naive idea of mentally transcending the human flesh, is exposed as an alienated philosophical myth and 'error'.

Johnson (2007) builds on the qualitative dimensions of perception and thought by drawing on phenomenological and neuroscientific insights. He refers to Gendlin's 'felt sense' of all intellectual engagements, 'this vast lost continent of feeling that underlies all our meaning, thought and symbolic expression' (Johnson, 2007, pp. 79-80). Johnson illustrates this 'felt sense' with the writing process, to which I can naturally relate, being myself in the process of thesis writing. No linguistic structure or logic could thereby ever imprint a detached and purely rational argumentative flow. Going through several years of research and trying to make sense of a sea of information, an employed argument feels properly contextualised, a chapter structure feels appropriate and the reader focus feels achieved. There is a constant flow of 'feeling-thinking', another linguistic attempt to overcome the dichotomous chasms, a 'felt sense of thinking' 
(Johnson, 2007). Johnson (2007, p. 78) refers to the highest form of human abstraction and sums up:

Insofar as logic pertains to real human inquiry, logic can't do anything without feeling. Logic alone - pure formal logic - cannot circumscribe the phenomena under discussion. Logic alone cannot define the problem you are trying to solve by inquiry. Logic cannot tell you what should count as relevant to your argument. Logic can only work because we take for granted the prior working of qualities in experienced situations.

The significance of feelings as the origin and continuous companions of thought made it necessary to further qualify my hermeneutic approach beyond texts and words, as already discussed in Chapter Two. Ricoeur (1981, p. 56) recognises that our phenomenological sense of 'being in the world' starts as a feeling, we 'feel ourselves ... before we orientate ourselves'. The empirical findings in this section as well as this concluding theoretical pondering facilitate the development of a hermeneutics which captures the interpretive actions, movements and performances of 'being in the world' beyond the limiting 'lingual condition...of all experience' towards 'embodied meanings' or "internal understandings".

How can we overcome the apparent predicament? A first step is a better understanding of how emotions and feelings work. According to Damasio (2000), emotions are unconscious and outward directed responses to the environment while feelings are inward directed reflections requiring consciousness. Remarkably, even the unconscious emotions have an evaluative and embodied interpretive dimension. Damasio (2003, p. 54) argues that: 'Emotions provide a natural means for the brain and mind to evaluate the environment within and around the organism, and respond accordingly and adaptively.' Consequently, these 'immanent' or 'embodied meanings' (Johnson, 2007) feed directly into our conscious interpretations. To put it succinctly, feelings 
have an inherently hermeneutic quality linking the conditions and processes of meaning-making in an embodied way, as we witness in the subsequent chapters.

\section{Relevance and interest}

Nothing in life exists ever in isolation. Any experience we undergo is connected to past experiences and any act of interpretation builds on prior understandings. Dewey (1934) insists on 'continuity' as a fundamental principle of the human experience. The past lives on in the present, which flows into the future. Hermeneutics establishes its interpretive theory on this 'continuity of experience' (Dewey, 1934). According to Ricoeur (1981, p. 57), interpretation depends on understanding 'for interpretation is above all an explication, a development of understanding'. Ricoeur (1981, p. 108) continues by asserting that 'the most fundamental condition of the hermeneutic circle lies in the structure of pre-understanding'. In other words, any act of interpretation builds on prior understandings and becomes itself a form of understanding for subsequent interpretive acts. Accordingly, the 'key hypothesis in hermeneutic philosophy', in Ricoeur's (1981, p. 109) words, 'is that interpretation is an open process which no single vision can conclude'. The interpretive complexity of life is exactly the reason why hermeneutics offers a nuanced understanding of human agency and worldmaking, as I have argued throughout this study. This chapter comes to a close by shedding light on relevance and interest as another condition of meaning-making.

By turning to Claudia's interview, we can observe the interpretive operation of a hermeneutic circle: 
... the fact that I recognised a lot, like that I knew it was a marae and, you know, I've seen a lot of these things before. So if I had walked in cold and had never been before to a Māori village or met Māori, I don't know if I would have found it as fascinating, just for me personally?! But I just had a bit of an introduction to it in the past so when I saw these things and recognised them, it gave me a 'oh, I've wondered about that!' And yeah, it gave me a chance to learn a bit more about something that I had been introduced to already. But it's hard when you walk in and you don't have any background on something, I mean coming from another country, I knew very little about Mäori and I had only heard about them because some friends of mine had been here and found it fascinating as well. So there are bits and pieces along the way that started piquing my own interest. But if I hadn't heard of it before walking into a museum with something that I was completely unfamiliar with?! I don't know, it's hard to say because depending on the person. Like for me, if it was something to do with the natural world, whatever I had heard of it or not before, it probably would interest me. But other things, like I am not a huge history buff so if there wasn't something that had piqued my interest in the past, an exhibit on history for instance probably would not interest me unless there was some connection already. And with the Mäori section I had already had that past connection.

Claudia's narration encapsulates the significance of "introduction", "background" and "connection" in interpretive processes. Without being able to establish such links of relevance, we are robbed of the opportunity to develop understandings. The consequence is a dissonance which is further amplified in cross-cultural contexts and the associated different forms of being, a phenomenon I explore in depth in the following chapters. Claudia also highlights the key role of interest in maintaining the interpretive engagement with a particular subject or topic. Relevance and interest are inextricably linked in any voluntary hermeneutic endeavour such as a museum visit.

Charlotte lends empirical weight to these assertions:

I thought that the immigration, the passport display was really good probably because that's relevant for us. Our ancestors sort of moved around between Australia and New Zealand and all over the place so that was interesting to look at from that perspective. And the sort of things that I went to look at were things that I knew were connected to my history ... that display we found interesting because it had like a historical connection to us. 
Charlotte's sense of "my history" provides further insights into the functioning of preunderstandings and their merging into interpretive processes. The evolution of understanding proceeds by embedding the object of inspection, in this case the Passports exhibition, in an interpretive context informed by the 'reader's world'. This, in Bauman's (1978, p. 230) words, 'intimate bond between the meaning and the reader's world' accompanies us in the next chapter on visitors' narrative journeys from bicultural meanings to cross-cultural dialogue, the dialogical processes which open the gates of the 'reader's world' towards an engagement with the Other.

We have already witnessed the role of human intervention in the form of guided tours at Te Papa in contextualising content and carrying the emotive dimension through face to face interactions.

Mike highlights another function of the tour host establishing relevant connections and "piqu[ing]... interest":

His function which he performed was to whet the appetite. And he, you know, I am sure it's very well structured and trained for position to just pick one item in each gallery with a very short story which piqued my interest. For instance, I mean I do know from a childhood education quite a lot about volcanoes and where they, how they are. I always knew about New Zealand and, you know, plates in the earth and...But he immediately went to that Chinese big iron bowl that they incredibly had invented, a way of measuring, presumably by triangulation I guess, earthquake lines which I thought was absolutely fascinating, I have never seen anything like it, anywhere. So he went to each of the galleries and pointed out a particular thing which then I thought 'ah, I go back and have a look at that.' So I didn't read the whole sign, we had to keep moving. So it's really cleverly done. I thought I have to go and have to read this how they did that. The rest of it now was quite interesting but probably the least interesting of the galleries for me, but that one was something I had never seen before. But he went through the other galleries like that, just pointed out the one thing which made you think 'yeah I should actually go back and see how that fitted'...he just purely laid it out there as a taster.

It is evident that the dimensions content, context and narrative as well as relevance and interest are performing in conjunction as conditions of meaning-making. It was "a very short story" delivered by the host which, according to Mike, "piqued my interest". The brief narrative 
contextualisation of a "particular thing" in "each of the galleries" works "as a taster...to whet the appetite". It provokes Mike to "go back and see how that fitted", to interpretively engage in the processes of meaning-making. As the follow-up interview indicates, the intervention itself "was a memorable thing" conditioning both meaning and memory:

...it led us to being told that there was a reasonably quick tour that briefly went around the museum, which I thought was really worthwhile doing because the museum is quite big and most people would probably only go there for a couple of hours. And if you don't do the tour then you sort of might start on the ground floor and never get to the top few floors. So we liked the little tour. It was great, we enjoyed having the guide there. And he sort of really pointed out a couple of things on each level. He didn't try to really expand on all the displays and the different rooms and what not, but just sort of I guess piqued our attention to what might be interesting on that floor if we want to come back to it. So I thought that was a memorable thing which I don't see too often in museums. And it was a really nice sort of friendly atmosphere.

Relevance and interest seem to have entered museological thinking more broadly than the emotive dimension, and the literature offers some useful examples dealing with the visitor experience (Silverman, 1995) and museum learning (S. Allen, 2004; Jones, 1995). Hennes (2002) departs from Dewey's 'problematic experience', the fact that any human inquiry starts with a question, a problem to solve. Expanding on this line of thought, Ham (2002) interrogates meaning-making within the context of museological interpretation. Ham (2007) concludes that the museum's main function is 'provocation' rather than 'instruction'. Questions need to be asked to build relevant connections and facilitate interpretation and meaning, instead of the linear teaching of definitive facts and ultimate 'truths'.

John offers insights into the dialogical dynamics of questions merging relevance and interest in the exploration of a 'problematic experience', in this case the encounter of a foreign culture and language: 
We had another person on the tour, there were three people actually today, another person from Australia. And he talked with each of us and then shared things that related to our countries which was very interesting. But he was excellent in answering questions as we came through different parts of the galleries. He did a very good job when I asked him about kiwis and about the extinction, the kiwis becoming less populated. And he answered several questions about the Mäori customs that we thought were very good and translated some words and things that we wanted to know how to speak. He spoke then and also translated some things for us - very, very good guide!... He was very good at relating everything so you felt it wasn't a memorised tour. It was more, more of a conversation.

John emphasises that his tour host was "excellent in answering questions" and simultaneously "relating everything...to our countries which was interesting". The guided tour's interpretive assistance creates relevant links between unfamiliar themes and the respective 'reader's world'.

In the process, a 'problematic experience' of another cultural world gains the quality of a "conversation" which helps maintaining the interpretive engagement.

Andrew expands on the tour's interpretive support in cross-cultural contexts, which lies at the heart of this study and will be interrogated in detail throughout the subsequent interpretive chapters:

When we came in we noticed that there were guided tours available. And we were quite pleased to see that because just from what I have read it was fairly overwhelming and so much to see and no idea where to start. I also think we are extremely lucky, we ended up with Ralph Smith as a guide. He is extremely knowledgeable in Mäori culture and very, very proud of the museum and that came across in his presentation to us. And he walked us through the whole museum. There were only three of us in the tour and I think that also made that somehow easier for us. We were able to ask lots of questions and had it just related to ourselves... anything I happened to notice and thought about I could just bring up and his knowledge is fantastic. He knew what he was talking about. He had a sense of pride in history of New Zealand that was very obvious. And I cannot think of a single thing we asked that he couldn't answer or explain to us... I don't think I would have had nearly a significant experience if we hadn't had a tour guide like Ralph.

Andrew gains more insights into "Māori culture" through the culture's personalisation in the form of the "guide...Ralph Smith". At this stage, I only want to touch on this dialogical feature 
without anticipating too much of my exploration of cross-cultural engagements. Within the context of the current discussion, the communicative function of "questions" which, according to Andrew, were "related to ourselves" is once again clearly emphasised. In fact, the exchange culminates in a "significant experience" which he would not have had otherwise.

The need to create personal connections and provoke interest also surfaced in the focus group I conducted with tour hosts. As stated in Chapter Two, I used their extensive experience in observing and interacting with global audiences at Te Papa to contextualise the narrative research material. Tama touches on building relevant links in cross-cultural encounters:

I am talking about 'People To People' now because they are young ones. And sometimes when we talk about Rangi and Papa and the separation I am trying to find something that is going to be familiar to them. So I will talk to them about the American revolution and how they separated from the motherland. And why did they do it, because things weren't going well for them. So when the Gods separated, the Earth and Sky, things weren't going well for them.

Tim refers to the same 'People to People' student exchange programme, which takes part in a 'Te Papa Highlights Tour' (see Appendix D), and stresses that to "set a spark", which transforms ignorance into interest and a moment of imagination and wonder, epitomises the fulfilment of his role as a tour host and story teller:

When I get those people, they are just here on vacations, or some of the 'People To People' tours, these kids come here and don't care, they have to come. But you can feel how to set a spark in their eye, or a smile or a grin because it's something unexplained. Because as a storyteller I just get excited myself when I am talking about it and I wish I could put it in a bottle somewhere and just hold on to it, but of course you can't, you just lose it then. But they are all fine when that happens. When I see that spark in that person that actually had no interest, but then all of a sudden something I said or showed them and they see sparked interest. 
Both professional perspectives indicate that the communicative impact of tour hosts is twofold.

On the one hand, they add another layer of meaning through the personalisation of museological content. On the other hand, tour hosts are able to consider the perspectives of visitors, make connections and engage them in dialogue and discussion (Pekarik, 2008; Tsybulskaya \& Camhi, 2009).

The productive potential of interpersonal dialogue becomes even more obvious when we consider the following failure to establish relevant conjunctions in exhibition settings. Here Andrew comments on his experience of the Golden Days exhibit, a nostalgic audio-visual collage of highlights in New Zealand's history:

I suppose the only thing I am slightly disappointed in, the people from New Zealand and even Ralph said how emotional the film was, and not being that knowledgeable about New Zealand history, I found it a little disjointed. So for trying to teach a foreigner something about New Zealand history, it would have had more impact if it had been chronological or something in it. I can see that for New Zealanders who understood their own history it would make a lot of sense, but for us as visitors it was just a little disjointed and we had trouble putting it together.

Without the guided tour's interpretive assistance, Andrew is left to approach the Golden Days exhibition without pre-understandings and "not being that knowledgeable about New Zealand history". He assumes that the exhibit "would make a lot of sense...for New Zealanders who understood their own history". But for a "foreigner", the "disjointed" lack of a "chronological" order makes it virtually impossible to establish relevant connections. Consequently, Andrew suffers an effect of interpretive dissonance and "had trouble putting it together". In other words, the processes of meaning-making are initiated without being hermeneutically anchored to their conditions failing the 'development of understanding' or 'growth of meaning'. 
Charlotte refers to the same Golden Days exhibit and offers more and closely resembling

evidence of such interpretive dissonance:

I found it a bit confusing ...the Golden Days shop. And I think that was because I didn't know the history in terms of they had the sporting stars up there and that. And I am looking at it and 'oh yes, somebody won a medal like the Olympics' and without actually knowing who and what. So maybe a little bit more of that in that particular display would have made it a bit more relevant.

Another dimension of missing links between "New Zealand", "North America" and "the world"

in a geological rather than cultural context is introduced by John:

The Gondwana, I thought that was a little short honestly. It just showed the parts coming together and I would have liked to have seen more of the world, like North America where we are from. And I thought it was just kind of brief and then just showed where New Zealand came from, which was fine, but I would have loved to have seen a little more of that. The whole earth breaking up would have been interesting.

These critical comments could be regarded as insignificant and mundane. Within the scope of this research, however, they offer a first indication of the complicated dynamics of cross-cultural dialogue, ruptures of relevance and interpretive dissonances. Causing these hermeneutic consequences, a museum might fail to "set a spark" and plant the seeds of interest which is, according to Jack, its main responsibility:

I have always thought that one of the big roles of museums, other than to house artefacts, is to stimulate learning, not to teach me there on the spot or to teach anybody on the spot, that's too much of a thing to do, but to stimulate the interest that people follow up. You learn something, it keeps your interest and it would really follow you up.

The focus group with Australian students, another contextualising stage of the research design introduced in the previous chapter, elaborated on the function of museums to "provoke an interest", branding it a "catalyst for interest" and "catalyst for discussions", the latter being increasingly important throughout the exploration of Te Papa as a forum or global public sphere. 
For now, "the big role[s] of museums...to stimulate the interest" sums up the circular hermeneutic negotiation between relevance and interest as conditions of meaning-making and the processes of meaning-making that I turn to in the following interpretive chapters. The empirical evidence presented in this study supports Fina's (1979) view of individual interest as personal affect which transforms an object or subject into a phenomenon. And only a phenomenon can become a meaning.

\section{Summary}

In this chapter, I explored the conditions of meaning-making. The narrative journey started with the experience of space, a fundamental characteristic of the human condition in its spatial and temporal parameters. The form of museological space and its elements such as architecture, exhibition design and display merge with the thematic content within the human experience. Form and content exist and work in a mutually dependent relationship: what we tell cannot be isolated from how we tell it. The dominance of "layout" and "structure" over "information" in Nicole's memory as well as Mike's long-term negotiation of a spatial and media "landscape" lent empirical weight to the conditioning processes. It became evident that "deliverance" and "message", or form and content, are inseparable in the construction of meaning and memory. The research material revealed the interplay of content, context and narrative. To Bruce, "stories" offered the hermeneutic means for a "writerly experience", or 'interactivity' as 'self-inscription'. In Mike's case, the narrative "linkage" flowed through meanings into memory. The empirical evidence highlighted the key function of narrative in 'structuring space and anchoring content to context' (MacLeod, 2005, p. 3), thereby facilitating meaning-making. In Te Papa's case, the 
bicultural architecture becomes an integral part of the bicultural story and the interpretation of bicultural meanings as we shall see in the following chapter.

The engagement with such space began on a sensory, emotive and embodied level. Susan elaborated on her spatial feeling and Claudia stressed that "you really get drawn into the scene" through "sensory experiences", a hermeneutic condition I termed emotive and sensory contextualisation. In fact, visitors' narrations exposed that emotions and feelings are not separate stages but continuous dimensions of the experience. The ontological sense of a feeling, the feeling of being, first precedes and is then permanently intertwined with intellectual and interpretive processes. While language performs as the main cultural tool for the 'growth of meaning', certain meanings remain on an embodied level as "internal understandings", as Claudia put it, and resist any attempt of formal verbalisation. I observed the entry of feelings into the realm of culture and in the next chapter I follow the emotive trajectory through the crosscultural journeys.

Relevance and interest represented further conditions of meaning-making. Relevance is linked to the ontological form of understanding which precedes meaning-making processes or interpretations and enables the entrance into a hermeneutic circle. Interest transforms an object or subject into a phenomenon and maintains the interpretive engagement by building on relevance. The analysis disclosed some successful and some ineffective examples of interpretive connections and relevant links in a museological context. While Charlotte was able to get a sense of "my history", Andrew experienced an interpretive dissonance and "had trouble putting it 
together". With regards to the conditions of meaning-making, I conclude that being means feeling, understanding and interpreting. 


\section{Chapter Four}

\section{Cross-cultural journeys}

\section{Introduction}

I do not accept that anyone is permanently fixed by his or her 'identity'; but neither can one shed specific structures of race and culture, class and caste, gender and sexuality, environment and history. I understand these, and other cross-cutting determinations, not as homelands, chosen or forced, but as sites of worldly travel: difficult encounters and occasions for dialogue. (Clifford, 1997, p. 12)

The preceding chapter revealed the conditions of meaning-making: the experience of a museum space and its interplay of form and content; the multisensory, emotive and embodied nature of the museum experience as well as the hermeneutic significance of relevance and interest. The empirical evidence disclosed the mutually dependent relationship of these interpretive spheres flowing into the cross-cultural journeys in this chapter.

I set out to explore the processes of meaning-making, the 'growth of meaning' and 'development of understanding' during cross-cultural encounters. Before I proceed, I want to reiterate once again that any analytical 'distinction' does not amount to its 'separation'. I am following emerging themes and dynamic traces which could never be neatly sealed and categorised but fuse, interpenetrate, blend and interweave within the human experience. They become graspable only in reflexivity, and this interpretive reflection is the genesis of the double-hermeneutics in this thesis. As seen earlier and further demonstrated in this study, the conditions and processes of meaning-making are inextricably linked and negotiated in a circular hermeneutic trajectory. 
The first section, 'Bicultural meanings', humanises and expands the 'contact zone' Te Papa. It moves beyond the conceptual vision's initial focus on museological production by shedding light on the meanings made by visitors. The interpretive 'contact work' (Clifford, 1997) departs from the 'reader's world' (Bauman, 1978). At this stage, the cultural Other is experienced through their own socio-cultural lens, the interpretive community of the Self. The hermeneutic 'zooming' (Pamphilon, 1999) in on the different dimensions of the narratives illuminates the multiple layers of meaning. I expose the partly 'doxic' (Bourdieu, 1984) nature of discursive spheres and their effects on interpretive processes, and provide the first insights into the hermeneutic complexities of cross-cultural engagements.

The next section, 'From bicultural meanings to cross-cultural dialogue', indicates the several routes such as self-representation, the reframing of understandings and tour intervention which open the gates of the 'reader's world' and pave the way from bicultural meanings to crosscultural dialogue. At this point, a dialogical 'Third Space' (Bhabha, 1994) is created which enables the translation of differences. Hermeneutically speaking, there evolve a 'fusion of horizons' (Gadamer in Ricoeur, 1991b) and 'higher forms of understanding' (Dilthey, 1976). The research material shows that the humanisation of culture, people and history renders possible the moral and political engagement with the Other and lays the foundation for a pluralist space.

In the last section, 'Cross-cultural hermeneutics: the shifting Self', I argue that 'contact zones' should be understood as pluralist cosmopolitan spaces which facilitate the negotiation of differences within a shared symbolic context belonging to everybody but to no-one alone. Crosscultural dialogue within a pluralist cosmopolitan space leads to a cross-cultural hermeneutics, the 
ontological endeavour of the shifting Self. The empirical insights emphasise that contemporary identities are characterised by processes of identification and othering. Self is the ontological project of interpretive actions, movements and performances subjecting otherness to an endemic relativity.

\section{Bicultural meanings}

[I]t has become necessary to imagine a world of generalised ethnography. With expanded communication and intercultural influence, people interpret others, and themselves, in a bewildering diversity of idioms - a global condition of what Mikhail Bakhtin called 'heteroglossia'. (Clifford, 1988, pp. 22-23)

In Chapters One and Two, I presented 'culture', 'identities', 'politics' and the 'public sphere' as hermeneutic actions, movements and performances instead of reified structures, systems and substances. Within this context, I introduced bicultural Te Papa as a 'contact zone' of cultural identity politics in a 'cosmopolitanised' world and insisted that research needs to investigate these inevitable 'interpretive contests'. Critical hermeneutic studies of experiences and meanings, as in this thesis, enable the analysis to avoid 'anemic' and objectifying cultural perspectives.

By establishing the theoretical and methodological framework, I set out to humanise Te Papa as a 'contact zone' through ethnographic research on global visitors. This study seeks to expand the idea of the 'contact zone' beyond Clifford's interrogation of museological production. It does so by examining the meanings actively made by visitors, who are broadly evaluated and categorised with regards to predefined education goals and learning outcomes but hardly understood in terms of their actual experience. In the process, I am able to move beyond the over-generalised and over-theorised critiques of biculturalism, which question its contemporary socio-cultural 
(O'Sullivan, 2007; Royal, 2008) and museological relevance (Henare, 2005; Message, 2006;

Thomas, 1994; Williams, 2003) without shedding any light on the potential for cross-cultural dialogue, processes and lives.

I turn to Julia, a New Zealand born Australian, to begin my exploration of the processes of meaning-making and moments of cultural worldmaking throughout the informants' cross-cultural journeys:

I loved the Màori side of it and it's wonderful to see that strength there. I mean I look at the Aborigines in Australia and it's a totally different culture, you can't compare that, but I think the Mäori are in a lot better position as a race in New Zealand than the Aborigines are over there. And I think, yeah Australia has got a lot of work to do really in that regard...And I loved the modern side of it as well, like the meeting house down there with all the pretty colors in it and made not out of traditional wood, that was just beautiful. Because to me that shows a more integration, it's showing New Zealand as being a integrated country, like we are not talking Māori and Pakeha, we are talking about Kiwis or New Zealanders, which is really good too...It was good to see that side of it, but that didn't dominate. It's a small part of this museum and this is giving it a more, I don't know, inclusive feel. So it's not all Mãori, it has got everything here, which is good... It just covers more area, like you have got the creation of the earth and incorporated in that is the Māori myths of how it all happened, which is really cool.

Julia, like any human being, cannot help but place her cultural experience in a context informed by her own discursive environment, the 'reader's world'. Consequently, the perceived integration of Māori and European in New Zealand is related to the apparently worse position of the Aboriginal population in Australia. The fact that Julia, as a New Zealand born Australian, is intimately familiar with the socio-cultural situations in both countries attests to the phenomenon of 'traveling cultures' in a 'cosmopolitanised' world which goes far beyond the travel encounters interrogated in this study and undermines the imaginary purity of any cultural 'reader's world'. Importantly, Julia highlights the advance of the emotive dimension into the cultural domain manifesting itself as an "inclusive feel". 
Julia's follow-up interview offers insights into her long-term negotiation of an "inclusive feel",

which merges the conditions and processes of meaning-making, or feelings and cultural

interpretations:

I think it was an important part of my trip and I found the experience really positive. It gave me (paused)... it's good for me, I really enjoyed the cultural aspects of it, the Mäori side of it, a lot. Especially the new area where the meeting house was made in a modern way, because it made me think of the Mäori culture not so much as a part of New Zealand's past, but as a living, breathing, evolving entity as well. Yeah, and it's an integrated part of New Zealand's way of life. Yes, so that was really important to me. I mean I found out afterwards that my father doesn't like that, that particular part of it. He likes seeing it as part of history I guess. Yeah, so that was interesting but I really enjoyed that feeling of it, still being very much alive and an evolving culture, not just part of history.

Julia thinks and feels Māori culture as a "living, breathing, evolving entity" that is "not just part of history". In fact, the dimensions of "think[ing]" and "feeling" culture are tightly interwoven and could never be dichotomised into separate stages. This highlights the almost complete neglect of such cultural feelings in cultural studies, which is a shortcoming of that approach.

John from the USA, in turn, indicates that sensory conditions merge with hermeneutic processes during cultural engagements:

The marae, that modern art, I thought that was very impressive. I mean the colors and everything were very, very good. And we liked that a lot...because so many marae are the same earth kind of tones, reddish brown tones. So the colors were great, and to see I think modern influences incorporated in the marae is very interesting. In Native American culture, where we are from, that's not the case... Well I shouldn't say that's not the case at all. There are Native Americans and Aleutians and Alaskans and Eskimo and all the way down the coast of Canada that are doing modern art made by Native Americans, but there is far less, the percentage is much smaller. Most Native American art tends to be the way Native Americans lived two hundred or more years ago. We thought that was very interesting, the Mäori agreeing to incorporate, bringing new modern things in a traditional meeting house design. We thought that was very clever, colorful and just very striking. 
As with Julia, the contemporary design of the marae (Rongomaraeroa) or communal meeting house leads John to construct a bicultural meaning of "integration" or "incorporat[ion]". Importantly, John's sensory experience highlights that 'culture' epitomises another human concept which, in Dewey's (1934, p. 119) words, 'we cannot possess...in its full force, until we have felt and sensed it, as much so as if it were an odor or color'. In the interpretive process, John equally draws on his own cultural background which frames and contrasts the cross-cultural experience.

J. Bruner (1990, pp. 12-13) elaborates on the 'concept of culture' as 'communal tool kit':

By virtue of participation in culture, meaning is rendered public and shared. Our culturally adapted way of life depends upon shared meanings and shared concepts and depends as well upon shared modes of discourse for negotiating differences in meaning and interpretation.

Such 'cultural resources' (Perin, 1992) and 'interpretive repertoires' (Potter \& Wetherell, 1987) provide, according to Ricoeur (1991b, p. 29), a 'context of description for particular actions' lending 'an initial readability to action.' In Chapter Two, I elaborated on the inherent cultural dimension of meaning and Self and its narrative negotiation, which is significantly complicated in cross-cultural encounters, as we see again in this chapter.

By listening to the Canadian visitor Jack, we can first observe once again that a cultural meaning evolves as a cultural feeling:

The other thing that strikes me is of course the - I don't see a predominance - the respect for Māori culture very evident. You know the space, the design afforded to everything like Waitangi, the presence of Māori blended, it is a blending of Māori artifacts with Western art, you know, the two together... One has a real sense of a country that sees itself as (paused); I hate the world 'melting pot' because it's so much linked with the Unites States and I come from a country where it's different cultures living together in harmony. And I sense I shouldn't say the Canadianism of that in this exhibit, but many 
have come from many different backgrounds but have formed the country together. So in that regard it felt Canadian to me I suppose (paused). In fact, it felt very Canadian in many ways except it was New Zealand and I haven't seen it done that well in Canada at all.

It is clear once again that the conditions of meaning-making such as the bicultural "space" and “design”, which I analysed in detail in the previous chapter, flow into the processes of meaningmaking. Jack infers a "blending” of Māori and Non-Māori “together”. His sense of "Canadianism" that "felt Canadian in many ways" reflects the ubiquitous 'cosmopolitanised' condition of the contemporary world. While there exist multifaceted differences among the postcolonial home countries of the respondents, it is also important to recognise the similarities between these nations 'because of shared experiences and common realities' (Maaka \& Fleras, 2005, p. 7). The literature provides comparative studies which interrogate the linked destiny of indigenous peoples in former settler states (Havemann, 1999; Maaka \& Fleras, 2005), stressing that the meaning of local realities is 'being recast in the context of globalization' (Boswell \& Evans, 1999, p. 23).

Charlotte, another New Zealand born Australian, carries the 'cosmopolitanised' dynamics of commonalities and differences into the realm of the human experience:

I think it was just the whole inclusion of it together. It's so different to the Australian perspective. So if you go to, not that I really go to a lot of Australian museums myself (laughing), but if you go and look at displays or tourist and culture things in Australia you have either got the Aboriginal cultural experience or you have got the European cultural experience. There is not really a lot of that cross-cultural stuff...if you go and see something like the museum of cotton that will have all the, you know, European developments of cotton but nothing about the people who work on the cotton, nothing at all about the role the indigenous played in the community... and then you can do the indigenous cultural tour which will give you all the significant landmarks and their cultural way of life and that sort of thing, but it doesn't necessarily relate how it looks into European settlement...so I guess in terms of coming here it's just, it's all in there. It's in the language, it's in the signage, in the place names and the location, it's all sort of just all included. You don't have to go separately looking for it, and in the culture 
like it's just part of it I guess, yeah. That is how I found it interesting... like the golden era display they had, you know, half a dozen shots of cute little white kids and then there was some Mãori cultural shots. So it didn't seem to matter what display you went into there was a part of, you know, Mãori culture in that display. It wasn't as separate you know.

Setting out from the "Australian perspective", Charlotte detects a "different...inclusion" in New Zealand. While the former lacks "cross-cultural" approaches, the latter offers tangible evidence of "included" cultural elements. "Māori culture... wasn't as separate”, Charlotte points out, but "it's just part of... and in" the overall "culture". It is obvious again that the interpretive lens of the 'reader's world' filters the inspection of another cultural world.

Claudia, a Canadian on a working holiday, shares this view on bicultural "inclusion" within Te

Papa as well as beyond the museum's walls:

I also really like the Māori exhibits. With my travels here in the country, I have gone to a few cultural performances and have been to some marae. So it was nice to get some further background on that because it is an integral part of the New Zealand culture...I think just knowing that the exhibit was here, that people thought it was important enough to have an exhibit that everybody could learn about anything of interest. It's not just if you wanna learn about Màori you go to a Māori village, but I mean this is the Museum of New Zealand and they are actually making a point to teach people who are interested facts about the culture. It's not just to learn about the British influence aspect, or the white man's aspect, you know, it broadens what people learn about the country.

On her "travels", Claudia experienced "Māori” as "an integral part of New Zealand”. Based on such cultural reality, she appreciates efforts of the "Museum of New Zealand" to present "further background" and "facts about the culture" beyond the "British influence". According to Claudia, this "broadens what people learn". It opens the doors to the hermeneutic complexity of human affairs. 
In this context, Susan, a student from the USA, expands on cross-cultural relations and the delicate issue of "treaties":

And I think the most thus far I really enjoyed was the Mäori display about the Aboriginals and their lifestyle and their treaties they have signed that are still being honoured today, which is really unique to an American because we don't honour, we have not honoured many of our treaties. So it's very interesting... And that culture is always just really fascinating because I lived in Hawaii for two years. And even though I lived there for two years working on a cruise ship, I didn't understand a lot of the Pacific Island traditions and culture and different things like that.

Susan's experience of the "Māori display" and "their treaties" appears "really unique to an American". We can see that the interpretive observation of foreign cultural phenomena is nurtured by their own interpretive community. Far from being a linear transmission, however, this process is characterised by circular hermeneutic negotiations. In other words, cross-cultural meanings feed back into a critical reflection on one's own discursive environment. "We have not honoured many of our treaties", Susan states, and I shed more light on the reflexive nuances of cross-cultural dialogue in the course of this thesis.

In a moral sense, a treaty embodies the 'faculty of promises', as Arendt (1958, p. 245) aptly puts it by referring to Nietzsche, it is 'the very distinction which marks off human from animal life'. Equally human, however, is the tendency to dishonour promise and treaty, as Susan reminds us. This leads to the inevitability of conflict which Mark, an Australian student, looks for but fails to discover at Te Papa:

It didn't really, from what I could see, it didn't delve too much into like how much they fought with each other. (paused) I am still quite unsure on like that first meeting. Like obviously some tribes would have been friendly towards the Europeans, whether the Europeans were friendly back though!? I am trying to think, whereabouts is there a section that's specifically on that?!... It's important to be showing both sides of the history of New Zealand. I think that this museum does it quite well. I think it got more stuff on Māori than it does on European settlement, which I think is good choice. It's the much more interesting side. But yeah I don't think it delves too much into the conflict that 
they had when Europeans first appeared... Actually I was reading one map which I found interesting that had all the different areas of New Zealand that were sold off to Europeans. They did say in the description that they were unhappy with that because they couldn't go to like their sacred grounds including burial places and stuff anymore. And yeah, it almost annoyed me that like the Europeans bought massive parts of New Zealand for like 300 pounds (laughing), which is nothing these days but I guess it was more back in the 1800s. So maybe I guess in that area which was covering more of the sort of both of them together.

Other terms the interviewees used to articulate their bicultural interpretations or meanings, apart from the ones mentioned above, were "merging", "interlinked" and "marriage". Not everyone agreed that there was an interrelationship however. In the case of Mark, the perceived lack of an interactive relationship is critiqued within a particular context. Mark is left to approach the bicultural encounter sanitised of conflict. This reminds us of Bauman's (1978, p. 230) view that 'the fullest understanding one can think of is still context-dependent and context-confined'.

Mark's interpretation also reflects Te Papa's partially dichotomous approach to biculturalism which separates the various ethnic groups into distinct categories at the expense of their interaction, exchange and conflict, as other scholars have pointed out (Henare, 2005; Message, 2006; Williams, 2003).

By following the thoughts of Mike from Australia, we can return to the 'reader's world' as point of origin for the making of bicultural meanings:

One of the reasons I came to this museum is that I didn't really know much about Māori culture...I actually know a lot about Aboriginals. I had to study quite a lot of things about Aboriginal painting and culture and the law of it and women painting this and men, you know, all the different complexities. But I actually had a preconceived rather negative view of Māori. And that comes from the Māori in Australia who generally, and this is a real generalisation, are labouring guys that have come out of New Zealand to earn money. You know, they are not rocket scientists. They are hard workers and they are hard players and they get into trouble (sighing laugh). That's the perception that I have had and I don't think I ever looked in or read about a very long Māori culture and tradition. And I didn't understand until I came to this museum that this is a really serious part of what this country is. And everything it really does has to take it into 
account. Because in Australia of course we, and maybe this is what New Zealand did probably twenty-five years ago, didn't take into account. Australia hasn't got quite to the stage of New Zealand. There was no treaty in Australia where, however faulty the treaty was here, there was at least a recognition and something you could go back to and say 'hang on that wasn't the intention at all', you know, 'here are some rules and guidelines'. But I think the most important thing I have learned at this museum is that this is a serious issue that's tied in with what's happened to this country, where it's been, how it got here and things that have happened to it over a period of time.

Mike starts from the 'cosmopolitanised' dynamics of 'traveling cultures': Māori people living and working in Australia. His "preconceived rather negative view of Māori" is reminiscent of Bauman's (1995, p. 257) claim that 'we generalise from what we see'. In the processes of "generalisation", Mike committed an act of 'underreading' to find 'interpretive closure' (Abbott, 2002). Such hermeneutic 'underreading' is a requirement of ordinary life to make sense of its complexity. Consequently, any interpretive characterisation 'involves some degree of flattening' (Abbott, 2002, p. 129). It gets dangerous, however, when these hermeneutic necessities lead to 'branding human beings as types' which 'denies them their full humanity' (Abbott, 2002, p. 129). In Mike's case, the Māori became a stereotype, the product of a biased reduction of complex reality, and 'doxic belief' (Ricoeur, 1992).

In Chapter Two, I introduced a critical hermeneutics to detect cultural norms and dynamics that tacitly leave an imprint on individual meanings. According to Bourdieu, it is incumbent upon the academic to bring 'previously doxic assumptions...to the level of reflective argument' (Crossley, 2004, p. 101), while in everyday life 'doxa' as 'adherence to relations of order' is 'accepted as self-evident' (Bourdieu, 1984, p. 471). Mike, however, shows that he himself is capable of revising views and reframing understandings through reflection, the inherently human condition of the 'double hermeneutics' in this thesis. In other words, the 'narrative unconscious', the 
'culturally-fashioned aspects of one's history' become conscious 'part of one's story' (Freeman, 2003, p. 339).

Before I expand on these dialogical features of cross-cultural journeys I turn to Bruce from the USA:

When we were sort of booking out our tour around New Zealand, one of the things they did ask us was whether we wanted to do a lot of Màori culture things. Originally our reaction was sort of like no because I think it's based on our experience with native culture in the United States. That sort of indigenous culture stuff you get in the United States is very contrived and kind of hokey. And there is a little bit of feel of imperialism to it that you sort of...you are looking at this culture not as being immersed in it or really trying to understand it, but you are looking at it as being the outsider and 'look isn't that cute'. You are not; it makes you feel bad about it is the easy way of saying it.

In Bruce's case, the discursive foundation of his interpretive community, the 'reader's world', not only affects but prevents the engagement with the cultural Other. Remarkably, Bruce did not relate to any cultural aspect in the initial interview I conducted with him about his visit to Te Papa. It was only after I asked him how he experienced New Zealand's cultures at the museum in the second stage of the narrative interview that he started elaborating on this point in the form of a 'suspicious hermeneutics' (Crossley, 2004) fuelled by the "experience with native culture in the United States" (see Chapter Two for a discussion of the narrative interview stages).

For Michelle, also from the USA, such 'suspicious hermeneutics' amounts to the projection of the Self on the Other. The apparent "parallel" is only interpreted through her own socio-cultural lens without leaving room for potential variations among colonial experiences:

There was a Treaty that the Màori signed with the British and there was quite a very large display on that...And the guide told us some information about that and how there was a misinterpretation from the English language to the Māori and how it's possible that either they were misled or they misunderstood. And different people have different interpretations on that depending on probably what cultural group you came from. So I 
kind of had the idea that they were really cheated just like the Americans cheated the American Indians ...And we did terrible things to the American Indian including killing them. Well, I kind of see that parallel here. The British came in, they wanted what they wanted and they deceived those people because of course their languages were totally different. And they could leave them to thinking perhaps one thing and of course they didn't understand it. So their land was taken from them. Yeah, you might see that differently if you are British (laughing) - just a misunderstanding!

In this section, I explored the negotiation of bicultural meanings. This first stage of the crosscultural journey sets out from the 'reader's world', their own interpretive community which frames interpretive engagements with other cultural worlds. The empirical evidence exposed the partly 'doxic' shading of discursive lenses threatening complex cultural phenomena with stereotypical reductions. We gained first insights into the multifaceted hermeneutic dynamics of cross-cultural encounters, interpretive processes which are further intensified when voyaging from bicultural meanings to cross-cultural dialogue in the next section.

\section{From bicultural meanings to cross-cultural dialogue}

What is theoretically innovative, and politically crucial, is the need to think beyond narratives of originary and initial subjectivities and to focus on those moments or processes that are produced in the articulation of cultural differences. These 'in-between' spaces provide the terrain for elaborating strategies of selfhood - singular or communal that initiate new signs of identity, and innovative sites of collaboration, and contestation, in the act of defining the idea of society itself. (Bhabha, 1994, pp. 1-2) (my emphasis)

In this section, the research material indicates the interpretive pathways such as self-

representation, the reframing of understandings and tour intervention, which facilitate the movement beyond the 'reader's world' of an "outsider" towards an "immersed... understand[ing]" of another world and help to erase the "feel of imperialism" 
entrenched in one's own discursive environment. I argue these visitors' stories provide insights into the journey that they undertake from bicultural meanings to cross-cultural dialogue.

\section{Self-representation}

We accompany Bruce as he reflects on his visit to Te Papa and discover the 'moment' or 'process' which transforms a 'contact zone' into a dialogical 'Third Space':

One of the cool things was that according to the tour guide it was basically presented by the Mäori not by, you know, a bunch of white guys saying what we present of the Mäori, which made a lot more tellable and believable and didn't have this sort of stench of imperialism on it. So it made it a lot easier to sort of, because if somebody is telling about themselves rather than somebody telling about somebody else, we call that hearsay in the law. So yeah that was pretty cool. You know I didn't feel like there were a lot of people walking around in hokey costumes and what-not, which was good. It was nice to see what the tribal buildings looked like and, you know, at least some level of what the cultural artefacts kind of piece together to some extent. I guess based on the stories that the Mäori put together for you.

Mediated by the tour host, Bruce dares to engage with another world after his initial reluctance.

He appreciates the self-representation of the cultural Other, which enables him to overcome the "feel of imperialism". Now he is "not looking at" the Other but is "immersed" in dialogue facilitating "understand[ing]" and dissolving the "bad...feel[ing]" of being an "outsider". It is the 'moment' or 'process' which translates a 'contact zone' into 'the production of meaning'. This 'requires that these two places...the I and the You...be mobilised in the passage through a Third Space' (Bhabha, 1994, p. 36), the 'pact of interpretation' or 'fusion of horizons' (Gadamer in Ricoeur, 1991b) through museological self-representation.

In Michelle's interview, we can see that she equally highlights the dialogical function of selfrepresentation in opening a 'Third Space': 
Well, you know, I didn't look at the exhibit on the Scottish people yet. But I thought that was really a wonderful idea that they feature a different culture, whether it's two years or what the period is, so that they allow each cultural group to come in and do something that is very significant to them. So I would like to go see that... The culture that I learned so much about was the Màori because I had no idea of anything about them. I just had heard their name, but you know where we live it's so exotic and no one knows much about it.

Pieterse (1997, p. 133) argues that 'self-representation' is the 'general guiding principle' that realises the shift from a 'colonial' to a 'cooperative' museology. This exhibitionary strategy might not, however, take full account of the 'differences within' as Pieterse (1997, p. 135) warns. I develop this crucial point in the course of this chapter by paying tribute to an inescapable pluralism from within. But regardless of the composition of Self and Other, it will always come down to the moral and political imperative of self-representation. "They", whoever that might be, want, in Michelle's words, to "do something that is very significant to them".

Language, this magic cultural tool, plays a fundamental role in representing Self and facilitating dialogue across differences both in and beyond museums. In this context, Julia says:

...the guides, you know, they introduce themselves in Māori...which to me means it's part of everybody's life here, it's like an integral thing. And even people down the street how they pronounce place names and stuff, compared to when I was a kid what the pronunciations were. There was this, I don't know, second-class citizen type feel, which is so wrong. So yeah, I think that makes you feel that it's as important as any aspect of New Zealand life. And I think it's really cool...in the back of that sort of meeting house it had all different types of people represented there. And I mean that's so cool, you know, that is so inclusive of all the different aspects of New Zealand. And I have not seen that before or felt that before. I was 'wow, this is great!', yeah, and really important, you know, because it's not just one group that make up the country. Our history didn't start two hundred years ago or whatever (laughing). So, yeah, it brings it all together really. And it felt good, you know, you can feel the vibe (laughing).

Julia's "inclusive feel" proceeds from the broader museum impression through face to face interactions and the experience of a specific exhibition. The fact that "the guides...introduce themselves in Māori" offers linguistic evidence of cultural integration. And the "meeting house" 
with "all different types of people represented there" embodies the perceived inclusivity.

Importantly, Julia's cultural interpretations, or processes of meaning-making, are once again interwoven with the sensory and emotive conditions of meaning-making. She has "not seen that or felt that before" and the newly built cultural meaning evolves as a "vibe...you can feel".

Susan offers more insights into the interdependency of language and cultural self-representation within the human experience:

...So I was like oh it's my birthday, I come around and have some random fun. And one of them looked of Mäori descent and I mean it's kind of harsh of me to say, but they are all quite Caucasian. And I mention oh it's my birthday and they are like 'oh, you want us to sing to you in Mãori?!' I am like 'what?' 'You want us to sing to you in Māori?' 'Sure I want you to sing to me in Māori!' There is no way I would be able to sing anything of any chant in any Native American language! (paused) Like is that something they would just randomly happen to pick up and know from a bar or is that something they are taught at school? I found that interesting. I also found it interesting that throughout the museum and in different parts of the city you have things in English and you have things in Mäori. You don't want this language to die. That's a big deal to not want this language to die. We have so many dead languages, beautiful dead languages. You don't want this language to die. You have classes that are for people just to read, to write in this language. You sell children's books in this language, it's amazing, it's amazing!... here it's in English and Māori because Māori was the original language. And in some places you find the Mãori first and like wait a minute, where is the English?! You have to look for the English. And it's almost like we invaded your country, we pushed you out, we made a mistake and now we are gonna try and make up for it. And it's trying to make up for it in a different way that I have not seen before...

It is evident that Susan's cross-cultural encounter moves from meaning to dialogue. The cultural engagement is, of course, framed by her interpretive community. However, the linguistic selfrepresentation of the Other creates a 'Third Space' of cross-cultural dialogue. In the process, Susan reflects on both her personal and her cultural sense of Self. According to her, "there is no way I would be able to sing anything of any chant in any Native American language". The discursive negotiation of a 'Third Space' gains a reflexive, critical and contested quality, as I show in more detail in the subsequent chapter. 
Given the centrality of self-representation within a postcolonial museology, the paucity of related research is somewhat surprising. Furthermore, the associated processes of cross-cultural negotiation operate mostly hidden behind the scenes and remain intangible in the product that is the final 'exhibition' (see Chapter Five). Krmpotich and Anderson (2005) show that visitors of Nitsitapiisinni in Canada barely recognised the collaborative spirit behind the exhibit and consequently did not equate it with self-representation or self-determination. The summative evaluation of the Mana Whenиa exhibition at Te Papa (see description in Appendix H) provides a more promising example by concluding that the partnership approach was the most successfully communicated message (McCarthy, 2001).

By returning to Bruce's experience of Te Papa, I conclude the interrogation of self-representation as a major avenue for the journey from bicultural meanings to cross-cultural dialogue:

There is some sort of indefinable hokeyness that in my experience tends to find its way or can find its way into presentations of non-dominant cultures or any culture really. I mean a non-present culture I guess is what I am talking about. I didn't get the same idea or the same response here. And I don't know whether that is just because the Mãori culture is more alive right now than say the Native American cultures in the United States, and still practicing Māori are involved in it?! Whereas in the United States there is not really, and I may be completely incorrect on this, but the sort of cultural understanding, the conventional wisdom is there is no real Native American culture left. It's more or less been subsumed into the American culture.

It is clear that the 'reader's world', in this case the indigenous/non-indigenous discourses in the USA, frame both meaning and dialogue. However, far from being over-determined Bruce engages reflectively and critically with the Self through the Other and admits that "he may be completely incorrect" with his version of "cultural understanding" or "conventional wisdom". In fact, it is the very mission of the National Museum of the American Indian to contest and revise this 'doxic belief' (Ricoeur, 1992) by simply and purely stating: 'we are alive'. Strikingly, Bruce 
departs from the specificity of the situation to assume a wider moral stance. He talks about "nonpresent cultures" in general and links their alien representation to the "hear-say" concept "in the law”, his own professional field (see p. 147). The multi-facetedness of the story shows, in Davidson’s (2006, p. 165) words, how 'narrative, identity and morality are irretrievably intertwined: without one another, they wither and die'.

\section{The reframing of understandings}

Bruce's admission that "he may be...incorrect" indicates the ubiquitous opportunity to reframe understandings, which offers another passage from bicultural meanings to cross-cultural dialogue. To substantiate this point, I turn again to Susan's interview:

I never knew New Zealand was still honouring treaties with their Aboriginal people. That's mind-boggling, mind-boggling! In the United States we broke, I don't know the actual number, but I am sure we broke more than half of our treaties we signed with the Native Americans. I just came from Australia where I learned they actually tried to breed out the Aboriginal people. (paused)You are still honouring, you are still trying to fix ties and honour and give them land. And that shows just how, how caring of a people New Zealand is, maybe?! Maybe caring is not the right word, but how, how much they realise that it's important that everybody is equal, how much they realise that the land is important. (paused) And it's just, they kind of have a different sense of everything.

Susan continues with her pondering on "treaties", which we encountered earlier in this chapter, in her follow-up interview. We can observe the motion from bicultural meanings to cross-cultural dialogue through the ongoing reframing of understandings:

Ifound fascinating that in New Zealand they are still trying to work with the tribes. I found interesting that the indigenous people are still set up in tribes. There are large family groups and tribes and the government is still trying to honour and work with them in the treaties with the tribes. And I can't remember the name of that precious greenstone that is similar and often taken for jade, but its not jade, how one tribe actually owns all stones found in New Zealand. And in order to use it they have to give royalties to this particular tribe. And I found that really fascinating. Especially coming from the United States where we do honour a few of our treaties but not nearly as well. And we give grants and scholarships, but it's not, it's not quite as prominent. In New Zealand you kind 
of get the feeling that everybody is aware of the indigenous people and they are trying to work with it and they are proud, they are proud of them. Whether the people are European descents or Māori descents, they are very proud of the indigenous people there.

Susan "never knew" but "learned" through reframing understandings. She offers a reflexive example of a 'subjective meaning' as 'internalised interaction' (Ricoeur, 1992). The interview excerpt shows that 'self-knowledge is a dialogue of the soul with itself', or, as Ricoeur (1981, pp. 109-110) puts it, 'an internalised communication'. In this context, Dilthey (1976, p. 223) discusses 'higher forms of understanding': 'When a person encounters, as a result of his understanding, an inner difficulty or contradiction of what he already knows, he is forced to reexamine the matter.' This reflects Dewey's 'problematic experience' (Hennes, 2002), which I discussed in the previous chapter and which always starts with a question. It also proves that 'thinking is doing' or 'cognition is action', a conviction at the heart of all pragmatist philosophy (Johnson, 2007, p. 92). Mirroring the circular hermeneutic trajectory of this thesis, Dilthey (1976, p. 225) further asserts that 'the objective mind and the power of the individual together determine the mind-constructed world'. To put it succinctly once again: we simultaneously mediate and are mediated. While we all depend on a 'common sphere', it is also clear that 'every mental state represents a new attitude, a new relation of the whole person to things and people' (Dilthey, 1976, p. 202).

By continuing Dilthey's (1976) line of thought, I argue that 'every mental state' embodies an act of interpretation. This is exactly the 'moment' or 'process' of cultural worldmaking, a hermeneutic 'turning point' or 'epiphany' (Denzin, 1989a). It follows that the 'business of understanding takes us into ever greater depths of the mind constructed world' (Dilthey, 1976, p. 225), which is reminiscent of Witcomb's (2003) laudable discussion of 'interactivity' as 'self- 
inscription' in a museological context culminating in the call for a 'polysemic exhibition

practice'.

Mike allows us to gain more insights into the hermeneutic human condition which excavates any interpretation from an 'internalised communication'. In other words, any meaning is a dialogue with the Self:

I have never studied New Zealand because you never study those things so close. I didn't realise what a young country it was, young geological country. You know I didn't realise that Māori really only have been here maybe a thousand years, whereas Australian Aboriginals have been there forty thousand years. So, you know, it started me thinking over lunch about the whole issues of land, land rights, people using the land, new people coming in, who are the new people?!... it was a primordial sort of country...it didn't have any people, which I didn't quite understand until I came here. Everything is relatively new. A thousand years is nothing in Europe and it's actually nothing in Australia. This country is quite different to other countries. So the story that they have woven in here is to demonstrate this is a new country, and the people have done some really dumb things in a short space of time. But this museum I guess sort of showed me that there is a lot of things that have been done in a short time, some good and some bad, but they all sort of somehow being hopefully put back into some sort of redress. And it's institutions like this that show people I think and it showed me that there is a circle in this when you actually go back and try and redress some of those issues that you so poorly handled so long ago.

Mike continues:

And that's why I think the museum has done a really great job in getting me to understand that the Māori thing is just part of a young country. They are not historically here which I didn't quite understand. I thought they lived in the North Island and moved south. That was in my mind what I thought happened. That is completely wrong and part of another Mäori relation altogether. And that brings into perspective some of the other issues, like what happened to the land, what they did to the land, what the white settler did to the land (sighing laugh). And now in fact, you know, the way the museum is set up it's almost as if there is a time coming where both groups will get together again and try and redress all the issues of the past. And I think that's why this museum does have a rather hopeful view of New Zealand, rather than just putting a historical perspective on everything, you know, which is fine if you are historian. But this museum does tend to try and drive you to a conclusion I think that things are certainly better than they were. 
Mike stresses that he "didn't realise" and "didn't quite understand" the cultural kaleidoscope of Aotearoa New Zealand before his Te Papa visit. According to him, the museum "started me thinking" and succeeded by "getting me to understand". The museum experience presents a thematic challenge which needs to be intellectually laboured. The hermeneutic back and forth carries Mike to 'higher forms of understanding'. He revises parts which were "completely wrong" while reframing the whole which "brings into perspective some of the other issues".

Mike reminisces in his follow-up interview and seems to have discovered the "complete circle of the concept" through the ongoing interpretive dialogue with himself, the continuous hermeneutic "think[ing]" and "link[ing]":

...for instance the gallery on earthquakes was a really interesting gallery. But most people quite understand earthquakes and how they've happened. They are not unique to New Zealand. But it made me think about the age of the country, where it was at in comparison with Australia. And then when you linked it up with what was happening with the Māori people. And that they hadn't been there forever, nor had the white people been there forever, and that the country was young, it sort of made a complete circle of the concept.

Other research findings have supported the 'reframing power' of exhibitions in cross-cultural negotiations of Self and Other, sameness and difference (Jones, 1995; Kelly \& Gordon, 2002; Sandell, 2007). In this thesis, it is my task to closely inspect the cultural frameworks and crosscultural journeys of global visitors to Te Papa. The proceeding analysis of dialogical 'Third Spaces' indicates that we, in Bhabha's (2008, p. 39) words, 'may elude the politics of polarity and emerge as the others of our selves' and travel beyond Rounds' (2006, p. 146) claim that 'otherness is tolerated rather than embraced'. Rounds' (2006, p. 148) theoretical speculation of 'identity works' simplifies and reduces 'reflexive activities' and 'identity' to 'behaviour' without delivering any empirical evidence since, according to the author, 'it would be difficult to prove that it is going on at all'. 
Through the merging of the empirical and the theoretical in the inquiry, I continue to draw a more nuanced hermeneutic picture than the postulation of such seemingly unattainable assumptions. By attending to Mark's thoughts, I conclude that one path from bicultural meanings to crosscultural dialogue occurs through reframing understandings:

I definitely learned a lot more about Mãori people today than I did in my whole prehistory course at Monash. Yeah, they didn't really delve too much into the people there except for the whole migration thing that was more in fossils, which I don't think there would be any fossils of humans in New Zealand (laughing). It's not too old enough yet...I guess the museum has helped me to understand the Mäori culture a lot more as far as what I knew about it beforehand. Basically the only main time when I see any Mãori in Australia is when I am watching rugby (laughing), when I see the All Blacks on TV.

As with Mike, "the museum has helped" Mark "to understand Māori culture" and its position with New Zealand's society. The interpretive exploration of a 'problematic experience' leads once again to 'higher forms of understanding'. Karp (1991) discusses the clashing of cultures within an actual exhibition space where the reframing of understandings becomes a dialogical necessity. It is worth quoting at length since it wraps up the current discussion and opens the gates to the next avenue from bicultural meanings to cross-cultural dialogue, which is investigated below:

Cross-cultural exhibitions present such stark contrasts between what we know and what we need to know that the challenge of reorganising our knowledge becomes an aspect of exhibition experience...Almost by definition, audiences do not bring to exhibitions the full range of cultural resources necessary for comprehending them; otherwise there would be no point to exhibiting. Audiences are left with two choices: either they define their experience of the exhibition to fit with their existing categories of knowledge, or they reorganise their categories to fit better with their experience. Ideally, it is the shock of nonrecognition that enables the audience to choose the latter alternative. The challenge for exhibition makers is to provide within exhibitions the contexts and resources that enable audiences to choose to reorganise their knowledge. (Karp, 1991, pp. 22-23) (my emphasis) 


\section{Tour intervention}

During the remainder of this section, I explore dialogical 'resources' and 'contexts' as

fundamental columns of discursive 'Third Spaces'. I turn to the narrative tour intervention as a

further pathway from bicultural meanings to cross-cultural dialogue and pass the word to Bruce:

...so we hadn't really had a lot to do with it and then part of the tour of course in the museum is sort of the merging of the two cultures. And one of the really interesting things that the tour guide talked about was the, you know, contract between the Māori and the basically British negotiators. And that sort of gave the, I guess the agreement some sort of a life. And it gave the whole relationship a little more context that we had before... well I mean part of it was just sort of the intersection of the two cultures...I thought it was very interesting because it seemed like a really genuine marriage of the Māori and the Non-Māori culture...I mean the very idea of the museum itself is probably not particularly a Māori idea but I guess you make do with the tools you have got.

We have already seen in this section that the tour host made Bruce understand the self-

representation of Māori at Te Papa and facilitated the journey from bicultural meanings to cross-

cultural dialogue. The above story offers more details of the dialogical support in the form of a

narrative tour intervention which "gave the...agreement some sort of a life and...the whole

relationship a little more context". The guided tour provides Bruce with the 'resources' and

'contexts' to communicate across cultures. He continues and it becomes clear that the tour host

helps to convert the 'shock of nonrecognition' into cross-cultural translation, dialogue and

understanding:

I don't think I would have gleaned that information otherwise...because it was something that he sort of made a point of and explained the governance structure of the museum. It sort of made clear that this is something that was being presented by the people themselves rather by somebody else. In general I think I really appreciated having the guide and the basic overview. I mean a lot of the things that we saw are things that walking around the museum you see anyway, but some of the contexts I don't think we would have gotten. Like the fact that everything to the sea is Māori culture and everything to the city-side is white person or mixed cultures, is something I don't think I would have even gleaned if somebody hadn't stopped and told me...I mean that sort of connections are the one that I think I wouldn't have made immediately. I mean it's a really neat structure and it was a good way to sort of put at least some parts of the building into perspective. 
In the previous chapter, I interrogated the tour host's role in the dynamic interplay of content, context and narrative. Bruce's narration is reminiscent of Nicole's access to the "macro level" through the interpretive aid of a guided tour. Without such communicative support or 'resource(s)', Bruce presumes that: "some of the contexts I don't think we would have gotten...that sort of connections are the one that I think I wouldn't have made immediately". The conditions of meaning-making such as the hermeneutic interdependence of content, context and narrative merge with the processes of meaning-making and their accent to cross-cultural dialogue.

Mark instead struggles with the 'shock of nonrecognition' without any narrative contextualisation. Consequently, the bicultural architecture of Te Papa remains obscured and Mark is left to construct a confused meaning leaving an unresolved question:

I thought it was a very impressive building design. The Museum in Melbourne that I go to about once every two or three years, you can't really see as much of the building from the outside as you can from this one. And because it's right on the harbour as well. It almost looks like the front bit has been, like a new bit that has been stuck on to another building!?...Is it all built at the same time because it looks like it's like a different design almost?!

Michelle narrates her experience of Te Papa's contemporary marae, or communal meeting place, and allows us to witness the tour intervention's interpretive assistance traveling from the broader "macro level" of cross-cultural relations to specific negotiations within a particular exhibit:

And then we joined the tour and the woman who led it was half-Chinese and halfMāori. I can't even say that very well: 'Māori'... Very, very nice and she spent about an hour-and-a-half with us...I was very impressed with the modern Mäori structure that they have there, just wonderful...And then she told us an interesting use of it, that it actually is used when someone really important dies and the body is exhibited in there...And I just thought that was really a wonderful way to honour the dead, to do it in that manner. So those stories were very interesting that the docent told us. And, you know, she also told us all the symbolism in the actual structure of the ancient buildings...it's so different from 
many things we know in America... The symbolism that I found really interesting was that each panel told the history of a person. And so depending on that design it would tell the story of that person's ancestry. So she said these only look the same to you, but they are actually different, the designs are different. And then that was true. We learned, not here, but that the tattooing on the face and the body were all very personalised to that person who was wearing those tattoos.

Michelle proceeds and her interview offers another example of interpersonal interaction as dialogical 'resource[s]' in a different museum 'context[s]':

And we learned that in the Auckland Museum because they actually had a group of people who did the dancing and the signing and played the instruments, and just did a whole show for us. And then afterwards you could talk with them. And the young man that we talked to said that you have to be twenty-one before you get the tattoos and so his goal was to have his whole, half of his upper body tattooed within a certain amount of time. And then he told us what the designs meant and what the genealogy was. And then he was gonna continue with more tattoos, when he got married, when he got children and the rest, you know, the stages of his life. So I had no idea that there was actually a story to these tattoos and it was really their genealogy that they were recording rather than just having a design. Because in our country the people that put tattoos on them they just choose an interesting picture or design or even write a name, but there is no history or genealogy to it. It's just decorative.

Neither the "use" nor the "symbolism" of the marae are yet cross-culturally translatable and understandable within the exhibition setting. This fact was addressed by incorporating such intangible concepts in tour programmes, especially when dealing with non-New Zealand audiences. Note that none of the interviewees referred to 'taonga', a treasure with living human links, which is an integral part of Māori identity (Hakiwai, 2006; Kirshenblatt-Gimblett, 1998; Smith, 2006), when describing Māori objects but instead used typical terms associated with their interpretive communities such as 'artefacts' and 'art'. At this point, cross-cultural dialogue ruptures since the 'existing categories of knowledge' (Karp, 1991, p. 22) cannot be 'mobilised in the passage through a Third Space' (Bhabha, 1994, p. 36). In the case of 'taonga', the depth of its meanings remains locked for the uninitiated and is devalued as cross-cultural doxa. 
To Mark, the unknown "use" and impressive "symbolism" of the marae would even have

prevented any cross-cultural engagement:

I didn't really expect to have this massive Māori meeting area as you call it. And they had the chairs there so we all sat down. She was telling us about how it was all made out of, what is it called, made out of second hand wood!?... And yeah, after a while she took us up into the actual area. We got to stand in there, which was a really different experience. If I was just by myself, then I probably wouldn't have even thought I was allowed to go up in there... yeah, when she was pointing out all the different symbols on the wall it actually made the whole thing a lot clearer to me. Like when I first looked at it, it just all looked the same. But then when she was actually pointing out like, you know, these represent Christians, then they got engineers, the wood cutters, all the different sorts of people, it made all seem a lot better... another thing I wouldn't have thought if it wasn't for Lauren pointing out, like how it had the sort of a Màori head on the top and his hands are like the walls coming down from the roof. And he is actually saying 'come inside' like that (gesticulating). I would have just totally missed that if I didn't go on the tour.

It is evident that the guided tour invites Mark to embark on a cross-cultural journey beyond meanings towards dialogue. First, he "wouldn't have even thought" he "was allowed to go up in there". When entering the "different experience" of the exhibition space, "it just all looked the same". After the tour host "was pointing out all the different symbols", however, "it actually made the whole thing a lot clearer" to Mark. He concludes: "I would have just totally missed that" cross-cultural understanding "if I didn't go on the tour". The voyage from bicultural meanings to cross-cultural dialogue gains a reflexive quality.

John sheds more light on the hermeneutic processes which interweave the interpretive agencies of Rongomaraeroa, tour host and visitor in cross-cultural dialogue, translation and understanding:

...there is a dissension among some Native Americans about whether they should be weaving traditional things that that more represent the traditional Native American or should they be doing modern art. So there is some dissension here. When we were with Robert, he said that the Māori in New Zealand that were consulted about doing that all agreed that it was wonderful to incorporate modern art in the meeting house. And not only did we think that it was beautifully done and beautifully presented, but the fact that they agreed that, and I realise that may be just Robert's opinion, but the fact that they 
agreed to move forward with that we thought was a very positive sign. That they won't say to their artists: 'hey, you have to do stuff, you have to make meeting houses, it's fine to make a meeting house but you have to make it look like it did three hundred years ago'. (paused) We liked that, and that's a neat thing for Te Papa to do is to encourage that design and have that go. (paused) Yeah, we thought that was very neat that they weren't gonna be stagnant in one time period and say: 'that's forever more, that's the way Mäori art has to be done, the way, you know, the way our ancestors did it'.

The empirical evidence supports the view that the contemporary marae epitomises Te Papa's most sophisticated museological experiment by exploring a cross-cultural approach to biculturalism. The exhibit reflects the idea that, as Bhabha (1994, pp. 35-36) writes, 'cultures are never unitary in themselves, nor simply dualistic in the relation of Self and Other', and erodes the common and artificial binaries by opening an 'in-between space', 'the cutting edge of translation and negotiation...that carries the burden of the meaning of culture' (Bhabha, 1994, p. 38). As the research material reveals at various points throughout this thesis, Rongomaraeroa carries these hermeneutic dynamics from museological representation into the realm of the visitor experience through the evolution of dialogical 'Third Spaces'. However, the processes of cultural contestation and museological production remain mostly hidden behind the scenes and do not appear in the product 'exhibition'. With the marae, John did not 'get it' by himself, but relied on the narrative tour intervention to gain insights into the cross-cultural consultations prior to the exhibition's conceptual design. Michelle and Michael likewise required interpretive aids to translate the "symbolism" and "use" of the marae into cross-cultural understandings.

By following Charlotte's recollection of her visit, we can observe the performative, ambivalent and contradictory nature of cultural co-construction throughout the journey from bicultural meaning to cross-cultural dialogue: 
I guess they all just build up a bigger cultural image that, yeah, I didn't have before...it gives you a better idea I guess of the history of the nation overall... and comparing it to what we had been told last time I was out at a marae, it's a different explanation. But then it was also good that it was kind of explained when they were talking about the Māori tribe that is in residence and how that changes every two years, and that the customs for the marae here change depending on which tribe is in residence. And this was an interesting thing to know and we thought that maybe something in regards to the story and the way that things are done differently is dependent on the tribe and everyone has their own little differences... the other thing that sort of struck me I guess was when we were taken around and shown the marae that in terms of my first experience at a marae last year I turned up and needed to go to the toilet. So I wandered on and went to the toilet. And then I just wandered across and went to the kitchen where everyone else was and got immediately escorted off (laughing) because I hadn't been welcomed on ...So to be taken around by the tour guide and shown the marae, and then for her to say 'this is the marae' and not have the walking on ceremony is kind of like: 'how do they I guess equate and justify that in terms of the cultural and as a nation when absolutely every other marae you go into you need to be welcomed on to appropriately?'...I guess it's part of the process here. That was one of the things that came up again as a little bit of an inconsistency in my knowledge of New Zealand culture.

To "build up a bigger cultural image" is a never ending process of hermeneutic revision. Based on prior understandings, Charlotte continues her experience of the cultural concept called 'marae'. In the case of Te Papa's Rongomaraeoa, her familiarity with Māori customs causes a cross-cultural dissonance and interpretive rupture. Charlotte needs to resort to the tour host's explanatory assistance since the exhibition itself does not offer the interpretive 'resources' and 'contexts' to facilitate the translation of the perceived "differences". As the follow-up interview indicates, Charlotte keeps on negotiating her "inconsistency in...knowledge", which is in fact the hermeneutic relativity of 'truth':

I think the thing that I found really interesting about the meeting house was when we went with the tour they explained the significance of the meeting house within the Mäori and New Zealand culture. But also it was very interesting that this is the one that is used for national and international functions in New Zealand. It was done by a variety of people. Anyone could sort of do a part of the meeting house and contribute. It was done by students, it was done by experienced carvers.

The issues of the particular characteristics and usage of Te Papa's contemporary marae seem to be satisfactorily resolved and accepted as another version for both "Māori and New Zealand 
culture". It still might contradict Charlotte's prior experiences and understandings, but after initial complications gained her approval of legitimacy within the national and international context of the museum.

Returning to Charlotte's initial interview, the tour host herself emerges as the embodied space of cross-cultural contestation:

And it was good that we went through and saw the main points. And I think it gave a good mix of the main cultural things, sort of the English culture and the Māori culture and looking at the other cultures like the Scottish culture and the Pacific Island culture that is all part of New Zealand... she did that well and the fact that that she was from South Africa is like 'oh okay', but I think it perhaps would have had a stronger impact had it been a Mäori tour operator or an English born, or a New Zealand born English speaking tour operator than South African. I mean she is identifying as New Zealander, that's great if she wants to adopt it here. But it was sort of I guess from our perspective.

The 'Third Space' of cross-cultural dialogue has reached its peak of ambivalence. Who and what is New Zealand: "English", "Māori”, "Pacific Island", "Scottish"? Whom does the tour host represent and whom is she "identifying" with: "New Zealand", "South Africa"? Charlotte clearly appreciates the "mix of the main cultural things...that is all part of New Zealand" within the broader spectrum of the nation. But she hesitates to accept a personalisation of this "mix" embodied in the South African host. Charlotte's 'suspicious hermeneutics' derives once again from the moral and political battle for self-representation: who is acting on behalf of whom? And who can differentiate and decide in this ubiquitous "mix"?

For Mark, the encounter with a culture through a person culminates in an even more complicated cross-cultural perplexity:

... well she was an interesting character with this. Like she said her mom is a tall blond with blue eyes and her dad is a really short Māori. And, yeah, so she said in her words 
that she is a bit of both (laughing)...From first appearance I thought ah okay she is just a New Zealander. But then when she actually started explaining all the different exhibitions, I could actually tell that she knew what she was talking about and that she probably knew a lot more about Māori culture than what she let on originally... she helped creating an atmosphere for the museum and, yeah, I definitely recommend. Like I am not sure if the other tour guides are as good or know as much about Mäori culture as she does or have the same sort of background in history, but it's definitely a good idea to get someone that knows about both sides. And she definitely seemed like she did, which was good. I keep saying like, you know, here is two different sides of New Zealand. But like there is not really anymore, like everyone is starting to get together, which is good of course.

Mark faces a bicultural person who "said in her words that she is a bit of both" Māori and NonMāori. According to him, "it's definitely a good idea to get someone that knows about both sides". But reflecting on this experience, he concludes that actually there is no "two different sides of New Zealand" anymore since "everyone is starting to get together". "From first appearance", however, Mark could not help but contrast Māori with "just a New Zealander". The ambivalent nature of this articulation shows that the relationship between culture and person is performed in a never-ending ambiguous tension which renders clear-cut categorisations impossible. Interpretive communities, which some time ago were incorporated into museological thinking (Hooper-Greenhill, 2000) and research (RCMG, 2001b), are overlapping, fluid and internally heterogeneous.

Luckily, the tour host, the embodied space of a 'suspicious hermeneutics' and cross-cultural perplexity, offers a way out of this maze by reversing the order of negotiation to travel the crosscultural journey from person to culture. Claudia puts it this way:

It was nice that our tour guide actually is Māori. So she was able to give us a Mäori welcome in Mäori and give us probably some further insights than, you know, somebody else would because she grew up, her family, her parents, her history - she knows things firsthand. So that was nice, we probably would have gotten a different perspective from somebody else. 
At a first glance, Claudia seems to offer more evidence for the significance of self-representation to gain "some further insights...firsthand" of the Other. However, she does not reduce the tour host to the sole function of cultural representation and embarks instead on a cross-cultural dialogue with a humanised Other, through "her family", "her parents" and "her history". In other words, the tour host is the person of departure to explore a culture. In the process, the abstract cultural category 'Māori' is transformed into a face with a story. Claudia confronts the 'other as a face, not mask’ (Bauman, 1995, p. 59), which leaves a lasting impression as the follow up interview indicates:

And our tour guide was Māori as well. So I mean she had a bit more insight that she could tell us, the things that I hadn't realised about what different symbols meant and why things were the way they were.

Person and culture cannot, of course, ever be separated. Without culture we are, as Geertz (1973) puts it, 'unworkable monstrosities'. But persons and their undeniable individuality can claim their deserved position in the foreground without being reduced to the cultural dimension by 'branding human beings as types' which 'denies them their full humanity' (Abbott, 2002, p. 129). Michelle elaborates on prior encounters with personalised cultures:

...we first experienced in Auckland, at the museum there. And the most interesting part of that museum was talking to the performers who were the dancers and the singers. I just felt that that was a real highlight because they were so gracious. They must have spent more than half an hour with us...So when we can talk to, you know, a real person who was part of that culture, that was very significant to us, because they weren't performing they were just being themselves and being very straightforward and honest about all the things that were really significant in their lives. And you don't get that kind of an opportunity very often ... that was really quite memorable.

Michelle does not "talk to" a culture, but to "a real person who was part of that culture". Crosscultural dialogue moves beyond its merely abstract meaning and becomes a real interpersonal dialogue among cultural human beings. Michelle's story, albeit in a different museological 
context, epitomises the essence of cross-cultural journeys disclosed in this research: the humanisation of culture. In fact, it is the moment of double-humanisation since the humanised cultural experience mirrors the humanised approach to the public sphere and cross-cultural dialogue in this research. Michelle continues with another example:

I think it would be nice if they could do that in all museums, if they have a cultural exhibit, if they could have some people there who represented that culture and who would just talk with anyone who wanted to ask questions. But that very seldom happens I think in a museum. The only other time I have done it is in Washington DC. There is a brand new museum called the Museum of the American Indian... And there were American Indian people who were leading the tours. And so they really personalised it, told you about their own family and their history as well as what was happening in the museum, and just made it so significantly, you know, more interesting I thought. Because they weren't just talking about something that they have learned about, they were talking about something they lived. And I just, you know, felt that was very valuable.

Michelle "felt that was very valuable" to get some insights into a "personalised" culture which someone "lived" rather than just "learned about". Once again, a cultural construct such as "American Indian" is humanised through a face with a story, "family" and "history". I personally witnessed the most remarkable museum interaction at the Australian Museum when the Aboriginal artist Richard Campbell created contemporary art in the exhibition setting while actively engaging diverse audiences. But despite scholarly attention to embodied experiences (Dudley, 2009; Gregory \& Witcomb, 2007; Witcomb, 2009), exhibitions mainly communicate in a detached and impersonal mode failing to give faces to the people involved. They continue to reify culture and difference, Self and Other.

It mostly requires human intervention in the form of guided tours to perform culture and make it "come alive", as in the case of Andrew from Canada for whom "Māori" becomes "Ralph":

I am still not very good with Māori pronunciation so I don't know the names, but I was very impressed with the meeting house...He started there and then he told us the story of how it would work or how it traditionally worked and how it is even used today for 
certain important functions... And Ralph's knowledge of that, he was just able to talk and explained a lot about it... I think the fact that Ralph had Māori ancestry too helped a little bit...But he made the tour, he made the museum for us really. I think we got a lot out of it even without him, but he certainly made it a more worthwhile experience...I think the best example would have been the way he explained the meeting house and how the host tribe, Iwi, is that what you call it? We sat on one side and the other Iwi on the other side and then they would just start by introducing themselves from the mountain and the river and the region so that the host would say 'well I know of your family or I don't'. And he just, he is a storyteller and he just made it come alive the way he would explain it... He introduced himself and he also introduced the culture and how the meeting room would work.

"Ralph" facilitates the marriage of story and face in the performance of culture and transforms a "symbol" into a "meaning" (see Chapter Three). "He is a storyteller and he just made it come alive", Andrew notes approvingly. Without this humanisation of culture, the marae remains a static cultural relic removed from any cultural practice. Andrew's interpretive task would be the deciphering of a cryptic cultural code without the outlook of understanding the ways and forms this place is lived beyond its museological representation. Andrew reminisces in his follow-up interview:

I was also very lucky having a Mr. Smith as our guide going around. And he was very knowledgeable and he could personalise some of the stories that were there and that meant a lot to us and added considerably to our visit... the one that comes to mind the most I guess is the welcoming ceremony. He explained the one where we stopped and sat at a place where he indicated how a visitor would be welcomed to a community. And he could just make the story come alive almost. He was like so proud of his own heritage. You know it was pretty obvious and it came across that way. I'd think we were very, very lucky to have him as a guide probably.

Between both narrations there was a gap of six months, the time between initial and follow up interview. It is obvious that the merging of face, story and cultural performance has imprinted itself on Andrew's memory. To him, Māori is still "personalise[d]" as "Mr. Smith" and the "story" of the marae "meant a lot" and is "alive". While an abstract concept such as 'culture' is hard to imagine, understand and remember; it is even harder to forget a face and story of a human 
being. In fact, the latter can be sensed and felt, and therefore seems to function as personalised condition for the ongoing negotiation of cross-cultural meanings.

The literature provides some useful case studies on the performative nature of guided tours (E. M. Bruner, 2007; Gable, 2006; Hooper-Greenhill, 2006). Interestingly, the issue also came up during one of the focus groups I conducted with Canadians. Although I was interested in a theoretical discussion of the 'museum forum' idea (interrogated in Chapter Five), the following stories emerged and are worth considering in this context of humanising culture:

One of my best museum experiences was when I was in Hanoi, in Vietnam. There were a couple of girls, students doing a survey. And they did the little survey on me. They were talking to English speakers. And I actually run into them when I was in line for the museum the next day. They were there and they said 'well, come in with us'. And they were able to take me into this museum in Hanoi and explain their point of view of the exhibitions in there, which I would never ever have known. They had little plaques that were translated into English at some of the displays, but their perspective on this person who this display is about and this is why this person was important to us. I would never have gotten that without those people being there.

Samantha's story prompted Chan's direct response:

Her initial comments reminded me of my best so to speak museum experience when I was in Gdansk, Poland. And I was working with an archeological thing there so I had the opportunity to have a tour guide through the archeological museum with an archeologist who worked there. But we had extra time in the day so she ended up taking us around town. And that was also coinciding with I believe the $25^{\text {th }}$ anniversary of the solidarity movement that started in that town. And so we actually went to a hall where they had exhibitions. And she started talking to us about what life was like when she was in that town as a teenager and all the communist oppression they had to deal with, all the secret ways of being subversive. And it just completely blew me away, like to have that level of personal contact. Yeah, I am not Polish and when I traveled there I was not even thinking about all these politics and things like that. But it's just that level of personal interaction that really stood out.

It is remarkable that both Samantha and Chan consider "that level of personal interaction" as their "best museum experience" respectively. The fact that these elaborations appeared unsolicited in a discussion on a different topic indicates the profound impact of the personal on meaning and 
memory. It attests to senses, feelings and embodiment as major condition of meaning-making feeding into the actual processes of meaning-making through cultural interpretations. Samantha and Chan explored Vietnamese and Polish culture, but they only started sensing, feeling and remembering once the culture was humanised through faces and stories.

The interview with Andrew provides further empirical support for this assertion and shows that the required personalisation does not necessarily depend on human intervention in the form of guided tours, but can be achieved in a static exhibition setting itself. Andrew talks about his experience of the Iwi exhibition (see description in Appendix I):

I spent a lot of time there, reading about the artefacts that have been collected and the history of that particular, I am not sure if they called it a tribe or not!?...The other thing that was impressive was the old artefacts, like the hand-carved stones and things. It's one thing to see there are new ones that were done to show what they were like, but to see that they actually were carved and they were there in the individual exhibits. And I think it also to us sort of personalised it. It wasn't just a general thing like this is the way it was done, but this is what these people did in this place. So I think it was very well done and that so impressed us there.

To Andrew, an "artefact[s]" ascends from "just a general thing" to something which "these people did in this place". The cultural denomination becomes "personalised", localised and meaningful. This allows Andrew to engage with "these people" rather than a monolithic race or ethnicity.

Fellow Canadian Nicole touches on a similar experience in her follow-up interview:

I think in the immigration section the Scottish were being highlighted when I was there. They had like the screens where you could get individual stories of Scottish immigrants who had come to New Zealand. And I just remember that really stuck out and being able to see different people's stories. 
As with Andrew, a cultural group is humanely deconstructed in an exhibition which facilitates an interpersonal dialogue among cultural human beings. "Being able to see different people's stories...really stuck out" for Nicole when visiting the Community gallery (see description in Appendix J). The abstract totality "Scottish", instead, lacks the humanised condition of crosscultural meanings.

By turning to the follow-up interview with Mike and his experience of the same exhibit, the metamorphosis from cross-cultural to interpersonal dialogue is completed:

So a lot of the galleries were memorable themselves and there were two or three of them which sort of stuck in my mind. I really enjoyed the immigration gallery. That was a good story told there about how the white man came to - just humanising the migration. It's easy to sort of say 'oh, you know, and white migrants arrived'. But when you actually start to put names and faces to individuals, it's real people that came and not just like a wave of humanity that arrived. You know, actual people, they had poor jobs and they came from poor farms. And a lot of them were English farmers and people that were struggling back in England and Scotland. And it made sense when you saw their faces and their pictures and I thought that was a good thing that the museum did. It's easy to be dry, it's easy to sort of say '10000 people arrived in the first year and 20000 in the second year'. It doesn't mean anything. But when you see that it's an actual person, that they left their house in wherever and then they arrived in New Zealand and that's where they settled, I thought that was well done.

Mike not only provides empirical evidence, but also offers an interpretive formulation which mirrors the heart of my argument and reflects the double-hermeneutic condition of this study. To Mike, only "humanising the migration" by putting "names and faces to individuals...made sense". Objectifying "immigration" as "a wave of humanity that arrived”, instead, "doesn't mean anything" - it has to be "actual people" and an "actual person". There remains nothing for me to add, apart from a subsequent theoretical proposition. 
The evidence gathered in this research suggests that the humanisation of culture and crosscultural dialogue transforms a 'Third Space' into a pluralistic space which pays tribute to the inescapable pluralism from within. Bhabha (1994) attempts to capture this 'difference within' through the term 'hybridity'. While this move successfully erodes binary oppositions and exposes 'cultural purity' as 'oxymoron' (Appiah, 2006), it is still a vein of thought which sets out from the cultural. Rather I postulate a pluralistic space which evolves through the face and story of a cultural human being. In other words, the individual is the genesis of culture and not vice versa. Only by deconstructing cross-cultural dialogue as interpersonal dialogue among cultural human beings can the Other be freed from its abstract cage and opened for moral and political engagement. The aforementioned dangers of 'underreading' (Abbott, 2002) in cultural characterisations are never completely prevented but laid bare for reflective scrutiny or reflexive humanisation.

Bauman reminds us that moral responsibility is triggered by the 'face of the Other' (1989) and calls for us to 're-personalise morality' (1993) by the 'resistance to objectification' (1995). In this context, Ricoeur (1981, p. 61) considers the 'paradox of otherness' as 'tension between proximity and distance'. Bauman (1989) expands on this line of thought in his brilliant analysis of Modernity and the Holocaust. He shows that modernity itself degenerated human closeness into 'social separation' through its own technological and bureaucratic achievements which are 'authorised', 'routinised' and 'dehumanised'. I argue that the human construction 'culture' in its ethnographic sense causes a similar 'separation' and 'distance'. It allows us to hide behind a cultural 'mask' instead of showing our human 'face'. Only the liberation of the latter can create a pluralist space which carries the phenomenon of cross-cultural dialogue from the world of 
abstract reasoning into the realm of lived experience, as in the case of Claudia who deserves not

to be interrupted:

We stopped in Maketu and actually were welcomed into a marae, spent the night there sleeping and had the hangi for dinner. And we were fortunate enough to have some Māori come to see what Uncle Boy, who ran this marae, does. So I had the further advantage of speaking to more Māori...When I think of Māori for some reason I am associating the marae ...it really resonated with me... When I saw it, it just brought back the feelings that I had had when I had been at the one in Maketu. (paused) I just really appreciated that this person was welcoming us into his life, his world and his family so to speak. Because when we left he did say, you know, 'I consider everyone that comes through here a part of my extended family now so you are welcome to come back'. And we did the hongi and it was something very personal for me ... there was something about it. I don't know whether it was his nature or because I do have a fascination with cultures, but it was a real personal experience for me. So when I came to the museum and saw the marae...it just kind of brought back the memories of sleeping in there. Because I remembered lying in the bed seeing the spine and the ribs and, you know, looking for comparisons between them and just it brought back like an enjoyable memory for me. Because when I think of the Māori exhibit that keeps flashing...I think it was because it was just so welcoming...And it touched me that they were that willing to, like I said, welcome us into their family, their life, their world and we were complete strangers...So I think that's why it made such an impact!? Because I am from the other side of the planet and yet now I technically have Mäori family connections on some level.

For Claudia, "Māori" does not exist as abstract cultural category, but is "associat(ed)" with the "marae" and a "person", "Uncle Boy". She "appreciated that this person was welcoming” her into his "family...life...world" although being "complete strangers". "Māori" is given the face of "Uncle Boy", which offers Claudia "a real personal experience" that "touched" her. The interpersonal dialogue among cultural human beings within a pluralist space creates a human 'proximity' transcending geographical 'distance'. Claudia's feeling of having "Māori family connections on some level" despite being "from the other side of the planet" is not primarily of cultural but of human origin. She reminisces in her follow up interview:

We actually stayed in a marae and we met some Māori and had a chance to speak with them and learn about what they did, what their lives were like, got involved in some dance and song performances. So it was very nice to kind of be welcomed into their world and seeing through a little window what someone else's life is like compared to mine. 
Claudia concludes her humanised cross-cultural dialogue with the, in Dilthey's (1976, p. 226) view, 'highest form of understanding', the 're-creating or re-living... on the basis of empathy or transposition'. By “seeing through a little window”, she is able to 're-experience' (Dilthey, 1976) "what someone else's life is like". The personalisation of the culture "Māori" through a face triggers in her the 'primordial capacity to transpose oneself into the mental life of others' (Ricoeur, 1981, p. 49), which would be impossible if the encounter remained on an abstract level. To put it differently, no-one could ever 'transpose oneself into the mental life' of a constructed cultural totality such as "Māori". Claudia feels "welcomed into their world" and in the course explores what another "life is like compared" to hers.

In this section, the hermeneutic analysis of the research material revealed the narrative journeys from bicultural meanings to cross-cultural dialogue. Different interpretive pathways such as selfrepresentation, the reframing of understandings and tour intervention allowed the interviewees to travel beyond the 'reader's world' and translated a 'contact zone' into a dialogical 'Third Space'. The humanisation of culture and Other led to the deconstruction of a detached cross-cultural dialogue as interpersonal dialogue among cultural human beings, creating what I term a pluralist space. This pluralist space lays the foundation for the political and moral engagement with a humanised Other. Claudia's interpretive reflection on "someone else's life...compared to mine" allows the transition to the voyage's last stage: Cross-cultural hermeneutics: the shifting Self.

\section{Cross-cultural hermeneutics: the shifting Self}

It is interesting seeing it and being here through Australian eyes I think now instead of Kiwi eyes. (Julia, New Zealand born Australian) 
After the empirical evidence established a pluralist space through the faces and stories of cultural human beings, it remains to interrogate the shared symbolic context for the discursive negotiation of differences and the facilitation of understandings. The research material offers insights into the functioning of a 'common sphere' (Dilthey, 1976) as the interpretive basis for any hermeneutic endeavour between Self and Other throughout cross-cultural journeys.

I turn to Michelle, who continues to elaborate on her encounter with a culture through "persons and their story":

I think it was just pretty much focussed on these persons and their story... what they did say was the Māori people do inter-marry. They don't have a feeling that they have to keep their culture pure. Many other cultures really want to stay pure...for example in New Guinea they really want to marry a person who is part of a tribe. But the Mãori people they are part Chinese and they are part Irish and they are part German, and just so many different cultures mixed. And there is no real 100\% Mãori people. So that was an interesting viewpoint for me because I had assumed that they really wanted to keep their culture within their own people. For example I am Armenian and so Armenian people like to have their daughters or sons marry Armenian people, keep the language alive and the culture. But it's not happening. I mean in California there is just so many ways to meet people that you go to college or university and that's usually where you meet someone that you gonna marry. So you can't do that any more, but years ago I think cultures really wanted their children to stay within the culture. I know that's very true for the Indian, East-Indian people, where they have arranged marriages and they are still pretty much into that mentality. Parents pick, you know, the partner for the person. So in Māori it seems that's not important. And so they just become part of the whole mixture of cultures...

Michelle embarks on her cross-cultural exploration "pretty much focussed on these persons and their story". But instead of leaving a singular 'reader's world' in order to shape the 'fusion of horizons', the 'Third Space' 'in-between' divides into a multitude of cultural differences.

Michelle draws interpretive connections between "Māori”, "New Guinea”, "Chinese”, "Irish”, "German", "Armenian" and "Indian" and in the process she reflects on the Self through the Other. Importantly, these contrasting comparisons can only be made because there does exist a 
shared interpretive domain with commonalities across differences. According to Michelle,

"many...cultures really want to stay pure". It remains, however, an illusionary attempt because of the ubiquitous phenomenon of 'traveling cultures' in a 'cosmopolitanised' world. "You can't do that any more", Michelle concludes.

The follow-up interview with John indicates that the "mixture of cultures", or cultural ideas and concepts, has indeed a history and is no contemporary novelty:

And it is amazing the similarity, that really fascinated us, the similarity...the meeting houses are so similar all through the western part of Canada, British Columbia, all the way up into Alaska the same kind of structure, the same kind of shape, the same kind of wood except they use different cedar up in Alaska, but the same shapes and the same reverence for the meeting places, almost a holy place. And we found that very interesting. And of course the origin of the people are similar, apparently coming across the Bering Strait and having that slightly Asian, South Pacific Islander look that carries through all the way from the Eskimo in Alaska to the Mäori all the way down to New Zealand. That we found very interesting, that they use the same kinds of meeting houses. Not just that they had the same fishing and boats and things like that, which you would expect because it's close to water. But that they carried through thousands of miles further across the globe the same ways that they stored food, the same ways that they had meeting houses, that was very interesting.

John is "fascinated" by the "similarity" across different cultural groups from the "Eskimo in Alaska to the Māori all the way down to New Zealand". This confirms that all cultures are characterised by 'complex histories of dwelling and traveling' (Clifford, 1997, p. 2) and in this case "carried...the same reverence for the meeting places...through thousands of miles further across the globe". John's interpretation reflects Appiah's (2006, p. 96) reasonable argument that due to 'our common biology and the shared problems of the human situation', such as living "close to water", 'cultures produce a great deal of variety, but also much that is the same'. This simultaneous existence of commonalities and differences reconfigures the discursive 'Third Space' as cosmopolitan space. 
Andrew enables me to interrogate the space's interpretive dynamics between Self and Other:

I think it was a significant part of the museum to me. I guess I have the Canadian definition of the Māori house, the greeting house, the house with all the hand-carved work around it. That was very, very impressive. I sort of equated it to the long house of the Iroquois in Canada. So I make the comparison between the two indigenous cultures.

As Andrew proceeds we see how his Canadian Self shifts from the Indigenous to the Scottish inclusion through the experience of the New Zealand Other within the wider context of "traveling cultures':

We were also very interested however in the section about the Scottish settlers right now. Again I can draw the connection because my family being from Scotland coming to Canada in the early 1800s. And stories were quite similar to what was recounted there...the similarities between the Scottish settlements in Canada and the Scottish settlements here is just amazing. I think there are probably more Scots spread around the world than there are left in Scotland now... and it's something that people are trying to keep their heritage alive I guess. And I just found it really interesting, the same things happen here that happen at home.

Andrew carries on by shifting the cultural Self/Other encounter to a personal and professional level:

I am a former politician so I am really interested in anything political. And gatherings of people from different places with tribal structures is a very political meeting. So I just found that fascinating and the fact that it's still used for greeting visitors and used for important ceremonies, like the tour guide had mentioned funerals and weddings had been held there, and that's very sentimental and meant a lot just to see that.

While describing his experience of a traditional marae he now shifts his Self back to the cultural and equates himself with the Aboriginal Other within the Canadian "we":

And I guess I am fairly interested in our own Aboriginal culture at home. And we, the Aboriginals in Canada would carve in cedar and we've got very few examples that have survived as well as that one.

The sense of the Canadian "we" is realigned through contrasting himself with the Aboriginal Other within the Canadian Self. This happens again through the experience of the New Zealand Other which leads to a cosmopolitan conclusion: 
I noticed you have a similar problem here that we have at home, and that's the number of Aboriginal land claims. A lot of Aboriginals here are claiming they were taken advantage of during the Treaty process and we have still got legal challenges going on. And I am not sure if the tour guide carries a prejudice into it, I don't know, but it would have appeared to me from his explanations to us is that New Zealand is somewhat ahead of Canada in resolving these issues. And I just found it very interesting to know there was a similar concern going on in both parts of the world.

Andrew reminisces on both his Scottish and Indigenous connections in his follow-up interview six months later:

Two things stood out in my mind. Number one is your recording of the influence of the European settlers that came there. And there was an extremely good exhibit of the Scottish settlers when I was there. And I guess I was impressed by that because it coincided with my own family's move to Canada. I think if I were to pick the most memorable part of it, it probably would have been the Aboriginal house and that sector where they had that real beautiful, I am not sure if it's restored or moved in, home that was sitting there.

Andrew's cross-cultural journey is characterised not only by the opening towards the Other but by a shifting sense of Self. The 'cosmopolitanised' condition of our time forces and enables Julia "seeing it and being here through Australian eyes...instead of Kiwi eyes". It causes Michelle to identify as both Armenian and American and leads to Andrew's 'multiple loyalties' (Beck, 2006a), the shifting Self which corresponds to an endemic relativity of otherness.

In Chapter Two, I introduced the relational nature of Self and its inextricable link to the Other. At this stage, I need to recall some points to flesh out my own theoretical proposition. Ricoeur (1992) convincingly argues that otherness is not confined to another person, but instead reveals the various ways of 'oneself as another'. To him, the 'great kinds' of Self and Other are ‘enjoined'. Combining Ricoeur's argument informed by phenomenological hermeneutics with J. Bruner's (1995, p. 28) notion of the 'Self' as 'the intersection of culture and individual identity', 
this research establishes a cross-cultural hermeneutics. In other words, I argue that cross-cultural dialogue is the interpretive ontological endeavour of what I call the shifting Self.

I need to stress that the shifting Self and its associated multiple identifications is no jubilant postmodern celebration, as critiqued by Bhabha (1994), but the mirror of a 'cosmopolitanised' world. In Chapter One, I highlighted the crucial sociological understanding that the 'human condition has itself become cosmopolitan' and therefore 'cosmopolitanism... has left the realm of philosophical castles in the air and has entered reality' (Beck, 2006a, p. 2). The examples of interviews with Andrew, Julia and Michelle emphasise the resulting 'performative construction of identity' via the 'situational self-positioning and positioning by others' (Kraus, 2006).

In the process, the contemporaneous presence of commonalities and differences creates a shared 'cosmopolitanised' terrain which represents the 'common sphere' (Dilthey, 1976) needed to transform cross-cultural dialogue into potential understandings. Most importantly, such a vein of thought transforms the 'neither/nor' predicament of a 'hybrid Third Space' (Bhabha, 1994) into a 'both/and' (Beck, 2006b) outlook of what I term a pluralist cosmopolitan space. The former simultaneously contests and perpetuates the either/or logic of binary oppositions while the latter builds a shared framework for multiple identifications.

'Without a shared world', Appiah (2006, p. 31) asks in regards to relativist scepticism, 'what is there to discuss?' Appiah (2006, pp. 98-99) continues:

The problem of cross-cultural communication can seem immensely difficult in theory, when we are trying to imagine making sense of a stranger in the abstract. But the great lesson of anthropology is that when the stranger is no longer imaginary, but real and 
present, sharing a human social life, you may like or dislike him, you may agree or disagree; but, if it is what you both want, you can make sense of each other in the end.

This is what a pluralist cosmopolitan space attempts to capture. It humanises the discursive domain by dealing with a 'real and present...stranger' within a 'shared world'. It follows that Bhabha's (1994) 'untranslatability' can in fact be eroded without dreaming of eternal agreements and postulating a reformist tolerance. I expand on the political and moral nature of the pluralist cosmopolitan space in the following chapter, but for now offer more empirical evidence of the hermeneutic actions, movements and performances of a shifting Self within.

These are the words of Charlotte, another New Zealand born Australian constantly shifting between cultural worlds:

I was born here and left when I was six so I have grown up in Australia so I am just Australian. I keep travelling on an Australian passport that's just that what it is. But to go back and looking in the 'Passports' section on different things, like we were actually the 1980s slump in population in New Zealand is us leaving the country (laughing). And then we looked back and, you know, mom was pointing out 'well that's when your grandfather originally travelled from Australia to New Zealand back in the 1920s or whenever... that's your grandfather arriving in New Zealand in that peak and that one back there is the other side of your family arriving'. So to go in and look at that wall was actually, all right that's here when my great-grandparents arrived... and oh yeah that's when I left the country (laughing). That was an interesting I guess link to your own existence with the history of the culture of the museum. It's not just stuff that was hundred, two hundred, three hundred years ago, all of that it's there, but it's also stuff that was twenty or thirty years ago, which makes it relevant I guess to the younger people and people who are travelling. And they go 'oh yeah, that's relevant to my history and my experience. So that's I guess why I found that area kind of interesting and also looking at the shipping stuff. My Australian heritage is Scottish and so the shipping display and looking at it 'oh yeah wouldn't like to be stuck on a ship for six months in that little space box'... I mean it is about New Zealand's culture but because Australia is so close you can sort of compare the two a little bit, a little bit, not a lot, but a little bit. Yeah, so that's why I found that bit really interesting.

Charlotte's experience of the museological representation of 'traveling cultures' within the particular context of Aotearoa New Zealand's migration history is both humanised and 
'cosmopolitanised' through the "link to your own existence with the history of the culture of the museum". She shifts between the personal, the "I", "my", "your" and "we", as well as the cultural, the "Australian", "New Zealand" and "Scottish". Charlotte stresses that being able to recognise that "the 1980s slump in population in New Zealand is us leaving the country" makes it "relevant to my history and my experience". The exhibit offers the platform for the interpretive negotiation of her "experience" and "history". Consequently, Charlotte's travel and museum experience is no cosmopolitan refashioning of an elitist cultural capital, as the standard overdetermined analysis suggests (Bennett, 2006), but the hermeneutic extension of a profoundly 'cosmopolitanised' life. Interestingly, she concludes by reminding us of both commonalities and differences among the countries she calls home in one way or another. Charlotte refers back in her follow-up interview:

And the other thing was the immigration history display. That was another thing that I guess when I think back to it jumps out on me. And I think I've said to you before that's because I look at that history line and go 'oops, I am part of it, that's when I left New Zealand in the late 70s'.

Jack from Canada is no "part of" New Zealand's "immigration...history line", the mirror of the 'biographical cosmopolitanisation' and 'polygamy of place' (Beck, 2006a) as in Charlotte's case, but he discovers multiple similarities and distinctions due to shared destinies. Furthermore, Jack allows us to return to the emotive dimension of cultural feelings:

I personally find the country extremely comfortable already and I just have been here a few days. I pretty much feel at home, except it's a lot prettier (laughing)...Canadians do feel a tie to the land. Environmental issues are very strong politically in Canada and I can see they are extremely strong in New Zealand, even stronger than in Canada. Just, you know, not being able to get off the ship without being searched by agriculture and import or whoever the inspector is...So in New Zealand that is very strong so we share that appreciation of the land and indigenous culture. Ours is very diverse and I appreciate Māori is diverse but it's almost a nation I guess you could say. In Canada the native population is much more divided but all of them, their whole ethic is around the land, which seems to be very closely to the Mäori beliefs. So we come into the 
environment and that has become a base of our culture as well so we have taken that from the indigenous peoples. We took everything else but learned that (sarcastic laugh). The histories aren't that much different. I think the Māori fare politically better than most of our indigenous peoples except for the Inuit. They are doing very well - thank you. They got beaches with lots of good oil, they will do fine.

Jack's reflection starts with a feeling, to "feel at home", and proceeds with the emotive assertion that "Canadians do feel a tie to the land". He infers that "we share that appreciation of the land and indigenous cultures". At the same time, however, Jack indicates prevalent differences such as ethnic diversities within indigenous populations and their respective political positions in Canada and New Zealand. But overall “the histories aren't that much different”, as he further explains:

But we are also a country of immigrants of many diverse nationalities. The base of course is British and French because we are a bilingual country. But in more recent times, well we should say on the East coast Chinese because they were really there in the early 1800s as well. So we have very diverse cultures that have come in and blended into a society but we are not a melting pot as the United States where it's all about to be American. Whereas in Canada or I think so in New Zealand you don't have to be Canadian or be New Zealander. Your culture is respected, it is part of the whole fabric and it is appreciated and it adds richness. And I have the sense that New Zealand sees itself as a tapestry of cultures. So in that regard yeah that's what I find Canadian about New Zealand. I get a sense for the very same things, appreciation of the land probably derived from indigenous cultures here, which has been added to by many other cultures but you not necessarily lose your identity. There seems contributing and blending into and so you end up with a richer cultural fabric. And that's what I feel I have seen so far in New Zealand, maybe by the end of the tour I will think differently. I certainly feel like it now.

Jack continues his exploration of Self through the Other and detects several aspects that he finds "Canadian about New Zealand". His multifaceted experience attests to the wider framework of this study. By comparing Canadian and New Zealand impressions, Jack draws an interpretive contrast between their "tapestry of cultures" and the "American...melting pot". His hermeneutic negotiation becomes globalised. While each of the interviewees is a citizen of a country, or in fact of countries, their experiences are framed by an inescapable 'globality' or 'world horizon' (Beck, 1997). Induced by an explosion in communicative and transport 'mobilities' (Urry, 2007), 
Clifford (1988, p. 22) is exactly right in highlighting that 'a world of generalised ethnography' in which 'people interpret others, and themselves, in a bewildering diversity of idioms' has become a 'global condition'. Consequently, I speak of 'global visitors' in this study (see also Chapter Two). Although all informants are linked to national places, they inescapably become part of the discursive dynamics of a pluralist cosmopolitan space.

Jack's broader life experience also provides glimpses of the hermeneutic complexity of history making and lends support to this thesis' 'contact perspective' complicating the linear trajectory of 'diffusionist models' (Clifford, 1997). According to Jack, "the base" of Canada "of course is British and French because we are a bilingual country". The post-colonial perpetuation of colonial power relations looks undisputable. However, the Canadian "appreciation of the land probably derived from indigenous cultures". Jack sums up that "we took everything else but learned that". There seems to be a niche for "indigenous cultures" in the shifting sense of "we" after all. As Jack proceeds, it becomes clear that the "value" of "differences" in postcolonial

Canada is no totalised reality but a heterogeneous complex of fragmented 'contact zones':

It's like in Vancouver where English has not been the first language for well over a decade. Mandarin Chinese is the language spoken first by most people who live there not English. And within that the Chinese community is very diverse, mainland Chinese, Taiwanese, the Hong Kongers, and they not necessarily get along. So it's not just that, now we have a huge Indian population, Vietnamese are coming in large numbers. I lived in Victoria for years, very old style and I just got bored with it because it was too, how should I say, white-bred. It's very English tradition. They don't like a lot of outsiders...Just the diversity and the colour and the richness of living in Vancouver wasn't there in Victoria so I couldn't wait to get back. So I find New Zealand seems to be that way, it seems to value differences.

The comparison between Canada and New Zealand resists any monolithic assessment and needs to be regionally qualified. While "the diversity and the colour and the richness of living in Vancouver wasn't there in Victoria", Jack infers that "New Zealand seems to be that way". In his 
follow-up interview, Jack shifts back to the national level to negotiate commonalities, differences and cross-cultural feelings:

There is definitely a link to Canada because actually most of us who go to New Zealand from Canada feel very much at home. Yeah, we share, I sure mentioned at the time, very much a similar culture experience. We had Indigenous peoples, many of them in this country, and we are a country made up of immigrants...I think New Zealand's Māori culture is a more uniform culture for the whole country. Here we have many different Aboriginal peoples.

For Claudia from Canada, the "similarities" equally dominate and manifest themselves as the

"same feeling" in her follow-up interview:

I have noticed a lot of similarities between Canada and New Zealand... I know there is a lot of differences, but as far as having lots of natural landscapes and lush trees everywhere. I mean there is different kinds of trees, but it's still sort of the same feeling...

Claudia leaves the ethnic dimension of the Self/Other relationship behind and explores the natural world connecting the two. She proceeds and shifts back to the "feeling" of "culture" beyond the latter's usual connotation of ethnicity:

I think the culture a little bit as well. I mean I thought that every time you are in a city, like being in Wellington, I can draw a lot of conclusions and similarities between Wellington and Halifax where I am from. Just size-wise, and kind of the feeling, the atmosphere on the streets and overall the sense you get from people. There is a lot of friendliness out there...I hear all things about home being that friendly, but I haven't actually witnessed it. So now being here I can kind of understand why people say that at home...because I am from there I don't see that. You know, I am not there with the tourist eyes. I am not looking for accommodation and so I don't see it. But from what I have heard of from where I am from (laughing) and what I have experienced here, there are a lot of similarities that way as well.... I think you tend to take for granted certain aspects when you live somewhere, which is sad but true.

Claudia's "tourist eyes" serve a dual function. They enable her to absorb the "feeling, the atmosphere on the streets and overall...sense...from people", in short the "friendliness out there". Almost more importantly, the temporary assumption of the "tourist eyes" in the world of the Other allows her to gain a refined perspective of the Self. Claudia can now "kind of understand" 
the "things about home" which remain hidden "because", according to her, "I am from there I don't see that'. Cross-cultural travel encounter and dialogue are again characterised by a shifting sense of Self through the Other, as opposed to a projection of Self on the Other exclusively determined by the discourse as claimed in the tourism literature (E. M. Bruner, 1991; GalaniMoutafi, 2000; Suvantola, 2002). Claudia's interview indicates that facing and interacting with the Other can in fact lead to new insights into the Self reframing the "aspects...you tend to take for granted... when you live somewhere".

To Nicole from Canada, by contrast, the "differences" appear in the foreground of both interest and interpretation. These very "differences", however, are still of a relational nature and make sense only within the 'cosmopolitanised' 'common sphere' caused by the shared phenomenon of colonial clashes and their postcolonial consequences:

I think coming from Canada where we also have Aboriginals I am just interested in the differences between Canadians and New Zealanders and how Aboriginal populations are treated. In Canada Aboriginal populations aren't treated very well, in my opinion. And I have always been interested in Aboriginal rights. So I worked for a research organisation that did research on Aboriginal rights, my dad is an Aboriginal rights lawyer, my aunt is Aboriginal. And so just I think that's probably why...I am not saying by any means it's perfect in New Zealand, but I just think that Aboriginal cultures here like the Māori culture is a lot more visible than it is in Canada. And it's looked upon in a more positive light...I know there is racism and I am not saying that. I just mean in comparison it seems a little bit better.

Nicole's cross-cultural "comparison" and the associated "differences" are framed through the national categories "Canada" and "New Zealand". But due to her personal experiences of working "for a research organisation that did research on Aboriginal rights" as well as having an "Aboriginal rights lawyer" as "dad" and an "Aboriginal...aunt", both Canadian "we" and crosscultural dialogue are humanised and culminate in an "opinion" driven by "interest". The 'cosmopolitanised' 'common sphere' transforms once again into a pluralist cosmopolitan space 
of a political nature, which will be further interrogated in the next chapter. For now, Nicole

provides an empirical example informing her interpretive distinction:

I walked into a store when I first got to New Zealand and somebody was speaking Māori. You would never in Canada walk into a gas station and somebody would be speaking Cree. You would never hear that unless you are on a reserve. And even then like a lot of Aboriginal languages in Canada are becoming extinct. And I am not saying that isn't happening here, but it's just to a lesser extent. And that's why I am just really interested in the whole situation how the Māori and the Non-Māori are living together and how it's a lot different than it's about to be in Canada I guess.

The struggle of "Aboriginal cultures...in Canada" to become "visible" beyond the confinement to "a reserve" is further highlighted by Claudia:

I haven't had a lot of interaction with our indigenous, like we have Native Americans in Canada. And you know I hear stories on the news about what they're going through but I haven't ever actually interacted with them directly. So as far as a native culture goes, I mean this might be really my first really in-depth level of interaction. And I've been enjoying it so that's a good thing.

I concluded the previous section on the journey from bicultural meanings to cross-cultural dialogue with Claudia's experience of "seeing through a little window what someone else's life is like compared to mine". The humanisation of the cultural category "Māori” through a face provoked in her the 'primordial capacity to transpose oneself into the mental life of others' (Ricoeur, 1981, p. 49) and facilitated an interpersonal dialogue among cultural human beings. At home however, Claudia has not "ever actually interacted with them", in other words the indigenous Other within the Canadian Self. The 'tyranny of distance' (Havemann, 1999, p. 8) forces us to coexist on an abstract level without any face to face "interaction". "Stories on the news about what they're going through" remain the only detached avenue to bridge geographical 'separation' with some sense of moral 'proximity'.

Mark from Australia touches on a similar situation and experience in a different part of the world: 
Aborigines in Australia as far as my city is concerned, there really aren't too many of them in Melbourne...I am trying to think whether any went to my school, none that reaches my mind straight away. Like I went to a couple of different high schools and they are very multicultural like have people from all parts of Asia, some Europeans, not really too many Americans, mainly parts of Europe and Asia. But yeah, I don't think that there were any actual Indigenous Australians in my year level. I guess if you were living in central Australia or Northern Territory like Darwin or Alice Springs then you definitely have a lot better contact with them.

Mark continues in this vein and thereby highlights the crucial role of museums to enable "contact", which otherwise does not exist, and humanise "them" as "people telling about their lives":

As far as the Melbourne Museum is concerned, it definitely has an indigenous area which is like Te Papa... I remember as I was walking through here they had those screens which had Māori people telling about their lives briefly and go from like one to the next. And I do remember they have that very similar if not identical at Melbourne Museum with Australian Aborigines.

In his follow-up interview, Mark embarks on a sort of double cross-cultural reflection, contrasting Australian Self with New Zealand Other based on the respective "treating" of indigenous Others:

I mean like the story of the Europeans coming over and treating the Māori as they did is quite similar to how they did with the Aborigines in Australia. I am not quite sure if the timeline was similar, but yeah it was very similar to how Aborigines were treated. And yeah it's basically like it's the same today as far as how both are respected as they are. Except like I don't know, have the New Zealand people done their apology to the indigenous people?! - the apology that Kevin Rudd issued about a year ago, that one was just for the 'stolen generation', which seemed to make massive news around the world.

To Mark, the "story of the Europeans coming over and treating the Māori" and "the Aborigines... as they did is quite similar" while "it's the same today as far as how both are respected as they are". He cites the Australian government's official "apology to the indigenous people" as a recent and significant example of the apparent progress. 
Charlotte from Australia, however, develops a different conclusion throughout her examination of Self through the Other:

It was interesting to look at, I guess from an Australian perspective, the different cultural stuff because the indigenous culture in Australia is not as included in mainstream culture. Or anything that is, is either derogatory or it's glossed over the negative aspects of how Europeans came to Australia.

Charlotte approaches New Zealand's “different cultural stuff...from an Australian perspective”.

In her clearly critical view, "indigenous culture in Australia is not as included" and its limited representations are either "derogatory" or "glossed over the negative aspects".

Mike lends support to this perspective and draws an equally critical picture of the Australian Self after confronting the New Zealand Other:

I would make one comment about this country. And it's because our country is wrecked with racial divide with Aboriginals and with other people after the last twelve years of, you know, conservative government where they promoted that difference of people rather than the commonality of people. Here it seems to be a little bit more of a relaxed and comfortable feel of different races working together.

Mike contrasts "the racial divide" in Australia caused by a conservative political agenda which "promoted that difference of people rather than the commonality of people" with "a little bit more of a relaxed and comfortable feel of different races working together" in New Zealand. He continues with particular experiences that evoked such cross-cultural feeling:

Māori are no different to anyone else. They appear to be having exactly the same jobs as everybody else. Whereas I said earlier in the interview, my coloured view of Māori in Australia is they are taking the worst paid jobs and the heaviest labor because they are the toughest people there are. Whereas here it's clear that this is a much more integrated society and there is a lot more of them percentage-wise. So therefore it seems to me when I go to bars or places, there is just a relaxed mix of people in this country. But whether I know that to be true or not is impossible to tell until you move outside or away from the privileged places that you come as a tourist. It just has that feeling that it works. 
Earlier in this chapter, I interrogated Mike's "coloured view of Māori in Australia" as stereotype and 'doxic belief'. It attests to the ambivalence of 'traveling cultures' in a 'cosmopolitanised' world that Mike needs to leave Australia's shores to reframe established understandings and dissolve former acts of 'underreading'. In other words, the "Māori in Australia" appear now in a New Zealand light. Mike stresses that to "know" the perceived "relaxed mix of people...to be true or not is impossible to tell until you move outside...the privileged places that you come as a tourist". He cannot help, however, developing a cross-cultural "feeling" and embedding it in the inescapable 'globality' or 'world horizon':

I mean we were in South Africa earlier this year on another holiday and I get the feeling it still doesn't work. It's just a feeling. I don't know the true position of any of the things in particular. But even though blacks are running South Africa it's a really uneasy country. These people are not - even after fifteen years of supposedly working together - they aren't together at all. Whereas it seems New Zealand, now that I understand the length of the history and how it all evolved, maybe they got more chance to treat each other better I have seen elsewhere?!

The "true position" is, of course, always context-dependent and hermeneutically relative. As I have argued throughout this thesis, any act of interpretation is subject to an endemic polysemy. At the same time, nothing ever exists in isolation so 'the world is composed of things connected together by myriad interrelated webs of meaning' (Hennes, 2002, p. 114).

While Julia, a New Zealand born Australian, naturally assumes a different perspective, she is nevertheless able to share Mike's "feeling that it works":

I think it really makes New Zealand special...there are issues and there have been big issues between Māori and Pakeha over the years and still with gangs I believe and all that sort of stuff. But it seems that New Zealand has got it working well. Other countries from what I feel don't have the same (paused), I don't know, understanding or acceptance of their (paused) Aboriginals, for want of another word, as New Zealanders have. I mean the language is taught I believe from infants even though Māori is not spoken outside of New Zealand. It's been included and it gives Pakeha a better 
understanding of the other culture that is an integral part of New Zealand I guess. You know, and I don't know that other countries do that...it's just my feeling on it.

To Julia, it also "seems that New Zealand has got it working well" whereas "other countries...don't have the same...understanding or acceptance of their Aboriginals" or cultural Others. Thanks to the inclusion of the Māori language, which was not the case in her childhood as we have seen before, "the other culture" becomes "an integral part of New Zealand" supporting the 'both/and logic of inclusive differentiation' (Beck, 2006b, pp. 4-5) in an inherently 'cosmopolitanised' society. Importantly, Julia's "feeling on it" does not sanitise her awareness of "big issues between Māori and Pakeha over the years" up until today.

Bruce from the US dissects such "big issue[s]" in a particular context and offers another interpretive layer of a cross-cultural hermeneutics and the shifting Self:

We didn't go back to re-read the contract because Maria and I are both lawyers and we feel we just end up arguing about what the contract had and didn't have and who had rights under it. And I think we got the important part which was that the Mäori contract was different than the English contract, which happens a lot in my line of work.

Bruce embarks on his exploration of the Other not on a cultural or ethnic level, but instead shifts the interpretive negotiation to the personal or professional dimension. The "contract" becomes the entry point into 'cross-cultural conversations' based on 'things that are shared by those who are in the conversation' (Appiah, 2006, p. 97). This creates the 'common sphere' needed to shape dialogue across differences into potential understanding. The "contract" triggers a "cosmopolitan curiosity' (Appiah, 2006) which is complicated by the fact that Bruce and "Maria...feel we just end up arguing”. It becomes clear that we do not need to move beyond our cultural Self to disagree with an Other but instead constantly face and battle with 'oneself as another' (Ricoeur, 1992) within our own cultural world. Bruce further elaborates on his "line of work": 
As a lawyer I work with hedge funds, primarily ones overseas at this point. While a lot of them are British, there are a couple, you know, in South America, a few in China and other countries with languages I don't speak. So there is always the question of how these things translate. There are some clients that insist on having documents in two languages and one of the fights we always have is 'you have to do it in one'. Because otherwise it's really cute to have some of the disclosure documents for somebody in their local language and you end up with different information for one person than you give to another, just because of the connotation of words which is unavoidable. And so there is always this question. I mean obviously when you do it at the time we would like to think that everybody does this because it's just the way words are and it's just the way translations are. But, you know, almost always it gets into court or it gets into any sort of argument and it's a question of sharp dealing.

While the Treaty of Waitangi is a particular legal arrangement or "contract" created in New Zealand, the associated 'force of mutual promise' (Arendt, 1958, p. 245) and its delicate ambiguity in cross-cultural contexts has in fact a global reach and history. Given the 'mélange principle' of interpenetrating, interconnecting and intermingling cultures (Beck, 2006a), the "question of how these things translate" is paramount and begs for its resolution in a "Third Space'. Due to the hermeneutic complexity, "any sort of argument" erupts while the moral imperfection of human beings raises the "question of sharp dealing", as Bruce further infers: And it seems like the Māori-English contract was an issue of sharp dealing. Although I mean I think it would be a perfectly reasonable argument to say that the English were fitting into their discourse community, and this is how the English understood how property and land works. And the Mäori were bringing in their framework or their narrative of how the world fits together.

Although Bruce suspects an "issue of sharp dealing" in the case of the "Māori-English contract", "it would be a perfectly reasonable argument to say that" the complications are the outcome of the clash of one "discourse community" with another "framework or...narrative of how the worlds fits together". Bruce added after revising the interview transcription that "where those two don't meet, you get problems not only with linguistic but also with cultural translation. At that point misinterpretation is inevitable" disturbing an 'experiment in cross-cultural translation' (Clifford, 1988, p. 8). Bruce's hermeneutic engagement creates now a cosmopolitan space 
spanning the "contract" and his "line of work". The fact that he and "Maria...think very

differently about how contracts work" attests to a 'human plurality' as 'the basic condition of

both action and speech' (Arendt, 1958, p. 175) and epitomises the inescapability of a pluralist

cosmopolitan space. Its continuous negotiation appears in Bruce's follow-up interview:

I remember thinking about the contract because I am a lawyer and a geek that way. I

remember thinking of the contract between the Western immigrants and the Mãori. It's up on the wall. I guess I still think about that from time to time in terms of, you know, uneven bargaining power. And I think I actually made some sort of analogy to it to a client, trying to explain why we do things in certain ways to sort of equalise bargaining power and make sure that everybody is in the same place... Yeah, I mean it's a good touchstone. I don't think it's a unique instance, but it's certainly something that is easy to explain to others as sort of an example of uneven bargaining or unfair bargaining power. So I think I have spoken to at least a few clients about it as sort of an analogy for something that they were putting in one of their documents...

The "contract" has entered Bruce's memory and lives on in his thoughts and professional life. He "actually made some sort of analogy to it to a client" when facing a distinct but still similar outlook of an "uneven bargaining power". Due to the latter's primordial status in human affairs, the Treaty is in fact no "unique instance" but "a good touchstone" to enable the 'translation' of difference within a shared symbolic context. According to Bruce, "the American culture is rife with the same sort of story". He carries on to conclude with the fundamental condition of a pluralist cosmopolitan space built on both differences and commonalities through "different viewpoints on the same thing":

I mean now whenever I think about it I sort of think of the pillars that stand in front of the contract with everybody, I can't remember what was in the pillars, I think it was sort of relating the experience that people had around that time. I guess I think of that it's sort of a way of visualising the disparate experiences that people have with the same stimulus. Like everybody saw the same contract but because of the way language worked or the way people were brought up with their belief systems you see it in different ways and there are different viewpoints on the same thing.

The "experiences" of "people" brings us back to the humanisation of culture and cross-cultural dialogue. Given the length and depth of my argument, I fully support Appiah's (2006, p. 113) 
stance that 'a tenable cosmopolitanism tempers a respect for difference with a respect for actual human beings'. Only by personalising culture through faces and stories can we bridge the chasms of ethnic 'separation' with human 'proximity'. By acknowledging our shifting sense of Self as well as the associated multiple both/and identifications and endemic relativity of otherness, we discover that differences are no cultural prerogative but the very human condition. In other words, abstract cultural divisions can be eroded, but without ever being completely safe.

\section{Summary}

In this chapter, the conditions merged with the processes of meaning-making during crosscultural engagements. The research material exposed the entry of the emotive trajectory into the realm of culture, manifesting itself as an "inclusive feel" in the case of Julia. The first stage of the cross-cultural voyage constructed bicultural meanings and originated in the 'reader's world', their own interpretive environment framing the experience of other cultural worlds. Jack's sense of "Canadianism" that "felt Canadian in many ways" offered empirical support for this assertion. The critical hermeneutic approach in this thesis detected the partly 'doxic' shading of discursive lenses reducing cultural complexity to stereotypical simplicity. In Bruce's case, the foundation of his interpretive community not only affected but prevented the engagement with the cultural 'Other' culminating in the "feel of imperialism" of an "outsider".

The narrative journey from bicultural meanings to cross-cultural dialogue enabled the interviewees to leave the 'reader's world' behind. Different interpretive avenues such as selfrepresentation, the reframing of understandings and tour intervention translated a 'contact zone' of physical encounter into a dialogical 'Third Space'. The tour host's mediation through the self- 
representation from an 'emic perspective' (Mieri, 2010) helped Bruce to engage with a foreign cultural universe after his initial reluctance. The empirical evidence highlighted that the humanisation of culture and Other served a dual function. On the one hand, it complied with the conditions of meaning-making by providing the means to feel and sense culture beyond the detached reasoning of abstract cultural categories. Mike stressed that "it made sense when you saw their faces and their pictures" in the exhibition, otherwise "it doesn't mean anything". On the other hand, the deconstruction of cross-cultural dialogue as interpersonal dialogue among cultural human beings created what I term a pluralist space as basis for the political and moral engagement with a humanised Other.

The respondents' interpretive voyage led to a cross-cultural hermeneutics. Julia's comment that "it is interesting seeing it and being here through Australian eyes...now instead of Kiwi eyes" embodied the interpretive ontological endeavour of what I call the shifting Self in the contemporary world. The associated multiple identifications emphasised the relativity of otherness and shaped what I term a pluralist cosmopolitan space. This discursive terrain represents the 'common sphere' that potentially transforms dialogue and translation into understandings. Its frame of reference is characterised by the simultaneous presence of a 'cosmopolitanised' horizon and the humanisation of culture through 'stories' and 'faces'.

I conclude this chapter with Michelle, who states that: "learning about culture to me is one of the really basic activities that I like to do, see a museum in different countries so that you can appreciate how they are different and just kind of expanding your ideas of what each culture brings". The appreciation of difference, in fact, goes hand in hand with the expansion of ideas. In 
the following chapter, the pluralist cosmopolitan space is morally and politically expressed, negotiated and contested. It should be no surprise that a persistent emphasis on the emotive dimension moves into the realm of political discourse and identity politics. 


\section{Chapter Five}

\section{Te Papa: a forum?}

\section{Introduction}

Each age and society re-creates its 'Others'. Far from a static thing then, identity of self or of 'other' is a much worked-over historical, social, intellectual, and political process that takes place as a contest involving individuals and institutions in all societies. (Said, 2003, p. 332) (my emphasis)

In the course of the previous two chapters, I interrogated the conditions and processes of meaning-making. Visitors' cross-cultural journeys from bicultural meanings to cross-cultural dialogue and the shifting sense of Self created a discursive terrain which I called a pluralist cosmopolitan space. This space facilitated the interpretive negotiation of differences leading to potential understandings. In this chapter, the cross-cultural hermeneutics evolves into an 'interpretive contest' (Said, 2003) of political and moral identifications that addresses the overarching question of this thesis - Te Papa: a forum for the world?

In the first section, 'Self-reflexivity, Self-critique and Self-transformation', I present an extension of the shifting Self nurtured by a growing sense of self-awareness and reflexivity. The respondents' interpretive ontological endeavour develops into a 'Self-ethnography' (Boomers, 2004) which converts the partly unconscious 'cosmopolitanisation' of Self/Other relationships into a 'politically ambivalent, reflexive outlook' (Beck, 2006a, p. 8). In the process, the endemic relativity of otherness is further intensified and highlighted. This heightened Self-reflexivity 
emerging from the research material offers moments of critique and traces of transformation which politicise and moralise the pluralist cosmopolitan space.

Throughout the second section, 'Political opinions and moral demands', the pluralist cosmopolitan space culminates in politically and morally contested interpretive instances of a forum. My humanised approach to the public sphere delivers empirical evidence of 'cultural action' in the form of hermeneutic movements and performances. The findings highlight the ubiquitous presence of the emotive dimension within the entire lived experience and therefore in any human situation: from sensory perception to the articulation or 'enunciation' of political opinions and moral demands. I continue to humanise 'Te Papa' as a forum through the stories and faces of political and moral actors in ways which erode the abstract totality 'public opinion' that, in Arendt's (2006, p. 218) words, 'kills true opinions everywhere'.

In the last section, 'Intersubjectivity?', I contrast the preceding narrative exploration of Te Papa as a global public sphere with an attempt to theorise the 'forum' concept gained from focus groups and expert interviews. Based on the discussions of a forum as physical meeting place and/or discursive dialogue, I interrogate various avenues in museum theory and practice which transform the hermeneutic 'common sphere' into an active 'intersubjectivity' (Habermas, 1999) as the lifeblood of a truly democratic enterprise. In this context, I argue that the 'museum forum' can help to achieve 'performative democracy, for the first time in history' (Weibel \& Latour, 2007, p. 107). 


\section{Self-reflexivity, Self-critique and Self-transformation}

At one point I was walking through the museum (paused) and I thought: what would the world be like without the white adventurer? What would the world be like without the white man traveling off to all these foreign countries? What would the world be like? And I remember sitting there and I didn't want to think about it for too long because I wasn't sure if I wanted to know the answer. (Susan)

I chose to begin this section with a quote from the interview with Susan since it sets the scene nicely for the subsequent discussion. We can observe very clearly her narrated reflexivity spurred by the Te Papa visit. The latter provokes a range of questions and, quite remarkably, Susan hesitates with their exploration since she "wasn't sure if [she] wanted to know the answer". While her interpretive reflexivity is beyond doubt, we can only speculate at this stage whether it evolves into 'moments' of critique and 'processes' of transformation. The following empirical evidence substantiates such an assumption and offers more insights into the hermeneutic complexities and dynamics of the Self.

The clear focus of this thesis is on 'cultural action' or worldmaking through the act of interpretation. In order to facilitate the transition of the shifting Self to the reflexive Self, however, it makes sense to first turn to Claudia's experience of a non-human Other:

...something in this vein where it talks about Mother Nature, there is something about the intrinsic factors (paused). I guess it removes you from being human in a way, you think about what else is out there. Because we tend to be really egocentric as a species and think about how we perceive things and feel things and it's really easy to assume that (paused), I don't know, other species are supposed to have the same thought processes.

Similar to Susan's pondering on "what would the world be like", Claudia indicates that the museum visit made her "think about what else is out there". To her, "Mother Nature" assumes the role of the Other. This 'situational self-positioning' (Kraus, 2006) leads to a form of reflexivity which, according to Claudia, even "removes you from being human in a way". Importantly, her 
shifting sense of Self is accompanied by a moment of reflexivity and critique of the human "we" as an "egocentric...species". Claudia continues and concretises her reasoning with a particular "experience":

I had an experience... I worked on a farm during the two months I have been here. And one of the exhibits there is where you can see life through the sheep's eyes. They must have had a camera, a sheep cam. And I was pushing the buttons and it actually upset me because I have worked with some sheep. It was my first experience on a farm and it's so easy to evoke terror in sheep, it's just their nature. And they had been clipping the tails of the lambs for hygienic purposes and I had to mark their ear. And it really upset me, like I had this crashing emotions and soul wrenching tears and it just really got to me. Because as a human we tend to think we can control and conquer the planet, make it run how we want. We are just one little piece of this planet. So when I am up there looking at that exhibit, there was one with the dog, crazy dog or barking dog, and I can totally visualise what those sheep were going through when the dogs were chasing them and they are scared to death.

In the previous chapter, Claudia concluded her humanised cross-cultural dialogue with the experience of "seeing through a little window what someone else's life is like compared to mine". She hermeneutically achieved what Dilthey (1976, p. 226) considers as the 'highest form of understanding', the 're-creating or re-living... on the basis of empathy or transposition'. As the above narration shows, the 'primordial capacity to transpose oneself into the mental life of others' (Ricoeur, 1981, p. 49) is not confined to the inter-human sphere but enables Claudia to "totally visualise what those sheep were going through". Her emphatic "crashing emotions" lead to a reflexive critique of the self-deluding "human" representing "just one little piece of this planet" as opposed to the pompous self-concept. Being able to "see life through the sheep's eyes" is, in Claudia's view, the form of reflexive remedy a museum experience can and should offer:

I guess when you come to a museum that exhibits this type of thing, if you are open to it, you can get outside of the human thought processes and just see that these other things existed (paused). I know we can't really comprehend how they feel and think and process, and if they do it at all!? I am sure they do it on some level. So for me that's I guess the sign of a good museum exhibit or a good museum is when I go in and it removes me from the constant thinking that always runs around in a human's mind as in a little hamster ball. And you are always focused on what you are feeling or what you wanna do 
next or what has been going on in your life, in your day. It just gives you a chance to experience other things, think of other things, learn about the world and not be so selffocused.

Based on her emotive experience and critical reasoning, Claudia asserts that "the sign of a good museum exhibit" is the empathetic and trans-positional characteristics which enable audiences to "get outside of the human thought processes" and "experience other things" instead of remaining "so self-focused". In other words, Claudia demands exhibitionary strategies that lay the hermeneutic foundation for the 'highest form of understanding'. The impact of such "a different way of looking" on meaning and memory becomes evident in the follow-up interview:

I think I remember bringing this one up as well as a last thought of our last interview. There was one exhibit where you could see through a sheep's eyes. And I had worked on a farm while I was in New Zealand and worked with the sheep. So that kind of gave me a different way of looking at what the sheep went through. So that brought up another memory or experience of being in New Zealand as well.

Claudia lends further weight to the significance of senses, feelings and embodiment as conditions of meaning-making flowing into the reflexive processes of meaning-making. She seems to prioritise the visual sense of "looking", but by experiencing "what the sheep went through" Claudia actually refers to an "internal understanding" or 'embodied meaning' (Johnson, 2007) which cannot be exhausted by a single sense or linguistic expression. As I concluded in Chapter Three: being means feeling, understanding and interpreting.

By turning to Bruce from the USA, we can observe that the interplay of feeling, understanding and interpreting flows through Self-reflexivity into the realm of human culture. Bruce narrates his experience of a traditional marae or communal meeting house at Te Papa:

We took off our shoes and walked into the little house and kind of looked at all that. It always amazes me how cultures retain information. I mean writing is a really cool thing but it takes a lot of being able to stay in one place and have a fairly complex society for it so it pops up...the sort of non-character ways of retaining information that the hut 
embodies, you know, that the pylons are the ancestors and by looking at them you can recall your history, I mean it's an interesting memory device. I suppose in computer terms it's a very lossy way of doing things losing information over time, but it keeps at least the highlights for you and it keeps them really present. I guess one of the things that came up while I was looking at those structures was that these are very connected societies that have a very close connection to predecessors and to the community.

In Chapter Three, I showed that senses, feelings, imagination, thought and understanding are not separate stages but interrelated, interdependent and overlapping dimensions of the conditions and processes of meaning-making. Bruce's own experience of the exhibition space, which is reminiscent of Greenblatt's (1991) idea of 'resonance and wonder', provides more evidence supporting such a claim. Note how his interpretive engagement gains a reflexive and critical quality while he further elaborates:

You are sort of necessarily in the community because one you are small and two because you have been a sort of commonality that we don't really have anymore...it's my understanding that this building would be used quite a bit for the community purposes and you would always be exposed to history at all times. Whereas when I think about now, think about even my home, I mean it's furniture, it's flat walls and if you stop and look at them you can say okay, that was carved in the 1860s when the brownstone was built and, you know, it's oak and we know a little bit of the process. But it doesn't really have any, it's syntactic, it's not symbolic. I mean it's a 'there', it's not a 'what', whereas the columns it's all what, it's information in itself, it's not a syntactic device. I mean the idea is that you are always exposed to it so you are always in a society where the past is present because your ancestors are there and your connections to everybody around you is sort of there. Whereas, you know, we live in a much more alienated society now where I may have a picture, I think I have a picture somewhere of my grandparents in the apartment, but it's not present. I mean the name 'Sony' is probably more present than the names of any of my parents. And I guess that is what occurred to me when I was looking at the building.

Bruce reflects on Self through Other each exemplified by the apparent characteristics of "syntactic" versus "symbolic". Based on his general interest of "how cultures retain information", he engages with the Other leading to a heightened sense of Self-reflexivity inspecting his own cultural world. Bruce's reflexive cross-cultural encounter culminates in the Self-critique of "a much more alienated society" where, according to him, the "name 'Sony' is probably more 
present than the names of any of my parents" and therefore more present than culture and history itself. This is the interpretive 'moment' when exoticism, the pure and plain interest in the cultural Other, embarks on a reflexive trajectory and evolves into a 'Self-ethnography' (Boomers, 2004), the hermeneutic dissection of the Self. In other words, the partly unconscious shifting Self transforms into a conscious reflexive Self. Bruce's follow-up interview shows that this reflexivity flows from experience to memory and enters the related context of language within the discursive cosmopolitan space of commonalities and differences:

I remember when I was there thinking that it's like current American culture because there is a lot of places in the United States like Manhattan or Detroit or Michigan or Connecticut, the names all come from native American names. And New Zealand was sort of similar. I mean there are names that are clearly Western like Queenstown that obviously come from immigrants. But then right next to it is like Wanaka that are Māori names and there is a lot of Mãori culture. There is a lot more connectedness I think between the two because almost everywhere we went everyone referred to not only the sort of Western name like 'this is the swamp hen' but this is also 'pukeko'.

Bruce's hermeneutic negotiation of "similar" cultural situations which differ in "connectedness" peaks again in reflexive critique:

And everyone gives you the sort of two names whereas here in the United States people have more or less forgotten most of the Indian names for things. I mean there are Indian names on some towns and vocations and whatever, but people generally don't remember where they came from and the stories about them are all kind of dead. Whereas when we first got to Wanaka we went on a tour and there was a gentleman who appeared to be of Màori descent who was driving the bus we were in who could tell us the story about every bump on the horizon and every island in the ocean. I think this is kind of lucky. We sort of lost that in the United States. We don't really remember what the stories are about the land. We just have the land and some of the names which are sort of devoid of meaning.

In the process of reflexive interpretive engagement with the Other, Bruce shifts his sense of Self to the cultural level, the US American "we". He clearly laments the loss of indigenous heritage which reduces cultural "stories" to "names...devoid of meaning". Bruce continues by pondering 
about languages in contemporary life and refers back to his experiences of museological representations:

I mean I have no idea about the stats, but as I understand it the Māori language for a while was stamped out but is starting to come back. And there are some schools which teach it whereas most Indian languages as far as I know in the United States are dead and survive mostly in books. A few people pass them on but they are not primary languages for anybody... I think I mentioned this when I was there, I mean the museum exhibits in the United States tend to be a lot more dead...like I was saying the Native American Indian culture is not really a living culture and so the representation of it they are coming more from the outside than from the inside. It just seems more objectified, not as alive, which was something I appreciated particularly about Te Papa, the sort of structure of, you know, one side being the Western side and the other side being the side presented and controlled by the Māori culture.

At this point, Bruce's Self-reflexivity and Self-critique is nurtured by a 'doxic belief' (Ricoeur, 1992), a phenomenon which I discussed in more detail in Chapter Four. According to him, "most Indian languages... are dead" and "Native American Indian culture is not really a living culture". But Bruce, by stating that "as far as I know", seems to limit his perspective and consequently offers the potential of reframing understandings. While Native American cultures have struggled to re-emerge from "books" to life in US American "cultural understanding" or "conventional wisdom", recent museological developments such as the National Museum of the American Indian produce 'counter-narratives' (Andrews, 2002) which are more “alive” and less "objectified".

Fellow American John, however, lists further examples of a lack of "connectedness" in the US American socio-cultural and political context compared to the New Zealand Other:

The American Indians are not nearly as integrated in America society as Māori are integrated in New Zealand society. And I know obviously they aren't 100\% integrated. There was talk when we were there during the election about having better Māori representation, but they are far more part of the government than American Indians are in the United States. 
John appreciates the opportunity to "see a Native group that has become integrated with the society". He goes on and it is obvious that once again a cultural meaning evolves as a cultural feeling:

I think seeing the Mäori culture is something that makes us feel that really was New Zealand because that was different than other places... I think the neat thing for us about New Zealand was that it was not hard to find Indigenous people. They were around in all kinds of offices and they were available. They gave tours and things like that whereas except in Alaska and Mexico I think that mostly we hadn't been that conscious of the Indigenous versus the current residents.

The 'tyranny of distance' (Havemann, 1999) in the USA causes a geographical 'separation' at the expense of human 'proximity' keeping the cultural category "American Indian" on an abstract rather than inter-personal level, as I showed in the previous chapter. While "Māori culture...makes" John "feel that really was New Zealand", he "hadn't been that conscious of the Indigenous" in his home environment. The former is tangibly humanised and becomes "available" as cultural face in "offices" and "tours", the latter instead remains hidden from face to face interactions and therefore from any reflexive engagement.

Similar to John, Bruce states that "not that I have ever dealt with Indigenous Americans". And Susan's experience further attests to the interplay of geographical and cross-cultural 'distance': Okay, I have lived in the United States for twenty-three years and in 2006 I worked on the elections and I was helping a Congressman get re-elected. And at the time I was twentyone and it was my first time ever stepping foot onto an Indian reservation, ever, all right!? As in Australia we don't really talk about it. They are out west, they are out in the south-west, they are there.

It took Susan "twenty-one" years to personally visit an "Indian reservation". According to her, the Indigenous Other disappears on the horizon of cultural awareness: we are here and "they are there". The geographical 'tyranny of distance' has obvious dialogical repercussions. "We don't 
really talk about it", Susan says, and highlights the seemingly identical situation in Australia.

Visiting New Zealand further amplifies her 'cosmopolitanised' reflections:

And you come to New Zealand and I have not taken any of the traditional tours...I haven't gone out and experienced the Māori experience. And yet I have learned so much about it I feel like I have. Just especially by walking into this museum and you look 'ah it's in two different languages'. It's ridiculous, it's stunning, it's stunning. And in that regard it's different. Like in the United States, we kind of did some bad stuff, we broke a lot of treaties, we've got the 'trail of tears' going on to most of our places. It's a really bad part of history. We are trying to sweep it under the rug.

The bilingual self-representation at Te Papa, which I discussed in the preceding chapter as one avenue from bicultural meanings to cross-cultural dialogue, alerts Susan to a "different" national context of postcolonial negotiations. Her experience of the cultural Other "New Zealand" leads to a critical reflexivity on the Self, "the United States...we". While the former embodies linguistically its bicultural nature, the latter has "a really bad part of history" and is "trying to sweep it under the rug".

In his follow-up interview, Jack moves the issue of cultural "consciousness" from the American

to the Canadian national sphere:

It's a similar experience but ours is more diverse but not as strong in the public consciousness probably as the Māori experience in New Zealand. So the Māori element of New Zealand's culture today I think comes out much stronger than Aboriginal culture in Canada does other than for a few select tribes. So in the museum I think it's presented correctly for New Zealand. It's a very significant part of the New Zealand culture today. Here we tend to, it's not so much in the public consciousness, it really isn't...I think even before one goes to New Zealand one is very conscious of the Māori as very much a living culture, very much integrated into the social structure. One just knows that. I had been to Waitangi itself before I went to Te Papa. So I sort of encountered you know those elements beforehand. But it was also what I expected in New Zealand too.

In his initial interview, Jack associated a "Canadianism" or "Canadian feel” with both Aotearoa

New Zealand in general and Te Papa in particular (see Chapter Four). It now seems that the longterm reflexivity within the discursive cosmopolitan space has led to a heightened awareness of 
differences with a "similar experience". While Jack was even "very conscious of the Māori as very much a living culture...integrated into the social structure" before arriving on New Zealand's shores, he points out that "Aboriginal culture in Canada" is "not as strong in the public consciousness". To put it differently, the prior "Canadian feel" based on commonalities is renegotiated through a cosmopolitan reflexivity unearthing prevalent differences in cultural "consciousness". This dynamic and ambivalent hermeneutic revision reflects the "endemic fluidity of meaning' (Bauman, 1978, p. 229).

Andrew, also from Canada, offers more insights into the interpretive reflections of a shifting Self which manoeuvres cross-cultural encounters in museum spaces and exhibition settings:

...in Canada our Indian cultures are so different and they seem to focus on one or two of them. And I think here I got a better overview of what happened in New Zealand so I do think this one does a better job in giving an overview of all of them. And even though you said there is a two-and-a-half year cycle for one specific Iwi there was still a good overview of the way the culture existed throughout the island. And we haven't managed to accomplish that in Canada yet.

In the space of one sentence articulating "Indian cultures...in Canada", Andrew shifts from an including "our" to an excluding "them". This mirrors the ubiquitous presence of the Other within the Self. Andrew's discursive positioning leads to a 'moment' of critique since, according to him, "we haven't managed to accomplish that in Canada yet" in comparison to the museological representation of Indigenous groups in New Zealand. He further reflects on this point in his follow-up interview:

...the one with the European settlement in this country because the link is there are so many things in common. The fact that we do our Robbie Burns supper and you refer to the Robbie Burns supper. The Irish in Canada do the same thing. I think they celebrate St. Patrick's Day here more than they do at home. And you refer to similar ones there. So for me that are the connections and similarities between New Zealand and Canada. We have not treated our Aboriginal people in Canada at all well nor have we restored their culture nor do we brag about it as well as you have done in that museum. There are 
efforts being made in Canada right now. And I am bringing a group of visitors in this year and we are going out to Blackfoot Crossing, which is a fairly new museum established to sort of salute the Western Canadian native heritage. And they do a fine job there, but I do think what you have done in your museum there is outstanding.

In the previous chapter, we witnessed Andrew's cross-cultural journey characterised by a shifting sense of Self and the corresponding relativity of otherness. As in the case of Jack, Andrew develops in the long-term over a period of six months a critical stance beyond the purely interpretive nature of a cross-cultural hermeneutics. While he still elaborates on "the connections and similarities between New Zealand and Canada", he makes also clear that "we have not treated our Aboriginal people in Canada at all well". In other words, the cosmopolitan space of hermeneutic negotiation becomes critically contested and political.

Fellow Canadian Nicole delivers more evidence of the dynamic interplay between the interpretive and the political, which springs off a particular cross-cultural experience:

...for example we were in Rotorua at Te Puia where they had the wood carving school and just that it was celebrated and really visible and people were encouraged to watch this taking place. And it wasn't treated as like something that was tokenistic...I kind of think in Canada if there is anything, I shouldn't generalise but it just seems to me that when there is something, like when there is a Powwow for example, it's very tokenistic. Like a Powwow happens when the Queen is here or white people are meant to see Aboriginal culture. I just find that it's really, if I was Aboriginal I would be mad because, you know, the Queen comes and 'oh let's have a hoop dance.' And then that's about the visibility of Aboriginal culture in Canada. Whereas here it's like a woodworking shop and people can just wander in and out. And it's celebrated, but it's not used as anything other than what it is. You know what I mean?! I think in Canada a lot of times Aboriginal culture is used when we, when the white person wants it to be used to show some form of culture, but other than that you just kick these people to the curb... those Aboriginals, you know, like that attitude, that mentality. Ah (sighing), I get angry about it.

Once again the experience of a cultural Other leads to a reflexive critique of the cultural Self.

Nicole contrasts the seemingly "celebrated" and "visible" status of Māori culture in the "wood carving school...Te Puia" with the "tokenistic...visibility of Aboriginal culture in Canada". For 
Nicole, the "attitude" and "mentality" of the "white person", or "we", towards "those Aboriginals" within the Canadian Self becomes tense and unbearable. The 'balancing act' (J. Bruner, 2002) between cultural conventions and individual identity erupts as a rebellious act of contestation. Nicole asserts that "if I was Aboriginal I would be mad" and sums up that "I get angry about it". The intensity of her articulations carries the emotive dimension into the realm of cultural identity politics and further highlights its ontological inevitability. To put it differently, being means feeling, understanding, interpreting and contesting. I return to this crucial point in more detail in the next section on 'Political opinions and moral demands'.

Charlotte allows us to switch to the Australian context and provides insights into the complex hermeneutic dynamics of a 'biographical cosmopolitanisation' (Beck, 2006a). As a New Zealand born Australian, Charlotte is used to a life 'in-between' differing, relational and overlapping worlds. Beck (1997) refers to this as 'polygamy of place' which requires the constant 'inner mobility' of a shifting Self:

... just within New Zealand looking at the culture that inclusion again where most of the places you go the signs are in both languages...again comparing to Australian culture there is not always a lot of (paused) people of indigenous origin involved in business and shops. Whereas in New Zealand you walk into a shop and it's not unusual to be served by a person who is a Màori culture or some other culture. Whereas in Australia just about everybody who serves you in a shop is white.

Charlotte's previously constructed meaning of bicultural "inclusion” (see Chapter Four) builds the interpretive basis for the subsequent reflexive interrogation of the Australian Self through the New Zealand Other. In her case, the "comparing to Australian culture" is no detached observation and analysis, but a 'cosmopolitanised' 'balancing act' embodied in her own biography and "family": 
...it really didn't faze me. I just sort of, yeah, do the business culturally in my family. My older brother actually looks more like a Māori/Pacific Islander than he does anything else so for me it's not unusual to see that, be served or interact with a person of that visual experience. But yeah, in Australia it actually is unusual. So in New Zealand when that happens to me it's just like 'yeah okay, next'. When that happens in Australia you sort of remember it as an event...I see that as part of that intermeshing of the cultures. I think the first person we spoke to, ah well no apart from customs and stuff, but the first person we spoke to when we got into Wellington was a Màori guy at one of the information booths or something downtown where we were trying to find somewhere.

In New Zealand, the "intermeshing of the cultures" reaches into Charlotte's "family".

Consequently, it "didn't faze" her and is "not unusual" to "interact with a person" of a different cultural origin. In other words, the cultural Other evolves from an 'abstract category' (Bauman, 1989, p. 188) into a person and is humanised through a face with a story. Cross-cultural dialogue evolves into an interpersonal dialogue among cultural human beings and paves the way from stereotyping and metaphysical reasoning to moral and political engagement (see Chapter Four). In Australia instead, such a face to face encounter "is unusual" so you "remember it as an event" rather than a common 'process' of a pluralist cosmopolitan space.

For Mark, the "event" of engaging with "Indigenous Australians" is equally "unusual". It follows that one-sided projections nurtured by his own perspective, the meanings of the 'reader's world', replace a potentially mutual dialogue:

I can't really think of any actual like full on conversations that I have had with Indigenous Australians. Although I'd love to meet and go off and see some tribal elders that still remembered back in the days when, you know, they would be living in almost a nomadic society, or not really a society I guess. But yeah, I think that sort of area is basically dying out now because everyone is realising Western culture basically, which is sad in a way but in another way there is plenty of benefits to Western culture...the only real actual TV contact that I remember with an Aborigine would be the one of the girls on Australian Idol...it was basically for the final there was an Indigenous Australian girl with an amazing voice and a guy from Scotland, and the Scottish guy won. So that was quite interesting, but yeah it's basically the only Indigenous Australian that I have seen on TV for a while. 
Mark cannot remember any "full on conversation" with any "Indigenous Australians". Although his interest in the cultural Other within the Australian Self seems genuine, it is grounded in primitivist notions of the past and lacks the sensitivity for contemporary realities and complexities. Through Mark's cultural lens, the traditional "nomadic society" appears to be "not really a society" and its remnants are "dying out now because everyone is realising Western culture". Importantly, his interpretive negotiation is driven not by a malicious intent, but by the fact that television functions as the only medium to facilitate "contact" and transform crosscultural 'distance' into 'proximity'. Since the televisual can never replace the interpersonal, the 'political, moral relationship' of a 'contact zone' (Clifford, 1997, p. 192) is perverted by the 'maximal impact' and 'instant obsolescence' ethos of 'over-saturated' and 'totally noncommittal' media productions (Bauman, 1996, pp. 25,28).

I return to Charlotte, who further elaborates on cross-cultural comparisons in her follow-up interview. It becomes clear that the ongoing Self-reflexivity culminates in Self-critique and Selftransformation in the long-term after returning from the New Zealand to the Australian world:

I guess in some of the things that I do I am more culturally aware of recognising the Indigenous culture in Australia and of trying to be I guess more inclusive of thinking that I am actually part of why Australia is not inclusive. Because I am not getting in there and getting to know the Indigenous culture... I think in my general attitudes and perhaps in things that I am interested in addressing personally it's sort of in there in the background still processing.

In the process of reflexivity, Charlotte gains a heightened awareness of her own individual position with the wider cultural domain. She realises that she is "actually part of why Australia is not inclusive". The 'balancing act' between 'autonomy' and 'commitment' (J. Bruner, 2002) jumps from an oscillating to a circular trajectory and becomes constitutive. To put it differently, Charlotte's discursive 'autonomy' itself helps to shape what cultural 'commitment' actually 
means. Her interpretive movement attests to the wider framework of cultural woldmaking in this thesis. It is reminiscent of Sartre's (1976) circular critique of dialectical reason and Gidden's (1991, p. 211) idea that 'human beings are able reflexively to 'use history to make history". We simultaneously mediate and are mediated. Charlotte proceeds to explain her experience and in doing so provides evidence of her mediating agency:

Probably the biggest thing for me is since returning from Te Papa I've actually had a new staff member from England come in. And I am needing to train her and she is asking for information in regards to Indigenous culture in Australia. So in that regard I guess I am using some of my knowledge of Māori culture and also my Indigenous Australian culture to explain to her differences between the two cultures and looking at issues like racism and also hidden racism and stuff like that. And that although all of our laws and whatever say this is what we shouldn't do, that there is a lot of hidden racism and stereotyping that still goes on. And when I think about that, I guess when I start discussing Indigenous culture I do automatically start thinking of Māori culture as well now, which is a bit funny... There was something the other day we were talking about Aboriginal rights and I started spreading something about the Treaty of Waitangi. And I am just sitting there going 'oops, where did that come from?!' (laughing) So yeah, I only just thought of that.

Charlotte is aware of the fallacy of a 'non-ambivalent, non-aporetic ethical code' (Bauman, 1993, p. 9) manifested in "our laws". However, by actively "looking at issues like racism and also hidden racism" she does not submit to its deficiencies but complies with her own "moral responsibility', the 'first reality of the Self' (Bauman, 1993, p. 13). This act of reflexive moral engagement itself critiques and transforms the very idea and nature of an 'ethical code' from within.

Fellow Australian Mike equally contrasts New Zealand and Australian cultural dynamics and in the course reflects on the Self through the Other:

I don't see the difficulties that we have in Australia with Aboriginals for lots of other reasons too. I mean I know there is exactly the same alcohol and drug problems in Australia as there is in New Zealand, maybe there is exactly the same, but the structures of Aboriginal life in Australia have broken down so badly that there is no leadership. 
There isn't a very strong tribal cultural view that somebody got to do something and it must be us, you know, and our elders. There is, and it's just the impression, it just seems like it may be a stronger family heredity bond with Māori as with Aboriginals. And that will inevitably lead to more peaceful living conditions for two people which are quite different. I mean we can't all be coffee coloured. I mean they are two different people so that's fine, it's good. But they seem to be getting on better here than they do over where I come from.

Mike's “impression" of Aotearoa New Zealand's indigenous situation provokes a form of 'Selfethnography' inspecting the equivalent phenomenon in the Australian context. Inescapably, the Australian "we" needs to be repositioned and shifted to allow for an Aboriginal Other, a different "us" and "our elders", within. Mike's hermeneutic performance modifies the 'cosmopolitanised' Self/Other relationships in postcolonial Australia into a 'cosmopolitan outlook', the 'reflexive awareness of ambivalences' (Beck, 2006a, p. 3), which accepts rather than overcomes differences. "We can't all be coffee coloured", he asserts, "they are two different people so that's fine". The decisive challenge ahead is to find ways "to be getting on better" which, in line with the argument of this thesis, is best achieved by developing a 'both/and logic of inclusive differentiation' (Beck, 2006a, pp. 4-5) within a discursive pluralist cosmopolitan space.

Julia, another New Zealand born Australian with a 'cosmopolitanised' biography of 'multiple loyalties', offers interpretive evidence of the inevitability of 'both/and' associations in a world of 'traveling cultures' and multiple Selves and Others:

I don't know, is that a pride in that you can see the country of your birth is sort of come together, got its act together on one level!? Maybe that's what it is, I don't know!? ... I mean, no way that this place is perfect but there is still a feel, a better inclusiveness.

Further on in her interview, Julia's "feel" of "inclusiveness" in her "country of...birth" is relativised even within the nuclear realm of her own family:

I am staying with mom and dad, you know, people in their seventies and seeing people of the similar age group sort of thing. So you've still got their views and opinions and 
things that came from my childhood, you know, where my childhood views came from. So I don't know if that's the same as what young people feel now?! I haven't had a chance to see people under forty. I don't know if they feel, or maybe under thirty, a more inclusive or more acceptance of each other?! And also I guess younger people have had the chance to be brought up with the education, the using both languages and stuff. So maybe it's just a matter of time as it grows through?!...I mean everywhere you go, to hop on the cable car or whatever, it's just this relaxed attitude and so helpful. And there doesn't seem to be any big deal of whether you are Māori or Pakeha or whoever. It doesn't matter. When I grew up it was very much, you know, 'don't go there!' And you don't realise it at the time. It's not until you walk away or get away from that attitude that you can re-assess it I guess.

Julia emphasises that her "childhood views" were the product of her parents" "views and opinions". While these still claim validity among "people in their seventies", Julia speculates that it might not be "the same as what young people feel now" due to perceivable changes in life. The artificial dichotomy of Self and Other is not only 'destabilised by accelerated globalisation', as Pieterse (1997, p. 125) argues. Careful analysis makes it clear that the historical Self is nothing other than the 'generational figure of the Other' (Ricoeur, 1992, p. 354). The cultural sense of Self shifts in the course of generational progression and thereby subjects otherness to an endemic relativity. In the case of Julia, it required a change in time and space to re-evaluate cross-cultural relations. "You don't realise it at the time", she says, and "it's not until you walk away...from that attitude that you can re-assess it". In her follow-up interview, we can see how the interpretive ontological endeavour of the shifting Self assumes the character of an ongoing self-reflexive ethnography:

It made me feel like I could certainly go and live in New Zealand I think very easily again I feel now...it was just a really amazing, quite a spiritual experience. Yeah, I think that was quite spiritual for me, which is interesting. And mom bought me a greenstone, a nice greenstone necklace for me, which I treasure. And I feel, I mean this sounds really weird, but I feel that gives me a spiritual connection to it too. And perhaps in the past I felt that had been more of a Māori prerogative. But it's not, you know, that's my land and that's where my roots are. So I think for me I didn't realise that I felt quite like that or I did know but I haven't been able to verbalise it before perhaps...I am feeling in a perhaps more comfortable place with my relationship with New Zealand if you like. 
Julia's cross-cultural encounter evolves as a very personal and "amazing...spiritual experience".

The hermeneutic re-negotiation of her "land" and "roots" is no abstract reasoning but an embodied process. In other words, a "connection" is "felt" rather than thought. Importantly, Julia's reflexive performance is accompanied by a 'moment' of critique, the contestation of a perceived "Māori prerogative". The outcome of her interpretive exploration is again a "feeling", one of a "more comfortable place with my relationship with New Zealand".

As we have seen above, Julia needed to "walk away" to "re-assess" her cultural Self. The spatial dynamics of 'traveling cultures' have perspective and interpretive ramifications. Susan from the USA offers more evidence of such reflexivity through travel:

At one point I was walking through the museum (paused) and I thought what would the world be like without the white adventurer? What would the world be like without the white man travelling off to all these foreign countries? What would the world be like? And I remember sitting there and I didn't want to think about it for too long because I wasn't sure if I wanted to know the answer...I mean I felt it before what would it be like if people didn't feel like they have to be missionaries?... we could actually be the minority...I've learned a lot in this trip. It really opened my eyes to a lot of parts of the world and I am excited to continue traveling.

For Susan, the experience of traveling and visiting a museum such as Te Papa spurs a chain of questions and associations. I used her hermeneutic reflexivity at the beginning to set the scene for this section. At this stage, I return to Susan's quote to complete the narrative journey to Selftransformation. We can observe that her interpretive reflexivity in the form of problematic questions, which I interrogated in Chapter Three in the context of the conditions of meaningmaking, provoke an exploratory mood interrogating Self, Other and the world. Susan concludes that "I've learned a lot in this trip". She clearly feels she has grown as a person and "it really opened my eyes to a lot of parts of the world". In short, Susan has undergone a transformation of Self through her multifaceted travel experience. 
In her follow-up interview, Claudia from Canada provides more glimpses of a long-term

reflexivity of the Self through the previous travel experience of the Other:

I am keen to learn about the west coast because being here and traveling so much of the country it made me realise how little of my own I have experienced. So I am looking forward to at least getting to know the west coast a little bit...I was surprised because it's the human nature to enjoy routine and having some routine in your life. And with traveling you really don't have any, things are constantly up in the air. And I mean I do from time to time need to stop and catch my breath. But it's just, I tend to think a lot and when I am traveling I don't have as much time to analyse. I am just rather experiencing and feeling things, which is so much better. You are so much happier then when you are not busy bogged down trying to analyse things, which is just a trait of mine. But for me, yeah, traveling turned out to be quite an enjoyable experience. And things are always new.

The extensive exposure to the cultural Other "made" Claudia "realise how little of my own I have experienced". In fact, it motivates her to embark on an exploration of the home country Canada. Once again the emotive dimension emerges. Self-discovery and transformation is no purely rational or analytical process but first and foremost an embodied endeavour, the "experiencing and feeling things". Rather than perpetuating a decadent superficiality, as pessimistic voices cry out, traveling might indeed offer an avenue to escape from the cage of reason and reflexively explore the "roots" of Self through the wings of the Other.

Once again I need to stress that themes such as Self-reflexivity, Self-critique and Selftransformation emerged from the empirical evidence gathered in this thesis. Different layers of meaning in the informants' narratives were unearthed as the interviews were analysed. Any qualitative research, however, does not offer a representative totality and might be suspected of biased representations. A legitimate question arises. Did every interviewee reach a level of Selfreflexivity? My hermeneutic perspective obliges me, of course, to maintain a sensitivity for the interpretive agency of individual parts. But we are all part of a whole and we all face the 
dynamics of Self and Other, so I feel that the research material enables me to assert that the encounter with the Other leads to a shifting sense of Self culminating in its reflexivity, whatever form this might assume. While this study found mostly critical and transformative examples to a different extent among all respondents, it is clear that there may be more stereotypical and racist variations among visitors to Te Papa.

The focus group with the tour hosts offers some cases. Since they represent 'second-hand' reports of someone else's experience, they do not serve as direct counter-examples to the narrative interview material. Nevertheless, these sources help to contextualise the narrative insights and I present them collectively to emphasise their significance:

One of the most memorable comments I have heard in the museum I heard on level one when I talk about the map and I talk about level four and the architecture on level four and that there are two sides, Mäori and Pakeha, and in the middle is where we talk about the Treaty. Now this memorable comment came from a South African guy who had recently moved to the north shore of Auckland where there is quite a lot of South African people. And he said to me 'why worry about the Māori people, they are defeated, they are a defeated race?!' (Bobby)

I do get that with Australians too because I think I probably push that a little bit more with them than other people. Being born in Australia I do touch a few pretty tricky areas on my tours and I say things like that as an Australian born I think New Zealand is doing a really good job. And I sometimes get responses from white Australians that 'Abos' are different or something similar. For me to get them to acknowledge that they do have an Aboriginal population is a real challenge. On level one I daily ask Australians 'when did people arrive in Australia?' And 90\%, this is a rough figure, 90\% of Australians would say, well they struggle for the year 1788 the date of the first fleet, so only $10 \%$ of Australians would recognise that they do have an Aboriginal population...Some of them are very open to be shown, some are very open to looking and seeing what we are doing, but some of them have a very strong resistance to it and get their back up when they see that the signs are in two languages: 'you got the indigenous language on the signs, what's the matter?' I have had that from Australians. (Bobby)

I guess being white myself it is interesting to hear what other white people from overseas say. Just to go on from what Bobby said, quite often when I was doing the tours and I was 
in the Treaty area you get the Australians look at you and they say 'oh you are so lucky'. And I would say 'why?' 'Because your Māori are more intelligent than our 'Abos'...And I still remember a colleague being really upset. She was in the marae and this Southern US American lady came up to her and said: 'I see you have got a few Māori people working in the museum'. And she said, 'oh yeah', she said, 'we have quite a few'. And she said: 'oh do you work alongside them?' And she was absolutely horrified...And you still get some tourists who believe that Māori people still live in little villages, in huts, eating sea eggs. (Kenneth)

I think what many people from overseas probably think is that Māori stops at 1840 and Pakeha begins then. And what actually happens is we didn't stop, Māori did not stop, we still kept coming through...So we are still living in that era... Often people would say: 'who did this marae?' And we would say: 'well it was built by Mãori people.' And they sort of say 'Oh', so 'Oh', and somebody actually asked me once if I know any Màori people?... 'Where did you learn English...did you have to go overseas or something?' And you go 'no just here, just here'...I don't think it's even any meanness because in our tourist brochures that's how you always see Māori. We are always there, our guys always in $19^{\text {th }}$ century so called Māori costume. And you are always doing a hongi, you don't actually sit in the office. And I said I have sat less than half a percent of my life in a socalled Māori costume. (Tama)

At first sight, the negative connotations of these encounters might cloud the arguably positive picture drawn by my analysis. I argue, however, that these snippets of cross-cultural engagements only represent different forms of the same hermeneutic phenomenon. To put it differently, any sense of Self and Other requires an interpretive reflexivity. In fact, Giddens (1991, p. 35; 75) claims that 'reflexive awareness...is characteristic of all human action' and that 'the self is seen as a reflexive project'. This research's empirical evidence therefore supports my theoretical proposition while leaving space for variations in its empirical manifestation. Given the methodological argument in this thesis, it is only possible to get a sense of this reflexivity by having a dialogue with that 'Self'. If I had interviewed the people in the above stories, then I might well have found evidence of Self-reflexivity as a result of the encounters described or other experiences in the museum. 
In this section, 'Self-reflexivity, Self-critique, Self-transformation', I expanded on the shifting Self under a heightened reflexivity. The interpretive ontological endeavour of the interviewees evolved into a 'Self-ethnography' amplifying the relativity of otherness. This intensified Selfreflexivity provoked the first 'moments' of critique and traces of transformation. The following section, 'Political opinions and moral demands', further politicises and moralises the discursive pluralist cosmopolitan space via 'cultural action' in the form of 'interpretive contests' and their 'enunciation'.

\section{Political opinions and moral demands}

Interest and opinion are entirely different political phenomena. Politically, interests are relevant only as group interests...Opinions, on the contrary, never belong to groups but exclusively to individuals, who 'exert their reason coolly and freely', and no multitude, be it the multitude of a part or of a whole society, will ever be capable of forming an opinion. (Arendt, 2006, p. 219)

...the promotion of a new and badly needed ethics for the new age can only be approached as a political issue and task. (Bauman, 1995, p. 281)

As we return to the phenomenon of the 'generational figure of the Other', the research material suggests a smooth transition from the interpretive to the moral and political without, of course, dichotomising these dimensions into separate categories. Michelle from the USA says:

I know that the Chinese came here because of the gold mining. That's exactly what they did in California and the Chinese were a very important part of our history. They came initially for the gold mining but actually they found that they made more money doing the laundry for the miners and cooking. And the Chinese were so discriminated against that they weren't allowed to own land. And holding on to that gold I think was very difficult, they would be robbed or beaten. And the Chinese also were responsible for building our transcontinental railroad. So without them we would have never accomplished many of the things that we did. So the Chinese it sounds have been influential in several cultures... 
Michelle proceeds by morally investigating the American "we", "our history" of "our country",

within the cosmopolitan space of commonalities and differences between Self and Other:

Well, it's imperialism!...I mean that's what our country did too. The US came into wherever they could and took over. And eventually they lose their own identity, their culture. American Indians have been put in terrible circumstances, put on reservations, not allowed to be part of the population but to be isolated. And yeah, they would kill them from the train as you would kill an animal. So I don't think the Māori were treated that way but I don't know enough about whether there was some discrimination against them. But the English come in just like the Americans and do bad things. Not only do they kill people but they spread diseases because the Americans infected the Indians with small pox and the common cold and things that they were never exposed to. I am sure the English came in and did those things too, for example they brought the rats on the ships. There is always, you know, as soon as you fool around with Mother Nature you destroy a lot.

Michelle's moral verdict on actions of "our country" transforms the American "we" into a detached "they". "They would kill them", she concludes, and "not only do they kill people but they spread diseases". The hermeneutic negotiation of the historical Self or 'generational figure of the Other' gains a moral quality and in the process there appears yet another Other: the 'conscience' as the 'voice of the Other' (Ricoeur, 1992, p. 353). Ricoeur (1992, p. 342) argues that 'under the impetus of conscience, the self is made capable of taking hold of itself in the anonymity of the "they". The relativity of otherness is magnified under the moral influence of conscience. Michelle further reflects in her follow-up interview:

I guess another part that I learned about which was completely new to me also wasn't there a treaty that was signed between the Mäori and the, I am trying to think, where they lost their land?!... And it kind of reminds me of what they did to the American Indians here... Well, you know, the American Indians were here first. And then the white people came and decided that they discovered America when that wasn't really true. I mean these people were already here. And then they either killed them or cheated them out of their land by giving them very little in exchange. You know, they give them some beads or whatever to have their lands. And so the Indians were really just treated very badly and called savages. I mean they probably were more civilised than we because they had so much respect for the land. And now we are just ruining everything by coming in and cutting down the trees and having no respect for the animals. But if the Indians were still in charge I think we might not have such, you know, they say industry is progress but 
(laughing) the Indians seemed to really respect the fact that we should live with nature and not try to control it.

Michelle seeks again refuge in the "anonymity of the "they" while morally assessing the deeds of her ancestors. Once she has traveled through the interpretive journey of historical progression to get to the contemporary stage, the detached "they" shifts to the personal "we". Importantly, even while remaining in the context of the present she shifts back to the "they" when facing a view she cannot morally or politically justify. "They say industry is progress", she remarks, an opinion and perspective she clearly contests. This highlights the ubiquitous presence of the 'sting of the stranger' (Boomers, 2004) within the Self, an 'inner strangeness' (Dworschak, 1994) corresponding to the relativity of otherness.

Susan from the USA moves the hermeneutic performance of the "anonymity of the "they" into the complex realm of history-making:

I have been told by people that have lived in Hawaii that Hawaii was stolen from the Hawaiians. We pretty much went in, we bought it and the princess or the queen made the agreement, the Hawaiians didn't make the agreement. And they feel like it was stolen...they said you not gonna ever really find the true Hawaiian history in history books because they wanted to take their memory away from them...It's crazy!...eventually the United States, we bought territory over there and the territory of Puerto Rico and the Virgin Islands and they decided to make it a state...And that's where I don't understand it and that's where my friends were trying to explain to me that that part of Hawaiian history is lost. And they are slowly starting to put it back into history books but you will never truly know what happened...I mean when I learned about Hawaii, Hawaii became a state in such and such a year. Oh cool, what's that mean!? It's just the latest part of the union. Oh, it's now part of the union. We got another star on the flag and it's just part of the union and now we can go over there and have their passport... Oh, okay, you learn about that in like fourth and fifth grade...That's all it was. We didn't learn anything else. I mean we did at later times, excuse me, I don't want to say we never learned anything else...Not until we got older and you are starting piecing things together and you are like 'oh, that make sense, now I understand'.

Susan reminds us of the hermeneutic ramifications of 'narrativity' and 'historicity' (see Chapter Three). Each interpretive performance inevitably embodies a political dimension which becomes 
more contested once historical negations are perpetuated to justify the present (Sibley, Liu, Duckitt, \& Khan, 2008). According to Susan, this is what happened in Hawaii. "They", her US American ancestors, "wanted to take their memory away from them". Once again a moral judgment driven by human conscience transforms the "we" into a "they". The fact that "they are slowly starting to put it back into history books" points to the circular trajectory of cultural worldmaking, the discursive space of hermeneutic contestation and revision in the "process of the formation and reformation of culture' (Calhoun, 2002, p. 157).

Mike from Australia offers another example of his long-term reflexivity as he reminisces on the stories of history in his follow-up interview:

I think the story was better told...the new world has all got stories of a new migrant and the indigenous population. The story told there is a little bit clearer and perhaps a little more honest than some of the other ones that I have seen. I mean in America for instance it's hard to find a linkage between the destruction of the Indian and the press to go west to open up land is not always necessarily linked together. And it made me think a little bit about where Australia is at with its Aboriginal. I guess it's not only its perception but its history and how its history is doled out. I mean history is written by people and often it's doled out to the reader or to the audience in a particular fashion at particular points of time quite differently. For instance when I was at school there was no concept that we, the white man, had done anything wrong whatsoever in the country. Now you start to see museums like yours and it pricks the conscience of that there is two sides of the story. And I don't think we still haven't got two sides of the story in Australia. They are often quite separated. You know we are quite proud of indigenous culture in painting and whatnot, but on the other hand we don't really want to acknowledge the destruction of a culture at the same time.

Mike's summary echoes Susan's reflections by emphasising the inherently contested nature of history and its continuous hermeneutic revision over time. He reinforces this insight by observing commonalities and differences across the 'cosmopolitanised' "new world". Importantly, Mike stresses that "history is written by people". "History books" are no prescription by an "invisible 
actor behind the scenes' (Arendt, 1958) nor an 'emanatist vision' (Bourdieu, 1990) but are purely human products.

According to Mike, the visit to Te Papa "made me think" and reflect upon the "we", "the white man" in Australia. The museum "story...pricks the conscience" and provokes a new 'mental state' which itself 'represents a new attitude, a new relation of the whole person to things and people' (Dilthey, 1976, p. 202). This is the 'moment' or 'process' of structural 'renewal' (Taylor, 1991) when interpretive agency changes discourse from within. As that happens, abstract categories such as 'history' and 'culture' are humanised, creating what I have termed in this thesis a pluralist cosmopolitan space. As scholars have also pointed out, "history is written by people" (Ricoeur, 1981; Said, 2003; Sartre, 1976). Everybody assumes a different 'mental state' or interpretive position. What Arendt (1958, p. 175) calls 'human plurality', is 'the basic condition of both action and speech'. To put it differently, there is no alternative to discursive pluralism within the hermeneutic negotiations of a cosmopolitan space.

In her follow-up interview, Charlotte from Australia seemingly builds on Mike's historical reasoning and critically reflects upon the inherent 'polysemy' of museological representations:

...knowing that I guess what all cultures present is sometimes significantly different to the realities of cultural life for different people...I guess I am just conscious of that at Te Papa. And we represent the very traditional cultural values and traditional cultural ways which people need to know about. But because of modern living, the same thing happens in Australia, there is a lot of unemployment, there is a lot of low socio-economic conditions, domestic violence, all that sort of stuff which is happening in all cultures, you know, white and Indigenous. But that sort of stuff necessarily isn't represented in museums and that's one of the things when I think back to. Well, here we are representing what this particular culture is like at that time, but we are only representing perhaps the positive aspects of what this culture was like and not the difficulties in relation to access to medicine or particular diseases which might have decimated the population because they weren't used to it, you know, European diseases coming in and 
affecting people, stuff like the way that the diet has changed which has affected the health of Indigenous people. I know that's certainly an issue in Australia and I think also in New Zealand...we have this really strong cultural heritage but what's happening to these people now?! And is it because of influence of white people or is it because of other things?!...And that sort of links back into the reconciliation that they talk about in Australia, which is a reconciliation between Indigenous and white Australians looking at trying to have better outcomes for Indigenous people and have a more inclusive society. Even when we are trying to do that sometimes it doesn't work.

Charlotte points to the apparently universal dilemma of cultural representations favoring the celebratory over the tragic aspects of "the realities of cultural life", a thought that echoes scholarly critique (O'Neill, 2006). Her impression also indicates that to "tell all our stories" which, according to Gorbey, was one of the founding principles of Te Papa, has in fact not been achieved. While Charlotte becomes aware of a "really strong cultural heritage", she does not find any answers to the question: "what's happening to these people now?" She concludes that with regards to efforts such as cross-cultural "reconciliation" in Australia, "even when we are trying to do that sometimes it doesn't work". We have reached the 'inescapable hermeneutic complexity in moral and political affairs' (Held, 2008, p. 161) which requires a closer interrogation.

Armenian-American Michelle allows this investigation by narrating her encounter with a Te Papa tour host who facilitates the journey from bicultural meanings to cross-cultural dialogue around the Treaty of Waitangi in the Signs of a nation exhibition:

...when she was describing the Treaty she said people look at this in many different ways. You may look at it as it was just a misunderstanding. Some people see it as a way of just taking land without having to compensate them in any way...from what I gather it still hasn't been decided how they are going to deal with it. Do they compensate these Māori people for what has been taken away from them?! Because she said that some people feel like 'well, these are all modern people now, it had nothing to do with them, why should you compensate them when they are generations away from what happened!?' And I think that's true in every country, you know. They say that the American Indian should be compensated and the Germans should be compensated, the Japanese should be compensated. We took away their arms in World War Two and we put them in, not concentration camps, but they were imprisoned because they were Japanese, not because 
they were enemies because they were citizens. But we did that, should we now compensate them?! I mean those aren't the same people. So there is this issue I think that goes along with any kind of unfair practices that happened with the indigenous people or the people who lived there and then what has been done with them. And I think those things, will they ever be settled, it's so complicated!? But she indicated that there were lots of viewpoints. So it kind of makes you think 'who is right?' Well, you know, no matter what you decide someone is gonna be unhappy.

The Treaty between Māori and the Crown is, just like any other legal arrangement especially in cross-cultural contexts, an immanently hermeneutic construct. According to the tour host, "people look at this in many different ways", which mirrors the 'polysemy' in 'interpretive contests'. The associated moral and political ambiguity is, as Michelle states, "true in every country". Given the human plurality of "lots of viewpoints", it will forever remain impossible to precisely determine "who is right". This endemic ambivalence, which various scholars have illuminated (Bauman, 1993; Beck \& Bonss, 2001; Bhabha, 1994, 2008), can never be dissolved but can only be embedded in a 'framework for the pursuit of argument, discussion and negotiation about particular spheres of value' (Held, 2008, p. 161). This is what political cosmopolitanism promises, as Held (2008) rightly argues. But once again, the discursive creation of a pluralist cosmopolitan space is subject to the inevitability of conflict since "no matter what you decide someone is gonna be unhappy". In her follow-up interview, Michelle lends further weight to this conclusion:

Well, the Indians now are allowed to build casinos for gambling so they are making a lot of money. And it's kind of a sad situation because the people that are running the casinos are mostly people from Las Vegas. And they are professionals and so they don't like the Indians to work in the casinos. They just give them part of the profit. And so what that has done to the Indians in many cases is it has made them rich but they don't have anything to do. And so they become alcoholics and many have not really done a lot of positive things for them. It gives them material possessions but it didn't really make them have a better life...So it's rather a strange situation. It's like we are paying them back for all the terrible things that we have done to the Indians. But it has not really improved their life because if they don't work, they may have a lot of time on their hands and eventually become alcoholics and just live a life that isn't particularly fulfilling. 
Michelle's pondering on the destiny of "the Indians" seems to partly assume the character of a stereotypical characterisation driven by a 'doxic belief', the equation of this cultural type with "alcoholics". Importantly, this is not an outcome of a malicious intent but an act of 'underreading' to fit an interpretation into existing cultural categories. The essentialised totality "the Indians" leaves thereby no room for individuality just as "mankind is an abstraction which never can become an active agent' (Arendt, 1958, p. 184). The main point at this stage, however, is the "rather...strange situation". Although efforts are made to morally and politically reconcile the cultural poles within US society, according to Michelle, "it has not really improved their life". This is reminiscent of Charlotte's earlier comment that "even when we are trying to do that sometimes it doesn't work".

Julia, a New Zealand born Australian, allows us to return to the New Zealand context and its 'interpretive contests' in cross-cultural relations:

And it is prominent here because the Māori have stood up, you know, 'we are important, we are part of this country!' That's what I feel has happened. They sort of demanded it, the recognition, which is great. It's really cool. And I don't know why that hasn't happened elsewhere, maybe it's because New Zealand is so small!? Whereas over there it's so much space that things get lost?!... That their voice is so small, yeah, that it's easy to push under the carpet or overlook whereas it's not here.

Julia clearly supports the moral and political demand of "recognition" articulated by Māori people during the course of history. "The Māori have stood up" whereas in Australia there is "so much space" that the indigenous "voice is so small...that it's so easy to push under the carpet or overlook”. The geographical 'tyranny of distance' prevents the 'proximity' needed for moral and political "recognition". Julia proceeds with some related anecdotes of her own life:

And I don't know any Indigenous Australians, you know, being and living there for 27 years and have not had an opportunity. I mean I was going to the observatory in Sydney. They had an open night and an indigenous family turned up. And I thought 'oh, how cool 
I'd love to go and talk to them'. I was going to do that and I thought 'oh, hold on this is', you know, it didn't feel right to just go up and 'ha, it's great to see you!' Who am I to say stuff like that to people?! ...I have never had any experience at all and that's sad. Whereas here it's never an issue, it's part of New Zealand...I travel with my job. I am a manufacturer's agent so I sell Manchester products on behalf of companies in New South Wales. So I do travel country areas as well and even in the country, you know, the store owners or whatever, I have not come across...there is no interaction from where I have been in my experience. I am sure if you lived in the towns it would be different, but, yeah (paused), I don't know why?! So it makes us feel different. It makes New Zealand unique really I guess that it's working. It must on at least a couple of levels. I don't know about the nitty-gritty stuff, I am visiting (laughing).

In Julia's "experience" there has been "no interaction" with "any Indigenous Australians". The cultural category remains once again on an abstract level without interpersonal humanisation. Julia clearly laments this situation which is "sad" and "makes us feel different". She reflects on this further in her follow-up interview and it emerges that her interpretive contrasting with "New Zealand", which appears "unique" since here "it's working", is being relativised within the generational shift of her own family. While Julia supports the contemporary significance of

Māori, her dad contests this position and prefers to keep the culture locked up in the past:

Well I didn't really talk to him much about it, but that was mom's comment when I was sort of carrying on and raving about it. And she said 'oh Dad doesn't like that bit'. He just doesn't feel that that's right, which was quite interesting really. I was sort of surprised. So it was my conclusion really that he wasn't comfortable with it being in a contemporary setting rather than something he had actually said to me himself. Yeah, but I think that was a really important point to be made. It's important that the Māori culture, because it's such a vital part of New Zealand, that it's seen in this new light. I think that's really important.

Julia continues with her long-term reflections and in the process relativises the "new light" of

"Māori culture" within her circle of friends:

Even though I have to say, I mean I've had friends coming back from New Zealand, expats, just on Saturday. And he is from Dunedin originally and he visited the North Island this time to see a great aunt or something. And he was really shocked at, I don't know, the level of violence that's reported in the paper, the niggly sort of stuff between Mäori and Pakeha over there. And that made him feel very uncomfortable ... he was really shocked with I guess what he perceived as an aggressive stance of the Māori, that he felt the Maori still felt that Pakeha owes them. You know, so I mean I just said that's 
just as the media portrays it and not everybody is like that...I just had that conversation on Saturday which was really interesting. But I know it's difficult. It's difficult in any country, you know, the cultural stuff. I don't know that New Zealand's got it on its own that's for sure.

The "new light" of cross-cultural relations in New Zealand is darkened by cases of conflict and violence. In this context, Julia alerts us to the generalising bias of media productions and proves a sensibility for the individual case. Although "the media portrays it", she states, "not everybody is like that". In general, however, Julia just knows "it's difficult" because the "cultural stuff" is “difficult in any country". This 'inescapable hermeneutic complexity in moral and political affairs' (Held, 2008, p. 161) gains a personal quality once Julia inspects a particular cross-cultural issue:

I mean the Aboriginals here have got a very, very strong connection with the land and they view themselves as caretakers of the land as opposed to ownership, which I really like. And perhaps I don't see that in New Zealand, to me their big deal is always about ownership. And I don't necessarily agree with that. I think that's perhaps a bit shortsighted. But the thing with the Aboriginals, I mean there are still big issues over here I guess. And certainly in my everyday life I would be lucky if I see Aboriginal people twice a year. They just don't live around where I live or they are not going to the city.

The shifting Self's intimate knowledge of various Others equips Julia with the ability and confidence to articulate a cross-cultural critique. Based on the perceived philosophical difference between Aboriginal "caretakers" and Māori "ownership" of land, she formulates her own opinion and associated position. At this point, the pluralist cosmopolitan space has become fully political, an interpretive instance of a forum. By facilitating such discursive actions, movements and performances beyond the confines of an 'ethnic structuralism' (Williams, 2003), museums represent unique places to stimulate the shift from a closed, reformist tolerance to an open, critical engagement and consequently from a pedagogic to a performative sense of democracy (Chakrabarty, 2002). I elaborate on this vein of thought in the final stages of this thesis, but for 
now we return to Julia and her political and moral engagement in a different cross-cultural 'interpretive contest':

Here my everyday life is Asian, mainly Asian or Indian, you know, that sort of ethnic group more than indigenous people...I am pretty quiet and don't have a problem with any ethnic group in particular at all. I mean it's what's inside the person and not where they are born in my book. But that being said the different way that some ethnic groups bring up their offspring, their children, concerns me a little bit. Especially if you get fanatical; fanatical in any group is a worry...There are some groups like you can walk in some areas of Sydney and are able to smile and say 'hello' to people. And there are areas in Sydney where you can't really do this. And that's more Muslim-based that ground and that's sad. But I say 'hello' to anybody I think. I think that gives a good, I don't know, it's an inclusive thing.

To Julia, the personal qualities of a human being, "what's inside the person", prevail over the alleged mentality of "any ethnic group". Being "inclusive” to her simply means to "say 'hello' to anybody". However, this does not prevent Julia from critiquing "fanatical" tendencies which "in any group is a worry". Although she emphasises the primary significance of a "person", Julia simultaneously refers to the abstract totality of a collective "group". We cannot help but place ourselves and others in cultural or cross-cultural contexts. The outcome is an ambivalence which lets us appreciate the individuality of human beings while experiencing "Muslim-based" phenomena at the same time.

Susan from the USA provides another example of an interpretive contestation within a pluralist cosmopolitan space culminating in the 'enunciation' of a moral demand:

And in Australia I learned more about the bad things that the government did with the Aborigines and trying to taking the children from them and putting them into orphanage... I had no idea, never heard of it, didn't hear anything about that...That's ridiculous. I had no idea they were stealing children from people, putting them in orphanages so they wouldn't remember. That's horrible. You can't do that to people and families. And I feel like that happened and it's a bad part of Australian culture and, you know, is a bad part of the history and they gonna kind of sweep that underneath the rug. And like you will hear in the news every so often 'oh parliament rediscover ties and they apologise for doing this or that'. And we did that a few times in the States. We've had 
presidents and governors all were apologising for this. And then people were going 'what are you talking about, I never heard about that in my history book?!' Whereas here it's a little different. You haven't done that or maybe not that I have seen or heard. You haven't done that to the people and you realise that you kind of took the land from them. And well, great we've got four million people spread apart two islands. We can't really like give you land back now so what are we gonna do?! And that's why you have like if people gonna sell the land they have to offer it to us first. You have to do just certain things. I find that very interesting.

Setting out from the specific Australian history of cross-cultural policies, Susan articulates a universal moral point of view. "Stealing children from people" is, according to her, a "horrible" crime which "you can't do...to people and families". The 'cosmopolitanised' space of discursive negotiation between Self and Other, or "we" and "they", gains a cosmopolitan quality. To put it differently, the 'moral responsibility' (Bauman, 1993) for "children", "people" and "families" leaves the particularity of a cultural context at a certain point in history behind and becomes a ‘universal concern’ (Appiah, 2006).

Claudia from Canada offers more evidence of such moral cosmopolitanism evolving through a cross-cultural encounter:

...it's all relative and I tend to confuse history (laughing). As I've said I am not a history buff, but my perception is that they were here first. Britain came, other foreign settlers came and basically human nature likes to try to wipe out certain sectors of the population. So I get this impression that they've had a rough time in the past. A lot things were lost, knowledge, traditions, rituals and it's slowly coming back. And I appreciate seeing that, you know, the modern culture is giving them more of a chance to be who they are. They are not forcing them to assimilate anymore. They are finally allowed to be who they are and let their own cultural things flow through to teach their children things. They don't have to get in trouble when they speak their native language. And I have never understood why cultures, and they not all do this, but you know parts of the human culture think theirs is the way to go. They have no tolerance for others. And I have never understood that vein of thought. So it's nice for me to be here and see that...people are allowed now to be who they were, what their generations past had started. You know (paused), they take them seriously now. It's not just something that people are tolerating or letting exist. They actually are real people and I even hate the sound of that when listening to in my head. And I don't like talking about a culture so strictly like that...people are who they are (paused), they just are. 
Claudia, although not being a "history buff", attempts to negotiate the complex history of Aotearoa New Zealand. She clearly appreciates the apparent progress of cross-cultural relations which gives Māori "more of a chance to be who they are". Claudia also moves beyond the specificity of that particular context and assumes a wider moral stance. She asserts that "I have never understood why cultures...have no tolerance for others". This seemingly universal phenomenon epitomises simply a "vein of thought" which she has "never understood". In the process of Claudia's hermeneutic contestation, the abstract category "culture" is humanised. She emphasises that "I don't like talking about a culture so strictly like that" since "they actually are real people".

Once again we can see here how cross-cultural dialogue is transformed into an interpersonal dialogue among cultural human beings. It shapes a 'tenable cosmopolitanism' which 'tempers a respect for difference with a respect for actual human beings' (Appiah, 2006, p. 113). This is exactly the discursive terrain a pluralist cosmopolitan space captures. And by turning to Claudia's follow-up interview we can observe that a humanised acceptance of the 'difference within', the fact that "people are who they are", might let the cultural constructions of "differences" appear as secondary to an inescapable 'human plurality' as 'the basic condition of both action and speech' (Arendt, 1958, p. 175):

I tend to, I probably I shouldn't do this, but I really blend cultures together. I don't pay a lot of attention to distinguishing a lot. I mean there are differences among every culture and I appreciate that. Not that I am trying to take away from that, but it doesn't stand out for me, the differences.

In this section, 'Political opinions and moral demands', I shed light on 'interpretive contests' in 'contact zones' and the hermeneutic nature of identity politics. The informants' cross-cultural 
journeys evolved through Self-reflexivity and Self-critique into the articulation or 'enunciation' of political opinions and moral demands. Here the pluralist cosmopolitan space became politicised and moralised encapsulating an interpretive instance of a forum. At this point in the thesis, I have completed the narrative exploration of Te Papa as a global public sphere through hermeneutic actions, movements and performances by cultural actors or visitors. It is still necessary to relate the preceding narrative-hermeneutic investigation to the concept of a museum as 'forum'. I turn to this task in the final section of the chapter.

\section{Intersubjectivity?}

The research presented in this thesis has shown that Te Papa functions as a political and moral space of hermeneutic contestations. From the interview material there emerged what I have referred to as interpretive 'moments' or 'processes' of a 'forum'. This culminated in the 'freedom of opinion' which, according to Arendt (2006, pp. 217-218), is incompatible with a 'public opinion' that 'by virtue of its anonymity, provokes a unanimous opposition and thus kills true opinions everywhere'. Consequently, the plurality of a discursive cosmopolitan space is inescapable.

Conceived as a discursive platform for moral and political engagement, or 'forum', a museum can help to shape 'performative democracy' (Weibel \& Latour, 2007) beyond essentialised and homogenised notions of the public and its illusionary representative and unitary value. I have followed such reasoning by humanising Te Papa as a global public sphere through the stories and faces of cultural worldmaking. Such 'action and speech, which are only in actuality, and therefore the highest activities in the political realm', as Arendt (1958, p. 49; 207) convincingly argues, 
create the 'public realm' as 'the proper place for human excellence'. While my narrative exploration uncovered the hermeneutic dynamics of this 'human excellence', it remains to further interrogate the 'public realm'. In other words, the interpretive actions, movements and performances need to be related to the potentially dialogical nature of an 'intersubjectivity' (Habermas, 1999) at the heart of a performative democratic praxis.

For that purpose, I draw on contextualising methods such as focus groups and expert interviews (introduced in Chapter Two), and contrast these with the narrative insights of individual experiences presented in this and the previous two interpretive chapters. Based on the multilayered findings that result from this approach to the analysis, I am able to examine the 'forum' concept as it is embedded in museum theory and practice. The analytical journey is concluded by returning to the emotive dimension of cultural politics within the discursive terrain of a pluralist cosmopolitan space.

\section{Meeting place and/or dialogical space?}

I proceed by inspecting the term 'forum' and its associations among both visitor focus group participants and museum experts. In Chapter Two, I laid out the research design and the rationale behind the choice of contextualising research materials. At this stage, I want to recall some points to facilitate the flow of my argument. Neither the focus groups nor the expert interviews aimed at illuminating the narrative construction of meanings as in the preceding chapters, but they provoked a debate on the idea of Te Papa as a 'forum'. I handed out Te Papa's mission statement (see Appendix L), which defines the museum as a 'forum', to each focus group as a trigger for a 
subsequent discussion. The two experts elaborated on the concept's history and their respective view.

One of the most prevalent themes emerging in all three focus groups was the apparent contrast between a 'forum' as a physical meeting place and a 'forum' as a debate requiring dialogical interaction. While inspecting the mission statement, Rick from the USA even stressed that "if you take 'forum' out and put 'place' there, to me that would make more sense". The following statements of the evolving discussion among Canadians, who have resided in Wellington for a longer time period than a typically brief travel visit, highlight Te Papa's function as a gathering place:

As a resident here, Te Papa is a meeting place. And so it has that sort of place in the city. And maybe it isn't a meeting place in the sense that we are all getting together and discuss things with each other, but we still go there, come together individually and get the same information individually...It's almost I think it becomes a shared experience. (Genevieve)

Many times when I have business meetings I will say 'let's meet at Te Papa at the cafe'' because it's easy parking and it's handy and nice environment. And it's not noisy like a lot of the cafes are. So again, it's another venue that people use. (Annette)

Speaking as an outsider and not a Kiwi, the building itself seems to have a value that I haven't seen in other places. For instance, how many New Yorkers have ever been to the Statue of Liberty or to Staten Island or something like this?! Whereas this seems to be a destination for a lot of people. (Charlie)

Yeah, I don't think you can find a Wellingtonian who hasn't been here. (Samantha)

Quite expectedly, these associations did not appear to the same extent in the other focus groups with Australian and US American visitors who were recruited from more mobile travel groups. Having experienced the urban dynamics in Wellington over a longer period, the above 
participants highlight that Te Papa indeed functions as a 'congregant space' (Gurian, 2006). The museum embodies a contemporary version of bourgeois establishments during the emergence of the public sphere in the Habermas' (1989) sense. One of the basic reasons, according to Genevieve, "is the fact that we don't pay to come in... in that sense it's almost like a public park". The whole group agreed with this standpoint which mirrors a precondition of a 'public space' as 'being freely and fearlessly accessible to everyone' (Hertie, 2008). The free access erases what Bourdieu (1984) called 'social distinction', at least in terms of monetary capital, and democratises the formerly bourgeois nature of the institution 'museum', as visitor profiles prove in the case of Te Papa (McCarthy, forthcoming).

While Te Papa seems to comply with this requirement, it remains to be seen to what extent it considers its 'visitors in the transformed role of participants', invites 'colloquy' and represents a 'safe place for the discussion of unsafe ideas'. These are, as Gurian (2006) argues, 'possible next steps' towards a museum as 'forum' which would re-shape Genevieve's "shared experience" as a dialogical engagement. I return to the research findings which paint a different picture with regards to Te Papa in particular and museums in general.

There was no initial association of a museum as 'forum' in its dialogical connotation among this research's participants. In fact, the discussions started with a sense of surprise and disbelief as the following comments reveal:

Forum doesn't enter into my thinking when I am going to a museum...And if somebody said I will take you to a forum, I wouldn't think about a museum at all. (Luke, US)

I wouldn't normally consider the term 'forum' to describe a museum... it would be a meeting, the exchange of ideas... whereas in a museum you sort of go and discover 
yourself, you don't have anyone there...it's more of a one-way absorbing of information...you can't really share your ideas with the museum. (Richard, Aus)

Interestingly, these views do not reflect a lack of understanding among visitors, but even echo the sceptical reservations of the museum experts who were involved in the conceptual design of Te Papa:

...the concept of 'forum', which is not a word I use often. It's very popular - museums are a forum, museums are places where we debate... So sometimes we don't follow through on these wordy words. Now I suspect that 'forum' is one of them because forum is hard. Forum is about a debate within a pluralistic society. (Gorbey)

Hakiwai carries the museological debate into the realm of Māoridom and touches on the very useful example of the marae, or Māori ceremonial meeting space, as a place of debate which at Te Papa takes the form of a contemporary marae Rongomaraeroa. More on this point later, but for now it is important to highlight the apparent lack of awareness of Te Papa as a "forum for the nation" among Māori communities:

So I suppose in that sense Te Papa is seen as a place of belonging, a Türangawaewae. Whether that does attend to a forum I am not quite sure?! But certainly it's the use of the marae as a place for all peoples to stand that's embraced. So I suppose the concept of a 'forum' where issues are debated on the marae I suppose it has resonance, but it's just whether Mäori actually actively know and are aware that Te Papa is a forum for the nation?!

Departing from this seemingly widespread misperception, I set out to more closely interrogate the reasons for the divergence between the conceptual 'forum' intent on the one hand and actual communicative dynamics on the other. All focus groups expressed interesting thoughts on the status quo as well as ideas of potential futures. The politically crucial issue of 'intersubjectivity' in its dialogical sense consistently emerged as the following participant highlights:

Immediately when I see the word 'forum' I think of something that's interactive, which is why it seems interesting here as a museum because usually a museum presents 
something very one-sided...there isn't really a feedback loop to the museum ... I think in terms of making a museum interactive it's very easy to make it kind of interactive on a surface level where people can push a button or touch things, which is great. It's nice that you can touch things. But in terms of it actually being a two-way conversation it is much harder to achieve because really who is listening to the visitor unless there are occasionally lectures here and things?!...people come and get information as opposed to a conversation about a topic. (Samantha, Canada)

It becomes clear that a necessarily "interactive" forum can hardly be reconciled with the predominantly "one-sided" representations of museums which do not offer a "feedback loop". Interestingly, Samantha alerts us to the various facets and layers of "interactiv[ity]" by contrasting its mechanical "surface level" version with an actual "two-way conversation". This reasoning is reminiscent of Witcomb's (2003) fruitful analysis of different forms of 'interactivity' which I introduced in Chapter Three. I come back to this point in more detail later in this section but continue first with Tony from Australia who also detects the lack of a "two-way conversation":

Communal discussion, I would say, because it's not necessarily like an audience, there is involvement... it's kind of hard to argue in here like in a forum because there is no opposite side, it's all factual really... I think it's hard to get it into a museum because you can't question a museum... And unless there was some sort of question on the wall in the museum no one would really see that because you just trust that the information is factual and truly factual. There is no room for questioning... so you wouldn't expect there to be any sort of bias even though there would be.

Tony stresses that the required "communal discussion" would actually transpose audiences "in the transformed role of participants', to use Gurian's (2006) words again, through active "involvement". Furthermore, Tony touches on the thorny issue of 'authority', which inherently prevents a dialogical engagement. The "authoritative voice" which, according to Gorbey, "was one of the first things that disappeared" at Te Papa still seems to linger on since "you can't question a museum". I offer a remedy in the following discussion on the implications for museum theory and practice but for now turn to another view on the museum 'forum': 
If this museum is trying to set itself up as a forum, then that's not happening. Like it's still us taking in the information and maybe we discuss it with the person we are with, but we are not discussing it with anyone else who is here or leaving our thoughts or anything like that...it doesn't wrap back into the museum I guess. I mean it takes it out to the wider world and there is discussion going on there. The forum is created here but it's not contained here. The museum perhaps isn't gaining anything from our taking in, from our discussions outside to make it better or to change it. (Genevieve, Canada)

Genevieve also emphasises that Te Papa does not comply with the basic characteristics of a 'forum' and critiques the lack of a "feedback loop" Samantha referred to earlier. Interestingly though, Genevieve points out that "the forum is created here", in the museum, "but it's not contained here". In other words, Te Papa fails to facilitate dialogue within its physical parameters but succeeds to "provoke an interest" and subsequent debates in the multiple, overlapping and multilayered public spheres beyond the museum walls. Following such argumentation, Richard from Australia considers a museum to be a "catalyst" rather than a "forum":

The idea of the museum seems to be to sort of provoke an interest in history and heritage of New Zealand. And I suppose that could lead to people discussing it among themselves a lot more. And essentially it's sort of like a catalyst for interest in these sorts of things...It still doesn't go well with the word 'forum' for me... I am just stuck on that particular definition. Although it has interactivity it's not interpersonal.

Once again the focus group participants do not contradict but mirror the opinions of the museum experts. Equally missing the "interpersonal" dimension of "interactivity", Gorbey asks the following question:

... where is 'forum' happening in Te Papa? Now for example I just don't see it. I've never seen it... we said we will be a 'forum'. Yeah, wonderful, but I have never seen a proper debate in Te Papa, a proper really stroppy debate where people were able to throw different ideas across the table at each other.

Hakiwai supports this view by listing a particular example of reducing the "Treaty debate series" to a "series of lectures": 
I don't think we have done a lot with respect to Te Papa as a forum and it's something we have highlighted in recent times that we need to do a lot more... I don't know whether we are at that place in time where Te Papa is seen truly as a forum, as a place for debating issues. You know we have the Treaty debate series. It's arguable and debatable whether it's actually a debate series! It's a series of lectures really with minimal time to debate.

The apparent divergence between the physical and dialogical dimensions of the 'forum' concept is summed up by Gabrielle from Canada who states that "I saw it as the interactive discussion, but I also perhaps saw it as a place, so a place to discuss or a place to have this dynamic". In this context, it is useful to distinguish between place and space. The former consist of the spatial configuration of three-dimensional elements while the latter is the outcome of the human interaction with such structural layout (Buschmann, 2010). In Chapter Three, I discussed the transformation of a physical into an interpretive space intertwining the conditions and processes of meaning-making. It is now my task to postulate a synthesis: a place of debate combining a physical meeting place with discursive dialogue which lays the museological foundation for a pluralist cosmopolitan space.

\section{The reflexive museum}

How could the chasm between gathering place and lack of 'interactivity' be bridged? What museological strategies might realise the communicative potential and create a place of debate?

Hakiwai presents an exciting point of departure:

In some cases we do embrace the forum through the concept of Mana Taonga. We embrace that not consciously I suppose...I think the way that we use forum is more in terms of we have a lecture theatre...or the Marae and the forum must be there. But we actually invoke the concept of a forum through the participation of Iwi and our communities in the processes. So back of house, meetings, whether it's here or in the country, we are actually debating, working through issues, and to me that's actually a concept of forum. But I think it's couched without intuitively saying 'oh, we are going through a forum process'. It's more of a Mana Taonga active engagement... 
Mana Taonga is the consideration of spiritual and cultural links between ancestral material treasures and people. It is one of Te Papa's founding principles which substantiates the forum idea within museum practice (McCarthy, forthcoming) (see also Appendix M). While this association is not consciously drawn, as Hakiwai points out, Mana Taonga clearly facilitates "active engagement...through the participation of Iwi and...communities in the processes" of museological production and representation. In short, it is a highly political concept of cultural negotiation, contestation and worldmaking. Importantly, the discursive and dialogical nature of Mana Taonga enables the move beyond the ethnic confines of biculturalism and humanises cultural politics. It sheds light on the 'moments or processes...in the articulation of cultural differences' (Bhabha, 1994, p. 1) and consequently corresponds to the hermeneutic approach to cross-cultural dialogue in this thesis. Hakiwai proceeds with another promising concept, the marae or communal meeting place:

...it's a forum. A pōwhiri is people getting together and it is political. People get on the marae and say what they want, which usually they do. But having said that, we engage in those arenas if you like not only here but also out in the community, whether it's talking about cultural centres, taonga or going out. I think Te Papa actively takes that sort of forum out. But we don't acknowledge that or we don't actually record it or document it.

At this stage, I need to recall some previous points made in Chapter One while discussing the 'public sphere'. According to Arendt (1958, p. 198), the 'public realm rises directly out of acting together, the sharing of 'words and deeds". Arendt (1958, p. 198) further asserts that 'action and speech create a space between the participants', the 'space of appearance'. A pōwhiri, a ceremonial welcome or communal meeting, on the marae creates exactly such 'space of appearance' and transforms a gathering place into a discursive space or a place of debate. Importantly, Hakiwai stresses that "Te Papa actively takes the forum out". The physical parameters of the marae are blurred through the political Mana Taonga engagement beyond Te 
Papa's walls shaping 'a space between the participants which can find its proper location almost any time and anywhere' (Arendt, 1958, p. 198). This dialogical terrain reflects the worldmaking of a public sphere 'from a substance...to a movement' (Weibel \& Latour, 2007, p. 101).

These political 'moments' or 'processes' characteristic of a 'forum' are, however, not revealed in museological representations at Te Papa and therefore remain inaccessible to visitors.

Remarkably, none of the interviewees and focus group participants in this research referred to concepts such as Mana Taonga. They relied instead on the interpretive support in the form of guided tours, as I highlighted in Chapter Four, to get at least a glimpse of the complex consultations and 'interpretive contests' occurring behind the scenes. It is again Hakiwai who supports such a critique:

I think the process is just as important, if not more, than the actual end product... we don't reveal the processes here well enough. It's quite intuitive and we perhaps know them in-house, but we are not that explicit in the front of house. I think if people knew exactly what we do to create these products or these things on the floor and experiences, they would be quite astounded. I dare say there are still members of the public who think that these exhibitions and so forth are done by a few people coming together. If they knew that there were in some cases hundreds and thousands of people involved in the creation, I think the mindset would be 'huh, that's empowering, that's really affirming, that's different'. And I think that's the point of difference and probably as we go forward there will be a bit more of that in terms of communicating that far more to the public...we might know that we work with a lot of tribes. And it has taken years and negotiations, hui, but that's not readily known. We don't communicate that. In some cases that's actually a very important part of the story, of the processes themselves. Rather than come in and see an exhibition, knowing that you have invested that time, that energy, the relationships that would actually help the visitors to understand what this museum stands for.

While Hakiwai only speculates about the lack of awareness of the political processes in museum practice among "members of the public", Chan from Canada lends empirical weight to this assumption with his discussion of a "second level of interactivity":

...with the whole idea of the forum there gotta be interactivity...normally when you think of interactivity as far as museums goes you think of interactivity with the exhibitions 
themselves. But when you use the word 'forum' I would actually think that the interactivity would go another step and it would be interactivity in the development of the exhibitions themselves. And I am not sure whether Te Papa does that or not, but when I think of the word 'forum' now I associate it with that kind of interactivity...in general that gets back to the idea of that second level of interactivity where it's not just the immediate pushing the buttons thing. You are actually contributing to how that exhibition is being designed.

Chan allows us to return to the issue of "interactivity" in the context of exhibition development, the active input in such processes, rather than the mechanical interaction with the finished product. In Te Papa's case there certainly exist extensive community consultations and contributions as through Mana Taonga, but the dynamic negotiations remain hidden back of house and do not enter the museum experience and the associated interpretive actions, movements and performances which I illuminated in the preceding chapters.

I have addressed elsewhere the chasm between museological production and representation and argued for a shift in conceptualising exhibitions: from products to be presented to processes to be revealed. By presenting the processes leading to the definition of categories and the interpretation of identities, and by giving faces to decisions made, the reflexive museum can become an epitome of democracy which does not silence controversies but awards diversity public voices (Schorch, 2009). Such an understanding of the reflexive museum is linked to recent thinking in museum theory. For example, R. Mason (2006, pp. 28-29) quotes Bal's 'metamuseal function' and states that 'museums would do well to foreground their own histories and contexts within the space of their displays'. Message (2006, p. 183) supports this assertion and by referring to Te Papa she argues that 'making a display of its own story in order to tell the interaction between institution and community would offer an extremely effective embodiment of biculturalism'. New strategies in museum practice correspond to such theoretical arguments, by developing from 'self- 
representation' to 'reflexive representation' (Pieterse, 1997) and from an 'informing museology'

to a 'performing museology' (Kirshenblatt-Gimblett, 2006). Macdonald and Basu (2007) provide an overview of contemporary 'exhibition experiments' insisting that any exhibitionary practice generates rather than reproduces knowledge and experience.

While the described shift to a processual representation opens the door to cultural 'productions' behind the scenes, it remains to establish a dialogical relationship or "two-way conversation" with the site of 'consumption', the visitor. It is again Chan who offers a suggestion:

\begin{abstract}
I think historically the Roman forum idea had the connotations of presenting and discussing ideas because the politicians and philosophers would come up there and actually use it as a place to speak. And then people would respond in the audience and so forth. I can't really think of a modern equivalent to that besides the internet. It's the one area where I think that could happen... If you think about the way our whole society is moving currently in the $21^{\text {st }}$ century. The internet really is the closest you can come to that. And if you look at the way the US election moved a lot of the grassroots to get on the ground and interact and take part. The impact of the internet was huge, just really the $21^{\text {st }}$ century version of the Roman forum I think.
\end{abstract}

The impact of the internet on social, cultural and political life is beyond any reasonable doubt. In fact, it is one of the driving forces shaping the 'cosmopolitanised' world we encounter in the $21^{\text {st }}$ century. In a museological context, modern means of communication have been successfully implemented to establish discursive interaction with visitors (Simon, 2010). However, the fact that contemporary communication media are almost unconditionally celebrated as the peak of the predominant development and progress ethos forecloses a critical perspective on the nature of the dialogue itself. Richard from Australia alerts us to the "serious" limits of the "easy" internet which does not guarantee the creation of a museum as 'forum':

But it's far more personal to actually go there, and certainly more interactive, more discussion-like I suppose, to actually go to a museum and see the exhibits rather than just read it off the internet... Well, there is hundreds of thousands of internet forums out there... Yeah, that's more of a not so serious thing. I don't think it's really productive 
in a sense... Well, there is just a lot of people just wasting time out there (others agreeing)... But the internet is just such an easy example because anyone can go there. And it's so easy to communicate, that's why it's so prominent.

Richard's point is significant because it epitomises a view which remains largely unexamined. While the new and "easy" 'form' of conversation is hailed as a breakthrough, its 'content' often lacks "serious" depth. In other words, internet interaction through channels such as Twitter degenerates into a communication for the sake of communicating, a focus on 'form' at the expense of 'content'. Furthermore, critical voices have highlighted that 'due to self-selection of sources of information and social networks, people rarely engage with those who hold opposing views' (Merritt, 2009, p. 16). This culminates in an 'irresistible uniformity' within communities of interest despite the almost axiomatic 'claims about the production and multiplication of diversity' (Slater, 2008, p. 78). In my view, the internet or other electronic avenues of communication can invigorate the 'space of appearance' and therefore the dynamics of a museum 'forum' involving production, representation and experience. This does not, however, automatically create a "personal” 'proximity' needed for moral and political engagement.

So while I certainly support the exploration of modern 'forms' of communication to bridge the gap between museological 'production' and 'consumption', I argue that it is even more important to create an inherently dialogic 'content' within exhibitionary representations. I call for a reflexive museum practice that pays tribute to the 'inescapable hermeneutic complexity in moral and political affairs' (Held, 2008, p. 161). In short, the reflexive museum as 'forum' lays open the inherently contested processes of cultural worldmaking, the endemic 'polysemy' and hermeneutic relativity in the 'construction of culture' and 'invention of tradition'. Such politicised and moralised representations would open the doors to the 'interpretive contests' backstage and 
encourage the hermeneutic actions, movements and performances of visitors within the discursive space of the 'museum forum'. In this case, both museological production and representation stimulate the political dynamics of the museum experience marrying the three dimensions within a pluralist cosmopolitan space. The outcome would be a vibrant public sphere, which breaks up and enriches the spaces 'in between' democratic actors and their 'enunciations' beyond homogenising and essentialising totalisations of state versus museum or museum versus visitor.

My view of the museum as 'forum' is again linked to related thinking in museum theory and practice. Witcomb (2003, p. 161) discusses the concepts of 'interactivity' and 'polysemic exhibition practice' and dissects a particular example of a 'museum open to historical interpretation' that 'can only be tentative and open-ended'. Bennett (2006, pp. 62-63) treats 'hybridity' and 'dialogism' as 'regulative principles for museum practices' attesting to the 'multiaccentuality of meaning'. This theoretical reasoning has been fruitfully translated into ‘experiments in dialogic representation’ by Hutchison \& Collins (2009).

Not surprisingly, all three laudable perspectives refer to the immanently dialogic nature of narrative or Bakhtin's terminology of 'polyphony' and 'heteroglossia' (Holquist, 2002). I presented these interpretive phenomena in more detail in Chapter Two and want to briefly recall them here to conclude my interrogation of the reflexive museum beyond other conceptualisations (Black, 2005; Lang, Reeve, \& Woollard, 2006). In Chapter Three, I highlighted the crucial role of narrative in contextualising content, structuring space and display, and facilitating meaningmaking. Following E. M. Bruner \& Gorfain (2005), I argue that narrative can lay bare the 
'struggles over meaning' and 'layers of contestation' characteristic of human affairs. E. M. Bruner \& Gorfain's (2005, p. 170) 'dialogic narration', which 'recognises that no story is "a" story or "the" story, but rather each story is a dialogic process of many historically situated particular tellings', would open a hermeneutic terrain of negotiation and contestation within a reflexive museum practice. To put it succinctly, 'dialogic narration' creates 'intersubjectivity' and therefore politicises and moralises the ambivalent discursive space that is the 'museum forum' through this dialogical interplay of museological production, representation and experience.

\section{Humanising cultural politics}

The 'dialogic narration' with its inherent multiplicity of viewpoints brings us back to the nature of a pluralist cosmopolitan space postulated in this thesis. Only by humanising cultural politics through stories, faces and personal opinions can a discursive space as a museum 'forum' become truly politicised and moralised. In this last section of the chapter, I present first some research findings before concluding with a theoretical refinement. I turn to visitor focus group informant Samantha from Canada, who stresses the significance of the "personal":

In my experience as a tour guide I often get people who have been here. And they are looking for somebody to talk to about it to be honest. They've looked at the displays and they've come up with some questions and they are looking for opinions from people who live here. And often they will ask about the Treaty of Waitangi or about Mãori culture. And so yeah, even though they don't live here and even though they are just passing through, they really take in what's here and then want more. They want more personalised opinion really, because what's here is obviously carefully constructed not to be too opinionated. They are looking for personal opinion, I find... So they learn about Màori culture, then they go 'so this treaty thing... what's the real story here, why are people still grumpy about it?' 
Chan, who was part of the same focus group, expands on the impact of "personalised opinion" to "bring something to life" and facilitate a different "level of understanding" through human intervention in the form of a guided tour in his own past museum experience:

The ability to bring something to life. You can look at a display about solidarity and you go 'oh, yes that very important'. But when somebody talks about it and says 'yes, I was there', suddenly just the whole level of understanding ... I think it's a stronger experience if you are physically there and meet the person face to face I think. You can get a version of it by having a discussion online, but I don't think it's quite as emotional.

Importantly, Chan stresses the limitations of "online" interaction which operates over an interpersonal 'distance' and fails to generate the "stronger experience" of "face to face" 'proximity'. This is reminiscent of my preceding discussion on senses, feelings and embodiment as conditions of meaning-making flowing into the processes of meaning-making and formation of opinions. Hakiwai agrees with Chan's view and offers the perspective of a museum professional: ...collections online and all those other things. Yeah, that's a part of it. But I don't think you can dismiss the personal, the interactive, the one on one, the kanohi ki te kanohi, the face to face, the meeting and experiencing.

Charlie, also from Canada, elaborates on particular exhibits at Te Papa which are not "carefully constructed not to be too opinionated" but instead offer an encounter with a "person face to face":

I kind of got that when I went through the Waitangi exhibit actually. You could basically flip the panels from one side to another and one side would be the Mãori perspective and the other side would be the European perspective. And I thought that actually was quite interesting because it actually generated some emotion in me when I was reading these things. And that's because of the opinion of it...I mean they had a display at some point of the whole nuclear free thing. And it presented a lot of what was in the newspaper and what people were protesting and what was going on. And you did get a sense of the emotional debate that would have been going on at the time.

Charlie's comment attests to the interplay of the "personal" and the "emotional" within the realm of cultural politics. In this case, both museological representation and experience clash in a dialogue of opinions and consequently politicise and moralise the discursive terrain called 
'museum forum'. The conceptualisation of a museum as pluralist cosmopolitan space would travel another step further by humanising the abstract categories "Māori perspective" and "European perspective" through stories, faces and opinions and therefore pay tribute to the ubiquitous 'difference within'. To put it another way, the individual is the genesis of cultural politics and not vice versa. Part of that is not only the humanisation of cultural representations but also the reflexive opening to cultural productions through the display of stories, faces and opinions of persons involved in exhibition developments. In short, all museum dimensions need to be geared towards the 'freedom of opinion' (Arendt, 2006) in order to create a 'museum forum' as a particular 'public realm' and 'place for human excellence' (Arendt, 1958, p. 49).

\section{Summary}

In the first section of this last interpretive chapter, 'Self-reflexivity, Self-critique, Selftransformation', the shifting Self evolved into a reflexive Self. Susan concluded that 'I've learned a lot in this trip" and underwent a transformation of Self since "it really opened my eyes to a lot of parts of the world". The interviewees' interpretive ontological endeavour assumed the character of a 'Self-ethnography' which consciously politicised and moralised the partly unconscious 'cosmopolitanisation' of Self/Other relationships. The research material disclosed 'moments' of critique and 'processes' of transformation of the Self while the relativity of otherness was further compounded throughout the shifting hermeneutic positioning.

'Political opinions and moral demands' represented the last stage of visitors' narrative journeys through Te Papa. The discursive pluralist cosmopolitan space became fully politicised and moralised through the 'articulation' or 'enunciation' of an 'interpretive contest' carrying the 
emotive dimension into the context of cultural identity politics and political discourse. Here I discovered interpretive instances of a 'forum' in visitors' narrations. Mike's assertion that "history is written by people" attested to the humanised hermeneutic condition of cultural worldmaking. At this point in the thesis, I completed the narrative exploration of Te Papa as a global public sphere.

The last section embedded the interpretive actions, movements and performances unearthed through in-depth narrative interviews with global visitors to Te Papa into a discussion of the 'forum' concept. In other words, I related the first order research questions to the second order research questions (discussed in Chapter Two) closing, if only tentatively, the overarching hermeneutic circle of this thesis. The pluralist cosmopolitan space, which arose out of the empirical evidence, gained a different quality with implications for museum theory and practice. I laid out the synthesis of the physical and dialogical dimensions of a 'museum forum' shaping a place of debate, and postulated the reflexive museum which consciously invigorates the discursive interplay of museologial production, representation and experience. In this context, the humanisation of cultural politics rendered moral and political engagements possible and facilitated the translation of 'performative democracy' from theoretical pondering into a vibrant praxis. 


\section{Chapter Six}

\section{Conclusion}

This 'idea of the human person'...For Durkheim the sacredness of the person could become one of the few cultural ideals capable of providing a crucial point of unification for an increasingly differentiated, yet interdependent, world. (Featherstone, 1990, p. 4)

The reflexive project of the self might therefore be the very hinge of a transition to a global order beyond the current one...the personal and the global are interconnected... (Giddens, 1991, p. 223)

This thesis set out to explore the 'museum forum' idea to find answers to the questions: What does it mean to experience a museological space and how is a public sphere lived? What does cross-cultural dialogue mean for the person experiencing it, and how is it negotiated within time and space? The nature of these questions required this study to be embedded in the academic fields of museum studies and museum visitor studies. I identified a lack of qualitative long-term visitor insights into the functioning of the new museology. I proceeded by establishing innovative and sophisticated theoretical and methodological frameworks to address these questions and help to fill the gaps in relevant knowledge. Drawing on a long-term narrative study of global visitors to Te Papa, I treated 'cross-cultural dialogue' and the 'public sphere' as interpretive actions, movements and performances, rather than detached abstractions. The hermeneutic analysis enabled me to illuminate the complex processes of cultural worldmaking within a discursive museum space such as Te Papa. This thesis humanised identity politics through the stories and faces of cultural actors revealing the narrative negotiation and contestation of cross-cultural meanings in time and space. 
Before I continue with an account of the empirical findings, my own interpretations and theoretical propositions, I need to qualify this research with regards to certain limitations. This thesis offers a rich in-depth case study of global visitors to Te Papa and is contextualised through a specific geographical place and historical point in time. It does not intend to provide representative claims relating to all museums in the world. However, I regard this as a limitation of the scope and not of the nature of this thesis. It requires further case studies and not decontextualised theorising to draw a nuanced picture of the museum world. I concur with Bourdieu's (1998, p. 2) view on 'research in which the theoretical and the empirical are inseparable'. Bourdieu (1998, p. 2) continues:

My entire scientific enterprise is indeed based on the belief that the deepest logic of the social world can be grasped only if one plunges into the particularity of an empirical reality, historically located and dated, but with the objective of constructing it as a 'special case of what is possible', as Bachelard puts it, that is, as an exemplary case in a finite world of possible configurations.

Adhering to this scientific ethos, I sought to shape 'a form of lens, a way of seeing things' (Gergen, 1991, p. 2) through a theoretically and critically informed empirical case study. It is ultimately up to the reader to decide if and to what extent this 'exemplary case' is useful to dissect other 'possible configurations'.

A further limitation is the research sample and its characteristics. Due to the qualitative spirit of this thesis, it was again not my goal to obtain representative data from among all visitors to Te Papa. The group of respondents was sampled based on defined criteria which inevitably affected and limited the entire research process. The sampling criteria of nationality especially might seem contradictory to the theoretical framework of this study which is embedded in a 'cosmopolitanised' world. But again, I consider this as a limit of this research's scope and not of 
its character. In the course of this concluding chapter, I offer suggestions to expand the scope of this study to reflect the human condition of the $21^{\text {st }}$ century in the human sciences in general as well as museum studies in particular. Within the context of this thesis, the national definition of place, or informants' country of origin, was counterbalanced by insights into Te Papa as a ‘cosmopolitanised' discursive space. As Giddens (1991, p. 187) reminds us: 'Although everyone lives a local life, phenomenal worlds for the most part are truly global.' In other words, a locally or nationally defined individual can offer insights into global experiences.

Although this thesis is situated within museum and visitor studies, its cross-disciplinary ramifications reach beyond clear-cut demarcations of academic fields. The unique character of this study in theoretical, methodological and empirical terms opens a trans-disciplinary terrain to explore the complex phenomenon of human experience. In my view, the research approach itself contributes to our understandings in the human sciences, which becomes even clearer once I subsequently discuss the conclusions in more detail. Importantly, any disciplinary considerations were provoked by the research question itself and not by pre-defined intellectual routes. That is, I used theoretical and methodological tools which assisted me in making sense of Te Papa as a 'museum forum' without being confined to particular disciplinary parameters.

The theoretical framework laid the foundation for the empirical investigation of cross-cultural dialogue in a discursive museum space. For this purpose, this thesis was embedded in the ubiquitous reality of 'Traveling cultures in a cosmopolitanised world'. This enabled me to interrogate a particular case within a global context venturing beyond the limiting definition of exclusively local, regional or national research problems. The theoretical argument did not stop at 
this stage but was geared towards its methodological translation and empirical analysis. I broke down the 'cosmopolitanised' world to theorise museums as particular 'contact zones' in the clash of cultures. The conceptual understanding of museums as 'contact zones' has been widely appropriated in the museum literature and beyond. But once again, the discussion lacks empirical insights. What does 'contact' mean? How is it lived, negotiated and contested?

I drew on the concept of 'Third Space' to theoretically transform the place of cross-cultural contact into a discursive space of cross-cultural dialogue. The 'Third Space' equipped me with the theoretical instrument to shed empirical light on the 'moments' and 'processes' of cultural worldmaking. This entailed humanising Te Papa as a particular global public sphere or forum through the empirical examination of 'cultural action' in the form of 'interpretive contests' and their 'articulation' or 'enunciation' by cultural actors or visitors. The ethnographic humanisation of theoretical concepts such as the 'public sphere' and 'cross-cultural dialogue' sets this thesis apart from other approaches in the related fields of museum studies, critical theory and cultural studies. This point of difference becomes even more evident once the theoretical argument is translated into a methodological framework.

I completed the theoretical framework by introducing 'narrative' as a human sense-making tool to elucidate the dynamics of cultural politics and worldmaking through interpretive actions, movements and performances. My discussion of 'Hermeneutic methodology: action, narrative, meaning, Self' allowed the transition from the theoretical to the methodological realm of my argument. This study was subject to a 'double hermeneutic' condition, meaning that I reflected on the informants' reflections and constructed a narrative out of their narrative constructions. The 
narrative-hermeneutic approach of this thesis has delivered empirical insights beyond most visitor studies, which often ignore both the complexities of 'situations' and the uniqueness of 'individualising qualities' characteristic of any museum experience.

My interpretive investigation did not produce narrow definitions of 'meaning' such as its equation with 'learning', the achievement of purely cognitive goals as postulated by Falk \& Dierking (2000). In my view, Falk's (2009) latest attempt to simplify and reduce the complex issue of 'identity' to 'needs', which can be categorised, measured and predicted, attests to the 'psychological fallacy' (Dewey, 1934) in the field. Human beings are degraded to rational and economic machines, and consequently such studies are useful only for marketing and very specific educational purposes, as Kesner (2006) aptly points out. This explains once again why I feel that this ethnographic study is more closely related to anthropological perspectives examining the site 'museum'.

The narrative-hermeneutic exploration enabled me also to circumnavigate the essentialising dilemma of theoretical totalisation by humanising the critique itself through the stories and faces of real persons or visitors. By following such humanised and nuanced interpretive paths in the course of this research, I theorised and critiqued through the experience of human beings and avoided 'anemic' cultural abstractions based on detached and mechanical reasoning. Another useful example of a related analytical strategy is Witcomb (2003, p. 81), who distances herself from the normative absolutism in most cultural studies and, again departing from Clifford's (1997) 'contact zone', interrogates the cultural frameworks of particular museums and suggests 
that we 'think of museums themselves as communities'. Staniszewski's (1998) attempt to 'anthropomorphise an institution' represents a further interesting case study.

After establishing the methodological framework, I set out to analyse the empirical findings. The research material revealed what I called the conditions of meaning-making, the interpretive foundations which facilitated the subsequent processes of meaning-making or interpretations. In my view, this analytical 'distinction' was fruitful since it offered fundamental insights into the hermeneutic condition of human actions, here within a museological context. However, this did not culminate in an experiential 'separation' of these spheres, since both the conditions and processes of meaning-making continuously mediated each other and were performed in a circular hermeneutic way. I identified different dimensions of the conditions of meaning-making; and I turn now to some concluding comments on their disciplinary contributions.

The empirical evidence exposed the interplay of content, context and narrative. Narrative facilitated the symbiosis of content and context conditioning the interpretive processes of meaning-making. These insights were invaluable for the revision of museological approaches overemphasising factual knowledge while disregarding the conditions of its attainment. Ricoeur (1981, p. 44) reminds us that 'a sensitivity to context is the necessary complement and ineluctable counterpart of polysemy', the characteristic by which all human phenomena 'have more than one meaning when considered outside of their use in a determinate context'. Any museum or art gallery operates in a specific 'determinate context'. Being self-aware of this inherent limitation and opening up to a multiplicity of contexts would pay tribute to the hermeneutic condition of human affairs and create a 'polysemic exhibition practice' (Witcomb, 2003). In the case of an art 
gallery, this might best be achieved through a communicative contextualisation and polysemic representational mode, as we have seen in the discussion on the media "landscape". This would enable the shift from the linear communication and education of 'facts', both historical and aesthetic, to the interpretive negotiation of human constructions such as 'history' and 'art'.

The engagement with a museum space started on a sensory, emotive and embodied level disclosing emotive and sensory contextualisation as conditions of meaning-making. Visitors' narrations revealed that emotions and feelings were not separate stages of the museum experience but were continuously interwoven with intellectual and interpretive processes. Importantly, the empirical evidence showed that certain meanings remained on an embodied level as an "internal understanding" and resisted any verbal 'expressibility'. This finding had methodological implications. It required a hermeneutic sensitivity beyond the spoken word to investigate the 'growth of meaning' or 'development of understanding'. In other words, I shed light on 'embodied meanings', or inherently interpretive feelings, without committing phenomenological de-contextualisation. This theoretical and methodological sensitivity clearly differentiated this thesis from other narrative approaches in museum visitor studies and related disciplines. With regards to the conditions of meaning-making, I concluded that being means feeling, understanding and interpreting. This ontological fundament had, of course, multifaceted implications for our understanding of human concepts such as 'Self' and 'Other'.

Visitors' 'Cross-cultural journeys' epitomised the heart of this study. The conditions flowed into the processes of meaning-making during cross-cultural encounters. Here I observed the entry of feelings into the realm of culture. The empirical findings of this study highlighted the ubiquitous 
presence of cultural feelings which are largely ignored in conventional approaches to cultural studies, not least museum visitor studies. On the one hand, the normative, which is undoubtedly an inherent dimension of any cultural meaning, is awarded the status of absolute dominance by an 'invisible actor behind the scenes' (Arendt, 1958) in the form of a monolithic state. At the same time, these 'anemic' perspectives degrade living men to lifeless shadows. In short, the 'complex prism which is culture' (Featherstone, 1990, p. 2) is naively reduced and reified producing significant shortcomings in our understanding of identity politics.

The voyage culminated in a 'Cross-cultural hermeneutics: the shifting Self'. The research material supported my argument that cross-cultural dialogue was processed not only through the opening towards the Other but through the interpretive ontological endeavour of what I termed the shifting Self. Importantly, the associated multiple identifications subjected otherness to an endemic relativity and transformed the 'neither/nor' dilemma of a 'hybrid Third Space' into a 'both/and' prospect of what I called a pluralist cosmopolitan space. This discursive terrain for the interpretive negotiations of a cross-cultural hermeneutics was characterised by a twofold movement of the frame of reference: the simultaneously expanding 'cosmopolitanised' horizon and contracting humanisation of culture through 'stories' and 'faces'.

In my view, the conceptual understanding of the shifting Self offers the clearest mirror of contemporary identity formations. In a 'cosmopolitanised' world, identities in their ethnographic sense are neither purely essential and coherent nor completely fragmented and fluid, as the dualistically opposed perspectives claim. The inescapable mixing of 'traveling cultures' requires us to shift between discursive positions, a simultaneously transient and continuous task. This 
interpretive ontological endeavour finds its expression in a 'situational localisation' (Boomers, 2004) of the Self. In other words, Self and Other, us and them, are articulated from a certain perspective until changing situations and circumstances provoke new 'moments' and 'processes' of selfing and othering. To put it succinctly, the sense of Self is at once both coherent and fluid it is shifting.

Scholars of museum studies have pondered 'third spaces' (Bodo, 2008), 'the cosmopolitan museum' (Kreuzzieger, 2008), 'integrated diversity' (Sandell, 2007) and the 'shift from discourse about others to discourse about othering' (Pieterse, 1997, p. 141). All these perspectives represent important pieces of the overall puzzle of a pluralist cosmopolitan space which shapes and strengthens our 'inner mobility' (Beck, 1997) to meet the daily challenges of a life 'in-between' differing, overlapping and contradictory worlds. In my view, museums are unique places to unearth and stimulate the 'moments or processes...in the articulation of cultural differences' (Bhabha, 1994, p. 1) sabotaging the reductionist trap of binary oppositions and melting the iron grid of an 'ethnic structuralism' (Williams, 2003). The pluralist cosmopolitan space emerging from the research material offered a discursive remedy for the pain of chronic 'underreading' in cultural characterisations and even eroded the 'untranslatable' (Bhabha, 1994) leading to 'higher forms of understanding' (Dilthey, 1976) without being trapped in the reformist projects of tolerance and diversity.

In the last interpretive chapter, the emotive dimension moved into the realm of political discourse and cultural identity politics. Here, the pluralist cosmopolitan space was morally and politically expressed and negotiated. Consequently, the cross-cultural hermeneutics evolved into an 
'interpretive contest' of political and moral identifications. At this point, I completed the narrative exploration of Te Papa as a global public sphere through interpretive actions, movements and performances by cultural actors or visitors. The unique narrative insights into the hermeneutic nature and meanings of identity politics and cultural worldmaking had implications for our understanding of 'the political', as I subsequently elaborate in more detail. For this purpose, I think it is helpful to further philosophise the empirical findings and theoretical propositions with the ultimate aim of shaping a theoretically and philosophically informed museum practice.

The empirical evidence emphasised that the humanisation of abstract totalities such as 'people', 'history' and 'culture' rendered the moral and political engagement between Self and Other possible. Only the existence of political and moral actors, their stories and faces, could create the discursive conditions of a pluralist cosmopolitan space for the negotiation and contestation of differences, commonalities and understandings. Here, as Arendt (2006, p. 23) insists, 'freedom as the political way of life begins'. 'The actual content of freedom', Arendt (2006, p. 22) continues, 'is participation in public affairs, or admission to the public realm'. In this research, I have shown that a museum such as Te Papa functions as a forum or discursive terrain facilitating the formation and 'enunciation' of opinions. Arendt (2006, p. 217) warns us, however, that there is a 'decisive incompatibility between the rule of a unanimously held 'public opinion' and freedom of opinion'. Only the latter can achieve 'political freedom' (Arendt, 2006) and the 'deuniversalisation of political subjects' breaking 'with all forms of essentialism' (Mouffe, 1999, p. 754). In other words, a humanised pluralism is the fundamental precondition of 'the political'. These are the stories and faces of a pluralist cosmopolitan space. 
'The modern loss of respect', Arendt (1958, p. 243) further argues, 'constitutes a clear symptom of the increasing depersonalisation of public and social life'. Accordingly, fellow anatomist of modern life Bauman demands 'the resistance to objectification' (1995) to 're-personalise' morality (1993). In the museum literature, Witcomb (2009) elaborates on 'the importance of the personal' and Chakrabarthy (2002) places 'museums in late democracies' by postulating a 'performative' model of democratic engagement which recognises that 'the personal is political' through the 'domain of the embodied and the sensual'. A 'museum forum' as a pluralist cosmopolitan space lays the discursive foundation for 'cultural action' in a public sphere which evolves 'from a substance...to a movement' (Weibel \& Latour, 2007). In this thesis, I have substantiated this perspective both empirically and theoretically. Importantly, this would enable the shift from a closed, reformist tolerance to an open, critical engagement and consequently from a pedagogic to a performative sense of democracy (Chakrabarty, 2002).

The emotive dimension carried through the interviewees' narrative journeys and remained at the heart of the human condition: from the experience of a museum space to the 'articulation' of political opinions and moral demands. Here, the conditions of meaning-making flowed into 'the political'. The long-term research drawn on in this thesis has offered empirical insights into the ongoing negotiation of embodied experience, memory and knowledge. I excavated interpretive examples of a performative sense of democracy within a discursive museum space enriching and moving beyond theoretical perspectives in the literature (Chakrabarty, 2002; Weibel \& Latour, 2007). The omnipresence of cultural feelings requires 'the political' to be re-conceptualised to leave the 'utopian self-abstraction' (Warner, 1993) of a rational consensus behind and 'mobilise those' inescapable 'passions towards the promotion of democratic designs' (Mouffe, 1999, pp. 
755-756). Mouffe (1999) reaches theoretically from the abstract world of the thought into the concrete realm of life and stresses that the political is characterised by an 'ineradicability of power, of antagonism' and of 'passions'. I lent empirical weight to this assertion and concluded that being means feeling, understanding, interpreting and contesting.

The profound impact of museum experiences that was observed in visitors' narratives attested to my conception of traveling as a 'cultural praxis' (Struck, 2004) negotiating 'in-between' cultures as 'contingent scheme[s] of meaning' (Ong, 1999) in a 'cosmopolitanised' world (see Chapter One). Of course this does not amount to a totalising claim of a representative reflexivity among all travelers, a position which would be best described as naive. But reducing travel to an elitist accumulation of cultural capital (Bennett, 2006) or apocalyptically prophesying that 'the tourist is bad news for morality' (Bauman, 1993, p. 242) does justice neither to the multifaceted nature and complex history of 'traveling cultures' nor to the diverse travel experiences of this research's informants. Ethnographic accounts and hermeneutic approaches as seen in this thesis, which marry understanding, explanation and critique, deliver a nuanced analysis instead of detached generalisations which totalise from a singular perspective without acknowledging their inherent limitations and being unaware of their own 'epistemic doxa' (Bourdieu, 1998).

What are this thesis' implications for museum theory, practice and future research? In this context, I expanded on the reflexive museum as potential embodiment of democracy by publicly expressing diversity instead of silencing controversy (Schorch, 2009). I critically assessed the role of modern forms of communication to bridge the gap between museological 'production' and 'consumption', and insisted that it is even more important to create inherently dialogic 
'representations'. The reflexive museum as 'forum' exposes the immanently contested 'moments' and 'processes' of cultural worldmaking and invites the visitor to take part in the 'interpretive contest' behind the scenes. In this case, both museological production and representation stimulate the political dynamics of the museum experience, marrying the three dimensions within a pluralist cosmopolitan space.

The translation of the reflexive museum from theory into practice brought us once again back to narrative and the humanisation of cultural politics. Based on the intrinsically dialogic nature of narrative captured in 'polyphony' and 'heteroglossia', I argued that E. M. Bruner \& Gorfain's (2005) 'dialogic narration' can lay bare the 'struggles over meaning' and 'layers of contestation' in cultural worldmaking within museological representations. This opens a hermeneutic sphere by creating 'intersubjectivity', which in turn politicises and moralises the discursive space that is the 'museum forum'. The dialogical interplay of museological production, representation and experience would shape a theoretically informed reflexive museum practice that pays tribute to the 'inescapable hermeneutic complexity in moral and political affairs' (Held, 2008, p. 161).

The 'dialogic narration' with its inherent multiplicity of perspectives can be realised through the pluralist cosmopolitan space postulated in this thesis. The humanisation of cultural politics through stories, faces and personal opinions represents the discursive precondition of a 'museum forum'. The empirical evidence highlighted the reciprocity of the "personal" and the "emotional" embodied in the meanings of identity politics. I insisted that the individual is the genesis of culture and not vice versa. This implies not only the humanisation of cultural representations but also the reflexive opening to cultural productions. In summary, all museum dimensions need to 
be geared towards the 'freedom of opinion'. This would sensitise us to the inevitability of conflict in cultural politics, which is subject to a hermeneutic complexity and can only ever achieve the ambivalent and contingent state of a 'conflictual consensus' (Mouffe, 1999). Here, 'performative democracy' evolves from theoretical reasoning into a lived praxis.

With regards to future research, I want to offer some suggestions. Firstly, I think that the unique museological interplay of production, representation and experience requires in-depth case studies. By exclusively focusing on one sphere or by completely neglecting another, research will always draw an artificially partial picture. While all dimensions demand an analytical 'distinction', this should never amount to their rigid 'separation'. In my view, the focus on the dynamic 'relation' between the different museological spheres delivers the most fruitful and comprehensive contributions to museum theory and practice by avoiding mechanical reductionism and determinism. The literature offers some laudable examples of such an approach (Macdonald, 2002; McCarthy, 2007; Witcomb, 2003). The unique facet of this thesis is an indepth and long-term understanding of the museum experience without, however, neglecting the interrelated dynamics of production and representation.

On the most general level, this study revealed the depth of meanings beyond simplistic success indicators such as the attracting and holding power of exhibits. These unique visitor insights should help both museum theorists and practitioners to reflect on the meanings of their respective positions and actions. Considering the long-term impact of the conditions of meaning-making such as spatial feelings of "layout" and "structure" as well as personal encounters on memories is crucial to understanding and initiating the processes of meaning-making in museum theory and 
practice alike. In this context, we saw that the narrative tour intervention humanised culture and cross-cultural dialogue through a face with a story and therefore enabled visitors to sense, feel, interpret and remember culture. This merging of the conditions and processes of meaning-making should consciously enter museological representations to facilitate an interpersonal dialogue among cultural human beings within exhibition settings.

I argue that visitor-centered research approaches as in this thesis can help to foster the dialogue between museum theory and practice. Although Te Papa defines itself as a bicultural museum, the empirical evidence has clearly highlighted the 'cosmopolitanised' nature of the museum experience. These discursive dynamics should flow into the conceptual design of exhibitions and programs creating a cross-cultural museum practice which places humanised cultural perspectives in a global context. This research's findings should also be used in conjunction with narrative and interpretive theory to transform Te Papa's narrative museological representations into a 'polysemic exhibition practice'. In my view, a theoretically and philosophically informed museum practice is much needed. On the other hand, empirically grounded approaches as seen in this study can produce situated, contextualised and rich theoretical propositions. A specific museum offers a particular place, space and empirical reality to interrogate seemingly universal concepts such as 'culture', 'politics' and 'knowledge'. In my opinion, empirically tested and refined human theories in general as well as museum theories in particular are also much needed. The museum might represent the perfect playground to fuse academia and public in the quest for understanding, explanation and critique. 
Another point relates to the frame of reference in cultural and sociological studies. Due to the 'cosmopolitanisation' of the contemporary world, it is of fundamental significance to deconstruct the predominant 'methodological nationalism' (Beck, 2006b) in the human sciences. In this study, I stressed that all respondents were linked to a particular national place while simultaneously being exposed to the experience of a ubiquitous 'cosmopolitanised' discursive space. Analytical strategies need to acknowledge these ever-changing realities, and the museological literature provides interesting cases (Baur, 2009; Beier-de Haan, 2005; Macdonald, 2003; Schorch, 2010). Based on this thesis, it would be very useful to examine the interpretive endeavor of the shifting Self in other regions of the world apart from the postcolonial frontier. I speculate that societies in the 'old world' which are still less 'cosmopolitanised' from within, such as Germany or the Scandinavian countries, might be characterised by the self-deluding attempt to maintain a more essential or fixed cross-cultural hermeneutics. Such speculation contradicts the apparent European focus of the cosmopolitan debate which requires sophisticated empirical investigations instead of further grand theorising.

Departing from this study, the 'tense interaction' between 'identity as a politics' and as 'an inheritance' (Clifford, 1997) deserves more attention in cultural studies. In this context, Macdonald (2003, p. 6) stresses that it 'is at present an open question...how widespread such conceptualisations' as 'identities predicated on cultural mixing and crossover, on intercultural traffic rather than boundary demarcation... are or will become'. Beck \& Bonss (2001) demand qualitative and theoretically informed strategies to examine these new phenomena and relations. I have listened to the empirical call and offered my modest contribution to answer the 'open 
question'. It is up to the reader to decide how far the disciplinary contributions of this research go.

I have come to the close of this thesis, the written expression of several years of research, thinking, reading, rethinking and rereading. I am about to complete the final circle of hermeneutic revision. This is, of course, a somewhat arbitrary and artificial act. I am required to discontinue the inherently organic and endless flow of any intellectual engagement to finalise the academic assignment ' $\mathrm{PhD}$ thesis' within its defined format and timeframe. However, the story I have told lingers on in you, the reader, and in the process of reading becomes subject to further examinations and dissections. This study is, in fact, unfinishable and to a certain extent a purely subjective phenomenon for both writer and reader. Consequently, I feel more like I am concluding my story about the thesis than the thesis as such. Ricoeur's (1991b) insights into the circular relationship of 'life' and 'narrative' illustrate the condition of writing and reading. On the one hand, I have been drawing on academic conventions and linguistic tools provided by cultural 'life' to formulate my dissertation. On the other hand, this specific form of 'narrative' lives on in the interpretive world of you, the reader. 


\section{Bibliography}

Abbott, H. P. (2002). The Cambridge introduction to narrative. Cambridge: Cambridge University Press.

Allen, G., \& Anson, C. (2005). The role of museums in creating multi-cultural identities Lessons from Canada. Lewiston, NY: Edwin Mellen Press.

Allen, S. (2002). Looking for learning in visitor talk: A methodological exploration. In G. Leinhardt, K. Crowley \& K. Knutson (Eds.), Learning conversations in museums. London: Lawrence Erlbaum Associates.

Allen, S. (2004). Designs for learning: Studying science museum exhibits that do more than entertain. Science Education, 88(1), 17-33.

Anderson, D. (2005). New lamps for old: Museums in the learning age. London: Victoria and Albert Museum.

Anderson, G. (Ed.). (2004). Reinventing the museum: Historical and contemporary perspectives on the paradigm shift. Walnut Creek, California: Altamira Press.

Andrews, M. (2002). Introduction: Counter-narratives and the power to oppose. Narrative Inquiry, 12(1), 1-6.

Anon (1940). New Zealand centennial exhibition: The Māori court. Souvenir. Wellington: Native Department.

Appadurai, A. (1993). Disjuncture and difference in the global cultural economy. In B. Robbins (Ed.), The phantom public sphere (pp. 269-295). Minneapolis \& London: University of Minnesota Press.

Appiah, K. A. (2006). Cosmopolitanism: Ethics in a world of strangers. New York \& London: Norton \& Company.

Arendt, H. (1958). The human condition. Chicago: University of Chicago Press.

Arendt, H. (2006). On revolution. London: Penguin books.

Ateljevic, I. (2000). Circuits of tourism: stepping beyond the 'production / consumption' dichotomy. Tourism Geographies, 2(4), 369-388.

Bauerkaemper, A., Boedeker, H. E., \& Struck, B. (Eds.). (2004). Die Welt erfahren: Reisen als kulturelle Begegnung von 1780 bis heute. Frankfurt / New York: Campus Verlag. 
Bauman, Z. (1978). Hermeneutics and social science: Approaches to understanding. London: Hutchinson.

Bauman, Z. (1989). Modernity and the Holocaust. Ithaca, New York: Cornell University Press.

Bauman, Z. (1993). Postmodern ethics. Oxford \& Cambridge: Blackwell.

Bauman, Z. (1995). Life in fragments: Essays in postmodern morality. Oxford \& Cambridge: Blackwell.

Bauman, Z. (1996). From pilgrim to tourist - or a short history of identity. In S. Hall \& P. Du Gay (Eds.), Questions of cultural identity (pp. 18-36). London: Sage.

Baur, J. (2009). Die Musealisierung der Migration: Einwanderungsmuseen und die Inszenierung der multikulturellen Nation. Bielefeld: transcript Verlag.

Beck, U. (1997). Was ist Globalisierung? Irrtuemer des Globalismus - Antworten auf Globalisierung. Frankfurt: Suhrkamp.

Beck, U. (2006a). Cosmopolitan vision (C. Corin, Trans.). Cambridge \& Malden: Polity Press.

Beck, U. (2006b). Kosmopolitisierung ohne Kosmopolitik: Zehn Thesen zum Unterschied zwischen Kosmopolitismus in Philosophie und Sozialwissenschaft. In H. Berking (Ed.), Die Macht des Lokalen in einer Welt ohne Grenzen (pp. 252-270). Frankfurt/New York: Campus Verlag.

Beck, U., \& Bonss, W. (Eds.). (2001). Die Modernisierung der Moderne. Frankfurt am Main: Suhrkamp.

Bedford, L. (2004). Working in the subjunctive mood: Imagination and museums. Curator: The Museum Journal, 47(1), 5-11.

Beier-de Haan, R. (2005). Erinnerte Geschichte - Inszenierte Geschichte: Ausstellungen und Museen in der Zweiten Moderne. Frankfurt am Main: Suhrkamp.

Bennett, T. (1995). The birth of the museum: History, theory, politics. London: Routledge.

Bennett, T. (1998). Culture: A reformer's science. St. Leonard's, New South Wales: Allen \& Unwin.

Bennett, T. (2006). Exhibition, difference and the logic of culture. In I. Karp, C. A. Kratz, L. Szwaja \& T. Ybarra-Frausto (Eds.), Museum frictions: Public cultures/global transformations (pp. 46-69). Durham \& London: Duke University Press.

Bhabha, H. K. (1994). The location of culture. London \& New York: Routledge. 
Bhabha, H. K. (2008). Notes on globalisation and ambivalence. In D. Held, H. L. Moore \& K. Young (Eds.), Cultural politics in a global age: Uncertainty, solidarity and innovation (pp. 36-47). Oxford: Oneworld Publications.

Black, G. (2005). The engaging museum: Developing museums for visitor involvement. London: Routledge.

Bodo, S. (2008). Developing 'third spaces': A new challenge for the promotion of intercultural dialogue in European museums. Paper presented at the Museums and intercultural dialogue.

Bohman, J. (2004). Expanding dialogue: The internet, the public sphere and prospects for transnational democracy. In N. Crossley \& J. M. Roberts (Eds.), After Habermas: New perspectives on the public sphere (pp. 131-155).

Boomers, S. (2004). Reisen als Lebensform: Isabelle Eberhardt, Reinhold Messner und Bruce Chatwin. Frankfurt/New York: Campus Verlag.

Boswell, D., \& Evans, J. (Eds.). (1999). Representing the nation: A reader. Histories, heritage and museums. London \& New York: Routledge and The Open University.

Bourdieu, P. (1984). Distinction: A social critique of the judgement of taste (R. Nice, Trans.). Cambridge, MA: Harvard University Press.

Bourdieu, P. (1990). The logic of practice (R. Nice, Trans.). Stanford: Stanford University Press.

Bourdieu, P. (1998). Practical reason: On the theory of action. Stanford, CA: Stanford University Press.

Bourdieu, P., \& Darbel, A. (1991). The love of art: European art museums and their public. Cambridge: Polity.

Brueckner, U. R. (2006). Szenografie als interdisziplinaeres Medium zur Dialogisierung zwischen Raum und Objekt, zwischen Inhalt und Rezipient. Berlin: IfM.

Bruner, E. M. (1986a). Ethnography as narrative. In V. W. Turner \& E. M. Bruner (Eds.), The anthropology of experience (pp. 139-155). Urbana \& Chicago: University of Illinois Press.

Bruner, E. M. (1986b). Experience and its expressions. In V. W. Turner \& E. M. Bruner (Eds.), The anthropology of experience (pp. 3-30). Urbana \& Chicago: University of Illinois Press.

Bruner, E. M. (1991). Transformation of self in tourism. Annals of Tourism Research, 18, 238250. 
Bruner, E. M. (1995). The ethnographer / tourist in Indonesia. In M.-F. Lanfant, J. B. Allcock \& E. M. Bruner (Eds.), International tourism: Identity and change (pp. 224-241). London: Sage.

Bruner, E. M. (2005). Culture on tour: Ethnographies of travel. Chicago \& London: University of Chicago Press.

Bruner, E. M. (2007). Abraham Lincoln as authentic reproduction: A critique of postmodernism. In S. J. Knell (Ed.), Museums in the material world (pp. 301-319). London \& New York: Routledge.

Bruner, E. M., \& Gorfain, P. (2005). Dialogic narration and the paradoxes of Masada. In E. M. Bruner (Ed.), Culture on tour: Ethnographies of travel (pp. 160-188). Chicago \& London: University of Chicago Press.

Bruner, J. (1990). Acts of meaning. London: Harvard University Press.

Bruner, J. (1995). Meaning and self in cultural perspective. In D. Bakhurst \& C. Sypnowich (Eds.), The social self (pp. 18-29). London: Sage.

Bruner, J. (1996). Frames for thinking: Ways of making meaning In D. R. Olson \& N. Torrance (Eds.), Modes of thought: Explorations in culture and cognition (pp. 93-105). Cambridge: Cambridge University Press.

Bruner, J. (2002). Making stories: Law, literature, life. New York: Farrar, Straus and Giroux.

Buschmann, H. (2010). Geschichten im Raum - Erzaehltheorie als Museumsanalyse. In J. Baur (Ed.), Museumsanalyse - Methoden und Konturen eines neuen Forschungsfeldes (pp. 149170). Bielefeld: transcript Verlag.

Butler, J. (2000a). Competing universalities. In J. Butler, E. Laclau \& S. Zizek (Eds.), Contingency, hegemony, universality: Contemporary dialogues on the left (pp. 136-181). London \& New York: Verso.

Butler, J. (2000b). Dynamic conclusions. In J. Butler, E. Laclau \& S. Zizek (Eds.), Contingency, hegemony, universality: Contemporary dialogues on the left (pp. 263-280). London \& New York: Verso.

Butts, D. (1994). The orthodoxy of bi-culturalism. New Zealand Museum Journal, 24(2), 32-34.

Calhoun, C. (2002). Imagining solidarity: Cosmopolitanism, constitutional patriotism, and the public sphere. Public culture, 14(1), 147-171.

Cameron, D. F. (1971). The Museum, a temple or the forum. Curator: The Museum Journal, Xiv(1), 11-24. 
Carbonell, B. M. (Ed.). (2004). Museum studies: An anthology of contexts. Malden, MA: Blackwells.

Chakrabarty, D. (2002). Museums in late democracies. Humanities Research, IX(1), 5-12.

Clandinin, D. J., \& Connelly, F. M. (2000). Narrative inquiry: Experience and story in qualitative research. San Francisco: Jossey-Bass Publishers.

Clifford, J. (1988). The predicament of culture. Cambridge: Harvard University Press.

Clifford, J. (1997). Routes: Travel and translation in the late twentieth century. Cambridge \& London: Harvard University Press.

Corsane, G. (Ed.). (2005). Heritage, museums and galleries: An introductory reader. London \& New York: Routledge.

Corvellec, H. (2007). Narrative analysis. In B. Gustavsson (Ed.), The principles of knowledge creation (pp. 187-204). Cheltenham, UK: Edward Elgar.

Coster, J. (1994). A bicultural Museums Association for Aotearoa New Zealand. New Zealand Museum Journal, 24(2), 22-27.

Crick, M. (1995). The anthropologist as tourist: An identity in question. In M.-F. Lanfant, J. B. Allcock \& E. M. Bruner (Eds.), International tourism: Identity and change (pp. 205-223). Sage: London.

Crossley, N. (2004). On systematically distorted communication: Bourdieu and the socio-analysis of publics. In N. Crossley \& J. M. Roberts (Eds.), After Habermas: New perspectives on the public sphere (pp. 88-112). Oxford: Blackwell.

Damasio, A. R. (1994). Descartes' Error: Emotion, reason, and the human brain. New York: Harper Collins Publishers.

Damasio, A. R. (2000). The feeling of what happens: Body, emotion and the making of consciousness. London: Vintage.

Damasio, A. R. (2003). Looking for Spinoza: Joy, sorrow, and the feeling brain. Orlando, FL: Harcourt.

Davidson, L. (2006). A mountain feeling: The narrative construction of meaning and self through a commitment to mountaineering in Aotearoa/New Zealand. Unpublished PhD, Monash University, Melbourne.

Davidson, L., \& Sibley, P. (forthcoming). Audiences at the new museum: A profile of visitors and their commitment to the Museum of New Zealand Te Papa Tongarewa. Visitor Studies. 
Deleuze, G. (1994). Difference and repetition (P. Patton, Trans.). New York: Columbia University Press.

Denzin, N. K. (1989a). Interpretive biography. Newbury Park: Sage.

Denzin, N. K. (1989b). Interpretive interactionism. Newbury Park, California: Sage.

Denzin, N. K. (2001). Interpretive interactionism (2nd ed.). Thousand Oaks: Sage.

Derrida, J. (1981). Positions (A. Bass, Trans.). London: The Athlone Press.

Dewey, J. (1934). Art as experience. London: George Allen \& Unwin Ltd.

Dilthey, W. (1976). Selected writings (H. P. Rickman, Trans.). Cambridge: University Press.

Dudley, S. H. (2009). Museum materialities: Objects, sense and feeling. In S. H. Dudley (Ed.), Museum materialities: Objects, engagements, interpretations (pp. 1-17). London: Routledge.

Dworschak, H. (1994). Kulturdiskurse: Zum Verhaeltnis von Tourismus und indigener Kultur. Muenster/New York: Waxmann.

Elliott, J. (2005). Using narrative in social research. London: Sage.

Everett, M., \& Barrett, M. (2009). Investigating sustained visitor/museum relationships: Employing narrative research in the field of museum visitor studies. Visitor Studies, 12(1), 2-15.

Falk, J. H. (2009). Identity and the museum visitor experience. Walnut Creek, CA: Left Coast Press.

Falk, J. H., \& Dierking, L. D. (2000). Learning from museums: Visitor experiences and the making of meaning. Walnut Creek, CA: Altamira Press.

Featherstone, M. (1990). Global culture: An introduction. In M. Featherstone (Ed.), Global culture: Nationalism, globalization and modernity (pp. 1-14). London: Sage.

Fina, K. (1978). Vom Exponat zum Dialog: Haptische Sachquelle und kritische Graphik in der Lehrerbildung. Schule und Museum: Das Museum in Unterricht und Wissenschaft, 6, 215.

Fina, K. (1979). Eine museumsdidaktische Theorie: Der phaenomenologisch-hermeneutische Ansatz. Schule und Museum: Das Museum in Unterricht und Wissenschaft, 11, 22-38.

Fisher, W. R. (1987). Human communication as narration: Toward a philosophy of reason, value, and action. Columbia: University of South Carolina Press. 
Fleras, A., \& Spoonley, P. (1999). Recalling Aotearoa: Indigenous politics and ethnic relations in New Zealand. Auckland: Oxford University Press.

Fraser, N. (1993). Rethinking the public sphere: A contribution to the critique of actually existing democracy. In B. Robbins (Ed.), The phantom public sphere (pp. 1-32). Minneapolis \& London: University of Minnesota Press.

Freeman, M. (2003). Identity and difference in narrative inquiry: A commentary on the articles by Erica Burman, Michelle Crossley, Ian Parker and Shelley Sclater. Narrative Inquiry, 13(2), 331-346.

Gable, E. (2006). How we study history museums: Or cultural studies at Monticello. In J. Marstine (Ed.), New museum theory and practice: An introduction (pp. 109-128). Malden, MA: Blackwell Publishing.

Gable, E. (2010). Ethnographie: Das Museum als Feld. In J. Baur (Ed.), Museumsanalyse: Methoden und Konturen eines neuen Forschungsfeldes (pp. 95-119). Bielefeld: transcript Verlag.

Gable, E., \& Handler, R. (2007). After authenticity at an American heritage site. In S. J. Knell (Ed.), Museums in the material world (pp. 320-334). London \& New York: Routledge.

Galani-Moutafi, V. (2000). The self and the other: Traveller, ethnographer, tourist. Annals of Tourism Research, 27 (1), 203-224.

Geertz, C. (1973). The interpretation of cultures. London: Fontana Press.

Geertz, C. (1986). Making experiences, authoring selves. In V. W. Turner \& E. M. Bruner (Eds.), The anthropology of experience (pp. 373-380). Urbana \& Chicago: University of Illinois Press.

Gergen, K. J. (1991). The saturated self: Dilemmas of identity in contemporary life. New York: Basic Books.

Giddens, A. (1987). Social theory and modern sociology. Stanford, CA: Stanford University Press.

Giddens, A. (1991). Modernity and self-identity: Self and society in the late modern age. Cambridge: Polity Press.

Greenblatt, S. (1991). Resonance and wonder. In I. Karp \& S. D. Lavine (Eds.), Exhibiting cultures: The poetics and politics of museum display. Washington, DC: Smithsonian Institution Press. 
Gregory, K., \& Witcomb, A. (2007). Beyond nostalgia: The role of affect in generating historical understanding at heritage sites. In S. J. Knell, S. MacLeod \& S. Watson (Eds.), Museum revolutions: How museums change and are changed (pp. 263-275). Oxon: Routledge.

Gurian, E. H. (2006). Civilizing the museum: The collected writings of Elaine Heumann Gurian. London and New York: Routledge.

Gwyn, R. (2000). 'Really unreal': Narrative evaluation and the objectification of experience. Narrative Inquiry, 10(2), 313-340.

Habermas, J. (1984). The theory of communicative action, Volume 1: Reason and the rationalisation of society (T. McCarthy, Trans.). Cambridge: Polity.

Habermas, J. (1987). The theory of communicative action, Volume 2: Lifeworld and system: a critique of functionalist reason (T. McCarthy, Trans.). Cambridge: Polity Press.

Habermas, J. (1989). The structural transformation of the public sphere (T. Burger \& F. Lawrence, Trans.). Cambridge: Polity Press.

Habermas, J. (1999). The inclusion of the other: Studies in political theory. Cambridge: Polity Press.

Hakiwai, A. (2006). Māori Taonga - Māori identity in New Zealand. In B. T. Hoffman (Ed.), Art and cultural heritage: Law, policy and practice. New York: Cambridge University Press.

Hall, S. (1996). Introduction: Who needs 'identity'? In S. Hall \& P. Du Gay (Eds.), Questions of cultural identity (pp. 1-17). London: Sage.

Haller, K. (2003). Lernen im Museum und im Science Center. Munich: Deutsches Museum.

Ham, S. (2002). Meaning making - The premise and promise of interpretation. Paper presented at the Scotland's first national conference on interpretation.

Ham, S. (2007). Can interpretation really make a difference? Answers to four questions from cognitive and behavioral psychology. Paper presented at the Interpreting World Heritage Conference.

Havemann, P. (Ed.). (1999). Indigenous peoples' rights in Australia, Canada \& New Zealand. Oxford: University Press New Zealand.

Healy, C., \& Witcomb, A. (2006). Experiments in culture: An introduction. In C. Healy \& A. Witcomb (Eds.), South Pacific museums: Experiments in culture (pp. 1.1.-1.5.). Melbourne: Monash University ePress.

Hecht, A. (2004). Past, place \& people: An ethnography of museum consumption. Unpublished $\mathrm{PhD}$, University College London. 
Held, D. (2008). Cultural diversity, cosmopolitan principles and the limits of sovereignty. In D. Held, H. L. Moore \& K. Young (Eds.), Cultural politics in a global age: Uncertainty, solidarity and innovation (pp. 157-164). Oxford: Oneworld Publications.

Henare, A. (2005). Museums, anthropology and imperial exchange. Cambridge: Cambridge University Press.

Hennes, T. (2002). Rethinking the visitor experience: Transforming obstacle into purpose. Curator: The Museum Journal, 45(2), 109-121.

Hertie (2008). Conference programme. Paper presented at the The decline and rise of public spaces, Berlin.

Hillier, B., \& Tzortzki, K. (2006). Space syntax: The language of museum space. In S. Macdonald (Ed.), A companion to museum studies (pp. 282-301). Malden, MA: Blackwell.

Holquist, M. (2002). Dialogism: Bakhtin and his world. London \& New York: Routledge.

Hooper-Greenhill, E. (1992). Museums and the shaping of knowledge. London \& New York: Routledge.

Hooper-Greenhill, E. (1995). Museums and communication: an introductory essay. In E. HooperGreenhill (Ed.), Museum, media, message (pp. 1-12). London \& New York: Routledge.

Hooper-Greenhill, E. (2000). Museums and the interpretation of visual culture. London \& New York: Routledge.

Hooper-Greenhill, E. (2006). Studying visitors. In S. Macdonald (Ed.), A companion to museum studies (pp. 362-376). Malden MA: Blackwell.

Howarth, D. R. (2008). Ethos, agonism and populism: William Connolly and the case for radical democracy. BJPIR-The British Journal of Politics \& International Relations, 10, 171-193.

Hutchison, M., \& Collins, L. (2009). Translations: experiments in dialogical representation of cultural diversity in three museum sound installations. Museum and Society, 7(2), 92-109.

Jackson, P. W. (1998). John Dewey and the lessons of art. New Haven \& London: Yale University Press.

Janes, R. R., \& Conaty, G. T. (2005). Looking reality in the eye: Museums and social responsibility. Calgary: University of Calgary Press.

Johnson, M. (2007). The meaning of the body. Chicago \& London: University of Chicago Press. 
Jones, J. P. (1995). Communicating and learning in gallery 33: evidence from a visitor study. In E. Hooper-Greenhill (Ed.), Museum, media, message. London \& New York: Routledge.

Kaplan, F. E. S. (1995). Exhibitions as communicative media. In E. Hooper-Greenhill (Ed.), Museums, media, message. London \& New York: Routledge.

Karp, I. (1991). Culture and representation. In I. Karp \& S. D. Lavine (Eds.), Exhibiting cultures: The poetics and politics of museum display. Washington \& London: Smithsonian Institution Press.

Karp, I., Kratz, C. A., Szwaja, L., \& Ybarra-Frausto, T. (Eds.). (2006). Museum frictions: Public cultures / global tranformations. Durham \& London: Duke University Press.

Karp, I., Kreamer, C. M., \& Lavine, S. D. (Eds.). (1992). Museums and communities: The politics of public culture. Washington: Smithsonian Institution Press.

Karp, I., \& Lavine, S. D. (Eds.). (1991). Exhibiting cultures: The poetics and politics of museum display. Washington: Smithsonian Institution Press.

Kelly, L. (2006). Measuring the impact of museums on their communities: The role of the 21st century museum. Paper presented at the ICOM conference.

Kelly, L. (2007). Visitors and learning - Adult museum visitors' learning identities. In S. J. Knell, S. MacLeod \& S. Watson (Eds.), Museum revolutions - How museums change and are changed (pp. 276-290). London \& New York: Routledge.

Kelly, L., \& Gordon, P. (2002). Developing a community of practice: Museums and reconciliation in Australia. In R. Sandell (Ed.), Museums, Society, Inequality (pp. 153174). London \& New York: Routledge.

Kendall, G., Woodward, I., \& Skrbis, Z. (2009). The sociology of cosmopolitanism: Globalisation, identity, culture and government. London: Palgrave Macmillan.

Kesner, L. (2006). The role of cognitive competence in the art museum experience. Museum Management and Curatorship, 21(1), 4-19.

Kincheloe, J. L., \& McLaren, P. (2000). Rethinking critical theory and qualitative research. In N. K. Denzin \& Y. S. Lincoln (Eds.), The handbook of qualitative research (pp. 279-304). Thousand Oaks, California: Sage.

King, M. (1999). Being Pakeha now: Reflections and recollections of a white native. Auckland, N. Z.: Penguin Books.

King, M. (2003). The Penguin history of New Zealand. Auckland, N. Z.: Penguin Books. 
Kirchberg, V. (2006). Zur individuellen Konstruktion medialer Museumserlebnisse - Die Abhaengigkeit der Vermittlung von eigenen Erfahrungen mit neuen Medien. Berlin: IfM.

Kirshenblatt-Gimblett, B. (1998). Destination culture: Tourism, museums and heritage. Berkeley: University of California Press.

Kirshenblatt-Gimblett, B. (2006). Exhibitionary complexes. In I. Karp, C. A. Kratz, L. Szwaja \& T. Ybarra-Frausto (Eds.), Museum frictions - Public cultures/global transformations. Durham \& London: Duke University Press.

Kraus, W. (2006). The narrative negotiation of identity and belonging. Narrative Inquiry, 16(1), 103-111.

Kreuzzieger, M. (2008). The cosmopolitan museum (of art). Paper presented at the Crossing cultures: Conflict, migration and convergence, Melbourne.

Krmpotich, C., \& Anderson, D. (2005). Collaborative exhibitions and visitor reactions: The case of Nitsitapiisinni: Our way of life. Curator: The Museum Journal, 48(4), 377.

Krueger, R. A. (1998). Developing questions for focus groups: Focus group kit 3. Thousand Oaks: Sage.

Laclau, E. (2000a). Constructing universality. In J. Butler, E. Laclau \& S. Zizek (Eds.), Contingency, hegemony, universality: Contemporary dialogues on the left (pp. 281-307). London \& New York: Verso.

Laclau, E. (2000b). Identity and hegemony: The role of universality in the constitution of political logics. In J. Butler, E. Laclau \& S. Zizek (Eds.), Contingency, hegemony, universality: Contemporary dialogues on the left (pp. 44-89). London \& New York: Verso.

Laclau, E. (2005). On populist reason. London \& New York: Verso.

Lanfant, M.-F., Allcock, J. B., \& Bruner, E. M. (Eds.). (1995). International tourism: Identity and change. London: Sage.

Lang, C., Reeve, J., \& Woollard, V. (Eds.). (2006). The responsive museum: Working with audiences in the twenty-first century. Hampshire: Ashgate.

Latour, B. (2005). Reassembling the social: An introduction to actor-network-theory. Oxford: Oxford University Press.

Lelliott, A., \& Pendlebury, S. (2009). "A large object with a small museum": A narrative analysis of Tlotlo's experience of an astronomy science center. Curator: The Museum Journal, 52(3), 241-260. 
Liu, J. H., Ng, S.-H., Gastardo-Conaco, M. C., \& Wong, D. S. W. (2008). Action research: A missing component in the emergence of social and cross-cultural psychology as a fully inter-connected global enterprise. Social and personality psychology compass, 2(3), 11621181.

Ludwig, K., Has, M., \& Neuer, M. (Eds.). (1990). Der neue Tourismus: Ruecksicht auf Land und Leute. Muenchen: Verlag C.H. Beck.

Maaka, R., \& Fleras, A. (2005). Indigeneity: Challenging the state in Canada and Aotearoa New Zealand. Dunedin: University of Otago Press.

Macdonald, S. (2002). Behind the Scenes at the Science Museum. Oxford, UK: Berg.

Macdonald, S. (2003). Museums, national, postnational and transcultural identities. Museum and Society, 1(1), 1-16.

Macdonald, S. (2010). Museen erforschen: Fuer eine Museumswissenschaft in der Erweiterung (J. Baur, Trans.). In J. Baur (Ed.), Museumsanalyse: Methoden und Konturen eines neuen Forschungsfeldes (pp. 49-69). Bielefeld: transcript Verlag.

Macdonald, S., \& Basu, P. (Eds.). (2007). Exhibition experiments. Oxford: Blackwell.

MacIntyre, A. (1981). After virtue: A study in moral theory. London: Duckworth.

MacLeod, S. (2001). Making museum studies: Training, education, research and practice. Museum Management and Curatorship, 19(1), 51-62.

MacLeod, S. (Ed.). (2005). Reshaping museum space: Architecture, design, exhibitions. London \& New York: Routledge.

Marstine, J. (2005). New Museum theory and practice: An introduction. Malden, MA: Blackwell.

Mason, P. D. M., \& McCarthy, C. (2006). 'The feeling of exclusion': Young peoples' perceptions of art galleries. Museum Management and Curatorship, 21, 20-31.

Mason, R. (2005). Museums, galleries and heritage: Sites of meaning-making and communication. In G. Corsane (Ed.), Heritage, Museums and Galleries: An Introductory Reader (pp. 200-214). London \& New York: Routledge.

Mason, R. (2006). Cultural theory and museum studies. In S. Macdonald (Ed.), A companion to museum studies (pp. 17-32). Oxford: Blackwell.

McCarthy, C. (2001). Mana Whenua - Summative evaluation report. Wellington: Te Papa Visitor \& Market Research. 
McCarthy, C. (2007). Exhibiting Mãori: A history of the colonial cultures of display. Wellington: Te Papa Press.

McCarthy, C. (forthcoming). Museums and Māori: Heritage professionals, indigenous collections, current practice. Wellington: Te Papa Press.

McLean, K. (2004). Museum exhibitions and the dynamics of dialogue. In G. Anderson (Ed.), Reinventing the museum: Historical and contemporary perspectives on the paradigm shift (pp. 193-211). Walnut Creek, CA: Altamira Press.

Merritt, E. (2009). Museum \& Society 2034: Trends and potential futures: Center for the future of museums - American Association of Museums.

Merz, H. G. (2006). Video - audio - disco: Lernen im Museum. Berlin: IfM.

Message, K. (2006). New museums and the making of culture. Oxford, UK: Berg.

Mieri, M. (2010). Are we there yet? In O. Guntarik (Ed.), Narratives of community: Museums and ethnicity (pp. 202-221). Edinburgh: MuseumsEtc.

Mouffe, C. (1999). Deliberative democracy or agonistic pluralism? Social Research, 66(3), 745758.

O'Neill, M. (2006). Essentialism, adaptation and justice: Towards a new epistemology of museums. Museum Management and Curatorship, 21(2), 95-116.

O'Neill, M. (2007). Kelvingrove: Telling stories in a treasured old/new museum. Curator: The Museum Journal, 50(4), 379-399.

O'Sullivan, D. (2007). Beyond biculturalism: The politics of an indigenous minority. Wellington: Huia.

O'Regan, G. (1997a). Bicultural developments in museums of Aotearoa: What is the current status? Wellington: Museum of New Zealand Te Papa Tongarewa National Services

O'Regan, G. (1997b). Biculturalism, the Treaty and the spirit of partnership. New Zealand Museum Journal, 26(2), 28-30.

Oedman, P.-J. (2007). Hermeneutics in research practice. In B. Gustavsson (Ed.), The principles of knowledge creation (pp. 113-130). Cheltenham, UK: Edward Elgar.

Ong, A. (1999). Flexible citizenship: The cultural logics of transnationality. Durham \& London: Duke University Press.

Pamphilon, B. (1999). The zoom model: A dynamic framework for the analysis of life histories. Qualitative Inquiry, 5(3), 393-410. 
Paris, S. G., \& Mercer, M. J. (2002). Finding self in objects: Identity exploration in museums. In G. Leinhardt, K. Crowley \& K. Knutson (Eds.), Learning conversations in museums (pp. 401-423). Mahwah, NJ: Lawrence Erlbaum Associates.

Pearce, S. (1995). Collecting as medium and message. In E. Hooper-Greenhill (Ed.), Museum, media, message (pp. 15-23). London \& New York: Routledge.

Pekarik, A. J. (2008). Docents as ambassadors. Curator: The Museum Journal, 51(2), 147-149.

Perin, C. (1992). The communicative circle: Museums as communities. In I. Karp, C. M. Kreamer \& S. Lavine (Eds.), Museums and communities: The politics of public culture (pp. 182-220). Washington, DC: Smithsonian Institution Press.

Phoenix, A. (2008). Analysing narrative contexts. In M. Andrews, C. Squire \& M. Tamboukou (Eds.), Doing narrative research (pp. 64-77). London: Sage.

Pieterse, N. (1997). Multiculturalism and museums: Discourse about others in the age of globalisation. Theory, Culture \& Society, 14(4), 123-146.

Polkinghorne, D. E. (1988). Narrative knowing and the human sciences. Albany: State University of New York Press.

Potter, J., \& Wetherell, M. (1987). Discourse and social psychology: Beyond attitudes and behaviour. London: Sage.

Preziosi, D., \& Farrago, C. (Eds.). (2004). Grasping the world: The idea of the museum. Aldershot: Ashgate.

RCMG (2001a). Making meaning in art museums 1. Leicester: RCMG Research Centre for Museums and Galleries.

RCMG (2001b). Making meaning in art museums 2. Leicester: RCMG Research Centre for Museums and Galleries.

RCMG (2003). Measuring the outcomes and impact of learning in museums, archives and libraries - The learning impact research project. Leicester: RCMG Research Centre for Museums and Galleries.

Redman, P. (2005). The narrative formation of identity revisited. Narrative Inquiry, 15(1), 25-44.

Ricoeur, P. (1981). Hermeneutics and the human sciences: Essays on language, action and interpretation (J. B. Thompson, Trans.). Cambridge: Cambridge University Press.

Ricoeur, P. (1991a). Discussion: Ricoeur on narrative. In D. Wood (Ed.), On Paul Ricoeur: Narrative and interpretation (pp. 179-187). London \& New York: Routledge. 
Ricoeur, P. (1991b). Life in quest of narrative. In D. Wood (Ed.), On Paul Ricoeur: Narrative and interpretation (pp. 20-33). London \& New York: Routledge.

Ricoeur, P. (1992). Oneself as another (K. Blamey, Trans.). Chicago \& London: University of Chicago Press.

Riessman, C. K. (2008). Narrative methods for the human sciences. Los Angeles: Sage.

Robbins, B. (Ed.). (1993). The phantom public sphere. Minneapolis \& London: University of Minnesota Press.

Roberts, B. (2002). Biographical research. Buckingham \& Philadelphia: Open University Press.

Roberts, L. C. (1997). From knowledge to narrative: Educators and the changing museum. Washington \& London: Smithsonian Institution Press.

Rounds, J. (2006). Doing identity works in museums. Curator: The Museum Journal, 49(2), 133150.

Rowe, S. M., Wertsch, J. V., \& Kosyaeva, T. Y. (2002). Linking little narratives to big ones: Narrative and public memory in history museums. Culture \& Psychology, 8(1), 96-112.

Royal, C. (2004). Matauranga Māori \& museum practice. Wellington: Te Papa National Services Te Paerangi.

Royal, C. (2008). Some thoughts about the Treaty of Waitangi in the New Zealand of tomorrow. Paper presented at the Treaty debate: Finding common ground.

Said, E. W. (2003). Orientalism: Western conceptions of the Orient (25th anniversary ed.). London: Penguin Classics.

Salmond, A. (1991). Two worlds: First meetings between Māori and Europeans 1642-1772. Auckland: Viking.

Sandell, R. (2007). Museums, prejudice and the reframing of difference. London \& New York: Routledge.

Sandell, R. (Ed.). (2002). Museums, society, inequality. London \& New York: Routledge.

Sartre, J.-P. (1976). Critique of dialectical reason: Theory of practical ensembles (A. SheridanSmith, Trans.). London: NLB.

Schaefer, H. (2006). Besucherforschung und Psychologie. In M. Schuster \& H. Ameln-Haffke (Eds.), Museumspsychologie: Erleben im Kunstmuseum (pp. 49-60). Goettingen: Hogrefe. 
Schorch, P. (2009). The 'reflexive museum' - opening the doors to behind the scenes. Te Ara Journal of Museums Aotearoa, 33(1-2).

Schorch, P. (2010). Humanising contact zones. In O. Guntarik (Ed.), Museums and ethnicity (pp. 262-287). Edinburgh: MuseumsEtc.

Scott, C. A. (2002). Measuring social value. In R. Sandell (Ed.), Museums, society, inequality (pp. 41-55). London: Routledge.

Scott, C. A. (2003). Museums and impact. Curator: The Museum Journal, 46(3), 293-310.

Scott, C. A., \& Soren, B. J. (2009). Introduction to the special issue - exploring the value of museums. Museum Management and Curatorship, 24(3), 189-193.

Shkedi, A. (2005). Multiple case narrative: A qualitative approach to studying multiple populations. Amsterdam: John Benjamins Publishing Company.

Sibley, C. G., Liu, J. H., Duckitt, J., \& Khan, S. S. (2008). Social representations of history and the legitimation of social inequality: The form and function of historical negation. European Journal of Social Psychology, 38(3), 542-565.

Silverman, L. H. (1995). Visitor meaning-making in museums for a new age. Curator: The Museum Journal, 38(3), 161.

Simon, N. (2010). The participatory museum. Santa Cruz, CA: Museum 2.0.

Sissons, J. (2005). First peoples: Indigenous cultures and their futures. London: Reaktion.

Slater, D. (2008). Glimpsing God in the internet. In D. Held, H. L. Moore \& K. Young (Eds.), Cultural politics in a global age. Oxford: Oneworld Publications.

Smith, H. (2006). The Museum of New Zealand Te Papa Tongarewa. In C. Healy \& A. Witcomb (Eds.), South Pacific museums: Experiments in culture (pp. 10.11-10.13). Melbourne: Monash University ePress.

Squire, C. (2008). Experience-centred and culturally-oriented approaches to narrative. In M. Andrews, C. Squire \& M. Tamboukou (Eds.), Doing narrative research. London: Sage.

Staniszewski, M. A. (1998). The power of display: A history of exhibition installations at the Museum of Modern Art. Cambridge, MA: MIT Press.

Strauss, A., \& Corbin, J. (1998). Basics of qualitative research: Techniques and procedures for developing grounded theory. Thousand Oaks: Sage. 
Struck, B. (2004). Einfuehrung. In A. Bauerkaempfer, H. E. Boedeker \& B. Struck (Eds.), Die Welt erfahren: Reisen als kulturelle Begegnung 1780 bis heute (pp. 163-169). Frankfurt/New York: Campus Verlag.

Suvantola, J. (2002). Tourist's experience of place. Burlington: Ashgate.

Taylor, C. (1991). Discussion: Ricoeur on narrative. In D. Wood (Ed.), On Paul Ricoeur: Narrative and interpretation (pp. 174-179). London/New York: Routledge.

Thomas, N. (1994). Colonialism's culture. Carlton, Victoria: Melbourne University Press.

Thompson, J. B. (1981). Critical Hermeneutics: A study in the thought of Paul Ricoeur and Juergen Habermas. Cambridge: Cambridge University Press.

Treinen, H. (1995). Ausstellungen und Kommunikationstheorie. In H. d. G. d. B. Deutschland (Ed.), Museen und ihre Besucher: Herausforderungen in der Zukunft (Vol. 60-70). Berlin: Argon.

Tsybulskaya, D., \& Camhi, J. (2009). Accessing and incorporating visitors' entrance narratives in guided museum tours. Curator: The Museum Journal, 51(1), 81-99.

Turner, V. W. (1986). Dewey, Dilthey, and drama: An essay in the anthropology of experience. In V. W. Turner \& E. M. Bruner (Eds.), The anthropology of experience (pp. 33-44). Urbana \& Chicago: University of Illinois Press.

Urry, J. (2007). Mobilities. Cambridge: Polity.

Vergo, P. (Ed.). (1989). The new museology. London: Reaktion Books.

Warner, M. (1993). The mass public and the mass subject. In B. Robbins (Ed.), The phantom public sphere (pp. 234-256). Minneapolis \& London: University of Minnesota Press.

Weibel, P., \& Latour, B. (2007). Experimenting with representation: Iconoclash and making things public. In S. Macdonald \& P. Basu (Eds.), Exhibition experiments (pp. 94-108). Malden, MA: Blackwell Publishing.

Weil, S. (1990). Rethinking the museum and other meditations. London: Smithsonian Institution Press.

Wengraf, T. (2001). Qualitative research interviewing: Biographical narrative and semistructured methods. London: Sage.

West, R. W. (1995). 'Talking circles' to touch-screens: Students discover Native Americans at NMAI. Washington: NMAI. 
Williams, P. (2003). New Zealand's identity complex: A critique of cultural practices at the Museum of New Zealand Te Papa Tongarewa. Unpublished PhD, University of Melbourne, Melbourne.

Witcomb, A. (2003). Re-imagining the museum: Beyond the mausoleum. London \& New York: Routledge.

Witcomb, A. (2007). The materiality of virtual technologies: A new approach to thinking about the impact of multimedia in museums. In F. Cameron \& S. Kenderdine (Eds.), Theorising digital cultural heritage: A critical discourse. Cambridge, MA: MIT Press.

Witcomb, A. (2009). Using objects to remember the dead and affect the living: The case of a miniature model of Treblinka. In S. Dudley (Ed.), Museum materialities: Objects, engagements, interpretations. London \& New York: Routledge.

Woelke, J., \& Paus-Hasebrink, I. (2005). Rezeptionsstrategien - Umrisse eines Forschungsprogramms. In V. Gehrau, H. Bilandzic \& J. Woelke (Eds.), Rezeptionsstrategien und Rezeptionsmodalitaeten. Munich: Verlag Reinhard Fischer. 


\section{Appendices}

\section{Appendix A: Focus group format with global visitors}

Opening: $\quad$ Please briefly introduce yourself and tell us how you got here to Te Papa.

Introduction: Introduction of the research project

Transition: $\quad$ Te Papa's mission statement will be handed out and participants are asked to take a few moments to read and think through it.

First stage: $\quad$ What do you associate with the term 'forum'?

Second stage: $\quad$ Elaboration intertwined with issues raised in stage one

Third stage: $\quad$ How does a museum such as Te Papa fit into this sphere?

How does this relate to your travel and museum experiences and life back home?

Ending: $\quad$ Do you have anything to add? 


\section{Appendix B: Focus group format with Te Papa tour hosts}

Opening: $\quad$ Please briefly introduce yourself and your position at Te Papa.

Introduction/

Transition: $\quad$ Introduction of the research project

First stage: $\quad$ Please tell me about your impressions of the bicultural Te Papa experience of global visitors.

Second stage: $\quad$ Elaboration intertwined with issues raised in stage one

Third stage: $\quad$ Are there aspects which visitors from different cultures, countries etc. have in common?

Are there differences between visitors from different cultures, countries?

How do these visitors relate the bicultural Te Papa experience to their travel and museum experiences and life back home?

Ending: $\quad$ Do you have anything to add? 


\section{Appendix C: Key informant interview format}

First stage: $\quad$ Please introduce yourself and your former role at Te Papa, and tell me about Te Papa's forum concept.

Second stage: $\quad$ Elaboration intertwined with issues raised in stage one

Third stage: $\quad$ How does Te Papa as a forum fit into the wider public sphere?

How does Te Papa as a forum fit into the global context? 


\section{Appendix D: Te Papa tour types}

\section{'Introducing Te Papa Tour - 60 minutes}

This tour provides an overview of Te Papa's highlights, Māori taonga (treasures), and New Zealand history.

\section{Taste of Treasures Tour -60 minutes}

Experience a taste of Māori culture and taonga Māori (Māori cultural treasures) in this informative introduction to Te Papa. The tour concludes with 'traditionally inspired' light refreshments: Kawakawa tea with mānuka honey, rēwena bread, piko-piko pesto, and kawakawa and manuka honey cookie. Ideal for visitors with an interest in learning more about the indigenous culture of New Zealand.

\section{Māori Experience Kapu Tī Tour - 90 minutes}

Discover Te Papa's taonga Māori (cultural treasures), and hear the stories of how these taonga are a living part of Māori history and culture. The tour includes a mihimihi (greeting) and a waiata (song) on the Marae (communal meeting place). Visit Bush City, a living, growing exhibition that brings New Zealand's great outdoors into the city, where the Host explains how early Māori gathered food, medicines, and materials for clothing from the forest. The tour concludes with kapu tī - a hot drink and traditionally inspired food. This hospitality is an important part of Māori culture and provides an ideal opportunity for further informal conversation with our Hosts and an opportunity for each guest to learn a personalised mihimihi. Indigenous Food Menu: Kawakawa (a bush herb) Tea served with Mānuka (tea tree) Honey,

Rēwena Bread (Māori potato bread) served with Piko-piko (fern frond) pesto, Kūtai (mussel) and Karengo (edible seaweed) Salad, Kūmara (sweet potato) Chips with Horopito (native bush pepper) Mayonnaise.

\section{Māori Experience Tour - 60 or 90 minutes}

Discover Te Papa's taonga Māori (cultural treasures), and hear the stories of how these taonga are a living part of Māori history and culture. The tour includes a mihimihi (greeting) and a waiata (song) on the Marae (communal meeting place). Visit Bush City, a living, growing 
exhibition that brings New Zealand's great outdoors into the city, where the Host explains how early Māori gathered food, medicines, and materials for clothing from the forest. The 90-minute tour provides a more in-depth experience.

Te Papa Highlights Tour - 90 minutes

A fun and informative tour of Te Papa's highlights, including the natural environment, Māori culture and treasures, art, history, and the colossal squid. The tour includes an exhilarating ride in OurSpace.

Fabulous Te Papa Tour - 90 minutes

A great way to sample New Zealand's unique treasures. The tour covers exhibition highlights from the natural environment, Māori culture and treasures, art, and colonial history.

Toi Te Papa Art Tour - 60 minutes

An enlightening tour through 1000 years of New Zealand's vibrant and diverse art history. Toi Te Papa Art of the Nation features over 300 works from Te Papa's collections.

Te Papa Sampler - 60 minutes

A condensed version of the Fabulous Te Papa Tour has been developed for people on a busy itinerary or as an introduction to a longer visit. The Te Papa Sampler covers key highlights in selected areas of the Museum to suit the nationality and interests of the group.

Kiwi Discoverer - 90 minutes

Recommended for families and primary and secondary school English-speaking international students. Groups are guided through the Museum focusing on activities in Te Papa's hands-on Discovery Centres and OurSpace exhibition.'

(Retrieved from Te Papa Tours wholesale rates agreement) 


\section{Appendix E: Te Papa tour host training}

'This course is intended to enable Te Papa Hosts to deliver four general Te Papa tours:

- 60 minutes Introducing Te Papa tour

- 60 minutes Te Papa Sampler Tour

- 90 minutes Te Papa Highlights Tour

- 90 minutes Fabulous Te Papa Tour

The overarching concepts for all tours are consistent - with the major variation being the length of time taken and the depth of information delivered during the tour experience. Training is to be broken into 7 essential training modules with a further module attached to enable Hosts to deliver the Māori Experience Tour products. The training modules are as follows:

Module 1 - Introduction 1 x 2-hour lesson - to include the 60 minutes Introducing Te Papa tour. Learning outcome: Hosts will understand the conceptual overview of the tour framework and appreciate the structure and delivery mechanisms of the training programme.

Module 2 - The Natural Environment ( $2 \mathrm{x}$ one-hour lessons)

Lesson 1 - The Map, Awesome Forces, Mountains to Sea

Lesson 2 - Bush City, Nature Space, Tai Awatea

Learning outcomes: Hosts will learn concept and content for the exhibition areas specified above.

Module 3 - Social History ( $3 \mathrm{x}$ one-hour lessons)

Lesson 1 - Plaza Rocks; Blood, Earth, Fire; Signs of a Nation

Lesson 2 - Passports \& Community Gallery, Slice of Heaven

Lesson 3 - Tiger Moth, Britten Bike, Phar Lap, Cannon, Anchor

Learning outcomes: Hosts will learn concept and content for the objects and exhibition areas specified above.

Module 4 - Māori Taonga ( $3 \mathrm{x}$ one-hour lessons)

Lesson 1 - Nga Waharoa, Te Ara a Hine

Lesson 2 - Rongomaraeroa, Pounamu

Lesson 3 - Mana Whenua and the Iwi Gallery

Learning outcomes: Hosts will learn concept and content for the objects and exhibition areas specified above.

Module 5 - Pacific Taonga (1 x one-hour lesson)

$1 \mathrm{x}$ one-hour lesson

Lesson 1 - Tangata o le Moana, Hawaiian Cloak

Learning outcomes: Hosts will learn concept and content for the object and exhibition area specified above.

Module 6 - Art (1 x one-hour lesson)

Lesson 1 - Toi Te Papa 
Learning outcomes: Hosts will learn concept and content for the artists and exhibition area specified above.

Module 7 - Tour Delivery ( 7 x one-hour lessons plus 4 hours for presentation preparation, delivery and overall debrief)

Lesson 1 - Tour Review, Interpretation, Theme and Key Messages

Lesson 2 - Learning Styles, Interpretive Techniques

Lesson 3 - Operations: Greeting, Orientation and Farewell

Lesson 4 - Group Management

Lesson 5 - Voice Production

Lesson 6 - Evaluation: Methods and Benefits

Lesson 7 - Creating Impact with your Presentation/ Presentations

Lesson 8, 9 - Presentations and De-brief

Learning outcomes: Hosts will learn how to deliver a successful tour at Te Papa.

Hosts must complete all 7 Modules before they are eligible to deliver any of the general Te Papa tours. The total course requirement is 24 contact hours - in addition there is a further module for Māori Hosts who wish to deliver the Māori Experience Tours and an additional training session for selected Hosts wishing to deliver the new 60-minute Taste of Treasures tour that will run in the high season as an alternative to the 11.00am Introducing Te Papa Tour.

Module 8 - Māori Interpretation (2 x one-hour lessons)

Lesson 1 - Māori Interpretation

Lesson 2 - Māori Experience Tours

Hosts will learn the concept and content for the Māori Experience Tour Products.

Hosts must also observe at least 4 tours conducted by three different people and produce a written evaluation of those observations using the Tour Training Peer Evaluation Form before doing their own 60-minute trial tour, accompanied by the Tour Trainer or an experienced tour guide. Having done that they will be eligible to deliver tours themselves and House Managers will be advised accordingly. In order to gain Tour Host accreditation the tour host will be required to do 6 Intro Tours and gain the following feedback: 2 examples each of Visitor and Peer Feedback and provide two examples of completed Self-Assessments. Having done this the Host can then apply to have an Accreditation Assessment and if this is "successful" they will be classified as a Tour Host for salary banding purposes. All Tour Hosts are expected to maintain a diary of all tours taken, with each entry noting date, time, type, visitor make-up, and very brief self-assessment (a short sentence or a couple of phrases). The diary can be electronic or hand-written. They will also be in a position to prepare for final assessment on the three Unit Standards which make up a major component of the National Certificate in Tourism - Attraction Guiding. Hosts will approach a Unit Standard Assessor when they feel ready for assessment (usually sometime after their $6^{\text {th }}$ tour). Specialist Tours: From time to time specialist tours of individual long-term or temporary exhibitions will be created and tour guides with knowledge and/or interest in those areas will be invited to train for those tours.'

(Introduction and overview provided by Te Papa tour host trainer) 


\section{Appendix F: Signs of a Nation}

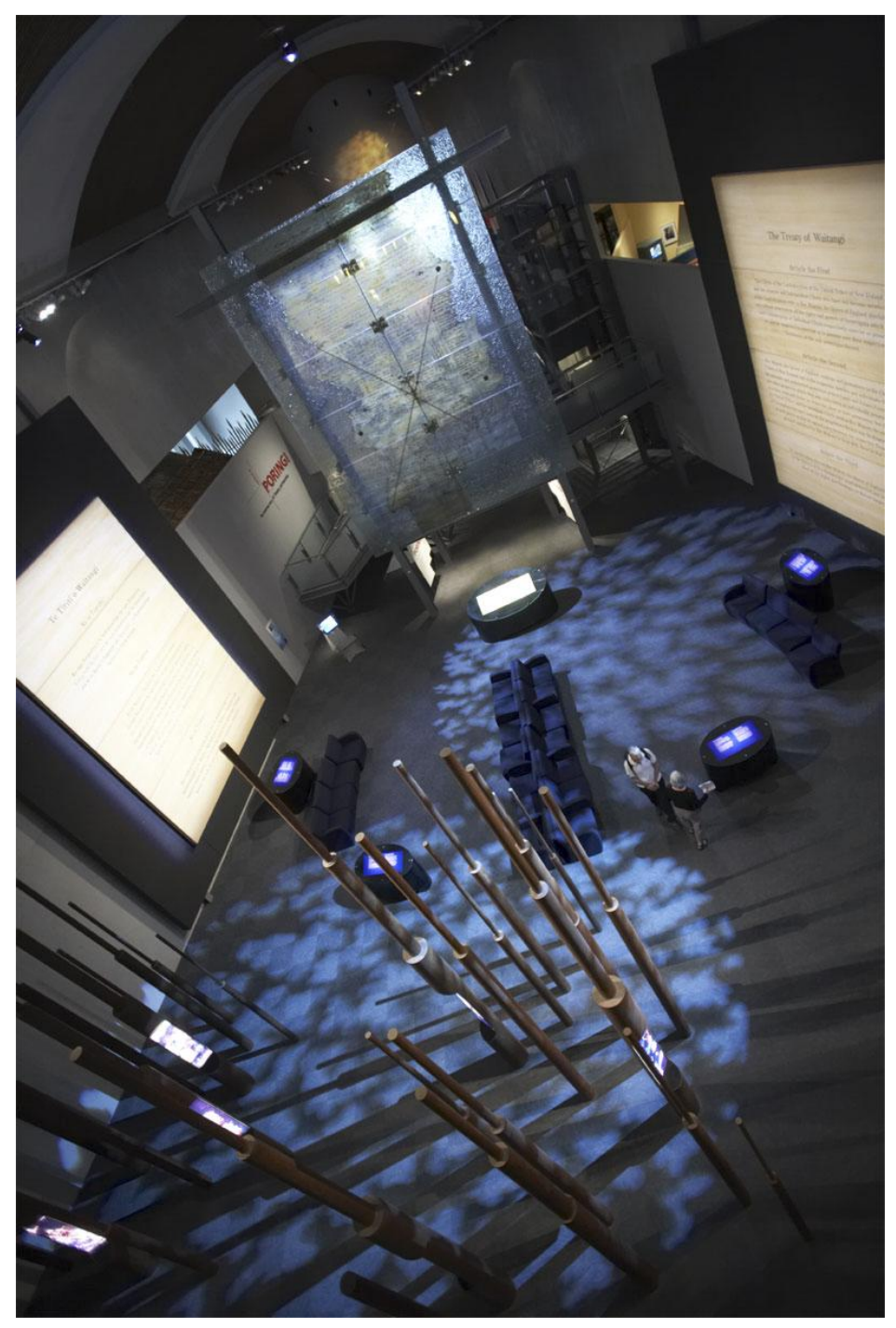

'The Treaty of Waitangi is living social document - debated, overlooked, celebrated. Is it a vision of peaceful co-existence or the cause of disharmony? An irrelevancy or the platform on which all New Zealanders can build a future? Signs of a Nation | Ngā Tohu Kotahitanga is a contemporary commentary on the Treaty of Waitangi and its centrality to the wider New Zealand community. The exhibition stands in an imposing wedge-shaped space, underneath a high cathedral-like ceiling. But with its comfortable seating and calm ambience, the setting offers a place for quiet 
contemplation. The Treaty document itself - both as a giant replica and with the words of its two versions set large on the walls - has a strong presence in the exhibition.

Moving into the space, you pass through a thicket of pole clusters. Here many voices can be heard, presenting the different views of New Zealanders on the Treaty, like snapshots in time, with quotes from the time of signing through to current opinions. In a space under the mezzanine, personal stories of people whose lives have been affected by the Treaty bring to life the words in English and Māori on the walls.

Signs of a Nation is also responsive to contemporary events and provides a forum for New Zealanders in which new analyses - creative, intellectual, and social - can occur. Up on the mezzanine, a special section, 'Pōringi', shows the Treaty partnership in action through the Treaty claims process. Panels on both sides of the space discuss grievances over breaches of the Treaty and show the process by which claims against the Crown are made and how they are settled. The Treaty is fundamental to our vision of this nation. This exhibition invites you to engage with New Zealand's founding document.

The glass replica of the Treaty

Te Papa's Treaty, a copy of the official 1840 version, stands eight metres high in the exhibition. It weighs three-quarters of a tonne. Thanks to modern technology, it has been enshrined in the beauty and permanence of glass. This double-layered icon speaks to us across time. The deepest layer carries an enlargement of the original signed Māori version of the Treaty in the tattered form it has come down to us today. Therefore some signatures are missing. This is a reminder both of its years of obscurity and its capacity to somehow survive. To supply the missing parts, the complete text is laid over the original document - so we can exactly see how the Treaty was when it was signed.'

(http://www.tepapa.govt.nz/WhatsOn/exhibitions/Pages/SignsofaNation.aspx; retrieved 29

November 2010) 


\section{Appendix G: Marae (Rongomaraeroa)}

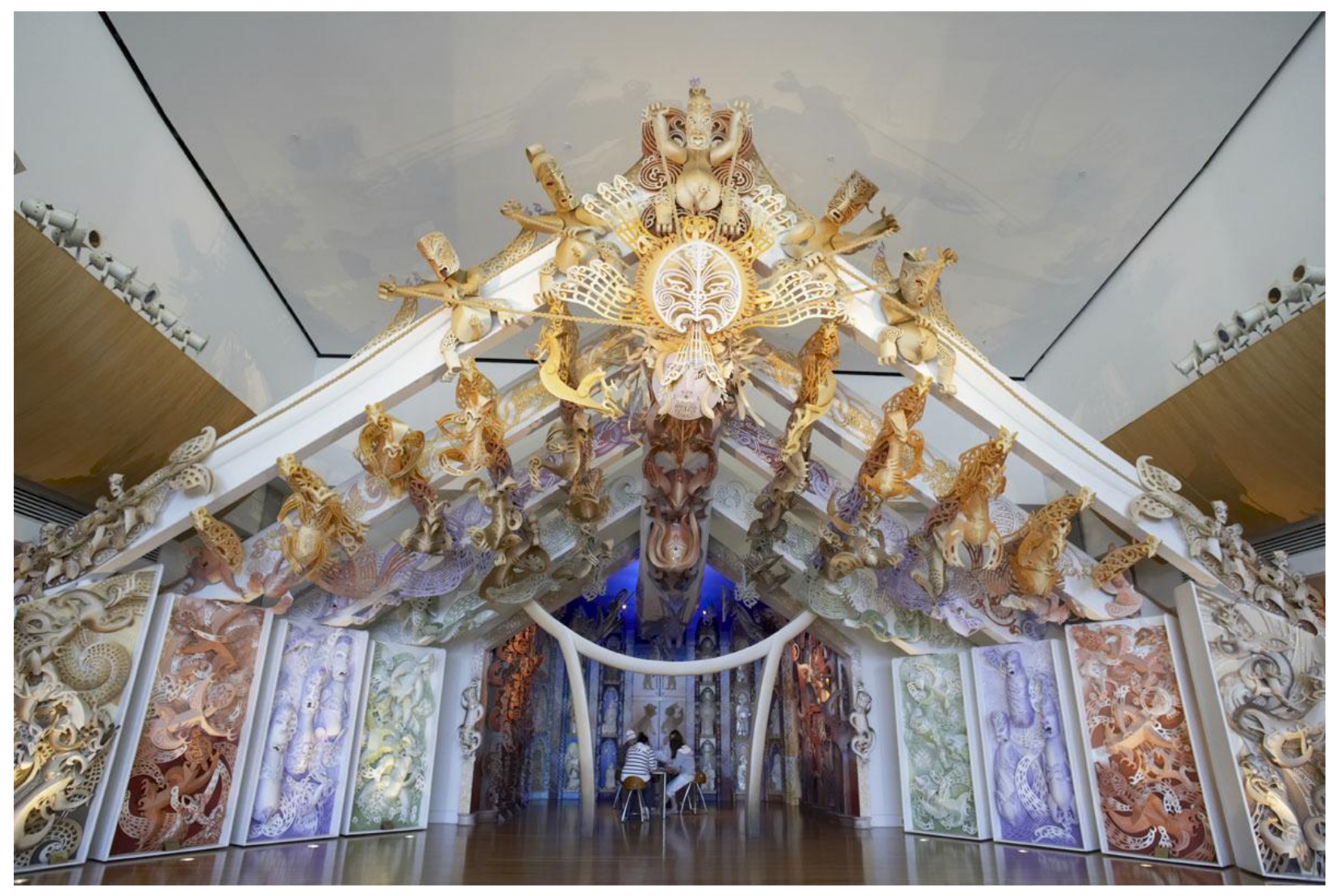

'The Marae offers a unique experience within Te Papa and is also unique within New Zealand. It is Te Papa's response to the challenge of creating an authentic yet inclusive marae (communal meeting place) for the twenty-first century. The space comprises a marae atea (place of encounter) and wharenui (meeting house) that cater for all the purposes such places customarily serve. It is also a living exhibition that interprets for visitors the meaning of the marae experience, and acts as a showcase for contemporary Māori art and design. Like other marae, this Marae is about identity - here, it is our nation's bicultural identity that is addressed. The Marae embodies the spirit of bicultural partnership that lies at the heart of the Museum, and is based on the idea that Te Papa is a forum for the nation. 
All people have a right to stand on this Marae through a shared whakapapa (genealogy) and the mana (power) of the taonga (treasures) held in Te Papa Tongarewa's collections. All cultures can feel at home on this marae. Iwi can identify and relate to their ancestors through the striking contemporary carvings. So too can other cultures. Carved ancestral images reflect the occupations and origins of newcomers over the last two hundred years - farmers, educators, clergy, parents, artists - linked with Pākehā, Asian, and Polynesian design references.

\section{The meaning behind The Marae}

All people live in Te Ao Marama, the world of light, created when our ancestral parents, Ranginui and Papatūānuku, were forced apart. The Marae floor can be seen as Papa, the Earth mother, with Rangi, the sky father, above. Our wharenui can be seen as Tāne, the son who forced his parents apart, thereby opening a space for us to live in. As the children of Rangi and Papa established themselves in this world, they each developed special responsibilities - Tāwhirimātea, for the wind, Tangaroa, for the oceans, Tāne, for the forest, and so forth. Thus it is appropriate that our Marae is situated here, at the confluence of these elements. When the elements come together, as when people come together, there can sometimes be turbulence. For this reason, it was necessary for the children of Rangi and Papa to develop protocols for meeting and ways for recognizing one another.

These protocols have been passed down for generations and are used on marae throughout the country, with minor variations. The protocols on Te Papa's Marae were developed after extensive consultation. This ensured their integrity as well as the flexibility needed to accommodate all iwi. The name of the wharenui on The Marae is Te Hono ki Hawaiki. This name speaks of the connection to Hawaiki, the place of our spiritual origins. Accepting this spiritual idea of Hawaiki enables all people to regard The Marae as a place for them to stand - a place to which they can belong.'

(http://www.tepapa.govt.nz/WhatsOn/exhibitions/Pages/TheMarae.aspx; retrieved 29 November 2010) 


\section{Appendix H: Mana Whenua}

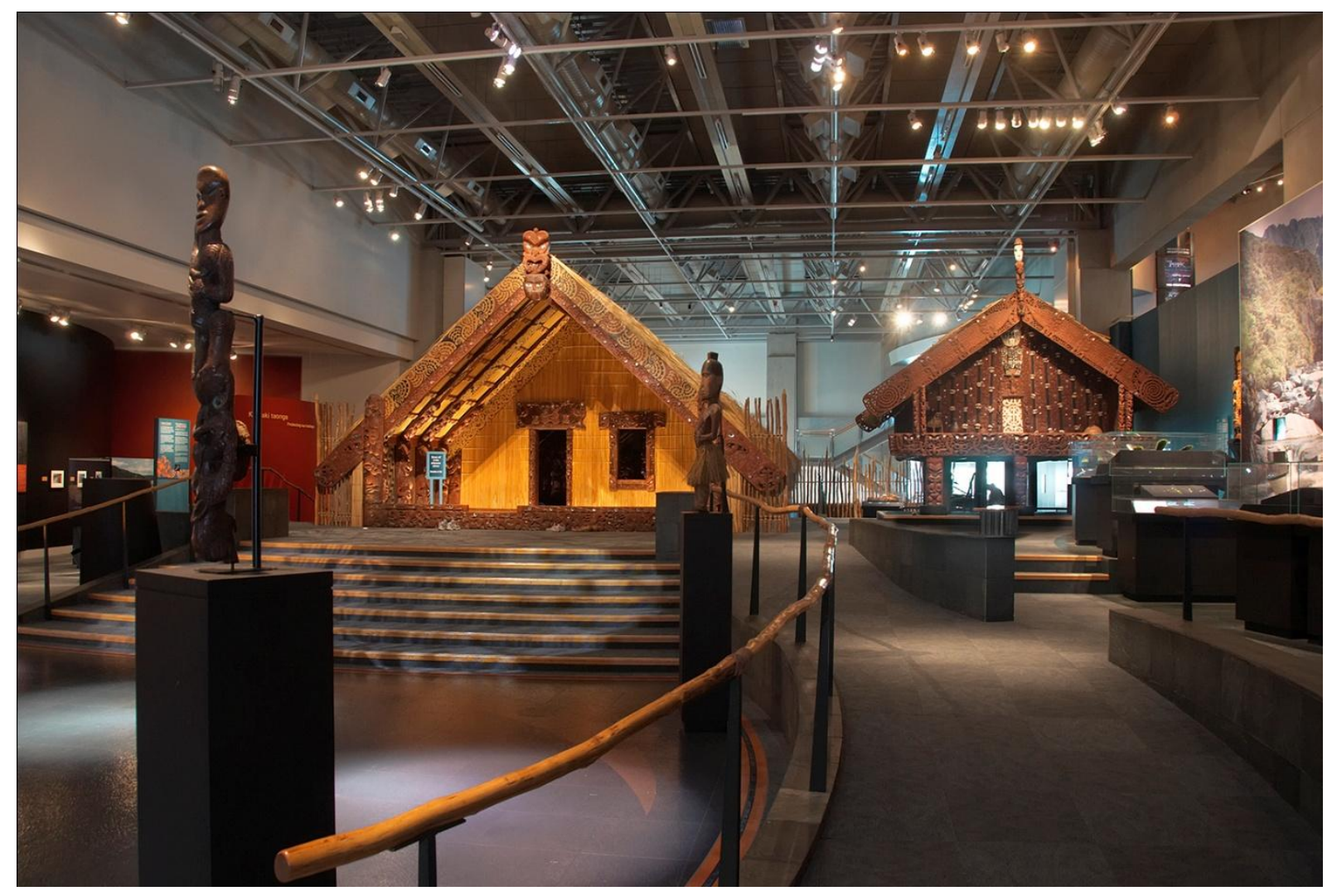

'Mana Whenua takes you on a stirring journey that explores and celebrates Māori as tangata whenua (original people) of Aotearoa New Zealand. Stories of voyaging, adaptation, survival, conflict, trial, and triumph are told through a powerful mix of taonga (treasures), oral histories, and contemporary works. Through the exhibition, you can experience something of the richness, complexity, and dynamism of Māori life and heritage. The concept of 'mana whenua' has many layers of meaning. It tells of important relationships that Māori have with whenua (land) and of the value placed upon the land within the culture. The exhibition celebrates the mana (power) of the culture through taonga tuku iho (treasures handed down) such as the woven and carved works, waka (canoes), and whare (buildings) such as the meeting house Te Hau ki Turanga and the storehouse Te Takinga. 
These taonga connect through whakapapa (genealogy) to living descendants and resonate through their voices in waiata (song) and kōrero (personal narratives). Contemporary Māori artworks explore and reinforce the continuum of tippuna (ancestral) culture and whakapapa, linking past generations to present day descendants and the dynamics of cultural continuity. Inside the body of Te Hau ki Turanga, one of the oldest and most significant meeting houses in existence, a sound and light presentation enables you to experience a unique perspective on the Māori world. Mana Whenua is also about journeys and voyages through time. The ancestral voyages from Hawaiki, a distant place of origin, are presented through the story of Te Aurere, a modern voyaging waka. Ngāti Hinewaka, the people of Palliser Bay, narrate their experiences of reconstructing a 500year-old wharepuni (domestic house).

\section{The challenge of developing Mana Whenua}

The unifying concept for the many themes and stories in Mana Whenua is whakapapa and identity, evoking an experience that Māori and many other peoples will readily identify with. The exhibition has been, and continues to be, developed through extensive consultation and partnerships with iwi (tribes) regarding their treasures. Iwis' direct involvement in the selection, presentation, and interpretation of taonga acknowledges the living nature of taonga. It also ensures that the exhibition speaks with the mana (authority) of the people rather than from an 'other' perspective. The special relationship between Māori and their taonga is a vital dimension in the life of Te Papa Tongarewa now and into the future.'

(http://www.tepapa.govt.nz/WhatsOn/exhibitions/Pages/ManaWhenua.aspx; retrieved 29 November 2010) 


\section{Appendix I: Iwi Exhibition}

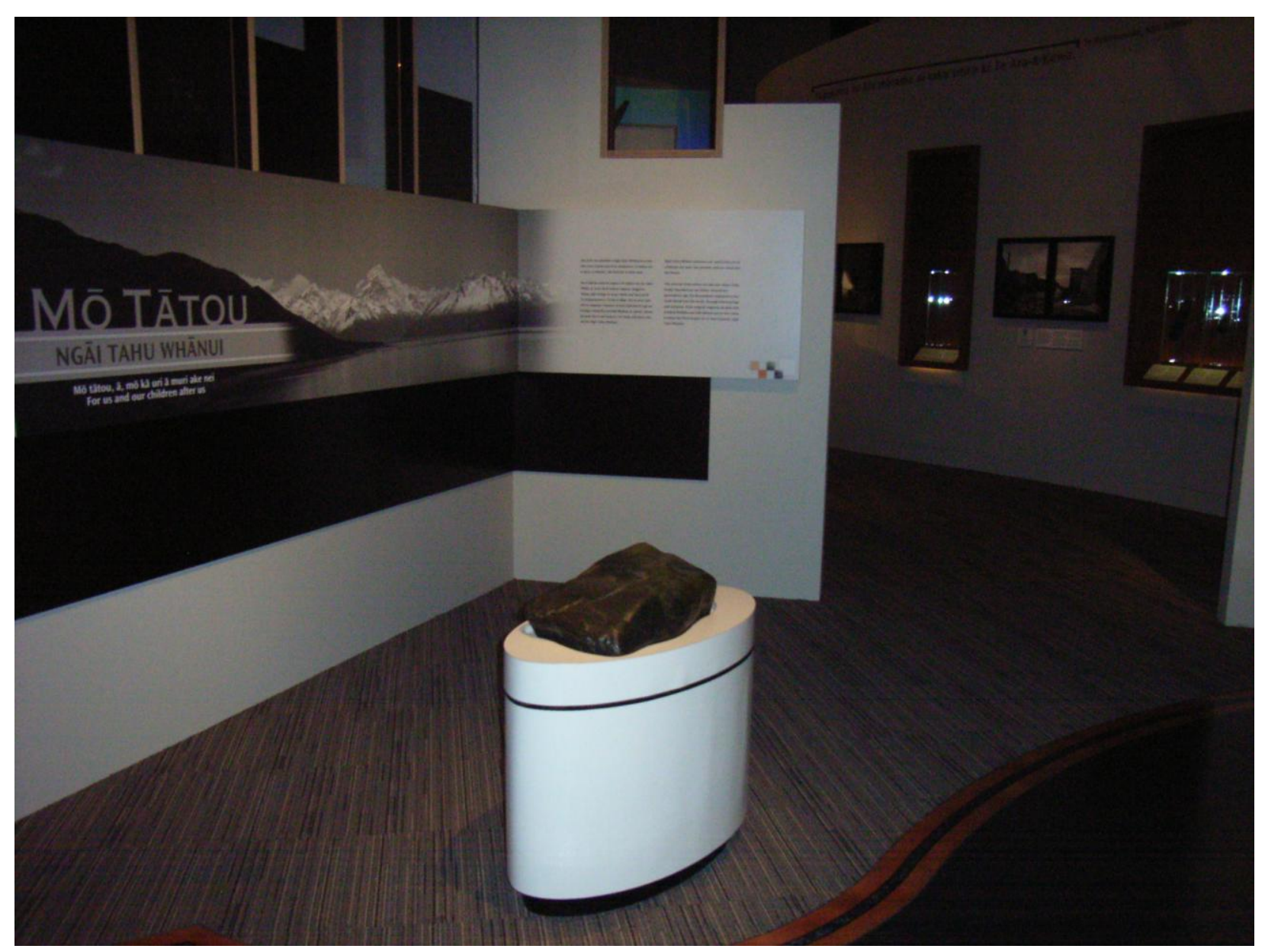

'Mō Tātou: The Ngāi Tahu Whānui exhibition

Mō tātou, ā, mō kā uri, ā muri ake nei. For us and our children after us.

We, Ngāi Tahu Whānui, the people of the South Island, invite you to celebrate our past and present, learn about our values, and share our vision for the future in this, the fifth iwi exhibition at Te Papa. 
Ngāi Tahu means 'people of Tahu' after our founder, Tahu Potiki. Around ten generations ago, his descendents migrated from the North Island of New Zealand to the South Island. Through intermarriage and conquest, these original migrants merged with the resident Waitaha and Kāti Māmoe tribes, to form Ngāi Tahu Whānui as it is today.

Embedded in the land, Ngāi Tahu Whānui have survived and progressed from near-decimation to tribal autonomy and self-reliance. Four cultural values, drawn from the tribal saying 'Mō tâtou, $\bar{a}$, mō kā uri à muri ake nei. For us and our children after us', are the organising principles for this exhibition and reflect our contemporary understanding of our past and our future. They are:

- Toitū te iwi - Culture

- Toitū te rangatiratanga - Tenacity

- Toitū te aō tūroa - Sustainability

- Toitū te pae tawhiti - Innovation

From our creation story to our most important taonga (treasures), to our representation on the world art stage, Mō Tātou celebrates the distinct and dynamic culture of the South Island's Ngāi Tahu people.'

(http://www.tepapa.govt.nz/WhatsOn/exhibitions/Pages/NgaiTahu.aspx; retrieved 29 November 2010) 


\section{Appendix J: Community gallery}

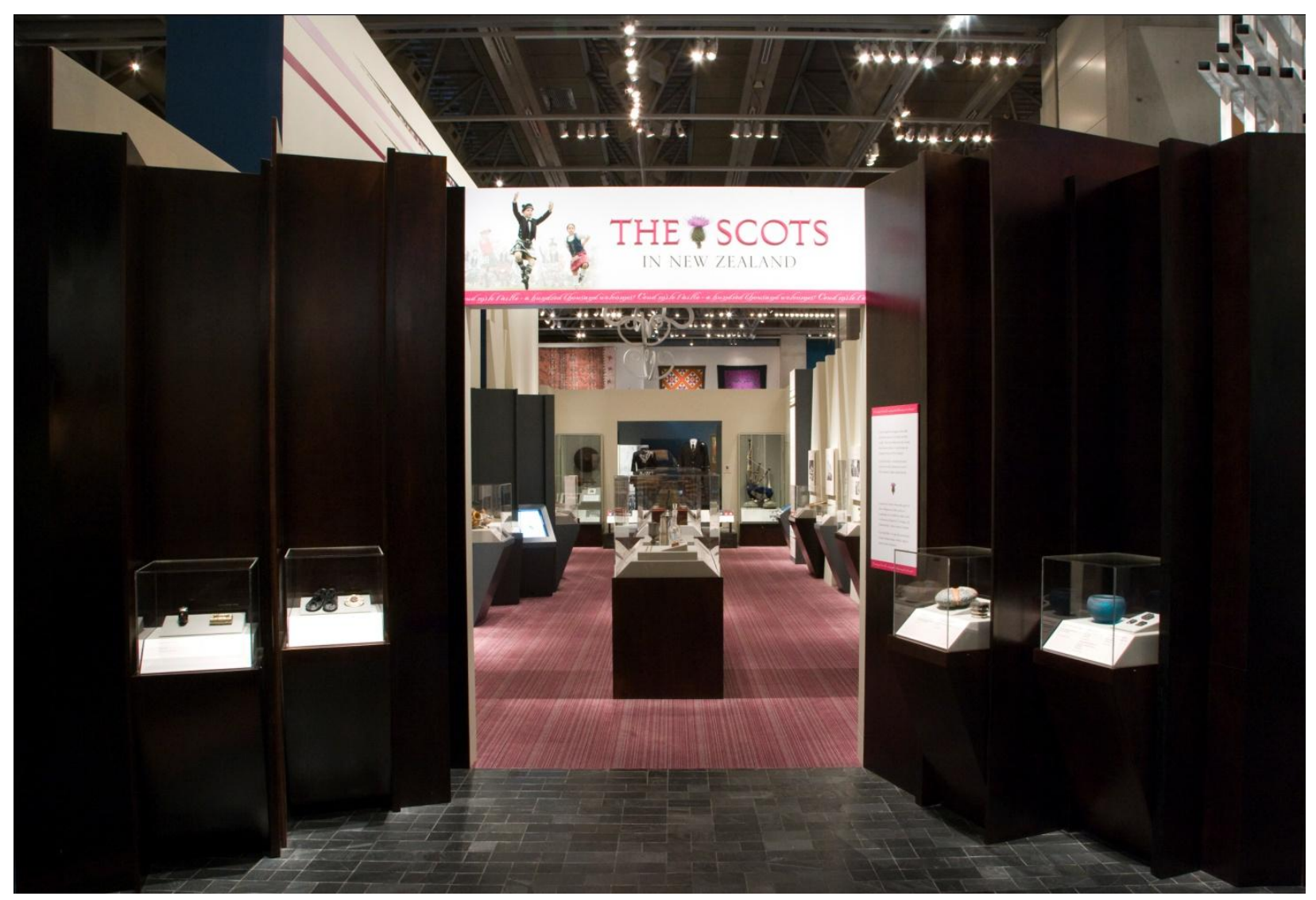

'The Scots in New Zealand: Think 'Scots in New Zealand', and your thoughts will probably turn to tartan, bagpipes, and 'Auld Lang Syne'. But look beyond these and you'll find a Scottish presence everywhere in New Zealand life. This exhibition tells the stories of the Scots in New Zealand through a selection of intriguing objects, images, and short films. The stories range from farmers, architects, and engineers, to charismatic church leaders, a Scottish lad who became prime minister, and feisty women who fought for the vote. Contemporary stories feature curlers, artists, musicians, bricklayers, and teachers. The Scots in New Zealand celebrates one of this country's most widespread migrant groups.'

(http://collections.tepapa.govt.nz/exhibitions/thescots/?redirectedurl=true; retrieved 29 November 2010) 


\section{Appendix K: Te Papa floor plan $\left(4^{\text {th }}\right.$ floor $)$}

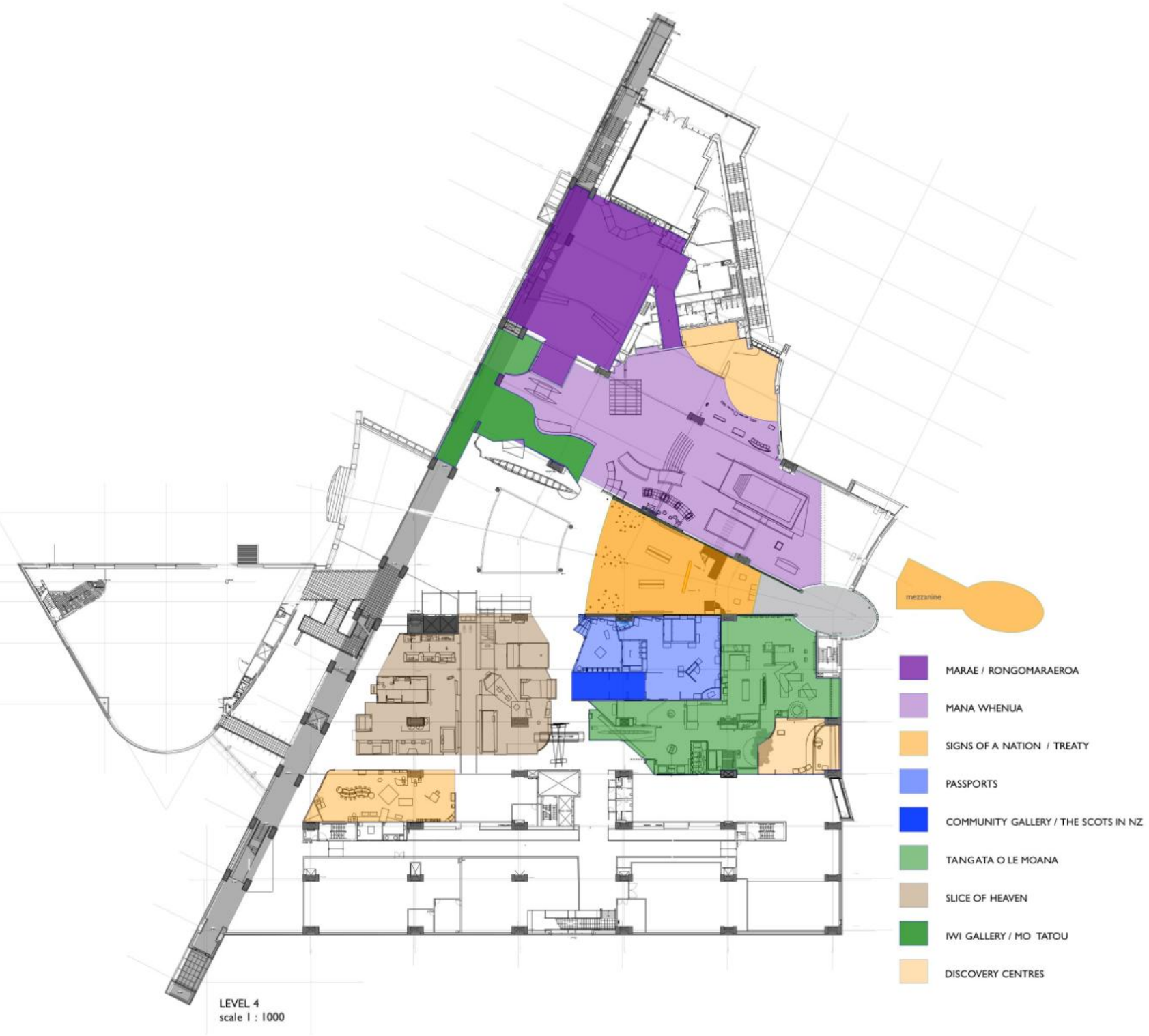

(Provided by Te Papa design team) 


\section{Appendix L: Te Papa Mission Statement}

'The Museum of New Zealand Te Papa Tongarewa Act 1992 establishes our purpose:

Te Papa is a forum for the nation to present, explore, and preserve the heritage of its cultures and knowledge of the natural environment in order to:

better understand and treasure the past

enrich the present and

meet the challenges of the future.'

(Retrieved from Museum of New Zealand Te Papa Tongarewa Act 1992) 


\section{Appendix M: Mana Taonga Principle}

'Mana Taonga: At its meeting of 30 September 1992 Ngā Kaiwawao (the Māori Advisory Group to the museums development board) resolved to recommend that the Board endorse the concept of Mana Taonga. This concept as defined by Te Papa, is central in laying the foundation for Māori participation and involvement in Te Papa. The concept was developed through consultation with iwi and other key stakeholders in 1989 - 1990, and was endorsed by the Museum's Board in 1992.

Broadly speaking the mana taonga concept as practiced by Te Papa, recognises the spiritual and cultural connections of taonga with their people through the whakapapa of:

i) The creator of specific taonga;

ii) The ancestors after whom the taonga is named; and

iii) The whanau, hapu or iwi to whom the taonga is an heirloom

The concept is defined as follows:

- The rights of iwi to Te Marae o Te Papa Tongarewa in equality with all other iwi - these rights are conferred through the taonga that are held by Te Papa on the behalf of iwi.

- Spiritual and cultural ownership rights conferred through the whakapapa in respect of the traditions and histories that taonga represent, as well as the whakapapa of the creator of the taonga.

- These rights accord to iwi the mana to care for their taonga, to speak for them, and to determine their use or uses by the Museum.

The rights of mana taonga cannot be erased and continue to exist for those taonga held within Te Papa's care. In a practical sense, mana taonga provides iwi and communities with the right to define how taonga within Te Papa should be cared for and managed in accordance with their tikanga or custom.'

(Retrieved from Te Papa Intranet) 


\section{Appendix N: Te Papa Bicultural Policy}

(Retrieved from Te Papa Intranet, begins next page) 